\title{
MODELO DE ATRITO ESTÁTICO EM INTERFACES DE CONTATO ENTRE CONCRETO E AREIA
}

\section{JESELAY HEMETÉRIO CORDEIRO DOS REIS}

Tese apresentada à Escola de Engenharia de São Carlos, da Universidade de São Paulo, como parte dos requisitos para obtenção do título de Doutor em Geotecnia

ORIENTADOR: Prof. Dr. NELSON AOKI EESC, Universidade de São Paulo

São Carlos

2006 
Ficha catalográfica preparada pela Seção de Tratamento da Informação do Serviço de Biblioteca - EESC/USP

Reis, Jeselay Hemetério Cordeiro dos

Modelo de atrito estático em interfaces de contato entre concreto e areia / Jeselay Hemetério Cordeiro dos Reis. -- São Carlos, 2006.

Tese (Doutorado) -- Escola de Engenharia de São Carlos-Universidade de São Paulo, 2006.

Área: Geotécnia.

Orientador: Prof. Dr. Nelson Aoki.

1. Fundações. 2. Atrito. 3. Modelo constitutivo. 4. Interação solo-estrutura. 5. Interface. 6. Ensaio de cisalhamento de direto. 7. Atrito lateral em estacas. I. Título. 
FOLHA DE JULGAMENTO

Candidato: Engenheiro JESELAY HEMETERIO CORDEIRO DOS REIS

Tese defendida e julgada em 30-03-2006 perante a Comissão Julgadora:

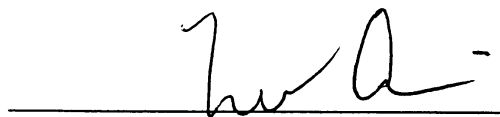

Prof. Dr. NELSON AOKI (Orientador)

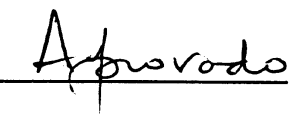

(Escola de Engenharia de São Carlos/USP)

\section{Teram}

Prof. Dr. ROBERTO QUENTAL/COUTINHO

(Universidade Federa/de Pepnambuco/UFPE)

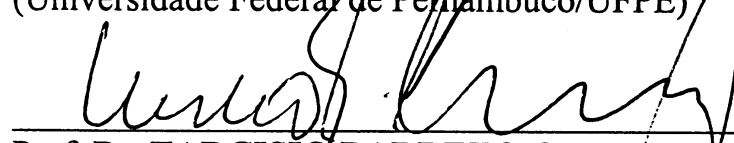

Prof. Dr. TARCISIÓ BARRETO CELESTINo

(Escola de Engenharia de São Carlos/USP)
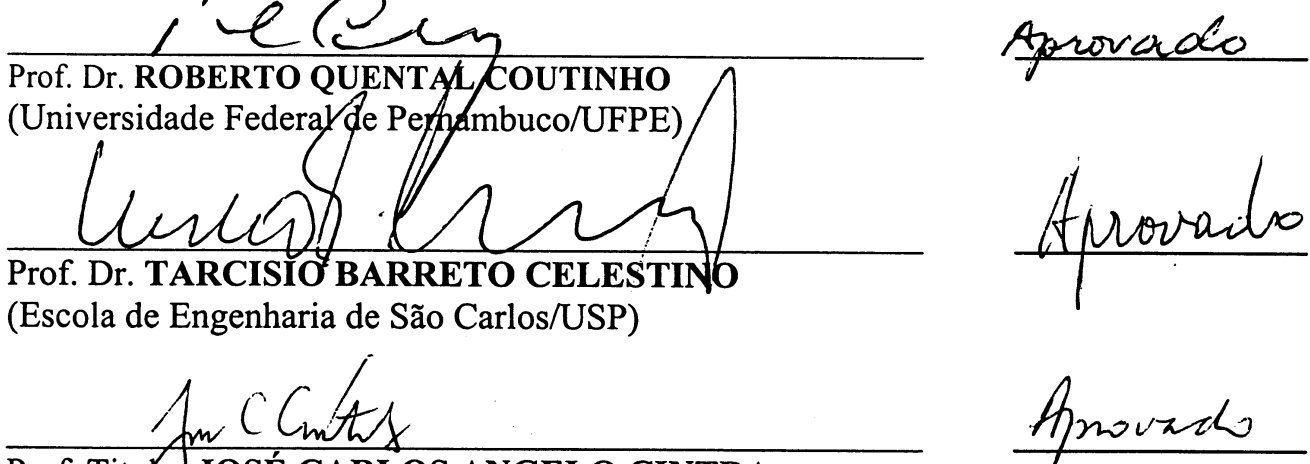

Prof. Titular JOSÉ CARLOS ANGELO CINTRA

(Escola de Engenharia de São Carlos/USP)

Bunadite Ragoni Danziger Profa. Dra. BERNADET RAGONI DANZIeER

(Universidade do Estado do Rio de Janeiro/UERJ)

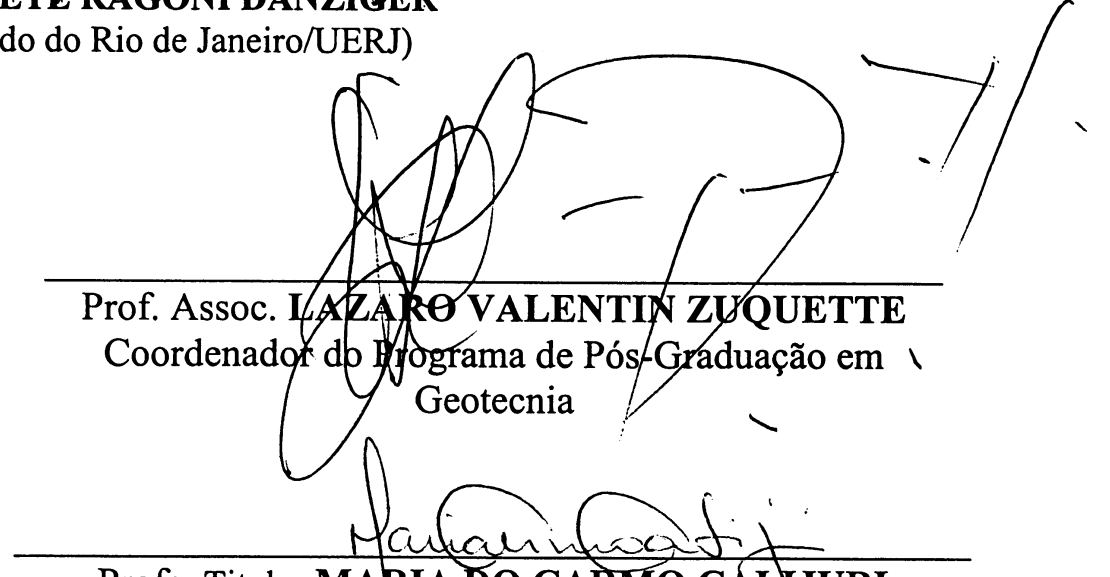

Profa. Titular MARIA DO CARMO CALIJURI

Presidente da Comissão de Pós-Graduação da EESC 


\section{AGRADECIMENTOS}

Ao Professor Nelson Aoki pela orientação e, principalmente, por acreditar em mim quando nem eu mesmo acreditava. Para mim foi uma honra trabalhar ao seu lado.

Ao Professor Airton Bortolucci por me disponibilizar o Laboratório de Mecânica das Rochas, permitindo assim a realização do programa experimental.

Ao Professor Benedito de Souza Bue no por me disponibilizar os equipamentos do Laboratório de Geossintéticos.

Ao Professor Tarcísio Barreto Celestino pelas idéias e sugestões.

Ao Professor Faiçal Massad pelas sugestões e questionamentos durante o exame de qualificação.

A coordenação do programa de pós-graduação em geotecnia nas pessoas dos Professores Lazáro Zuquete e José Carlos Ângelo Cintra que não mediram esforços para a concretização de mais essa Tese.

Ao Engenheiro Kleber Azevedo Dourado por sua valiosa amizade e fraternidade.

Ao Professor Antônio Belincanta pela amizade e relevantes conselhos.

A Professora Nelci Helena Maia Gutierrez pelo apoio em todos os momentos.

Ao Departamento de Engenharia Civil da Universidade Estadual de Maringá na pessoa do Professor Paulo Fernando Soares pelo apoio para conclusão dessa tese.

Ao Professor Francisco Ladaga pelo incentivo e pela infraestrutura a mim disponibilizada para conclusão desta tese.

Ao Professor Márcio Miranda Soares (in memoriam) pelo incentivo profissional. hospitalidade.

Aos Geológos José Jânio, Paulo Maurício e Domingos pelo abrigo e

A Geológa Sandra Fernandes Silva pela compreensão durante os momentos difíceis.

Ao Professor Paulo Gustavo Lins pelas idéias e apoio durante a fase inicial desse trabalho.

Ao Engenheiro Valério Almeida pelo companheirismo e pelas dicas de programação.

Ao Engenheiro Benedito Souza que me acompanhou durante todo o trabalho experimental.

A Professora Maria Aparecida Sert pelo seu amor e carinho, pelo incentivo e pela presença em todas as horas.

A CAPES pela bolsa de estudos e por patrocinar esta tese.

Aos funcionários, professores, colegas e amigos da Geotecnia de São Carlos pela saudosa convivência que me proporcionaram durante minha estada aqui.

E por fim, o mais importante, agradeço a Deus, clemente e misericordioso, e a Jesus Cristo, seu únido filho e nosso senhor. 
Dedico está tese aos meus pais, Juvêncio Hemetério Neto e Francisca Cordeiro da Silva.

Aos amigos José Jânio, Luiz Baras, Ana Valéria.

A minha querida e amada Maria Aparecida Sert. 
Cruel vaidade humana, a de ser,

e ter de mostrar o que é, sem, ao menos, saber viver. 
LISTA DE FIGURAS

LISTA DE TABELAS viii

LISTA DE SÍMBOLOS ix

RESUMO Xi

ABSTRACT xii

1. INTRODUÇÃO

1.1.Objetivos do trabalho 4

1.2. Ordenação dos capítulos

2. MODELO DE ATRITO ESTÁtICO EM INTERFACES SOLO- 6 ESTRUTURA

2.1. Revisão bibliográfica sobre modelos matemáticos em interface 6

2.1.1. Resistência devido ao atrito em interfaces 7

2.1.2. Dilatância 19

2.1.3. Rearranjo das partículas 23

2.2. Revisão bliográfica sobre modelos experimentais em interfaces 27

2.2.1. Ensaios de cisalhamento direto 28

2.2.2. Ensaios de cisalhamento simples 32

2.2.3. Outros ensaios 32

2.2.4. Avaliação dos trabalhos experimentais em interfaces solo-estrutura 33

2.3. Modelo matemático para atrito estático em interfaces 34

2.3.1. Tipos de trajetórias de carregamento em ensaios de cisalhamento direto $\quad 38$

2.3.2. Equação de tensão tangencial mobilizada na interface em função do deslocamento $u$ para o caso de cisalhamento com tensão normal constante

3. ESTUDO EXPERIMENTAL DE INTERFACES SOLO-ESTRUTURA 50

3.1. Equipamento $\quad 50$

3.2. Instrumentação $\quad 52$

3.3. Materiais utilizados 54 
3.5. Resultados experimentais dos ensaios de cisalhamento direto com carga normal constante em interface concreto-areia

4. CALIBRAÇÃO E INTERPRETAÇÃO DA NATUREZA DOS PARÂMETROS FÍSICOS

4.1. Avaliação da natureza do módulo de dilatância $\mathrm{k}$

4.2. Avaliação da natureza do coeficiente de rearranjo $\eta$

4.3. Previsão do ângulo de atrito verdadeiro na interface $\delta$; módulo de dilatância $k$ e o coeficiente de rearranjo $\eta$.

\section{INTERAÇÃO SOLO-ESTRUTURA}

5.1. Revisão bibliográfica sobre elementos de interface

5.2. Modelos constitutivos utilizados em elementos de interfaces

5.3. Aplicação do modelo proposto em análises numéricas pelo método dos elementos finitos

6. TRANSFERÊNCIA DE CARGA EM ESTACAS POR ATRITO LATERAL

6.1.1. Resultados Experimentais de Orlando (2000)

6.1.2. Análise numérica dos ensaios de Orlando (2000) através de modelos unidimensionais

6.2. Modelos bidimensionais

6.2.1. Estaca submetida a compressão Bernardes (1989)..

6.2.2. Simulação numérica dos resultados de Bernardes (1987) com elementos finitos bidimensionais

\section{CONCLUSÕES E SUGESTÕES}

7.1. Conclusões gerais

7.2. Sugestões para futuras pesquisas. 


\section{LISTA DE FIGURAS}

Figura 2.1 - Modelo rígido plástico 6

Figura 2.2 - Envoltória de Mohr-Coulomb para material granular seco onde 7 $\sigma=\sigma^{\prime}$

Figura 2.3 - Mecanismo de atrito seco entre um bloco rígido e uma superfície horizontal rígida indeslocável: a) um bloco é puxado sobre uma superfície horizontal; b) diagrama de forças atuantes sobre o corpo.

Figura 2.4 - Cone de ruptura para interfaces entre blocos rígidos/critério de Mohr-Coulomb (Meriam, 1977).

Figura 2.5 - Modelo Hiperbólico de Duncan e Chang (1970

Figura 2.6 - Ajuste do modelo de Clough e Duncan (1971) a resultados de ensaios de cisalhamento direto típicos de interface concreto areia (Gómez, 2000): a) comparação entre os resultados de ensaios e o modelo hiperbólico; b) ajuste da reta aos valores linearizados para determinação dos parâmetros $a$ e $b$.

Figura 2.7. - Envoltória de ruptura de Mohr - Coulomb.

Figura 2.8 - Modelo de ruptura de Patton (1966).

Figura 2.9 - Modelo de ruptura quando vencidas as descontinuidades (Patton, 1966).

Figura 2.10 - Critério de ruptura de bi-linear de Patton (1966).

Figura 2.11 - Classificação das rugosidades e previsão da resistência de juntas não planas (Barton, 1976).

Figura 2.12 - Modelo de ruptura Rowe (1962).

Figura 2.13 - Resultado típico de ensaios de cisalhamento direto em areias.

Figura 2.14 - Parcelas de resistência das areias (Rowe, 1962).

Figura 2.15 - Parcelas de resistência em função do nível de tensão confinante (Ponce e Bell, 1971).

Figura 2.16 - Modelo tridimensional de componentes de resistência ao cisalhamento das areias em função da pressão normal aplicada e da densidade inicial da areia (Ponce e Bell, 1971). 
Figura 2.17 - Roda submetida a uma força $\mathrm{P}$, aplicada de modo a provocar o rolamento do cilindro sobre a superfície (Meriam, 1977).

Figura 2.18 - Roda submetida a uma força $(P+d P)$, aplicada de modo a provocar um deslocamento $d u$.

Figura 2.19 - Modelo de contato concreto-areia

Figura 2.20 - Curvas de tensão normal $\sigma(u)$, tensão tangencial $\tau(u) \mathrm{e}$ variação de volume $V(u)$ em função do deslocamento $u$.

Figura 2.21 - Curvas de interpretação do atrito em interfaces submetido ao cisalhamento com deslocamento normal constante: a) $\sigma(u) x u$;b) $\tau(u) x u$; c) $\sigma(u) x v$.

Figura 2.22 - Curvas de interpretação do atrito em interfaces submetido ao cisalhamento com rigidez normal constante: a) 40 $\sigma(u) x u$;b) $\tau(u) x u$; c) $\sigma(u) x v$.

Figura 2.23 - Curvas de interpretação do atrito em interfaces submetido ao cisalhamento com tensão normal constante: a) $\sigma(u) x u$;b) $\tau(u) x u$; c) $\sigma(u) x v$.

Figura 2.24-Curvas representativas das parcelas correspondentes.

Figura 2.25 - Curva tensão tangencial mobilizada versus deslocamento $u$ (Equação 2.80).

Figura 2.26 - Linha de estado crítico

Figura 3.1 - Prensa de cisalhamento

Figura 3.2. - Caixa de cisalhamento

Figura 3.3 - a) Superfície de areia anterior à inserção do bloco de concreto na parte superior; b) bloco de concreto utilizado no ensaio; c) contato areia concreto antes do ensaio vista anterior; d) contato areiaconcreto antes do ensaio: vista posterior; e) superfície de areia cisalhada após a retida do bloco de concreto; f) estado da superfície de areia após o cisalhamento.

Figura 3.4 - a) Transdutor de deslocamento vertical com cursor de $\pm 35 \mathrm{~mm}$; b) transdutor de deslocamento horizontal com cursor de $\pm 10 \mathrm{~mm}$; c) atuador de carga vertical com capacidade de $500 \mathrm{kN}$; d) atuador de carga horizontal com capacidade de $500 \mathrm{kN}$; e) vista frontal do ensaio; f) vista lateral do ensaio. 
Figura 3.5 - a) Negativo da superfície rugosa utilizada no bloco de concreto utilizado; b) modelo digital da superfície rugosa utilizada no bloco 56 de concreto utilizado.

Figura 3.6 - Curva granulométrica 57

Figura 3.7 - Imagens microscópicas da areia A1 58

Figura 3.8 - Imagens microscópicas da areia A2 58

Figura 3.9 - Resultados de ensaios de cisalhamento direto em amostras de areia.

Figura 3.10 - Curva de índice de vazios inicial versus variação de volume na ruptura.

Figura 3.11 - Linha de estado crítico pelo método de Casagrande.

Figura 3.12 - Envoltórias de resistência de Mohr-Coulomb para areia A1

Figura 3.13 - Envoltórias de resistência de Mohr-Coulomb para areia A2

Figura 3.14 - Valores do ângulo de atrito máximo mobilizado (de pico e residual) obtidos em ensaios de cisalhamento direto: a) areia A1; b) areia $\mathrm{A} 2$.

Figura 3.15 - Variação do módulo eodométrico secante da areia A1 em função da tensão normal aplicada .

Figura 3.16 - Variação do módulo oedométrico secante da areia A2 em função da tensão normal aplicada .

Figura 3.17 - Curvas tensão tangencial versus deslocamento tangencial e variação de volume versus deslocamento tangencial para a areia

A1 compacta em contato com superfície rugosa de concreto.

Figura 3.18 - Curvas tensão tangencial versus deslocamento tangencial e variação de volume versus deslocamento tangencial para a areia A1 compacta em contato com superfície rugosa de concreto.

Figura 3.19 - Curvas tensão tangencial versus deslocamento tangencial e variação de volume versus deslocamento tangencial para a areia A1 compacta em contato com superfície lisa de concreto.

Figura 3.20 - Curvas tensão tangencial versus deslocamento tangencial e variação de volume versus deslocamento tangencial para a areia A1 fofa em contato com superfície rugosa de concreto. 
Figura 3.21 - Curvas tensão tangencial versus deslocamento tangencial e variação de volume versus deslocamento tangencial para a areia

A1 fofa em contato com superfície lisa de concreto.

Figura 3.22 - Curvas tensão tangencial versus deslocamento tangencial e variação de volume versus deslocamento tangencial para a areia

A2 compacta em contato com superfície rugosa de concreto.

Figura 3.23 - Curvas tensão tangencial versus deslocamento tangencial e variação de volume versus deslocamento tangencial para a areia

A2 compacta em contato com superfície lisa de concreto.

Figura 3.24 - Curvas tensão tangencial versus deslocamento tangencial e variação de volume versus deslocamento tangencial para a areia A2 fofa em contato com superfície rugosa de concreto.

Figura 3.25 - Curvas tensão tangencial versus deslocamento tangencial e variação de volume versus deslocamento tangencial para a areia A2 fofa em contato com superfície lisa de concreto.

Figura 3.26 - Ângulos de atrito em superficie de contato areia concreto.

Figura 3.27 - Resultados de recarregamento em interfaces de contato entre a areia grossa A1 e Superfície RU.

Figura 3.28 - Resultados de recarregamento em interfaces de contato entre a areia grossa A1 e Superfície SL.

Figura 3.29 - Resultados de recarregamento em interfaces de contato entre a areia grossa A2 e Superfície RU.

Figura 3.30 - Resultados de recarregamento em interfaces de contato entre a areia grossa A2 e Superfície SL.

Figura 4.1 - Comparação entre resultados experimentais e os do modelo calibrado para areia fina densa

Figura 4.2 - Comparação entre resultados experimentais e os do modelo calibrado para areia fina fofa

Figura 4.3 - Comparação entre resultados experimentais e os do modelo calibrado para areia grossa A2 compacta

Figura 4.4 - Comparação entre resultados experimentais e os do modelo calibrado para areia grossa A2 fofa

Figura 4.5 - Modelo de rugosidade 
Figura 4.6 - Curvas de tensão cisalhante versus deslocamento de blocos com diferentes tamanhos, submetidos a tensão normal de $2 \mathrm{MPa}$

Figura 4.7 - Comparação entre o Módulo de Dilatância teórico e experimental

Figura 4.8 - Comparação entre o coeficiente de rearranjo teórico e experimental.

Figura 5.1 - Elemento de junta em coordenadas locais (Goodman et al., 1968)

Figura 5.2 - Modelo hipotético de comportamento mecânico em uma junta (Goodman et al., 1968).

Figura 5.3 - Elemento de junta com rotação (Goodman, 1977)

Figura 5.4 - Determinação da rigidez rotacional (Goodman, 1977)

Figura 5.5 - Formulação de elemento de interface considerando a espessura da junta (Wilson, 1977): A) elemento bidimensional; B) elemento de interface e seus deslocamentos nodais correspondentes; C) deslocamentos nodais da banda superior e deformações do elemento; D) deformações do elemento em função dos deslocamentos nodais.

Figura 5.6 - Relações tensão-deslocamento em interface solo-estrutura (Desai e Nagaraj, 1988): (a) tensões normais; (b) tensões cisalhantes.

Figura 5.7 - Modos de deformação na interface (Ng et al., 1997)

Figura 5.8 - Modelo de comportamento mecânico na interface (Frank, Guenot e Humbert, 1992)

Figura 5.9 - Curva tensão versus deslocamento para "§oftening behaviour" (Desai, 1977).

Figura 5.10 - Modelo constitutivo para o comportamento da tensão cisalhante em função do deslocamento (Goodman, 1977).

Figura 5.11 - Dilatância no cisalhamento de rochas mantida a tensão normal constante (Goodman, 1977).

Figura 5.12 - Proporção da área de contato na parede da junta durante o cisalhamento (Goodman, 1977)

Figura $6.1 \quad$ - Estaca de referência

Figura 6.2 - Elemento de infinitesimal 
Figura 6.3 - Comportamento de cisalhamento na interface.

Figura 6.4 - Comportamento de cisalhamento na interface (Randolph, 1985).

Figura 6.5 - Distribuíção de tensões verticais em torno de uma estaca imbutida em meio sólido elástico (Martins, 1945 apud Grillo,1948).

Figura 6.6 - Diagramas de transferência de carga considerados por Geddes (1969).

Figura 6.7 - Diagramas de atrito lateral local e total

Figura 6.8 - Mobilização de tensão lateral em função do deslocamento que ocorreu em estacas cravadas em areia, (Coyle e Sulaiman, 1967).

Figura 6.9 - Mobilização do atrito lateral (Lopes, 1986).

Figura 6.10 - Modelo mecânico de uma estaca carregada axialmente (Reese, 1978)

Figura 6.11 - Modelo de cálculo de recalques em estacas sobre apoios elastoplástico perfeito (Bernardes, 1989)

Figura 6.12 - Comportamento elástico linear perfeitamente plástico

Figura 6.13 - Estacas sobre apoios elásticos não lineares (Bernardes, 1989)

Figura 6.14 - Curva de variação de tensão cisalhamente na interface estacasolo (Zhu e Chang, 2002)

Figura 6.15 - Modelo simplificado de análise de interação estaca-solo: a) estaca sobre apoios elásticos; b) tensão tangencial mobilizada em função do deslocamento (Liu et al., 2004)

Figura 6.16 -Modelo tri-linear para tensão tangencial mobilizada em função do deslocamento (Guo, 2001)

Figura 6.17 - Curva Granulométrica da areia utilizada por Orlando (2000)

Figura 6.18 - Ângulo de atrito de pico: a) em função do peso específico; b) em função do índice de vazios (Orlando, 2000).

Figura 6.19 - Envoltória de Morh-Coulomb para a resistência da areia (Orlando, 2000).

Figura 6.20 - Curva carga-deslocamento para os ensaios em modelo com areia fofa e $\frac{L}{D}=10$ (Orlando, 2000).

Figura 6.21 - Curva carga-deslocamento para os ensaios em modelo com areia fofa e $\frac{L}{D}=10$ (Orlando, 2000). 
Figura 6.22 - Modelo numérico da estaca $\frac{L}{D}=10$ de Orlando (2000).

Figura 6.23 - Curva carga-recalque medida e calculada para a estaca de $\frac{L}{D}=10$ executada em areia fofa.

Figura 6.24 - Diagrama de esforço normal calculado na simulação da prova de carga no modelo $\frac{L}{D}=10$ executada em areia fofa.

Figura 6.25 - Curva carga-recalque medida e calculada para a estaca de $\frac{L}{D}=10$ executada em areia compacta.

Figura 6.26 - Diagrama de esforço normal calculado na simulação da prova de carga no modelo $\frac{L}{D}=10$ executada em areia densa.

Figura 6.27 - Possibilidades de trajetória de tensões de uma estaca até a ruptura (Lopes, 1979).

Figura 6.28 - Comparação entre as trajetórias de carregamento (Lopes, 1979):

(a) em torno de fuste de uma estaca, (b) em ensaio triaxial convencional em um solo não dilatante, (c) comparação entre eles.

Figura 6.29 - Estaca instrumentada utilizada por Bernardes (1989).

Figura 6.30 - Dados gerais da areia utilizada por Bernardes (1989)

Figura 6.31 - Ângulo de atrito versus porosidade (Bernardes, 1989)

Figura 6.32 - Resultado dos ensaios de carregamento estático em modelo de estaca submetida apenas ao atrito lateral (Bernardes, 1989)

Figura 6.33 - Deformada obtida na simulação dos resultados de Bernardes (1987) pelo método dos elementos finitos.

Figura 6.34 - Curva carga-recalque medida e calculada na simulação dos resultados de Bernardes (1987).

Figura 6.35 - Diagrama de esforço normal calculado para estaca 5 de Bernardes (1987).

Figura 6.36 - Diagrama de distribuição das tensões principais menor

Figura 6.37 - Diagrama de distribuição das tensões principais maior

Figura 6.38 - Diagrama de distribuição das tensões na direção radial

Figura 6.39 - Diagrama de distribuição das tensões cisalhantes

Figura 6.40 - Diagrama de distribuição das tensões na direção vertical

Figura 6.41 - Vetores da direção das tensões principais. 


\section{LISTA DE TABELAS}

Tabela 2.1 - Ângulos de atrito em interfaces entre vários materiais de fundação e solo (Bowles, 1988).

Tabela 2.2 - Ângulos de atrito em interfaces estaca-areia (Randolph, 1986).

Tabela 2.3 - Perfil de referência para estimativa de JRC (Barton e Coubey,

1977).
Tabela 3.1 - Valores de ângulos de atrito e coeficientes de adesão entre solo e diversos materiais de construção (Potyondy, 1961).

Tabela 3.2 - Resultados de ensaios de cisalhamento direto em interfaces areiaconcreto (Gómez, 2000).

Tabela 3.3 - Características do concreto fresco.

Tabela 3.4 - Propriedades do concreto endurecido.

Tabela 3.5 - Propriedades da Superfície.

Tabela 3.6 - Índices Físicos.

Tabela 3.7 - Valores de peso específico seco, índice de vazios inicial e variação de volume na ruptura para as areias A1 e A2.

Tabela 3.8 - Valores de índice de vazios crítico das areias A1 e A2 para cada nível tensão normal.

Tabela 3.9 - Valores dos ângulos de atrito das areias A1 e A2 obtidos apartir das relações $\frac{\tau_{\text {pico }}}{\sigma}$ e $\frac{\tau_{\text {residual }}}{\sigma}$ e seus correpondentes índice de vazios inicial, para cada nível de tensão normal.

Tabela 3.10 - Valores dos ângulos de atrito nas interfaces estudadas obtidos a partir das relações $\frac{\tau_{\text {pico }}}{\sigma}$ e $\frac{\tau_{\text {residual }}}{\sigma}$ e os correpondentes índice de vazios inicial da areia que formou a interface para cada nível de tensão normal.

Tabela 3.11 - Valores dos ângulos de atrito nas interfaces estudadas obtidos apartir das relações $\frac{\tau_{\max }}{\sigma}$.

Tabela 4.1 - Valores do ângulo de atrito verdadeiro na interface $\delta$; módulo de dilatância $k$ e o coeficiente de rearranjo $\eta$

Tabela 4.2 - Propriedades da superfície.

Tabela 4.3 - Índices físicos.

Tabela 4.4 - Valores do ângulo de atrito verdadeiro na interface $\delta$; módulo de dilatância $k$ e o coeficiente de rearranjo

Tabela 6.1 - Parâmetros utilizados na simulação simulação da Estaca de $\frac{L}{D}=10$ executado em maciço de areia no estado fofo.

Tabela 6.2 - Parâmetros utilizados na simulação simulação da Estaca de $\frac{L}{D}=10$ executado em maciço de areia no estado compacto.

Tabela 6.3 - Parâmetros utilizados na simulação simulação dos resultados de Bernardes (1985). 


\section{LISTA DE SIMBOLOS}

$\tau_{s}$ é tensão de cisalhamento

$\sigma$ é tensão normal à superfície

$c$ é a coesão

$\phi$ é o ângulo de atrito do solo

$\delta$ é o de ângulo de atrito efetivo da interface

$\mu$ é o coeficiente de atrito da interface

$u$ é o deslocamento tangencial

$u_{o}$ é o deslocamento tangencial na ruptura

$k$ é uma constante que depende de cada material

$\sigma_{1} e \sigma_{3}$ são as tensões principais atuantes sobre o solo

$\varepsilon$ é a deformação axial

$R_{f}$ é a razão de rup tura e seu valor poderia variar entre 0,75 a 1,0

$E_{i}$ é módulo tangente inicial

$\sigma_{3}$ é a tensão principal menor ou tensão de confinamento

$p_{a}$ pressão atmosférica

$n$ e $k$ são números puros determinados através do ajuste de uma série de resultados experimentais.

$q_{u}$ resistência à compressão simples

$k_{s i}$ a rigidez inicial da interface

$K_{I}$ um número de rigidez adimensional (definido em função do ajuste da curva)

$n_{j}$ um expoente de rigidez adimensional (definido em função do ajuste da curva)

$\sigma_{n}$ a tensão normal atuante na interface

$\delta$ o ângulo de atrito máximo mobilizado na interface

$u$ é o deslocamento tangencial à interface

$J R C$ é o coeficiente de rugosidade da descontinuidade

JCS é o coeficiente de resistência da descontinuidade

$\phi_{b}$ é o ângulo de atrito básico, geralmente igual ao ângulo de atrito residual

$V_{c r i}$ é o volume crítico

$V_{0}$ é a interseção da linha de estado crítico com o eixo de volume

$\Lambda$ é a inclinação da linha de estados críticos

$e_{c r i}$ é o índice de vazios crítico

$\Gamma$ é a interseção da linha de estado crítico com o eixo de vertical

$\lambda$ é a inclinação da linha de estados críticos

$\phi^{\prime}$ é o ângulo de atrito efetivo do solo

$\phi_{c v}$ é o ângulo de atrito plano

$\psi$ é o ângulo de dilatância.

$K$ é o coeficiente de rigidez normal ao cisalhamento

$\Delta v$ é o deslocamento vertical, devido à variação do volume provocado pelo cisalhamento

$\Delta \sigma$ é a variação da tensão normal. 
$\frac{a}{r}$ é o coeficiente de atrito de rolamento

$r$ é o raio do cilindro

$u$ é o deslocamento na direção $u$

$H_{0}$ é areia seca de espessura

$u$ deslocamento tangencial

$\tau(u)$ é tensão tangencial média mobilizada em função de $\mathrm{u}$

$v_{f}$ é variação de deslocamento vertical

$V(u)$ variação de volume em função do deslocamento tangencial $\mathrm{u}$

$\Delta \sigma(u)$ é a variação da tensão normal em função do deslocamento tangencial u

$\Delta \sigma_{r}(u)$ é a variação da tensão normal reativa mobilizada na interface em função do deslocamento imposto $u$ devida ao rolamento das partículas

$\eta$ é o coeficiente de rearranjo que é definido como o coeficiente de proporcionalidade entre a variação da tensão normal e a taxa de variação da tensão tangencial mobilizada na interface em função do deslocamento $u$

$\frac{d \tau(u)}{d u}$ é a taxa de variação da tensão tangencial mobilizada na interface em função do deslocamento $u$.

$\Delta \sigma_{d}(u)$ é a variação da tensão normal reativa mobilizada na interface em função do deslocamento imposto $u$ devida à variação de volume na interface

$k$ é o módulo de dilatância que é definido coeficiente de proporcionalidade entre a variação da tensão normal na interface e a taxa de variação de volume em função do deslocamento $u$.

$\sigma_{0}$ é a tensão normal inicial aplicada na interface

$N_{0}$ força normal inicial aplicada na interface

$\delta$ é o ângulo de atrito mobilizado na interface

$\sigma_{0}$ a tensão normal inicial aplicada sobre o contato

$\lambda$ a inclinação da reta crítica

$G$ é o módulo de elasticidade transversal

$R_{\max }$ é a rugosidade máxima ou a maior deflexão na superfície do contato

$L_{\text {médio }}$ largura média da bacia de rugosidade ou o comprimento médio da bacia de rugosidade na direção do deslocamento

$R_{n}$ rugosidade da superfície de contado

$A$ é a área do plano de contato (propriedade geométrica do contato)

$C_{c}$ é o coeficiente de curvatura

$D_{50}$ é o diâmetro médio das partículas

$D R$ é a densidade relativa do solo

$E_{\text {oed }}$ é o módulo de elasticidade oedométrico 


\section{RESUMO}

REIS, J. H. C. (2006). Modelo de atrito estático em interfaces de contato entre concreto e areia. Tese (Doutorado) - Escola de Engenharia de São Carlos, Universidade de São Paulo, São Carlos, 2006.

Esta tese apresenta os princípios e a formulação de um modelo não-linear de atrito estático em interface de concreto areia. A hipótese básica para desenvolvimento das equações consiste na ocorrência do atrito de deslizamento (atrito verdadeiro), do atrito de rolamento (rearranjo das partículas) e da dilatância (variação de volume durante o cisalhamento). A solução analítica do modelo considera o efeito da rugosidade da superfície de contato, da curva granulométrica da areia e do seu estado de compacidade inicial. Foram realizados ensaios de cisalhamento direto com carga normal constante em interface de contato entre concreto e areia com seção de $500 \mathrm{~mm}$ x $500 \mathrm{~mm}$ com o objetivo de permitir a calibração do modelo proposto. É discutida e sugerida a incorporação da equação constitutiva desse modelo em análises de interação soloestrutura via método dos elementos finitos. Sua aplicabilidade é demonstrada através da análise 1D e 2D de estacas de atrito executadas em areia e submetidas a carregamentos de compressão.

Palavras-chave: atrito, modelo constitutivo, interação solo-estutura, interface, ensaio de cisalhamento direto, atrito lateral em estacas. 


\begin{abstract}
REIS, J.H.C. (2006). A model for the static friction between concrete-sand interface contact. Doctor thesis - The School of Engineering at São Carlos, the University of São Paulo, São Carlos, 2006.
\end{abstract}

This thesis presents the principles and formulation underlying a concrete-sand interface nonlinear static friction model. The basic hypothesis employed in the development of the model equation takes into account the interface sliding friction (true friction), a rolling friction (particle rearrangement) and dilatancy (volume variation during shear). The model analytical solution considers the effect of roughness of the contact surface, the grain size distribution and its initial state of compactness of the sand. To calibrate the proposed model, a direct shear stress test under constant load was carried out along a $500 \mathrm{~mm} \times 500 \mathrm{~mm}$ section concrete-sand interface. Furthermore, a discussion and suggestion of the inclusion of the model constitutive equation applied to the analysis of soil-structure interaction using the finite element method are presented. The applicability of the proposed model is proven through the analysis of 1-D and 2-D skin friction piles made of sand mass subjected to compression load.

Keywords : friction, constitutive model, soil- structure interaction, interface, direct shear test, lateral friction in piles. 


\section{CAPÍTULO I \\ INTRODUÇÃO}

Atualmente, apesar da evolução tecnológica que ocorreu em todos os ramos da indústria da construção civil, a prática de projetos de fundações ainda se baseia em procedimentos empíricos.

Muitos desses modelos possuem caráter puramente local ou regional, no entanto são largamente empregados sem qualquer adaptação ou comprovação científica de sua validade.

Aliado a esse fato, percebe-se ainda que a maioria dos modelos teóricos disponíveis possuem grande número de propriedades mecânicas, cuja dificuldade de determinação experimental acaba por inviabilizar sua utilização.

Dessa maneira, recorre-se sempre aos modelos clássicos de análise. Em engenharia de fundações, esses modelos servem principalmente para previsão da capacidade de carga.

Essa realidade condiciona a técnica de projetos de tal forma que, na maioria dos escritórios, o projeto de fundações se restringe à determinação da capacidade de carga ou como define a NBR 6122/96, à verificação do estado limite último.

No entanto, essa mesma norma rege que as verificações de projeto sejam a de segurança contra a ruptura do elemento estrutural e do maciço de solos (estabilidade interna e externa) e de segurança contra máximos deslocamentos e deformações suportados pela superestrutura.

A dificuldade que se encontra para verificação dos deslocamentos de apoios de uma edificação existe devido à complexidade das relações de transferência de carga entre os diversos elementos que compõem esta edificação. Essa complexidade é causada pelas multiplicidades entre as propriedades mecânicas e geométricas encontradas destes elementos. 
Quando se trata especificamente das fundações, nota-se que se somam à essas dificuldades, as questões relativas ao problema de transferência de esforços na interface estrutura-solo.

A distribuição de tensões ao longo da interface do elemento estrutural com o maciço de solos tem importância fundamental no dimensionamento estrutural e, principalmente, na avaliação das deformações e dos deslocamentos.

A avaliação do comportamento da interface estaca-solo sempre foi do interesse da maioria dos pesquisadores da área de fundações, onde a maior parte dos trabalhos tem como objetivo a verificação da resistência do sistema.

Quando se trata de fundações profundas em estacas, percebe-se que, no mesmo problema, se identificam duas interfaces estaca-solo diferentes: a interface da base e a interface lateral.

No caso específico de estaca sujeita a uma carga vertical axial de compressão, a interface da base se caracteriza por resistir a esforços predominantemente de compressão, enquanto que a interface lateral se caracteriza por resistir a esforços de cisalhamento.

O mecanismo de cisalhamento na interface solo-estrutura tem influência significativa no comportamento de estruturas que trabalham com resistência ao atrito, como estacas, ancoragens, estruturas de contenção e solo grampeado. A compreensão desse mecanismo resulta na adoção de modelos mais condizentes com o comportamento da curva carga-deslocamento, com o valor da capacidade de carga e com a transferência de esforços da estrutura para o maciço de solos.

De maneira geral, os problemas mecânicos relacionados à interfaces submetidas a esforços de cisalhamento têm sido tratados com a utilização do critério de MohrCoulomb, independentemente do tipo de interface e se restringindo, portanto, ao estudo da resistência ao cisalhamento.

Uma análise completa, deve considerar a deformabilidade do maciço de solos e do elemento estrutural e, principalmente, do comportamento mecânico mobilizado na interface.

A interação solo-estrutura é definida como o conjunto de problemas cuja previsão do comportamento mecânico depende não somente do comportamento reológico dos materiais que constituem o meio, mas principalmente das relações de compatibilidade que se estabelecem entre suas partes. 
A análise de interação solo-estrutura tem se constituído em uma ferramenta poderosa para análise e compreensão de problemas geotécnicos em geral, principalmente com o desenvolvimento de ferramentas computacionais capazes de resolver grandes sistemas de equações não lineares.

No estudo de interfaces de estaca-solo submetidas ao cisalhamento vários pesquisadores têm desenvolvido técnicas numéricas de solução eficazes e que podem incorporar vários modelos constitutivos dos materiais.

Apesar disso, os modelos constitutivos para interfaces submetidas ao cisalhamento existentes são geralmente do tipo elástico linear ou elástico linear perfeitamente plástico. A determinação dos parâmetros dos modelos corresponde ao cálculo do coecifiente de rigidez normal e de cisalhamento e da tensão de ruptura, através de um critério de ruptura.

Os modelos não lineares disponíveis, por sua vez, acabam sendo inviáveis para uso geral devido ao grande número de parâmetros reológicos cuja, determinação é, na maior parte dos casos, feita através de métodos empíricos ou pelo simples ajuste de curvas de resultados experimentais.

Esses procedimentos acabam por descartar algumas variáveis importantes no fenômeno de cisalhamento, como a granulometria do material, o estado inicial de compacidade do maciço de solos e o nível de tensão aplicada. Além disso, limitam a compreensão completa do fenômeno de deslizamento em interfaces.

O fenômeno de deslizamento entre corpos rígidos e deformáveis também é largamente estudado pela mecânica clássica. A esse ramo do conhecimento dá-se o nome de Tribologia.

Dove e Jarrett (2002), estudando o comportamento de interface entre areia e alumínio, considerando o efeito da dilatância, denominam de Geotribologia o fenômeno de atrito em interfaces de juntas de maciços rochosos, em interfaces entre solo e geomembrana e interfaces entre solo e materiais de construção.

Em tribologia, o atrito é classificado em três tipos: o atrito de deslizamento, o atrito de rolamento e atrito fluido. $\mathrm{O}$ atrito de deslizamento é encontrado em superfícies de contato entre dois sólidos sem lubrificação. $\mathrm{O}$ atrito de rolamento é encontrado em superfícies de contato entre um corpo plano e outro circular ou cilíndrico. $\mathrm{O}$ atrito fluido é encontrado quando as camadas adjacentes a um fluido movem-se com velocidades diferentes. 
Nesta tese, propõe-se um novo modelo constitutivo para o comportamento de interfaces de areia-concreto submetidas a tensões de cisalhamento no caso particular de tensão normal constante.

Considerando a areia no estado seco e sendo formada por material granular depositado em uma determinada compacidade inicial com variação de volume durante o cisalhamento, o modelo aqui proposto tem por hipóteses básicas a ocorrência de:

- atrito de deslizamento;

- atrito de rolamento (rearranjo das partículas);

- variação de volume quando submetida a tensões normais constantes (dilatância e contração).

As variáveis independentes consideradas para solução do modelo proposto são:

- nível de tensão normal aplicada na interface, considerada constante durante o cisalhamento;

- rugosidade da superfície de contato;

- granulometria da areia;

- compacidade inicial da areia;

- deformabilidade da areia;

- deslocamento tangencial.

\subsection{Objetivos do trabalho}

O objetivo deste trabalho é apresentar um modelo constitutivo de atrito em interfaces, utilizando os conceitos de variação de volume, de rearranjo das partículas e de atrito de deslizamento.

Mostra-se a dedução formal da equação de tensão tangencial mobilizada na interface em função do deslocamento $u$, para o caso de cisalhamento com tensão normal constante.

De acordo com a condição de contorno principal (tensão normal constante durante todo o cisalhemento) a calibração da equação foi realizada através de ensaios de cisalhamento direto de carga normal constante em interfaces de contato entre concreto e areia.

Para ilustrar a utilização prática desta proposição, foram analisados modelos de estacas de atrito disponíveis na literatura, através do Métodos dos Elementos Finitos uni e bidimensionais. 
1.2. Ordenação dos capítulos

Esta tese está dividida em seis capítulos, a comecar por esta introdução, na qual constam os seus objetivos.

O capitulo II detalha o desenvolvimento da formulação do modelo constitutivo para atrito mobilizado em interfaces de areia concreto. Nesse capítulo são apresentados os fundamentos de um modelo constitutivo geral para atrito em interfaces; a equação geral proposta; a aplicação da equação geral em cada caso de cisalhamento e por fim a dedução da equação de tensão tangencial mobilizada na interface em função do deslocamento $u$ para o caso de cisalhamento com tensão normal constante.

O capítulo III apresenta uma descrição do trabalho experimental realizado e que serviu de base para a calibração do modelo aqui prosposto. Descrevem-se detalhes de montagem, propriedades dos materiais e, por fim, os resultados obtidos em ensaios de cisalhamento direto com tensão normal constante realizados em interfaces de contato entre concreto e areia. Os ensaios foram realizados com dois tipos de superfícies de contato, dois tipos de areias diferentes e dois estados de compacidade inicial.

No capítulo IV mostra-se as curvas de calibração do modelo e a interpretação dos parâmetros constitutivos oriundos dessa calibração.

O capítulo $\mathrm{V}$ mostra uma possível formulação de adaptação do modelo aqui proposto para análise de interfaces via Método dos Elementos Finitos.

O capítulo VI mostra a análise de estacas de atrito submetidas à carga vertical de compressão publicadas nos trabalhos de Orlando (2000) e Bernardes (1989). As análises foram realizadas através do método dos elementos finitos unidimensionais e bidimensionais de Goodman et al. (1968).

Finalmente, no capítulo VII, apresenta-se as conclusões e sugestões para futuras pesquisas e aperfeiçoamento do modelo aqui proposto. 
CAPÍTULO II

MODELO DE ATRITO ESTÁTICO EM INTERFACES SOLOESTRUTURA

2.1. Revisão bibliográfica sobre modelos matemáticos em interface

A mobilização da resistência ao atrito estático em solos é um dos assuntos mais estudados e debatidos em mecânica dos solos e das rochas. Diversos autores têm contribuído para a evolução do conhecimento e melhoria da interpretação da resistência ao cisalhamento de solos e rochas.

Tradicionalmente, esse problema é tratado através do uso de um modelo rígido plástico (Figura 2.1), onde a resistência máxima é atingida sem que ocorram deslocamentos (Chicata, 2003).

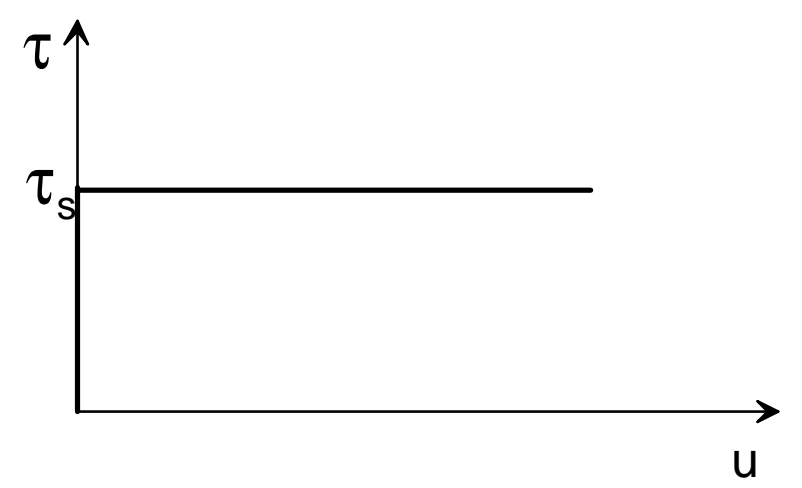

Figura 2.1 - Modelo rígido plástico

Com esse tratamento, o equacionamento do atrito mobilizado se resume à determinação da resistência ao cisalhamento $\tau_{s}$. Para isso, é necessária a utilização de uma equação que represento valor limite em função do estado de tensão ao qual um elemento esteja submetido. A essa equação dá-se o nome de critério de ruptura. 
O critério de ruptura mais aceito e utilizado para cálculo da resistência ao cisalhamento dos solos é o critério de ruptura de Mohr-Coulomb, onde a envoltória de resistência no plano cartesiano $\tau$ versus $\sigma$ é representada por uma função linear.

$\tau_{s}=\sigma \cdot \tan \phi+c$

Em que:

$\tau_{s}$ é tensão de cisalhamento;

$\sigma$ é tensão normal à superfície;

$c$ é a coesão;

$\phi$ é o ângulo de atrito do solo.

Em mecânica dos solos, a equação de Coulomb costuma ser apresentada em termos de tensões efetivas no plano carteziano $\tau$ versus $\sigma^{\prime}$, através de diagrama de Mohr (Figura 2.2). Dessa representação, resulta a equação que é mais familiar a todos os engenheiros geotécnicos, conhecida como envoltória de Mohr-Coulomb e, que para solos, granulares pode ser escrita na forma:

$\tau=\sigma^{\prime} \operatorname{tg} \phi$

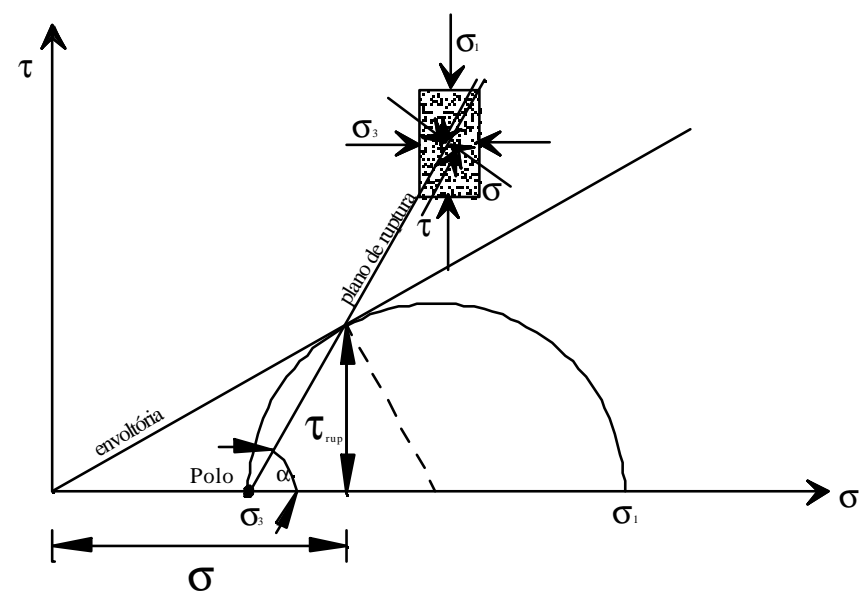

Figura 2.2 - Envoltória de Mohr-Coulomb para material granular seco onde $\sigma=\sigma^{\prime}$

2.1.1. Resistência devido ao atrito em interfaces

É de conhecimento geral que o deslocamento relativo entre um bloco de massa $m$ no campo gravitacional $g$ em contato com uma superfície plana rígida requer a aplicação de uma força tangencial $P$ (Figura 2.3a). Inúmeros trabalhos experimentais demonstram que esta força tangencial é diretamente proporcional à força normal reativa 
$N$ e independe da área de contato. As equações de equilíbrio estático deste sistema mostram que $P$ é numericamente igual à força horizontal reativa mobilizada denominada de força de atrito estático $F$ e que $N$ é numericamente igual a força $m g$. $\mathrm{O}$ diagrama de forças atuantes encontra-se na Figura 2.3b.

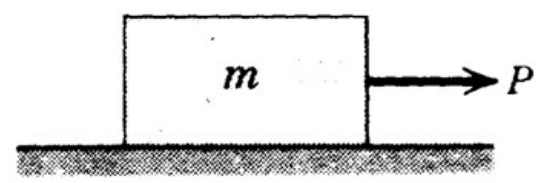

(a)

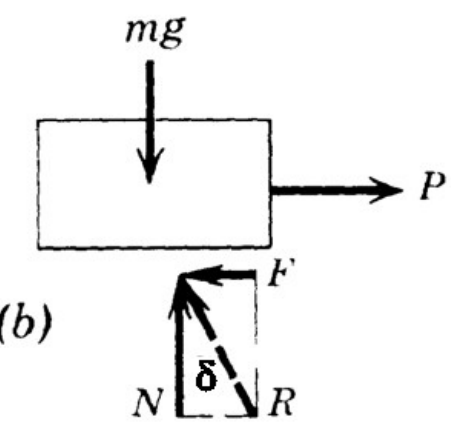

Figura 2.3 - Mecanismo de atrito seco entre um bloco rígido e uma superfície horizontal rígida indeslocável: a) um bloco é puxado sobre uma superfície horizontal; b) diagrama de forças atuantes sobre o corpo.

A Figura 2.3 mostra que o ângulo $\delta$ da resultante $R$ das forças reativas $N$ e $F$ vale $\operatorname{tg} \delta=\mu=\frac{F}{N}$

Onde $\delta$ é denominado de ângulo de atrito efetivo da interface e sua tangente define o chamado coeficiente de atrito da interface $\mu$.

Mulplicando-se e dividindo-se a Equação (2.3) pela área $A$ de contato entre o bloco e a superfície, resulta:

$$
\mu=\frac{F / A}{N / A}
$$

Denominando:

$\tau=F / A$

$\sigma=N / A$

Resulta:

$\operatorname{tg} \delta=\mu=\frac{\tau}{\sigma}$ 
sendo, $\tau$ a tensão média de cisalhamento mobilizada e $\sigma$ tensão média normal efetiva. Ou ainda:

$\tau=\sigma \operatorname{tg} \delta$

Onde: $\tau, \sigma$ e $\delta$ são definidos pelas Equações (2.5), (2.6) e (2.7)

A resultante $R$ possui inclinação limite dada em função do critério de Mohr-Coulomb de acordo com Meriam (1977). Este autor observa que a linha envoltória define claramente a inclinação limite da resultante $R$, de modo que, se o bloco estiver na iminência do deslocamento, a força $R$ será tangente à geratriz de um cone circular reto de abertura $2 \delta, \mathrm{o}$ chamado cone de ruptura (Figura 2.4).

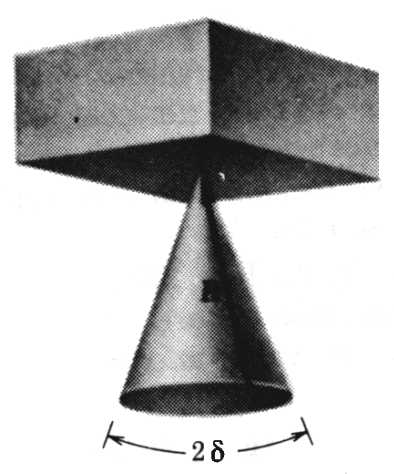

Figura 2.4 - Cone de ruptura para interfaces entre blocos rígidos/critério de MohrCoulomb (Meriam, 1977).

Bowles (1988) apresenta uma relação de valores do ângulo de atrito máximo $\delta$ mobilizado em interfaces de solos com diversos materiais, como mostrado na Tabela 2.1 .

Outros pesquisadores, como Meyerhof (1973), admitem o uso do ângulo de atrito da interface $\delta$ como aproximadamente igual ao ângulo de atrito do solo em casos de maciço argiloso.

Randolph (1985) recomenda os valores listados na Tabela 2.2 para interfaces de estaca-areia, mas chama a atenção para a importância do fenômeno da dilatância, de modo que esses valores devem ser corrigidos de acordo com a densidade relativa da areia. Além disso, o autor comenta sobre a não linearidade da envoltória de resistência ao cisalhamento em interfaces, defendendo que essa não linearidade é semelhante a encontrada em resultados de ensaios triaxiais em solo, de modo que a resistência mobilizada seria função do deslocamento relativo na interface. 
Tabela 2.1 - Ângulos de atrito em interfaces entre vários materiais de fundação e solo/rocha (Bowles, 1988).

\begin{tabular}{lc}
\hline \multicolumn{1}{c}{ Tipos de interface } & $\delta$ (graus) \\
\hline Concreto massa & 35 \\
Rocha sã & $29-31$ \\
Pedregulho a areia grossa & $24-29$ \\
$\quad$ Areia fina a areia média, silte médio a grosso, pedregulho siltoso. & $19-24$ \\
$\quad$ Areia fina siltosa ou argilosa, silte e arenoso. & $17-19$ \\
Silte arenoso & $22-26$ \\
$\quad$ Argila rija a dura ou pré-adensada & $17-19$ \\
$\quad$ Argila mediamente rígida & \\
Aço $\quad$ & 22 \\
$\quad$ Pedregulho a areia grossa & 17 \\
$\quad$ Areia fina a areia média, silte médio a grosso, pedregulho siltoso. & $11-14$ \\
$\quad$ Silte arenoso a areia fina siltosa ou argilosa, silte arenoso. & $22-26$ \\
Concreto moldado com forma & $17-22$ \\
$\quad$ Pedregulho a areia grossa & $14-17$ \\
$\quad$ Areia fina a areia média, silte médio a grosso, pedregulho siltoso. & $14-16$ \\
$\quad$ Silte arenoso a areia fina siltosa ou argilosa, silte arenoso.
\end{tabular}

Tabela 2.2 - Ângulos de atrito em interfaces estaca-areia (Randolph, 1985)

\begin{tabular}{lc}
\hline \multicolumn{1}{c}{ Tipos de interface } & $\delta$ (graus) \\
\hline Areia muito fofa e silte arenoso médio compacto & 15 \\
Areia fofa a mediamente compacta e silte compacto & 20 \\
Areia mediamente compacta a compacta & 25 \\
Areia compacta a muito compacta & 30 \\
Pedregulo compacto e areia muito compacta & 35 \\
\hline
\end{tabular}

Observa-se que todos estes trabalhos não fazem referência à variação da tensão de tangencial mobilizada em função do deslocamento tangencial imposto ao sistema.

De acordo com Vésic (1975) a tensão tangencial mobilizada pode ser relacionada ao deslocamento tangencial através de uma função de transferência de carga. O autor apresenta funções da tensão tangencial mobilizada em função do deslocamento propostas por Kezdi (1957) e outros.

Nesta mesma linha de raciocínio, Potyondy (1961), através da observação de seus resultados experimentais, concluiu que a tensão tangencial moblizada é uma função do deslocamento tangencial $u$ e que para interfaces entre materiais de costrução e solos granulares esta função obedece a uma curva exponencial, na forma:

$$
\tau=\sigma^{\prime} \tan \delta\left(1-e^{-k \frac{u}{u_{0}-u}}\right)
$$


Em que $\tau$ é a tensão de cisalhamento; $\sigma^{\prime}$ é a tensão normal; $\delta$ é o ângulo de atrito em interfaces; $u$ é o deslocamento tangencial; $u_{o}$ é o deslocamento tangencial na ruptura; $k$ é uma constante que depende de cada material.

Modelo semelhante foi apresentado por Teixe ira (2003) ao estudar o mecanismo de interação entre solo-geogrelha através de ensaios de arrancamento.

$\tau=\tau_{u l t}\left(1-e^{-k_{i} \frac{u}{\tau_{u l t}}}\right)$

Em que:

$\tau_{u l t}=c+\sigma^{\prime} \operatorname{tg} \delta$

e

$k_{i}=m \gamma_{w}\left(\frac{\sigma^{\prime}}{P_{a t m}}\right)^{n}$

Sendo $m$ e $n$ parâmetros adimensionais a serem determinados através de ajuste de resultados experimentais; e $\gamma_{w}$ é o peso específico da água.

Um dos modelos não lineares mais utilizados para solos é o modelo hiperbólico de Duncan e Chang (1970). O equacionamento desse modelo se baseia no ajuste de uma hipérbole aos resultados de ensaios triaxiais em areia (Figura 2.5). Considerando o caso de areia seca têm-se que as tensões efeitivas são iguais as tensões totais, ou seja,

$$
\sigma_{1}-\sigma_{3}=\frac{\varepsilon}{a+b . \varepsilon}
$$

Onde $\sigma_{1} e \sigma_{3}$ são as tensões principais atuantes sobre o solo; $\varepsilon$ é a deformação axial; $a$ e b são constantes de ajuste da hipérbole ( interseção e inclinação da linha no diagrama transformado, respectivamente).

A constante $b$ ficou definida como a resistência à compressão simples por um fator chamado de $R_{f}$ que recebeu a denominação de razão de ruptura e seu valor poderia variar entre 0,75 a 1,0 .

A constante $a$ é uma função do módulo de elasticidade tangente, que possui uma relação empírica com a tensão de confinamento. 
$E_{i}=\frac{1}{a}=k \quad p_{a}\left(\frac{\sigma_{3}}{p_{a}}\right)^{n}$

Onde $E_{i}$ é módulo tangente inicial; $\sigma_{3}$ é a tensão principal menor ou tensão de confinamento; $p_{a}$ pressão atmosférica; $n$ e $k$ são números puros determinados através do ajuste de uma série de resultados experimentais.

O módulo tangente pode ser obtido para cada nível de tensão dependendo apenas da resistência à compressão simples $q_{u}$, do nível de tensão confinante e módulo inicial.

$$
E_{t}=E_{i}\left(1-\frac{R_{f} \sigma_{3}}{q_{u}}\right)^{2}
$$

Admite-se que é válido o critério de ruptura de Morh-Coulomb em termos de tensões efetivas:

$$
\begin{aligned}
& \left(\sigma_{1}-\sigma_{3}\right)_{f}=\frac{2 c \cos \phi-2 \sigma_{3} \operatorname{sen} \phi}{(1-\operatorname{sen} \phi)} \\
& E_{t}=E_{i}\left(1-R_{f} \frac{\left(\sigma_{1}-\sigma_{3}\right)(1-\operatorname{sen} \phi)}{2 \sigma_{3} \operatorname{sen} \phi-2 c \cos \phi}\right)^{2}
\end{aligned}
$$

Clough e Duncan (1971) ampliaram a utilização do modelo de Duncan e Chang (1970) para interfaces. Nesse tipo de problema, a equação hiperbólica foi ajustada para resultados de ensaios de cisalhamento direto (Figura 2.6).

$$
\tau=\frac{u}{a+b \cdot u}
$$

Cuja equação linearizada é:

$$
\frac{u}{\tau}=a+b u
$$



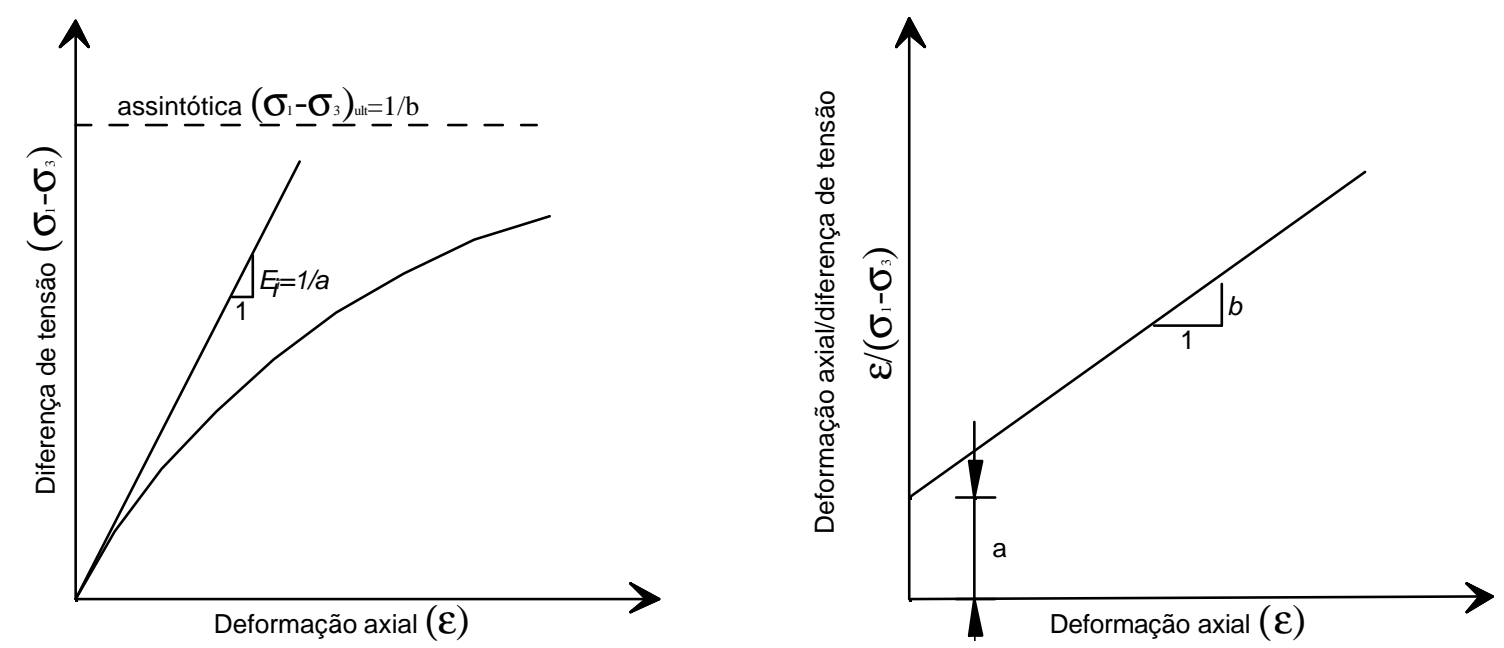

Figura 2.5 - Modelo Hiperbólico de Duncan e Chang (1970)

Os parâmetros a e b são fortemente ligados à rigidez ao cisalhamento inicial na interface, de modo que a Equação (2.18) pode ser escrita na forma:

$$
\tau=\frac{u}{K_{I} \gamma_{w}\left(\frac{\sigma_{n}}{p_{a}}\right)^{n_{j}}}+\frac{R_{f}}{\sigma_{n} t g \delta} \cdot u
$$

Em que:

$$
a=\frac{1}{k_{s i}}=\frac{1}{K_{I} \gamma_{w}\left(\frac{\sigma_{n}}{p_{a}}\right)^{n_{j}}}
$$

$\mathrm{e}$

$$
b=\frac{R_{f}}{\sigma_{n} \operatorname{tg} \delta}
$$

Sendo $k_{s i}$ a rigidez inicial da interface; $K_{I}$ um número de rigidez adimensional (definido em função do ajuste da curva); $n_{j}$ um expoente de rigidez adimensional (definido em função do ajuste da curva); $R_{f}$ a razão de ruptura; $\sigma_{n}$ a tensão normal atuante na interface; $\delta$ o ângulo de atrito máximo mobilizado na interface; $u$ é o deslocamento tangencial à interface.

Para problemas de análise incremental, Clough e Duncan (1971) recomendam que se utilize o coeficiente de rigidez tangente $\left(k_{s t}\right)$ para qualquer ponto, durante o 
cisalhamento. Esse valor é calculado em função do coeficiente de rigidez inicial $\left(k_{s i}\right)$, na forma:

$k_{s t}=k_{s i} \cdot\left(1-\frac{R_{f} \tau}{\sigma_{n} t g \delta}\right)^{2}$

Ou ainda:

$k_{s t}=K_{I} \gamma_{w}\left(\frac{\sigma_{n}}{p_{a}}\right)^{n_{j}}\left(1-\frac{R_{f} \tau}{\sigma_{n} t g \delta}\right)^{2}$

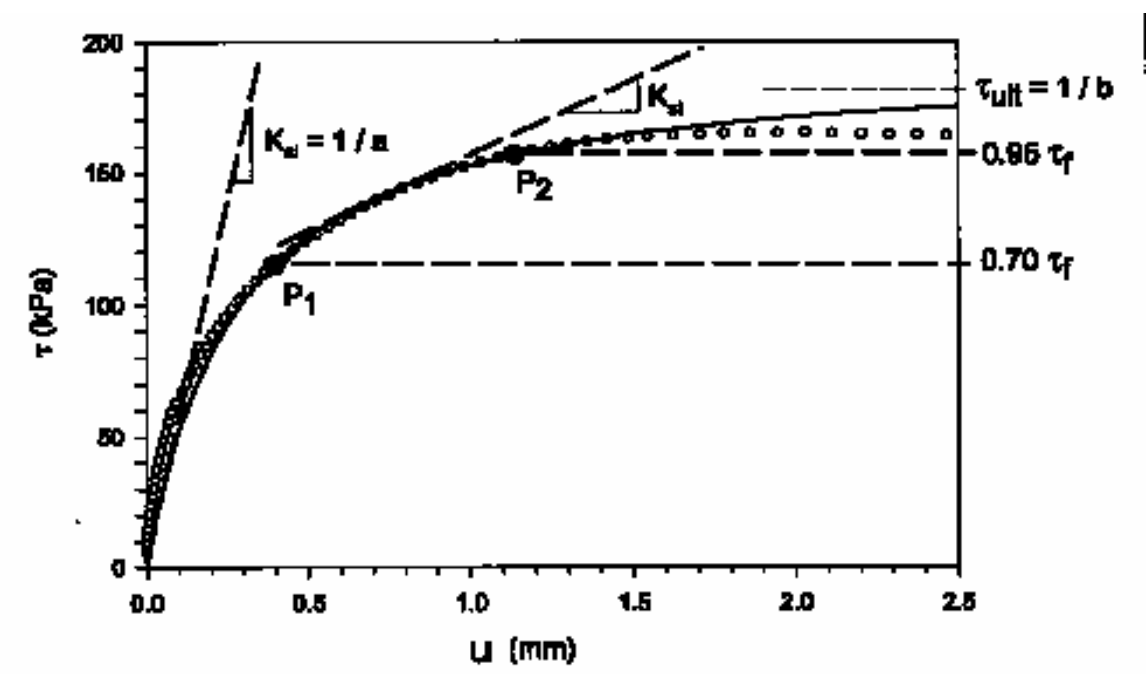

a)

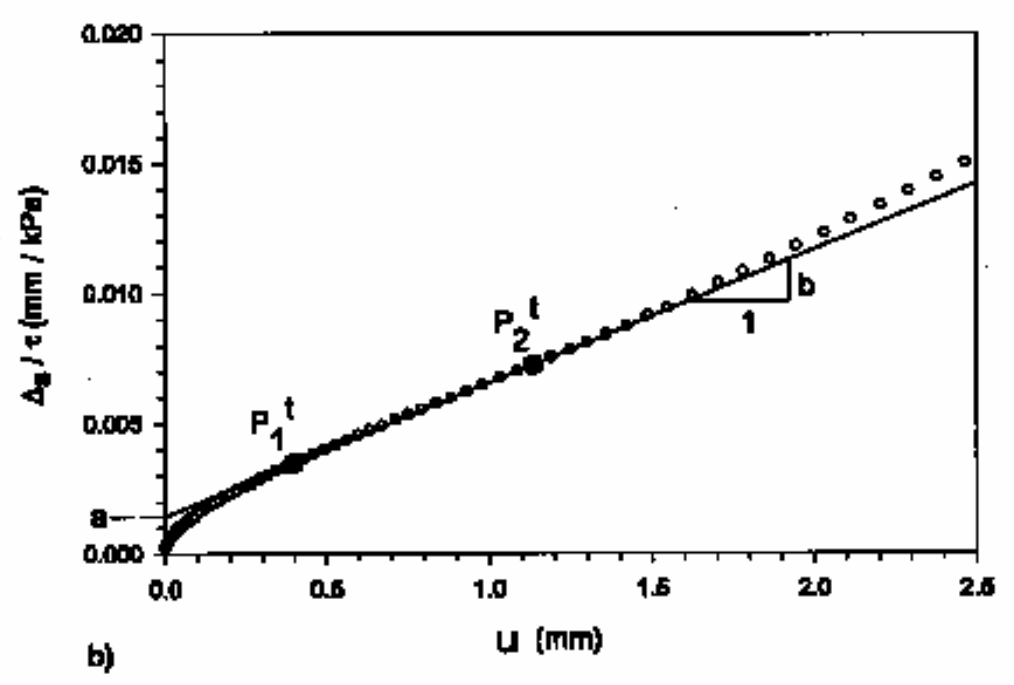

Figura 2.6 - Ajuste do modelo de Clough e Duncan (1971) a resultados de ensaios de cisalhamento direto típicos de interface concreto areia (Gómez, 2000): a) comparação entre os resultados de ensaios e o modelo hiperbólico; b) ajuste da reta aos valores linearizados para determinação dos parâmetros $a$ e $b$. 
Em mecânica das rochas, o estudo do comportamento de interfaces teve grande desenvolvimento devido a problemas de juntas em maciços rochosos fraturados.

Durante muitos anos se admitiu que a resistência ao cisalhamento de juntas seria calculada através de duas envoltórias de Mohr-Coulomb: uma para resistência de pico e outra para resistência residual (Figura 2.7). Essa interpretação, apesar de fornecer bons resultados práticos, vai de encontro à realidade fisica de muitos casos. $\mathrm{O}$ ajuste de uma equação linear para a resistência de pico e outra para a resistência residual pode acarretar uma interceptação com o eixo das ordenadas levando-se a considerar uma resistência ao cisalhamento, quando da ocorrência de tensão normal nula. Isso apesar de possível matematicamente, fisicamente não se verifica.

Patton (1966) publicou um trabalho onde ficou demonstrado que o critério de ruptura de Mohr-Coulomb não leva em consideração as irregularidades da superfície de contato que na grande maioria das vezes condicionavam o comportamento das juntas. Após este trabalho, tornourse clássica a utilização do critério de resistência de Mohr Coulomb apenas para superfícies lisas.

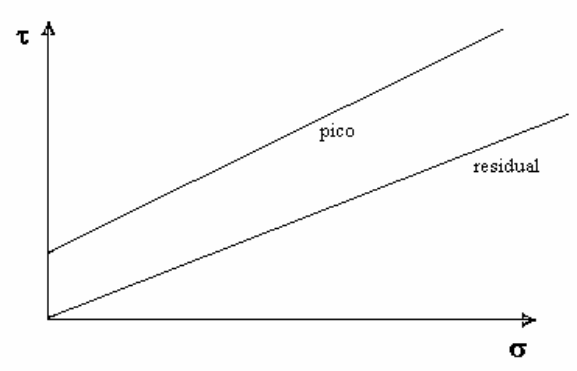

Figura 2.7 - Envoltória de ruptura de Mohr - Coulomb.

Nas superfícies rugosas, a resistência recebe a contribuição da descontinuidade (irregularidade). Patton (1966) desenvolveu um modelo mecânico, onde o deslizamento só é possível após a transposição das rugosidades (Figura 2.8).

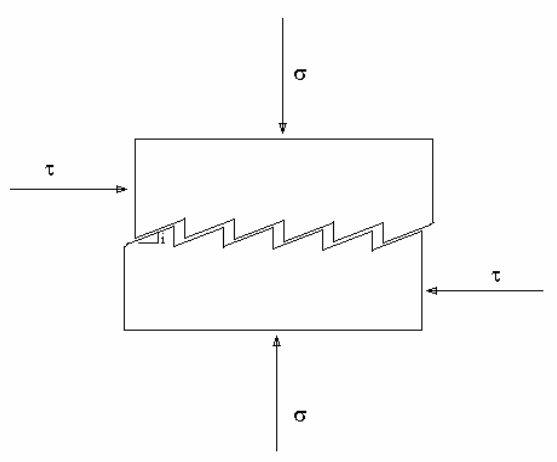

Figura 2.8 - Modelo de ruptura de Patton (1966). 
Para Patton (1966), após o ompimento da descontinuidade (Figura 2.9), o sistema voltaria a obedecer ao critério de ruptura de Mohr-Coulomb.

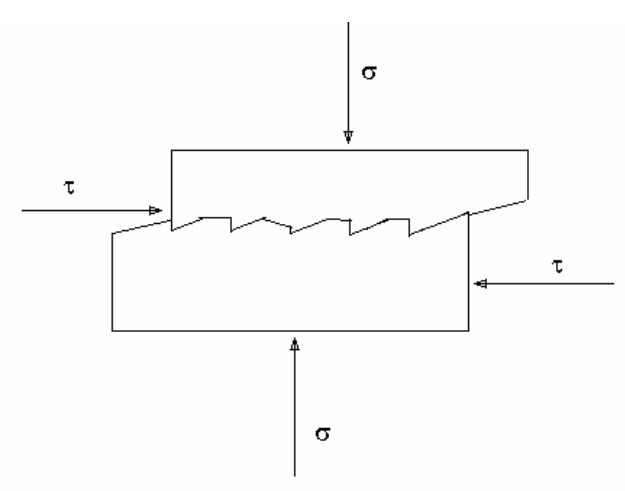

Figura 2.9 - Modelo de ruptura quando vencidas as descontinuidades (Patton, 1966).

Para representar essas duas situações, Patton (1966) montou um modelo bi-linear (Figura 2.10), onde o primeiro trecho é definido pela equação:

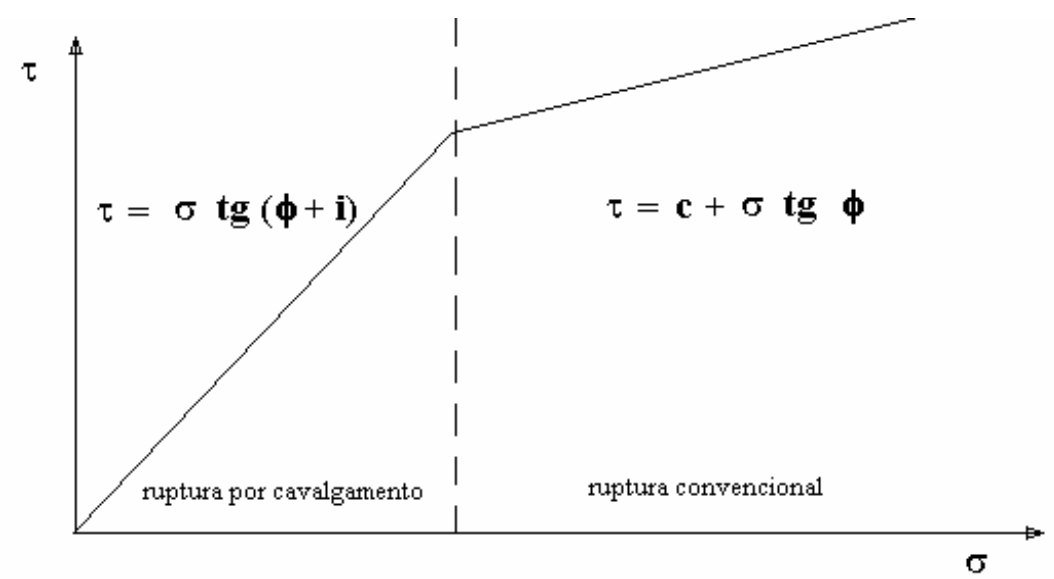

Figura 2.10 - Critério de ruptura de bi-linear de Patton (1966)

$\tau=\sigma \tan (\phi+i)$

Em que $i$ é a inclinação da descontinuidade.

O segundo trecho limitado pela ruptura ao cisalhamento, após a quebra das descontinuidades, é definido por:

$\tau=c+\sigma . \operatorname{tg} \phi$

Observando resultados de campo, Barton (1976) propôs uma envoltória de ruptura empírica não linear que ajustasse os resultados do modelo bilinear de Patton (1966) e que se representasse uma função contínua. Essa equação se escreve na forma: 
$\tau=\sigma \tan \left(J R C \log _{10}\left(\frac{J C S}{\sigma_{n}}\right)+\phi_{b}\right)$

Onde $J R C$ é o coeficiente de rugosidade da descontinuidade (varia de 0 a 20, Tabela 2.3); JCS é o coeficiente de resistência da descontinuidade (aproximadamente igual à resistência à compressão simples da rocha sã. Para rochas alteradas, deve ser reduzido para até $1 / 4$ ); $\phi_{b}$ é o ângulo de atrito básico, geralmente igual ao ângulo de atrito residual.

Tabela 2.3 - Perfil de referência para estimativa de JRC (Barton e Coubey, 1977).

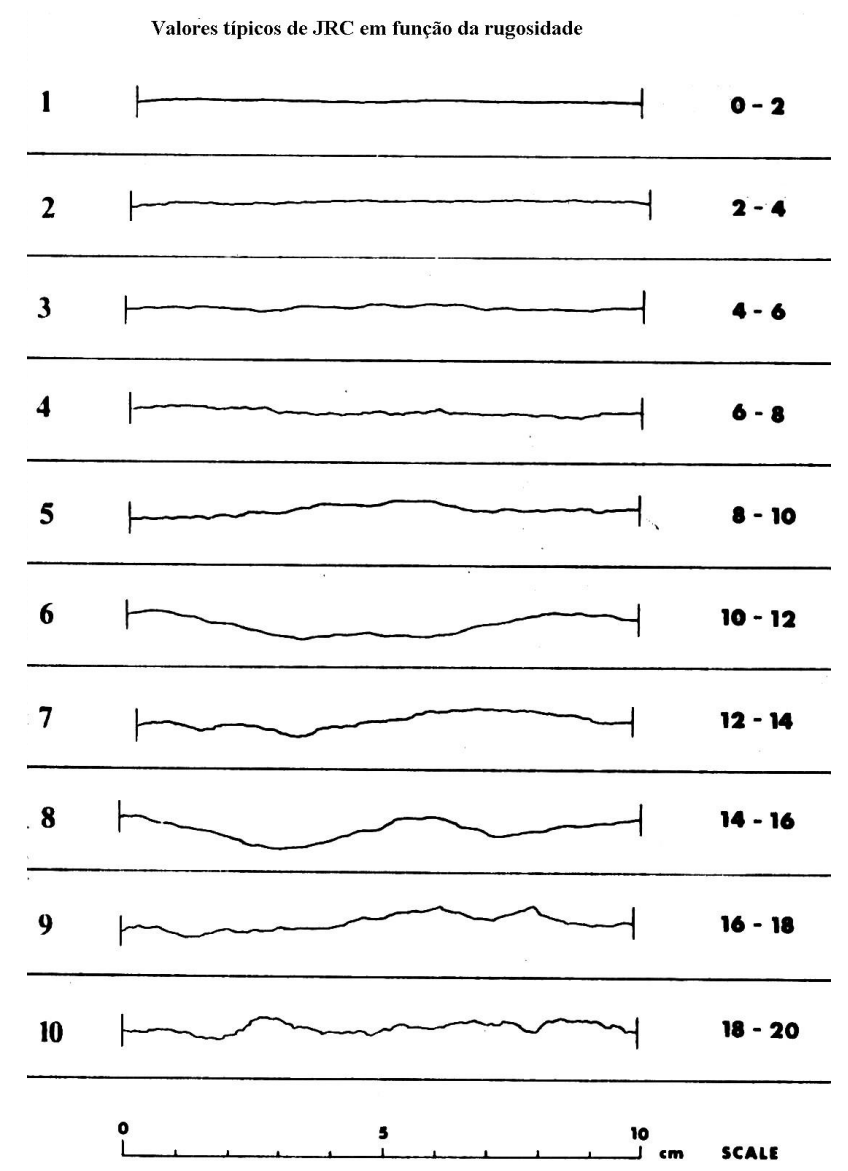

A Figura 2.11 mostra o comportamento da Equação (2.27), de acordo com a variação do coeficiente de rugosidade $(J R C)$. Nota-se que quanto maior o valor de $J R C$ (quanto maior a rugosidade da junta) maior o comportamento não linear da envoltória de $\tau$ versus $\sigma$. Para pequenos valores de JRC (superfície da junta lisa) a envoltória é praticamente linear.

A Figura 2.11 mostra, também, a forma da curva $\tau$ versus $\sigma$ em função de JCS. Percebe-se que o valor de JCS é quem determina o comportamento bilinear da curva e, consequentemente, qual o tipo de cisalhamento que está ocorrendo. 
(A)
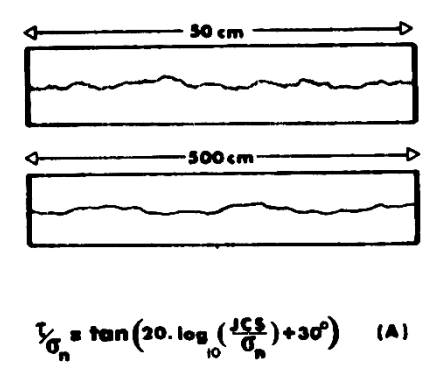

(A)

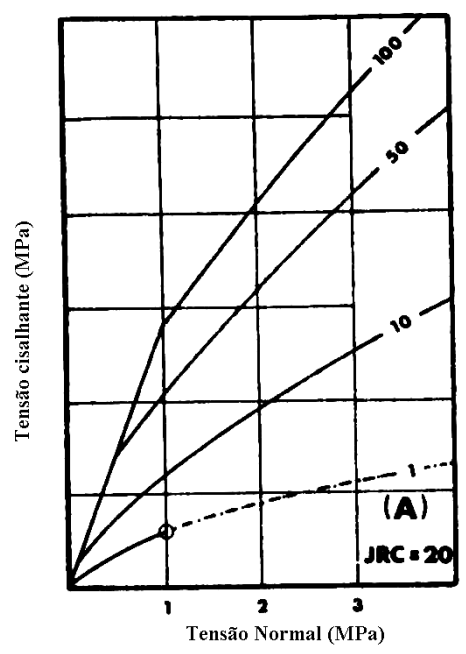

(B)
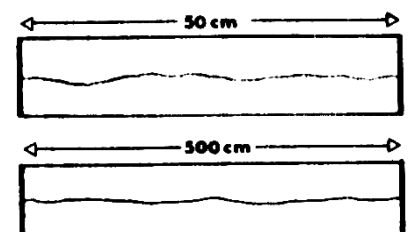

$\tau / \sigma_{n}=\tan \left(10 . \log \left(\frac{\operatorname{ccs}}{\sigma_{n}}\right)+30^{\circ}\right) \quad$ (a)
(C)
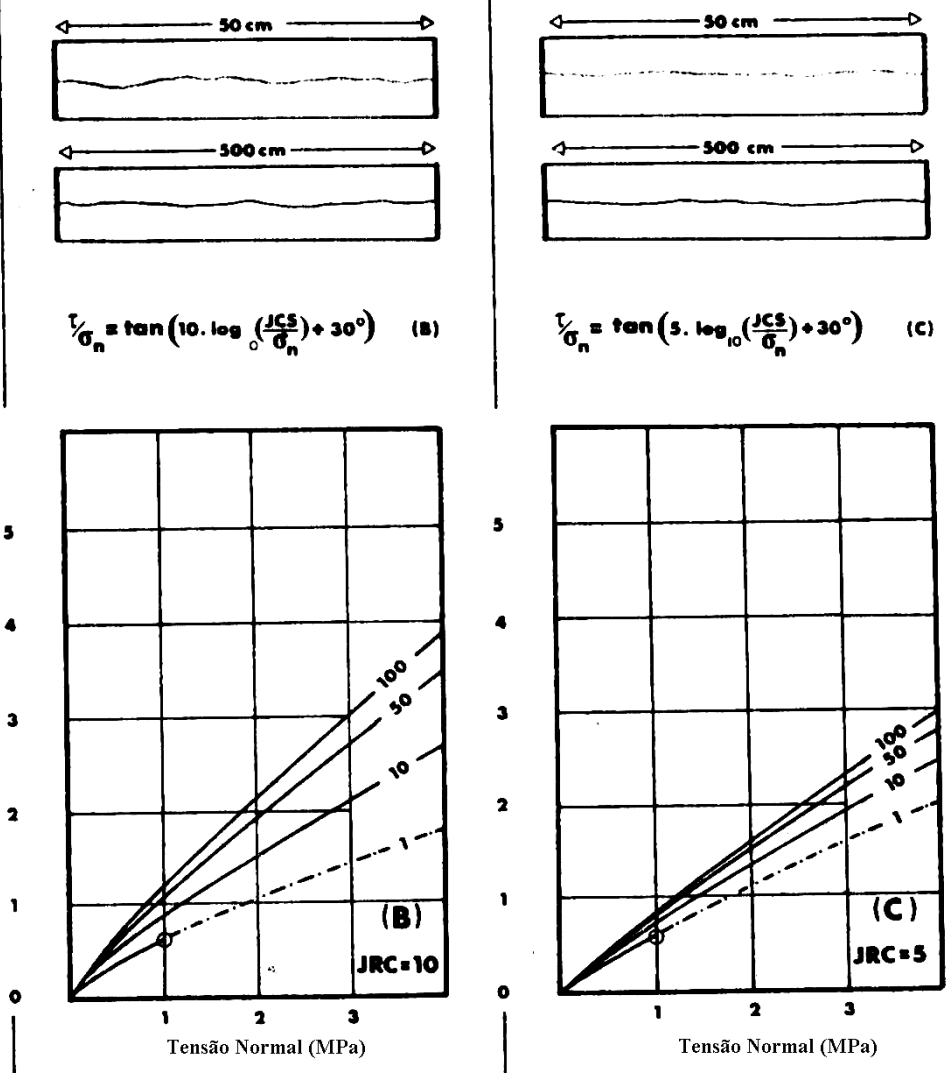

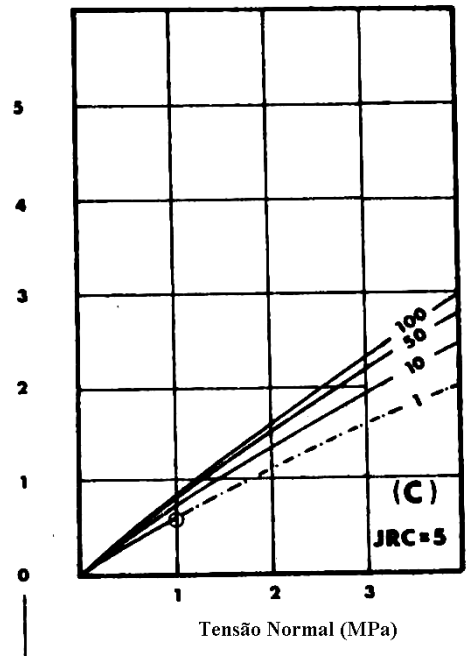

Figura 2.11 - Classificação das rugosidades e previsão da resistência de juntas não planas (Barton, 1976).

Comparando-se a equação proposta por Patton (1966) com a de Barton (1976), verifica-se que:

$i=J R C \log _{10}\left(\frac{J C S}{\sigma_{n}}\right)$

Em que $i$ é definido como ângulo de dilatância.

Para casos de rochas sãs, o valor de JCS deve ser assumido como aproximadamente igual à resistência à compressão simples. No entanto para casos de preenchimento ou de confinamento muito elevado, JCS deve ser tomado igual à tensão desviatória de ruptura:

$i=J R C \log _{10}\left(\frac{\left(\sigma_{1}-\sigma_{3}\right)_{\text {ruptura }}}{\sigma_{n}}\right)$ 
O comportamento de descontinuidades preenchidas depende da espessura do material, da altura das rugosidades, da resistência do material de preenchimento e da história de tensões e deformações a que a junta foi submetida.

\subsubsection{Dilatância}

A dilatância em solos é um fenômeno que se deve ao aumento de volume durante o cisalhamento. Seu efeito na resistência pode ser verificado quando se observa a Figura 2.12 que faz analogia entre duas superfícies irregulares com forma de dentes de serra. Nota-se que para o bloco entrar em movimento, ele deve vencer, além da resistência ao atrito limite do material, a inclinação da rampa, ou seja, a parcela devido a dilatância. Essa analogia foi idealizada por Rowe (1962) e é conhecida como analogia "dente de serra".

A inclinação do dente $\psi$ é a responsável pela variação de volume durante o processo de cisalhamento. Em um sistema onde $\psi=0$, a resistência seria dada pelo ângulo de atrito básico, que corresponde ao ângulo de atrito para cisalhamento com volume constante. Esse ângulo é chamado de ângulo de atrito crítico. Havendo $\psi \neq 0$, durante o cisalhamento, haverá também um deslocamento na direção vertical, o qual será chamado de dilatância.
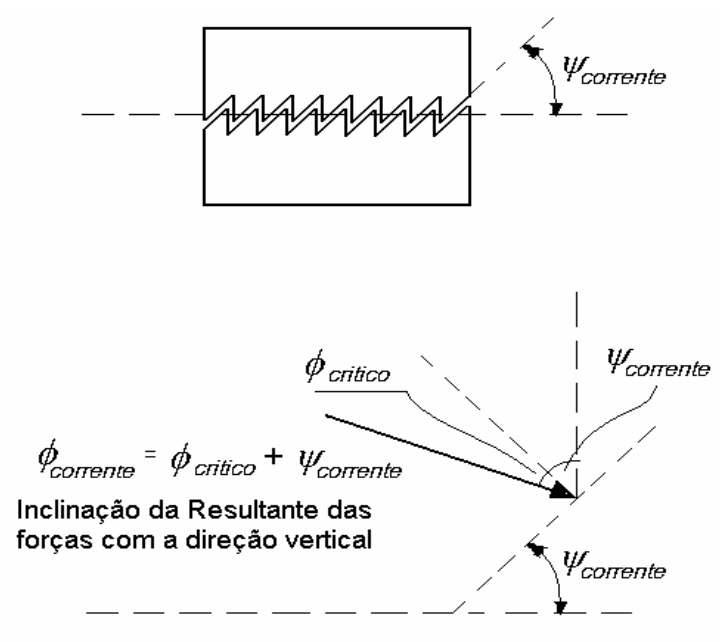

Figura 2.12 - Modelo de ruptura Rowe (1962)

A dilatância é um fenômeno que ocorre principalmente nas areias, onde a resistência ao cisalhamento é influenciada pelo deslizamento e pelo rolamento entre os grãos. A ocorrência de deslizamento e de rolamento é influenciada pela rugosidade superficial e pela forma das partículas. 
Outro fator importante é a compacidade da areia ou o entrosamento entre os grãos, de forma que, quanto maior a compacidade maior será o aumento de volume durante o cisalhamento, ou seja, maior será a dilatância.

A Figura 2.13 mostra resultados típicos de ensaio de cisalhamento direto areias com compacidade distinta em função do deslocamento $u$. Para os casos de areia inicialmente compacta percebe-se que a resistência mobilizada atinge um pico bem definido, caracterizando a resistência de pico. A partir de então, a resistência começa a diminuir em função do deslocamento até atingir um patamar chamado de resistência residual. Olhando para a aurva de variação de volume correspondente, nota-se, que durante o cisalhamento, ocorre um aumento de volume até um valor estabilizado.

Para os casos de areia inicialmente fofa, percebe-se exatamente um inverso, ou seja, a resistência é sempre crescente com o deslocamento até o valor limite, enquanto a o volume diminui continuamente, até a ruptura do sistema.

Para um observador mais desatento, parece que os dois comportamentos distintos estão seguindo caminhos completamente opostos; no entanto, ao se observar à curva de índice de vazios ou volume total por deslocamento, pode-se concluir, que em ambos os casos, o processo de cisalhamento conduz o sistema para a mesma condição de resistência e de volume. Essa condição acontece para grandes deslocamentos e se caracteriza pela resistência e pelo volume que não varia mais com o deslocamento. A esse estado físico do solo dá-se o nome de estado crítico.

Houlsby (1991) demonstra formalmente que o processo de dilatação é função preponderante da condição em que se encontra o solo em relação ao seu estado crítico.

O estado crítico de uma areia depende preponderantemente da tensão normal atuante sobre ela. Essa relação é expressa em termos de uma equação denominada de linha de estados críticos (ANEXO A).

$V_{c r i}=V_{o}-\Lambda \cdot \ln \sigma$

Em que $V_{c r i}$ é o volume crítico; $V_{0}$ é a interseção da linha de estado crítico com o eixo de volume; $\Lambda$ é a inclinação da linha de estados críticos; $\sigma$ é a tensão normal atuante.

A Equação 2.30 pode ser reescrita na forma de índice de vazios:

$e_{c r i}=\Gamma-\lambda \cdot \ln \sigma$ 
Em que $e_{c r i}$ é o índice de vazios crítico; $\Gamma$ é a interseção da linha de estado crítico com o eixo de vertical; $\lambda$ é a inclinação da linha de estados críticos; $\sigma$ é a tensão normal atuante.

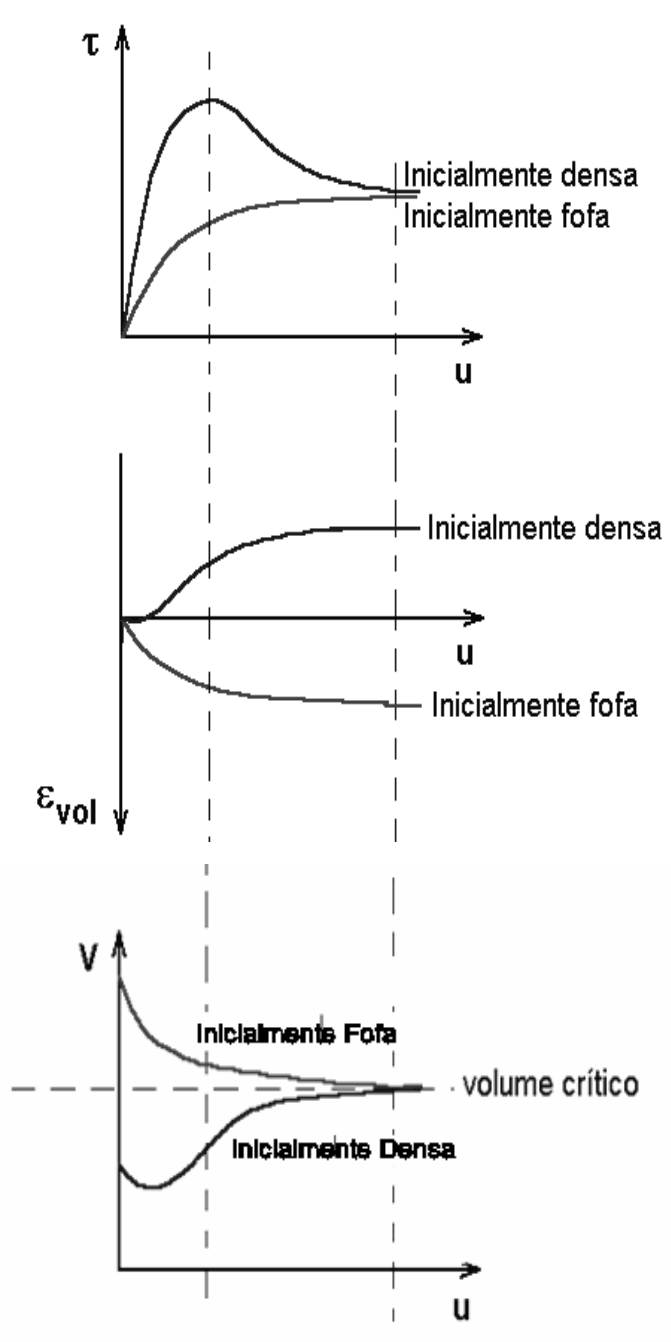

Figura 2.13 - Resultado típico de ensaios de cisalhamento direto em areias.

Taylor (1948) escreve que o trabalho realizado durante o cisalhamento é:

$\dot{W}=\sigma^{\prime}{ }_{n} d v+\tau \quad d u=\operatorname{tg} \phi_{c v} \sigma^{\prime}{ }_{n} d u$

Ou ainda,

$\tau d u=\operatorname{tg} \phi_{c v} \sigma_{n}^{\prime} d u-\sigma_{n}^{\prime} d v$

Diferenciando ambos os termos por $d u$ : 
$\tau=\operatorname{tg} \phi_{c v} \sigma^{\prime}{ }_{n}-\sigma^{\prime}{ }_{n} \frac{d v}{d u}$

Chamando:

$\psi=-\frac{d v}{d u}$

E substituindo na Equação (2.30) e considerando que, para ângulos pequenos, $\psi=\operatorname{tg} \psi$ :

$\tau=\operatorname{tg} \phi_{c v} \sigma^{\prime}{ }_{n}+\sigma^{\prime}{ }_{n} \operatorname{tg} \psi$

Ou ainda,

$\tan \phi^{\prime}=\tan \phi_{c v}+\tan \psi$

Em que $\phi^{\prime}$ é o ângulo de atrito efetivo; $\phi_{c v}$ é o ângulo de atrito plano; $\psi$ é o ângulo de dilatância.

Dessa forma, pode-se escrever de forma aproximada que:

$\phi^{\prime}=\phi_{c v}+\psi$

Observando os resultados experimentais, Bolton (1986) mostra que a Equação (2.38) ainda superestima o valor do ângulo de atrito e sugere uma correção:

$\phi^{\prime}=\phi_{c v}+0,8 . \psi$

Powrie (1997) mostra um caso onde até mesmo a proposta de Bolton (1986) superestima o ângulo de atrito efetivo, demonstrando a limitação desse tipo de abordagem.

Muitos autores defendem que esse problema ocorre devido à grande influência da trajetória de tensões nos valores da dilatância.

Partindo da constatação de que o aumento de volume em ensaios de carga constante, corresponde a um aumento de tensão normal em ensaios realizados com volume constante, vários pesquisadores desenvolveram o ensaio de cisalhamento com Rigidez Normal Constante (RNC), onde é considerado o efeito da variação de volume na variação tensão normal através de um coeficiente de proporcionalidade, chamado de rigidez normal, devido ao cisalhamento.

$K=-\frac{\Delta \sigma}{\Delta v}$ 
Em que $K$ é o coeficiente de rigidez normal ao cisalhamento; $\Delta v$ é o deslocamento vertical, devido à variação do volume provocado pelo cisalhamento; $\Delta \sigma$ é a variação da tensão normal.

Segundo Porcino et al. (2003), os ensaios do tipo RNC demonstram que uma superfície rugosa tende a apresentar um comportamento dilatante mais pronunciado para baixos níveis de tensão normal aplicada. Essa afirmação nos faz concluir que uma interpretação correta do real comportamento mecânico de uma interface passa pela identificação do mecanismo de cisalhamento para baixos níveis de tensão normal.

\subsubsection{Rearranjo das partículas}

São raros os trabalhos sobre a resistência ao cisalhamento em condições de baixas tensões de confinamento. Nesse sentido, uma importante contribuição foi dada por Rowe (1962) que, ao estudar o cisalhamento de areias submetidas a baixas tensões normais, demonstrou que as areias muito densas apresentaram resistência de pico e residual. A inclinação da envoltória de resistência residual define o ângulo de atrito verdadeiro e a diferença entre a inclinação da envoltória de resistência de pico e residual define um acréscimo de resistência devido a dilatância. Para as areias mais fofas o ângulo de atrito encontrado foi maior do que o ângulo de atrito verdadeiro, mesmo acontecendo uma diminuição do volume. Esse ganho de resistência foi atribuído como conseqüência do processo de rearranjo das partículas (Figura 2.14).

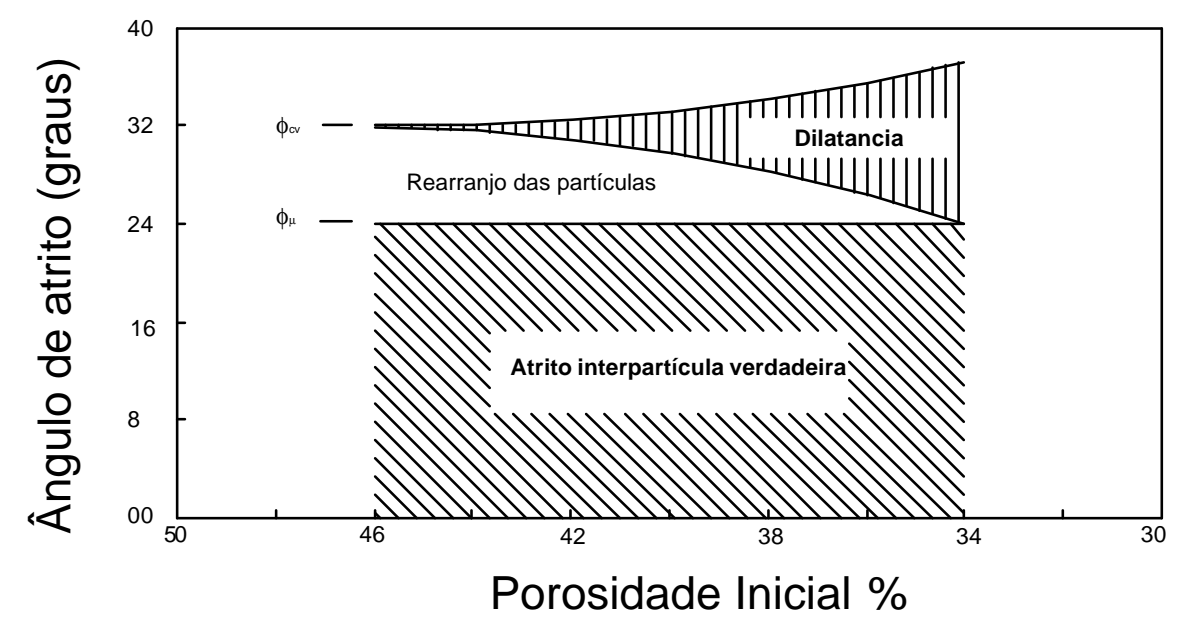

Figura 2.14 - Parcelas de resistência das areias (Rowe, 1962)

Pode-se perceber que para solos porosos ocorre ganho de resistência devido a um rearranjo das partículas. Segundo Ortigão (1993), essa variação de resistência se dá devido à maior ou menor facilidade de rolamento das partículas no interior da massa. 
Para ilustrar esse mecanismo, o autor relata que uma massa de areia de rio ou seixos rolados, que constituem grãos arredondados e com pouca rugosidade superficial, terá menor resistência que uma massa de pedra britada que possui grãos angulosos com rugosidades pronunciadas, de modo a aumentar a parcela de atrito ao deslizamento e do atrito de rolamento. Ortigão (1993) também esclarece que o desenvolvimento desse mecanismo depende fundamentalmente do entrosamento entre os grãos mas que não pode ser confundido com o a dilatância. Segundo ele, a dilatância depende da compacidade que é uma função do estado em que o material se encontra no momento do cisalhamento (densa ou fofa). Já o atrito ao deslizamento e ao rolamento é uma propriedade da partícula, dependendo apenas da sua forma e da sua rugosidade.

Ponce e Bell (1971) demonstraram, através de ensaios triaxiais, a influência das tensões de confinamento na resistência ao cisalhamento de areias. Verificaram que, para baixos níveis de tensões, uma grande parcela da resistência ao cisalhamento das areias ocorre devido à dilatância e ao rearranjo das partículas (Figura 2.15) e que a magnitude de cada parcela de resistência é função da densidade inicial da areia e do nível de confinamento ao qual ela for submetida (Figura 2.16).

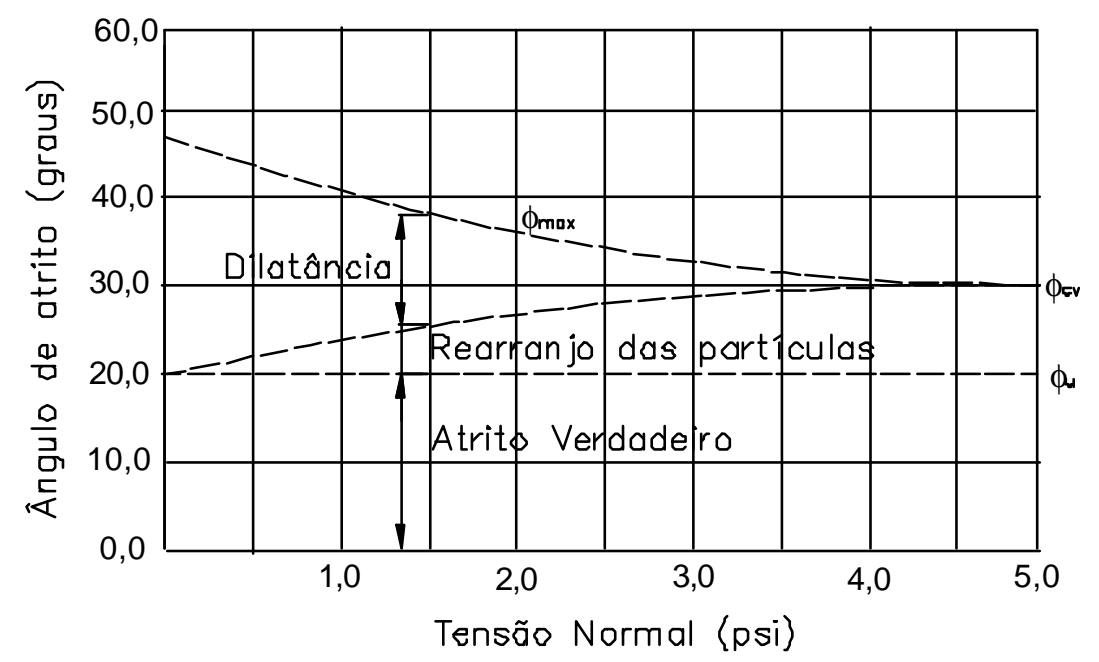

Figura 2.15 - Parcelas de resistência em função do nível de tensão confinante (Ponce e Bell, 1971).

Ponce e Bell (1971) recomendam também, que um modelo físico-matemático para a resistência ao cisalhamento das areias deva seguir a separação em parcelas de resistência, devido ao atrito verdadeiro, à dilatância e ao rearranjo das partículas.

Segundo Bowles (1988), a resistência ao cisalhamento de materiais granulares se dá devido à combinação do rolamento, do deslizamento e do entrosamento das 
partículas. Desse modo, um modelo para sua previsão do atrito estático em materiais granulares tem de levar em consideração o atrito de deslizamento, o atrito de rolamento e a dilatância.

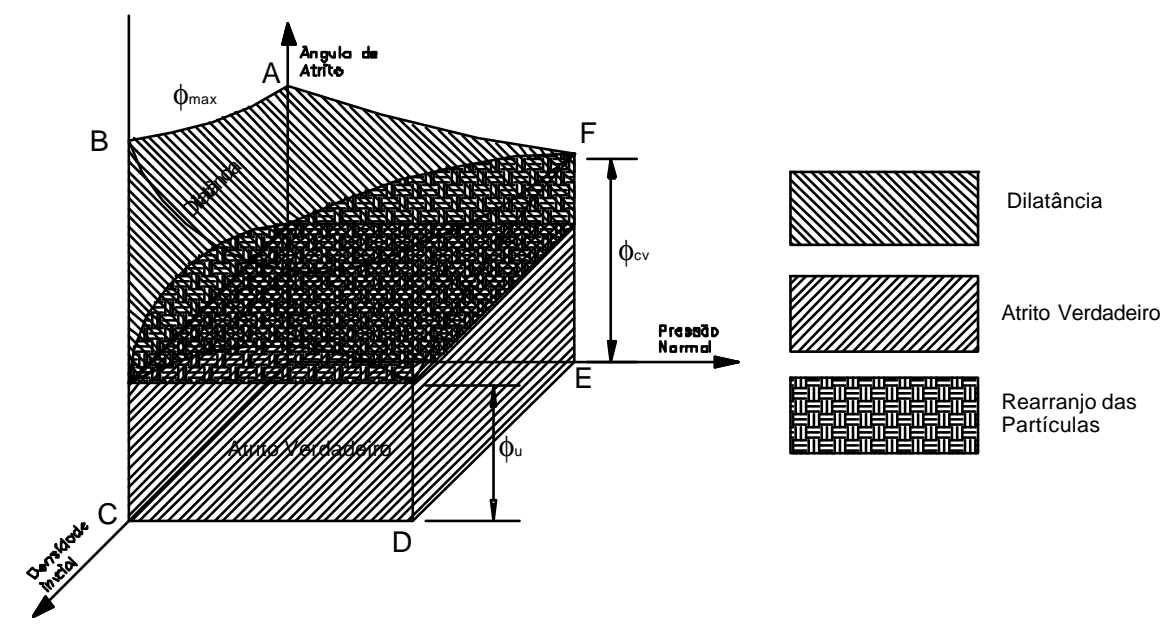

Figura 2.16 - Modelo tridimensional de componentes de resistência ao cisalhamento das areias em função da pressão normal aplicada e da densidade inicial da areia (Ponce e Bell, 1971).

$\mathrm{O}$ atrito de rolamento consiste na resistência mobilizada entre uma superfície plana e um cilindro com força normal $N$ e raio $r$, quando este cilindro for submetido a uma força tangencial $\mathrm{P}$ aplicada no centro do cilindro. Nesse caso, um pequeno movimento provocado por uma força de atrito $F$ é capaz de gerar uma excentricidade $a$ de modo a equilibrar o sistema (Figura 2.17).

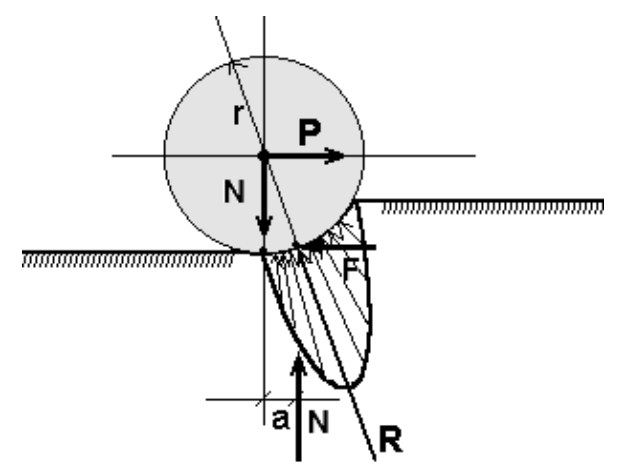

Figura 2.17 - Roda submetida a uma força P, aplicada de modo a provocar o rolamento do cilindro sobre a superfície (Meriam, 1977).

Na Figura 2.18, a deformação entre o cilindro e a superfície está exagerada; no entanto, a distribuição de pressão no contato é similar a que ocorre de fato, de modo que no centro de cargas desse diagrama atuará sua resultante $R$ e que também passará pelo centro do cilindro. 


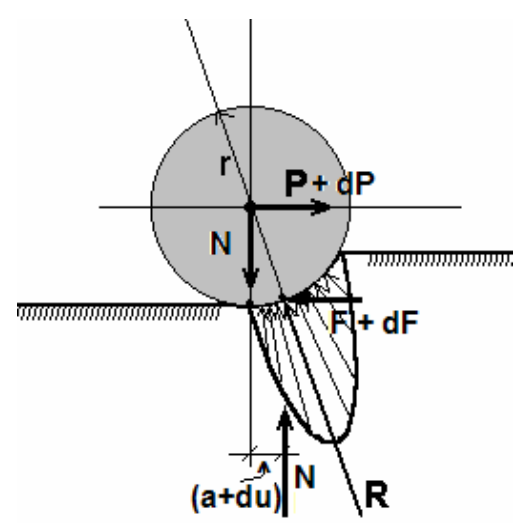

Figura 2.18 - Roda submetida a uma força $(P+d P)$, aplicada de modo a provocar um deslocamento $d u$ (Meriam, 1977).

A distância $a$ entre o ponto de aplicação da resultante $R$ e o eixo vertical é definida em função da deformabilidade da superfície e do cilindro, do diâmetro da roda e da aspereza da superfície de contato. Segundo Meriam (1977), o valor depende de vários fatores, os quais, na sua maioria, não são possíveis de serem medidos. Assim, não existe uma teoria completa para explicação do atrito ao rolamento. Ainda, segundo Meriam (1977), o único fato que é consenso entre os pesquisadores é o de alguns ensaios demonstrarem uma pequena variação de $a$ em função do raio, de modo que para casos práticos ele recomenda que a grandeza seja considerada independente do raio do cilindro.

Pela condição de equilíbrio de um problema plano, pode estabelecer que a força $P$ é utilizada para mobilizar a $F$ de atrito ao rolamento e que a força $N$ na superfície é a mesma que atua sobre o cilindro, de acordo com a equação de equilíbrio de forças na direção horizontal e na direção vertical, respctivamente.

No entanto, pode-se estabelecer uma relação entre essas forças através da equação de equilíbrio de momentos em torno do centro da roda. A força $F$ formará um momento de valor F.r no sentido do movimento, enquanto que no sentido contrário ocorrerá um momento de N.a. A equação de equilíbrio de momentos se torna:

$F . r-N . a=0$

Onde $F$ é a força de atrito mobilizada pelo rolamento do cilindro; $r$ é o raio do cilindro; $N$ é a força normal atuante no sistema; $a$ é a excentricidade gerada pelo atrito entre o cilindro e a superfície.

Da Equação (2.41), tem-se:

$F . r=N . a$ 
Ou ainda:

$$
F=N \cdot \frac{a}{r}
$$

onde a grandeza $\frac{a}{r}$ é definida como coeficiente de atrito de rolamento.

Supondo que sobre o sistema da Figura 2.18 ocorra um acréscimo de carga na força $P$, o cilindro tenderá a girar sobre seu eixo, provocando um deslocamento na direção horizontal, de modo que o equilíbrio de momentos resultará em:

$$
(F+d F) \cdot r-N \cdot(a+d u)=0
$$

Ou ainda,

$$
F . r+d F . r-N . a-N d u=0
$$

Substituindo a Equação 2.42 na Equação 2.45, tem-se que:

$$
F . r+d F . r-F . r-N d u=0
$$

Logo:

$$
d F . r=N d u
$$

Diferenciando ambos os termos em função do deslocamento u.

$$
N=\frac{d F}{d u} \cdot r
$$

Escrevendo a Equação 2.48 em termos de tensões, tem-se que:

$$
\sigma=\frac{d \tau}{d u} \cdot r
$$

Em que:

$\tau$ é a tensão tangencial mobilizada na interface entre o cilindro e a superfície; $\sigma$ é a tensão normal atuante sobre o cilindro; $r$ é o raio do cilindro; $u$ é o deslocamento na direção u.

2.2. Revisão bliográfica sobre modelos experimentais em interfaces

Ao longo do tempo, muitas pesquisas foram desenvolvidas através da simulação de interfaces solo-estrutura em laboratório. Inicialmente, esses ensaios foram feitos com 
o objetivo de se determinar o ângulo de atrito na interface, para serem utilizados em projetos de estruturas de contenção, estruturas enterradas, solo reforçado, estacas, etc.

Recentemente, esses ensaios têm sido feitos com o objetivo de se obter parâmetros de modelos constitutivos do comportamento mecânico de interfaces do tipo solo-estrutura, solo-rocha, rocha-rocha (comportamento de juntas preenchidas ou não).

Nesses ensaios, os materiais e os modos de carregamento são os mais variados possíveis e são definidos de acordo com a propriedade ou o fenômeno que se deseja definir.

Os modos de ensaios mais utilizados são os de cisalhamento direto e os de cisalhamento simples.

Os ensaios de cisalhamento direto têm como principal característica promover o deslocamento tangencial devido a um carregamento tangencial de um corpo de prova submetido a uma tensão normal atuante sobre a interface.

Os ensaios de cisalhamento simples se caracterizam por manter o estado de cisalhamento puro durante todo o ensaio, de modo que os deslocamentos na interface são praticamente nulos, ocorrendo apenas distorções.

\subsubsection{Ensaios de cisalhamento direto}

O pioneiro no uso de ensaios de cisalhamento direto em interface estrutura-solo foi Potyondy (1961), que avaliou o ângulo de atrito máximo mobilizado e a adesão entre diversos materiais de construção (aço, madeira e concreto) e vários tipos de solo.

Nesse estudo, o autor considerou para cada material dois tipos de superfície (rugosa e lisa) e a variação na carga normal aplicada à superfície de cisalhamento. Os resultados obtidos estão mostrados na Tabela 2.4.

Clough e Duncan (1971) realizaram ensaios de cisalhamento direto para previsão da curva tensão tangencial-deslocamento. Nesse caso, o corpo de prova foi montado colocando-se um corpo de prova de concreto ocupando a metade inferior da caixa de cisalhamento direto. A metade superior foi montada com corpo de prova em areia, com diferentes densidades. 
Tabela 2.4 - Valores de ângulos de atrito e coeficientes de adesão entre solo e diversos materiais de construção (Potyondy, 1961).

\begin{tabular}{|c|c|c|c|c|c|c|c|c|c|c|c|c|c|c|c|c|c|}
\hline \multirow{9}{*}{$\frac{\frac{\pi}{\omega}}{\frac{\pi}{2}}$} & & \multicolumn{8}{|c|}{ Seco } & \multicolumn{8}{|c|}{ Satur ado } \\
\hline & & \multicolumn{4}{|c|}{$\sim 50 \mathrm{kPa}$} & \multicolumn{4}{|c|}{$\sim 150 \mathrm{kPa}$} & \multicolumn{4}{|c|}{$\sim 50 \mathrm{kPa}$} & \multicolumn{4}{|c|}{$\sim 150 \mathrm{kPa}$} \\
\hline & Material & $\phi$ & $\delta$ & $\phi / \delta$ & $\operatorname{tg} \delta / \operatorname{tg} \phi$ & $\phi$ & $\delta$ & $\phi / \delta$ & $\operatorname{tg} \delta / \operatorname{tg} \phi$ & $\phi$ & $\delta$ & $\phi / \delta$ & $\operatorname{tg} \delta / \operatorname{tg} \phi$ & $\phi$ & $\delta$ & $\phi / \delta$ & $\operatorname{tg} \delta / \operatorname{tg} \phi$ \\
\hline & Aço liso & $44^{0} 30^{\prime}$ & $24^{0} 10^{\prime}$ & 0.543 & 0.457 & $43^{0} 30^{\prime}$ & $24^{0} 00^{\prime}$ & 0.55 & 0.47 & $39^{\circ} 00^{\prime}$ & $24^{0} 50^{\prime}$ & 0.64 & 0.57 & $37^{0} 00^{\prime}$ & $23^{0} 30^{\prime}$ & 0.64 & 0.57 \\
\hline & Aço rugoso & $44^{0} 30^{\prime}$ & $34^{0} 00^{\prime}$ & 0.765 & 0.68 & $43^{0} 30^{\prime}$ & $33^{\circ} 40^{\prime}$ & 0.78 & 0.7 & & & & & & & & \\
\hline & Madeira lisa & $44^{0} 30^{\prime}$ & $35^{0} 00^{\prime}$ & 0.79 & 0.71 & $43^{0} 30^{\prime}$ & $33^{0} 20^{\prime}$ & 0.766 & 0.69 & $39^{0} 00^{\prime}$ & $33^{0} 20^{\prime}$ & 0.85 & 0.82 & $37^{0} 00^{\prime}$ & $33^{0} 00^{\prime}$ & 0.89 & 0.86 \\
\hline & $\begin{array}{l}\text { Madeira } \\
\text { rugosa }\end{array}$ & $44^{0} 30^{\prime}$ & $39^{0} 00^{\prime}$ & 0.88 & 0.82 & $43^{0} 30^{\prime}$ & $38^{0} 30^{\prime}$ & 0.885 & 0.84 & $39^{0} 00^{\prime}$ & $33^{0} 30^{\prime}$ & 0.89 & 0.85 & $37^{0} 00^{\prime \prime}$ & $34^{0} 30^{\prime}$ & 0.93 & 0.91 \\
\hline & Concreto liso & $44^{0} 30^{\prime}$ & $39^{0} 30^{\prime}$ & 0.89 & 0.84 & $43^{0} 30^{\prime}$ & $38^{0} 30^{\prime}$ & 0.885 & 0.84 & $39^{\circ} 00^{\prime}$ & $34^{0} 40^{\prime}$ & 0.89 & 0.85 & $37^{0} 00^{\prime}$ & $33^{0} 20^{\prime}$ & 0.9 & 0.87 \\
\hline & \begin{tabular}{|c|}
$\begin{array}{c}\text { Concreto } \\
\text { rugoso }\end{array}$ \\
\end{tabular} & $44^{0} 30^{\prime}$ & $44^{0} 00^{\prime}$ & 0.99 & 0.98 & $43^{0} 30^{\prime}$ & $44^{0} 00^{\prime}$ & 0.98 & 0.97 & & & & & & & & \\
\hline \multirow{9}{*}{$\frac{\Phi}{\bar{\omega}}$} & & \multicolumn{8}{|c|}{ Seco } & \multicolumn{8}{|c|}{ Saturado } \\
\hline & & \multicolumn{4}{|c|}{$\sim 50 \mathrm{kPa}$} & \multicolumn{4}{|c|}{$\sim 150 \mathrm{kPa}$} & \multicolumn{4}{|c|}{$\sim 50 \mathrm{kPa}$} & \multicolumn{4}{|c|}{$\sim 150 \mathrm{kPa}$} \\
\hline & Material & $\phi$ & $\delta$ & $\phi / \delta$ & $\operatorname{tg} \delta / \operatorname{tg} \phi$ & $\phi$ & $\delta$ & $\phi / \delta$ & $\operatorname{tg} \delta / \operatorname{tg} \phi$ & $\phi$ & $\delta$ & $\phi / \delta$ & $\operatorname{tg} \delta / \operatorname{tg} \phi$ & $\phi$ & $\delta$ & $\phi / \delta$ & $\operatorname{tg} \delta \operatorname{tg} \phi$ \\
\hline & Aço liso & $40^{\circ} 00^{\prime}$ & $31^{0} 30^{\prime}$ & 0.79 & 0.73 & $39^{0} 10^{\prime}$ & $31^{0} 00^{\prime}$ & 0.79 & 0.74 & $29^{0} 50^{\prime}$ & $20^{\circ} 10^{\prime}$ & 0.68 & 0.66 & $32^{0} 30^{\prime}$ & $24^{0} 30^{\prime}$ & 0.75 & 0.71 \\
\hline & Aço rugoso & $40^{\circ} 00^{\prime}$ & $39^{0} 50^{\prime}$ & 1 & 0.99 & $39^{0} 10^{\prime}$ & $37^{0} 20^{\prime}$ & 0.95 & 0.94 & & & & & & & & \\
\hline & Madeira lisa & $40^{\circ} 00^{\prime}$ & $37^{0} 00^{\prime}$ & 0.92 & 0.9 & $39^{0} 10^{\prime}$ & $36^{0} 15^{\prime}$ & 0.92 & 0.9 & $29^{0} 50^{\prime}$ & $26^{0} 00^{\prime}$ & 0.87 & 0.84 & $32^{0} 30^{\prime}$ & $30^{\circ} 10^{\prime}$ & 0.92 & 0.91 \\
\hline & $\begin{array}{c}\text { Madeira } \\
\text { rugosa }\end{array}$ & $40^{\circ} 00^{\prime}$ & $39^{0} 20^{\prime}$ & 0.98 & 0.98 & $39^{0} 10^{\prime}$ & $38^{0} 40^{\prime}$ & 0.98 & 0.98 & $29^{0} 50^{\prime}$ & $28^{0} 50^{\prime}$ & 0.97 & 0.95 & $32^{0} 30^{\prime}$ & $31^{\circ} 00^{\prime}$ & 0.95 & 0.94 \\
\hline & Concreto liso & $40^{\circ} 00^{\prime}$ & $39^{0} 50^{\prime}$ & 0.99 & 0.99 & $39^{0} 10^{\prime}$ & $39^{0} 10^{\prime}$ & 1 & 1 & $29^{0} 50^{\prime}$ & $29^{0} 50^{\prime}$ & 1 & 1 & $32^{0} 30^{\prime}$ & $31^{\circ} 10^{\prime}$ & 0.96 & 0.95 \\
\hline & $\begin{array}{c}\text { Concreto } \\
\text { rugoso }\end{array}$ & $40^{\circ} 00^{\prime}$ & $40^{\circ} 00^{\prime}$ & 1 & 1 & $39^{0} 10^{\prime}$ & $39^{0} 10^{\prime}$ & 1 & 1 & & & & & & & & \\
\hline \multirow{8}{*}{$\frac{\frac{5}{5}}{\frac{5}{4}}$} & & \multicolumn{8}{|c|}{ Mistura 1} & \multicolumn{8}{|c|}{ Mistura 2} \\
\hline & Material & & & $\phi$ ov $\delta$ & c ou ca & $\begin{array}{c}c_{\max } \text { ou } \\
\mathrm{ca}_{\text {Max }} \mathrm{lb} / \mathrm{ft}^{2}\end{array}$ & $\delta / \phi$ & $\mathrm{ca} / \mathrm{c}$ & $\mathrm{ca}_{\max } / \mathrm{c}_{\max }$ & & & $\phi \circ v \delta$ & c ou ca & $\begin{array}{c}\mathrm{c}_{\max } \text { ou } \\
\mathrm{ca}_{\mathrm{Max}} \mathrm{lb} / \mathrm{ft}^{2}\end{array}$ & $\delta / \phi$ & $\mathrm{ca} / \mathrm{c}$ & $\mathrm{ca}_{\max } / \mathrm{c}_{\max }$ \\
\hline & Aço liso & & & $16^{0} 30^{\prime}$ & 750 & 1175 & - & - & - & & & $11^{0} 30^{\prime}$ & 460 & 675 & - & - & - \\
\hline & Aço rugoso & & & $9^{0} 00^{\prime}$ & 200 & 600 & 0.55 & 0.27 & 0.51 & & & $6^{0} 30^{\prime}$ & 140 & 360 & 0.56 & 0.3 & 0.53 \\
\hline & Madeira lisa & & & $10^{\circ} 00^{\prime}$ & 350 & 350 & 0.61 & 0.47 & 0.84 & & & $5^{0} 50^{\prime}$ & 265 & 580 & 0.5 & 0.58 & 0.86 \\
\hline & $\begin{array}{c}\text { Madeira } \\
\text { rugosa }\end{array}$ & & & $11^{\circ} 00^{\prime}$ & 300 & 1020 & 0.67 & 0.4 & 0.87 & & & $7^{0} 00$ & 210 & 600 & 0.61 & 0.46 & 0.89 \\
\hline & Concreto liso & & & $13^{0} 50^{\prime}$ & 390 & 1000 & 0.82 & 0.52 & 0.85 & & & $8^{0} 00^{\prime}$ & 230 & 620 & 0.69 & 0.5 & 0.92 \\
\hline & $\begin{array}{c}\text { Concreto } \\
\text { rugoso }\end{array}$ & & & $16^{0} 10^{\prime}$ & 425 & 1175 & 0.97 & 0.57 & 1 & & & $9^{0} 30^{\prime}$ & 240 & 675 & 0.82 & 0.52 & 1 \\
\hline
\end{tabular}

Wernick (1978) também realizou ensaios de cisalhamento direto em interfaces de solo-estrutura e seus resultados experimentais comprovam a existência de uma zona de contato entre estrutura e solo, definida como "interface", onde se concentram grandes deformações e deslocamentos de cisalhamento. Na interface, dependendo da compacidade do meio, durante o cisalhamento, os deslocamentos gerados provocam, no solo, uma tendência de dilatação (aumento de volume) ou contração (diminuição de volume). Esse fenômeno é chamado dilatância. 
Em todos os casos, os deslocamentos tangenciais máximos obtidos foram da ordem de $15 \mathrm{~mm}$, gerando dúvidas sobre o comportamento da interface em estruturas, quando submetidas a grandes deslocamentos (Al-Douri e Poulos, 1991).

Boulon et al. (1986), utilizando uma prensa de cisalhamento direto para ensaios com deslocamento vertical nulo, verificaram que a dilatância provoca um aumento ou diminuição da tensão normal efetiva atuante, correspondente ao aumento ou à diminuição de volume que ocorria nos ensaios com carga constante. Os pesquisadores identificaram uma relação entre o aumento de volume em ensaios de cisalhamento direto com carga normal constante $\mathrm{CNC}$ e o aumento de tensão em ensaios de cisalhamento direto com deslocamento normal constante DNC.

Boulon et al. (1986) concluíram também que um estudo de interfaces que considerasse o real comportamento de dilatância necessitaria de uma modalidade de ensaio de cisalhamento que tornasse possível a avaliação da relação entre a variação de tensão normal e sua correspondente variação de volume. Desenvolveram assim, um método de ensaio especial, chamado de ensaio de cisalhamento direto modificado. Nessa modalidade de ensaios, durante a fase de cisalhamento, é controlado e mantida constante a relação entre a variação da tensão normal aplicada e a variação de deslocamento vertical, denominando-o de ensaio de cisalhamento direto com rigidez normal constante (RNC)

Em seus ensaios, Boulon et al. (1986) utilizaram uma prensa de cisalhamento direto, cujas caixas se compunham de anéis com diâmetros de 60 a $100 \mathrm{~mm}$. As interfaces formadas por areia e placa metálica rugosa foram levadas a ruptura com deslocamentos da ordem de $3 \mathrm{~mm}$. Os deslocamentos máximos atingidos durante os ensaios ficaram em torno de $10 \mathrm{~mm}$.

Merece destaque o trabalho de Lee et al. (1996) que realizaram ensaios de cisalhamento direto em interfaces de concreto-areia, com seção transversal de 100 x 100 mm, submetidas a um carregamento estático com tensão normal constante. Nesse trabalho, os autores procuraram ajustar o modelo hiperbólico aos resultados experimentais.

Ensaios de cisalhamento direto em interfaces de $153 \mathrm{~mm}$ x $254 \mathrm{~mm}$ foram realizados por Tei (1993). Nesses ensaios, foram executados carregamentos estáticos com carga normal constante sobre interfaces formadas por areia e uma placa de alumínio, obtendo coeficientes de atrito da ordem de 0,5 a 1,15.

Palmeira (1987), realizando estudo sobre a interação solo-reforço através de ensaios de laboratório de grande escala, concluiu que vários fatores afetam $\mathrm{o}$ comportamento do reforço em areia. 
Percebendo que em ensaios de pequenas dimensões muitos efeitos do fenômeno de cisalhamento em interfaces poderiam estar sendo negligenciados, Shallenberger e Filz (1996) desenvolveram uma prensa de cisalhamento direto, especialmente para ensaios de interface. Esta prensa foi equipada com uma caixa de cisalhamento com dimensões internas em planta de $711 \mathrm{~mm}$ por $406 \mathrm{~mm}$. As principais vantagens de um equipamento com essas dimensões, segundo os autores, são a possibilidade de atingir grandes deslocamentos, a minimização dos efeitos causados por excentricidades nas cargas.

Gómez (2000), pesquisando a utilização do modelo hiperbólico de Duncan e Clough (1971) em interfaces concreto areia de muros de gravidade, realizou uma série de ensaios de cisalhamento direto em interfaces considerando diversas trajetórias de tensões com carregamento estático. Esses ensaios foram realizados em interfaces com seção transversal de $635 \mathrm{~mm}$ x $305 \mathrm{~mm}$. A superfície de cisalhamento foi confeccionada para possuir resistência elevada e assim minimizar a influência da caixa de cisalhamento. Também se procurou criar uma superfície com textura característica das condições de campo e minimizar os efeitos de deformação do concreto. A interface foi montada através da superposição de um corpo de prova de concreto sobre um corpo de prova de areia compactada através da técnica de chuva de areia. Em seus ensaios, Gómez (2000) procurou levantar a influência da granulometria do solo e do seu grau de compactação no comportamento da interface, utilizando graus de compactação de $49 \%$ e $75 \%$ para areia mais grossa e de $80 \%$ para areia mais fina. Um resumo dos resultados dos ensaios realizados por Gómez (2000) está mostrado na Tabela 2.5.

Além desses ensaios realizados com carregamento estático, deve-se citar os experimentos praticados por Desai et al (1985) que, através de ensaios de cisalhamento direto com tensão normal constante em interfaces de concreto-areia com seção de 305 mm x $305 \mathrm{~mm}$, avaliaram o comportamento mecânico dessas interfaces, quando submetidas a carregamentos cíclicos.

Tabela 2.5 - Resultados de ensaios de cisalhamento direto em interfaces areia-concreto (Gómez, 2000).

\begin{tabular}{|c|c|c|c|c|c|c|}
\hline & \multicolumn{2}{|c|}{$\begin{array}{c}\text { Deslocamento } \\
\text { tangencial (mm) }\end{array}$} & \multicolumn{2}{c|}{$\begin{array}{c}\text { Ângulo de atrito da } \\
\text { interface (graus) }\end{array}$} & \multicolumn{2}{c|}{$\begin{array}{c}\text { Razão entre o ângulo } \\
\text { de atrito do solo e a } \\
\text { interface }\end{array}$} \\
\cline { 2 - 8 } & $\begin{array}{c}\text { De pico } \\
u_{p}\end{array}$ & $\begin{array}{c}\text { Residual } \\
u_{r}\end{array}$ & $\begin{array}{c}\text { De pico } \\
\delta_{p}\end{array}$ & $\begin{array}{c}\text { Residual } \\
\delta_{r}\end{array}$ & $\begin{array}{c}\text { De pico } \\
\delta / \phi_{o}\end{array}$ & $\begin{array}{c}\text { Residual } \\
\delta_{r} / \phi_{c v}\end{array}$ \\
\hline $\begin{array}{c}\text { Areia compacta- } \\
\text { concreto }\end{array}$ & $1-2$ & $6-13$ & 31 & 28 & 0,86 & 0,82 \\
\hline $\begin{array}{c}\text { Areia mediamente } \\
\text { compacta - concreto }\end{array}$ & $2,5-3,5$ & $12-20$ & 29.5 & 28.5 & 0,71 & 0,86 \\
\hline $\begin{array}{c}\text { Areia Light Castle } \\
\text { compacta-concreto }\end{array}$ & $1-2$ & $6-11$ & 33.7 & 29.5 & 0.79 & 0.81 \\
\hline
\end{tabular}




\subsubsection{Ensaios de cisalhamento simples}

Um pouco menos utilizado para interpretação da interação solo-estrutura em interfaces, mas não menos importante, é o ensaio de cisalhamento simples. Esse modo de ensaio foi bastante desenvolvido nos últimos 20 anos e seus resultados demonstram a importância da consideração das distorções no comportamento de interfaces.

Dentre os principais trabalhos experimentais que utilizaram esse modo de ensaio, destaca-se o de Uesugi e Kishida (1986a) e (1986b), que testaram interfaces de aço-areia com dimensões em planta de $100 \mathrm{~mm}$ x $40 \mathrm{~mm}$.

Percebendo a influência das dimensões na interface em seus resultados, Kishida e Uesugi (1987) refizeram seu trabalho experimental em interface aço-areia, com seção em planta de $400 \mathrm{~mm}$ x $100 \mathrm{~mm}$, e identificaram uma relação direta entre a rugosidade da placa e o ângulo de atrito máximo mobilizado na interface. Esses ensaios foram realizados com tensão normal constante e a fase de cisalhamento se deu com carregamento estático.

Uma das desvantagens desse ensaio consiste no fato de não se determinar o deslocamento tangencial na interface, o que dificulta a interpretação da resistência e comportamento mecânico quando submetido a tensões residuais.

\subsubsection{Outros ensaios}

Outros ensaios menos utilizados para avaliação do comportamento de interfaces são os ensaios de Cisalhamento Torsional (Ring Shear) e os de arrancamento (Pull Out).

Os principais trabalhos em interfaces de concreto-areia utilizando um aparato de Cisalhamento Torsional foram realizados por Uesugi e Kishida (1987) que destacaram como vantagens à possibilidade de deslocamentos angulares ilimitados, o que favorece os estudos da resistência residual e do comportamento pós-ruptura; a garantia do carregamento centrado e a possibilidade de se obter parâmetros relativos ao comportamento da interface quando submetida a um estado de cisalhamento puro.

Esse modo de ensaio, no entanto, tem seu uso limitado devido a sua complexidade de montagem. Essa complexidade se dá principalmente no sistema de aplicação das cargas e da própria instalação do corpo de prova. Além disso, a aplicação dos seus resultados para simulação do comportamento mecânico de interfaces em estruturas reais fica limitado, devido à impossibilidade de se obter deslocamentos tangenciais ao plano de contato. Outro ponto fraco desta modalidade de ensaios, consiste no fato das tensões cisalhantes ao longo da interface não serem constantes, dificultando a interpretação da curva $\tau \times \gamma$.

Já os ensaios de arrancamento têm uma utilização maior, devido aos ensaios de campo realizados em tirantes e grampos, tornando o ensaio mais utilizado quando se trata do estudo de solos reforçados. 
Tei (1993) realizou diversos ensaios de arrancamento para simulação da resistência mobilizada em solo grampeado, utilizando elementos circulares metálicos inclusos em areia. Nesse estudo, o autor fez uma série de avaliações sobre a influencia da rugosidade da superfície, a granulometria da areia e sua compacidade. Levantou também a influência do comprimento e do diâmetro da inclusão.

As grandes vantagens dessa modalidade de ensaio consistem na facilidade de montagem e na possibilidade da aplicação direta dos seus resultados para previsão da carga de ruptura de inclusões. No entanto, quando se deseja estudar o comportamento de interação solo-estrutura surgem dificuldades com relação à interpretação da real distribuição de esforços ao longo da inclusão e de como a rigidez ou deformações da inclusão afeta o resultado da curva carga-deslocamento (Bakeer et al., 1998).

\subsubsection{Avaliação dos trabalhos experimentais em interfaces solo-estrutura}

Destaca-se na revisão da literatura sobre trabalhos experimentais em interfaces que muitos fatores interferem na avaliação do comportamento de interfaces submetidas a carregamento estático, tais como: rugosidade da superfície, granulometria e densidade do solo, além do nível de carga normal (Potyondy, 1961; Duncan e Clough, 1971; Uesugi e Kishida, 1986a e 1986b; Kishida e Uesugi, 1987; Shallenberger e Fil, 1996; Gómez, 2000).

Em muitos casos, a curva tensão tangencial por deslocamento tangencial é caracterizada por apresentar resistência de pico e posterior decrescimento para um valor residual. Também é constatado que esse comportamento de pico é proporcional à rugosidade da superfície de contato, à granulometria e à densidade do solo.

Percebe-se também que nesse fenômeno há fortes indícios da ocorrência de efeito escala, principalmente quando se trata da determinação da resistência de pico (Shallenberger e Filz, 1996), de modo que um programa experimental que deseje obter parâmetros de projeto mais realistas deverá utilizar seus ensaios em corpos de prova moldados com dimensões de escala real.

Em casos de interfaces entre estrutura-areia compacta, nota-se forte influencia do fenômeno de dilatância (Tei, 1993), o que sugere que um estudo completo do fenômeno de atrito em interfaces tem de seguir a diretriz dos estudos de comportamento das areias, que é definido a partir da linha de estados críticos.

Em todos os estudos consultados, verificoutse que o ensaio básico para avaliação do comportamento mecânico das interfaces solo-estrutura foi o de Cisalhamento Direto com Carga Normal Constante (CNC). Este tipo de ensaio é considerado como de referência até mesmo em programas experimentais baseados no Ensaio de Cisalhamento Direto com Rigidez Normal Constante (RNC) (Boulon, 1989, 1991; Boulon e Nova, 1990; Boulon et al, 1988; Ooi e Carter, 1987, Tabucanon et al., 1995; Porcino et al. 2003). 
Outro fator que também exerce forte influência sobre o comportamento das interfaces é a trajetória de carregamento em que o ensaio é conduzido (Gómez, 2000) e da velocidade de carregamento (Desai et al., 1985).

\subsection{Modelo matemático para atrito estático em interfaces}

Esta tese propõe um modelo teórico analítico para a previsão da resistência ao cisalhamento em interfaces de contato entre superfícies de concreto e areia considerando, simultaneamente, as parcelas de resistência devido ao atrito de deslizamento, à dilatância e ao rearranjo das partículas (atrito de rolamento).

A hipótese básica para o equacionamento matemático desse modelo é a consideração de que a tensão normal $\sigma(u)$ atuante em uma interface solo-concreto é resultado da tensão normal aplicada na interface, acrescida da parcela de tensão normal mobilizada durante o cisalhamento devido a variação de volume e ao rearranjo das partículas (atrito de rolamento).

A Figura 2.19 mostra esquematicamente as fases de imposição do deslocamento $u$ durante ensaios de cisalhamento direto.

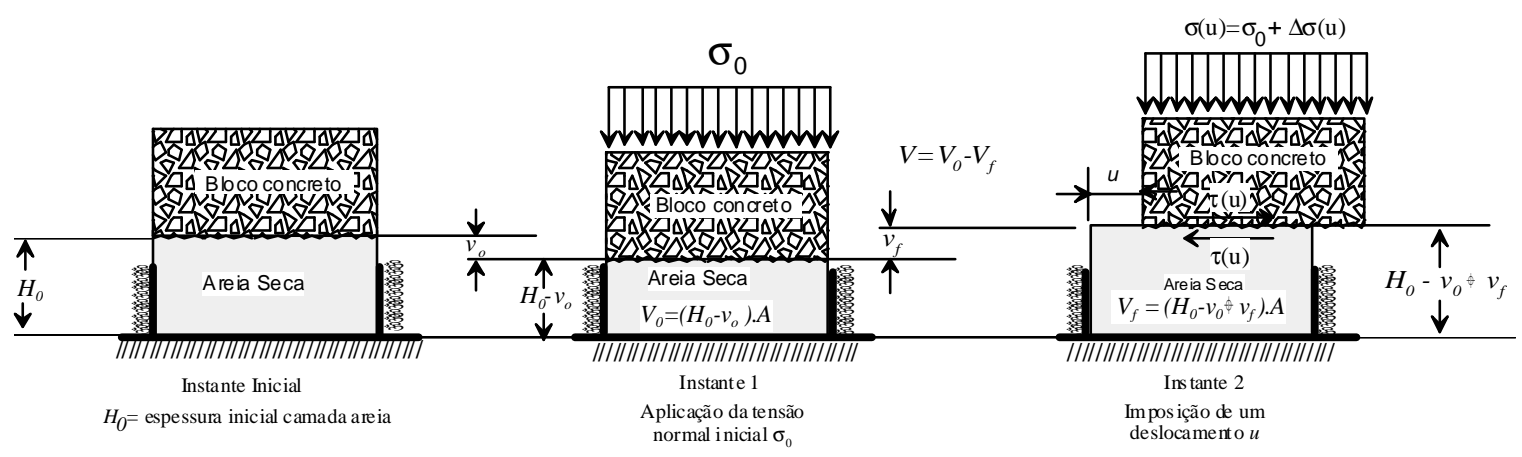

Figura 2.19 - Modelo de contato concreto-areia

No instante inicial o bloco de concreto entra em contato com a superfície de areia seca de espessura $H_{0}$.

No instante 1 , aplica-se a tensão inicial média $\sigma_{0}$ que provoca um deslocamento vertical $v_{0}$. $\mathrm{O}$ volume inicial da camada de areia com uma área de interface de contato $A$ será:

$V_{0}=\left(H_{0}-v_{0}\right) \cdot A$ 
No instante 2, impõe-se o deslocamento tangencial $u$, mobilizando-se a tensão tangencial média $\tau(u)$ e uma variação de deslocamento vertical $v_{f}$. $\mathrm{O}$ volume final da camada de areia será:

$V_{f}=\left(H_{0}-v_{0} \pm v_{f}\right) \cdot A$

A variação de volume $V$ será igual a:

$V=V_{0}-V_{f}= \pm v_{f} \cdot A$

A interpretação do fenômeno de atrito na interface, submetida a um deslocamento imposto $u$, é feita através da análise das seguintes curvas mobilizadas para o deslocamento imposto $u$ :

- curva de variação de volume mobilizada $V(u)$ versus deslocamento $u$;

- curva de tensão normal média mobilizada $\sigma(u)$ versus deslocamento $u$;

- curva de tensão tangencial média mobilizada $\tau(u)$ versus deslocamento $u$.

A variação de volume $V(u)$ é dada pela expressão:

$V(u)=V_{0}-V_{f}(u)= \pm v_{f}(u) \cdot A$

Onde $V_{0}$ é dado pela Equação 2.50 e $V_{f}(u)$ calculada pela Equação 2.51 para cada deslocamento vertical mobilizado em função do deslocamento tangencial imposto $u$.

A variação de volume $V(u)$ negativa corresponde ao aumento de volume que ocorre quando o material granular se expande (dilatância). A variação de volume $V(u)$ positiva ocorre quando o material granular se contrai (contração ou diminuição de volume).

A forma das curvas de tensão normal mobilizada, tensão tangencial mobilizada e variação de volume em função do deslocamento $u$ apresenta infinitas possibilidades em função da trajetória de tensões e das condições de contorno aplicadas em cada caso de cisalhamento (Figura 2.20).

Observando a Figura 2.20a, percebe-se que durante o cisalhamento, para cada nível de deslocamento imposto surge uma correspondente variação da tensão normal mobilizada na interface. Lambe e Whitman (1969) justificam essa variação da tensão normal $\Delta \sigma(u)$ como sendo provocada pelo rearranjo das partículas a partir do rolamento e do cavalgamento entre os grãos. 


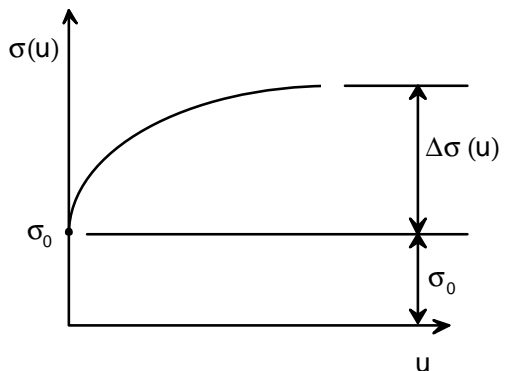

a) Tensão normal vs deslocamento $u$.

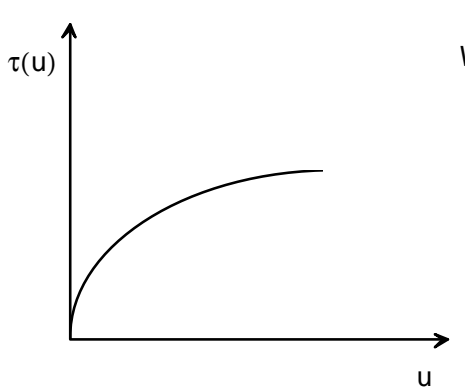

b) Tensão tangencial vs deslocamento $u$.

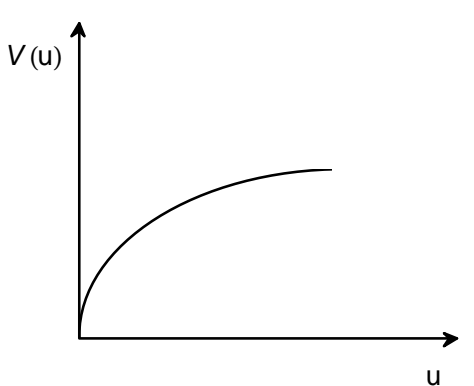

c) Variação de volume vs deslocamento u.

Figura 2.20 - Curvas de tensão normal $\sigma(u)$, tensão tangencial $\tau(u)$ e variação de volume $V(u)$ em função do deslocamento $u$.

Dessa forma, a tensão normal mobilizada em função do deslocamento pode ser expressa por:

$\sigma(u)=\sigma_{0}+\Delta \sigma(u)$

O rearranjo dos grãos durante o deslocamento provoca o rolamento entre os grãos e, consequentemente, a variação da tensão normal na interface. Essa variação da tensão normal devido ao rolamento de partículas de material granular pode ser considerada, de modo simplicado, linearmente proporcional à taxa de variação da tensão tangencial mobilizada na interface em função do deslocamento $u$, como sugerido na Equação (2.49).

$$
\Delta \sigma_{r}(u)=\eta \frac{d \tau(u)}{d u}
$$

Onde $\Delta \sigma_{r}(u)$ é a variação da tensão normal reativa mobilizada na interface em função do deslocamento imposto $u$ devida ao rolamento das partículas; $\eta$ é o coeficiente de rearranjo que é definido como o coeficiente de proporcionalidade entre a variação da tensão normal e a taxa de variação da tensão tangencial mobilizada na interface em função do deslocamento $u$; $\frac{d \tau(u)}{d u}$ é a taxa de variação da tensão tangencial mobilizada na interface em função do deslocamento $u$.

No entanto, o rearranjo das partículas não se caracteriza somente pelo rolamento das partículas, mas também pela compressão inelástica dos grãos, cavalgamento das rugosidades da interface e pela deformação da estrutura do solo (Lambe e Whitman, 1969). Nesse sentido, também ocorre uma variação da tensão normal mobilizada na 
interface devido à compressão (diminuição de volume) ou dilatação (aumento de volume). Esta tese considera que existe uma relação linear entre a variação da tensão normal e a derivada da variação de volume em função do deslocamento $u$. Assim:

$\Delta \sigma_{d}(u)=k \frac{d V}{d u}$

$\Delta \sigma_{d}(u)$ é a variação da tensão normal reativa mobilizada na interface em função do deslocamento imposto $u$ devida à variação de volume na interface; $k$ é o módulo de dilatância que é definido coeficiente de proporcionalidade entre a variação da tensão normal na interface e a taxa de variação de volume em função do deslocamento $u$.

Dessa forma, a variação da tensão normal reativa em função do deslocamento tangencial $u$ pode ser obtida a partir da soma das parcelas das Equações (2.55) e (2.56).

$\Delta \sigma(u)=\Delta \sigma_{r}(u)+\Delta \sigma_{d}(u)$

Substituindo a Equação (2.57) na equação (2.54), encontra-se a equação geral proposta nesta tese para cálculo da tensão normal reativa à superfície de interface correspondente ao deslocamento imposto $u$.

$\sigma(u)=\sigma_{0}+\Delta \sigma_{r}(u)+\Delta \sigma_{d}(u)$

Analisando o deslizamento de bloco rígido sobre superfície rígida lisa, pode-se notar que o deslizamento ocorre após a completa mobilização do atrito verdadeiro (Figura 2.1) que permanece constante para qualquer valor do deslocamento (Chicata, 2003). Este autor destaca, ainda, que o atrito é mobilizado integralmente de acordo com a lei de Coulomb sempre que houver deslocamento relativo entre as superfícies em contato.

Champaney (2002) comprova que existe uma relação entre o deslocamento tangencial e a tensão tangencial mobilizada entre dois corpos em contato. Este autor propõe que o deslizamento mobiliza bruscamente a resistência ao cisalhamento dado pela Lei de Coulomb:

$\tau(u)=\sigma_{0} \cdot \operatorname{tg} \delta$

em que $\sigma_{0}$ é a tensão normal inicial aplicada na interface obtida como sendo a força normal $N_{O}$ aplicada na interface dividida pela área da seção transversal da interface. 
$\sigma_{0}=\frac{N_{0}}{A}$

$\delta$ é o ângulo de atrito mobilizado na interface quando ocorrer o atrito de deslizamento (atrito verdadeiro).

Nota-se que o atrito verdadeiro é constante para qualquer valor de $u$ (Figura 2.1). De modo que se pode escrever:

$\tau(u)=\sigma_{0} \cdot \operatorname{tg} \delta$

$\sigma_{0}=\frac{\tau(u)}{\operatorname{tg} \delta}$

Substituindo as Equações (2.62), (2.56) e (2.55) na Equação (2.58), obtém-se a equação diferencial geral para cálculo da tensão normal mobilizada na interface em função do deslocamento $u$.

$\sigma(u)=\frac{\tau(u)}{\operatorname{tg} \delta}+\eta \frac{d \tau(u)}{d u}+k \frac{d V(u)}{d u}$

$\mathrm{Na}$ Equação (2.63), definem-se como propriedades físicas da interface os parâmetros: $k$ (módulo de dilatância), $\eta$ (coeficiente de rearranjo) e $\delta$ ângulo de atrito básico (volume constante) da interface.

2.3.1. Tipos de trajetórias de carregamento em ensaios de cisalhamento direto

Existem basicamente três possibilidades de carregamento em ensaios de cisalhamento de direto que são listadas a seguir.

a) Ensaio de cisalhamento direto com deslocamento normal constante (DNC);

b) Ensaio de cisalhamento direto com rigidez normal constante (RNC);

c) Ensaio de cisalhamento direto com tensão normal constante (TNC).

A interpretação de cada modo de ensaio segundo o modelo matemático para atrito estático em interfaces aqui proposto (Equação 2.63) é mostrada na sequência.

a) Ensaio de cisalhamento direto com deslocamento normal constante (DNC)

O ensaio de cisalhamento direto com deslocamento normal constante se caracteriza por ter o deslocamento normal à interface impedido durante toda a fase de 
cisalhamento. Devido a essa restrição do deslocamento vertical, a imposição de um deslocamento tangencial $u$ provoca a mobilização de tensão tangencial na interface (Figura 2.21b) acompanhada de uma variação da tensão normal (Figura 2.21a). A variação de volume é nula devido ao deslocamento normal nulo. A variação de tensão normal pode ser positiva ou negativa em função do estado inicial (Figura 2.21c).

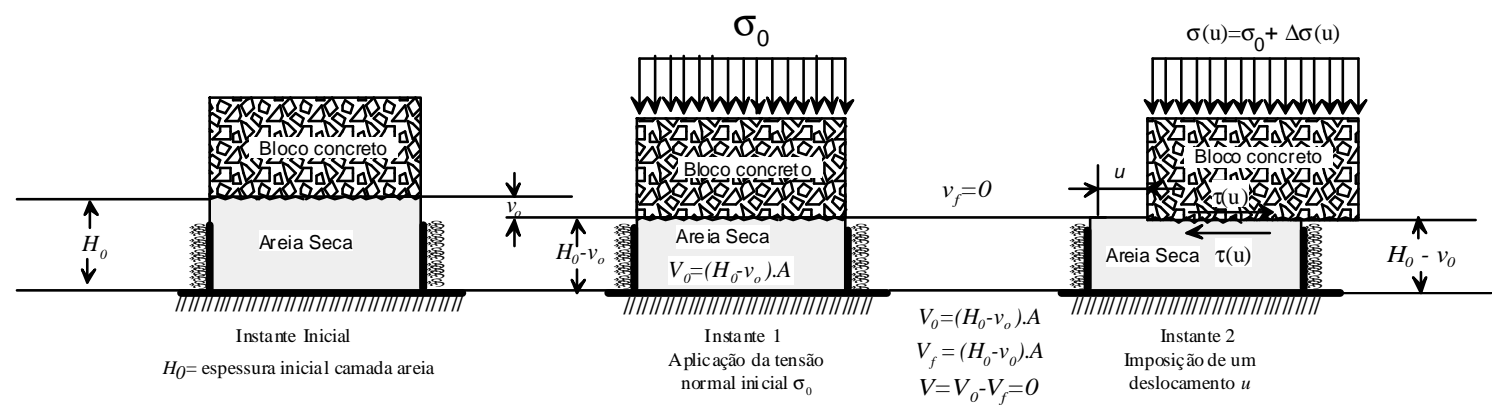

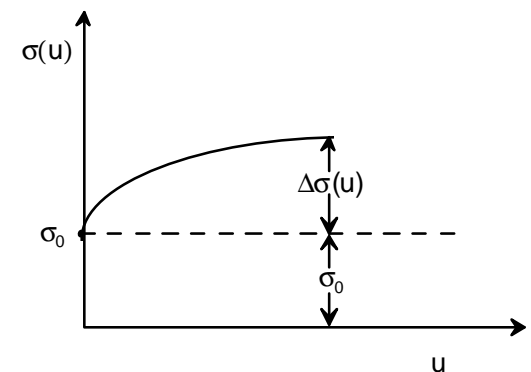

(a) $\sigma(\mathrm{u})$ versus $\mathrm{u}$

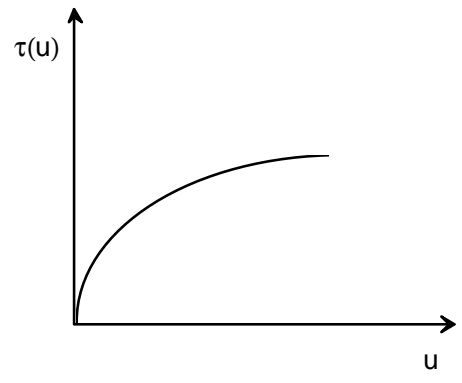

(b) $\tau(\mathrm{u})$ versus $\mathrm{u}$

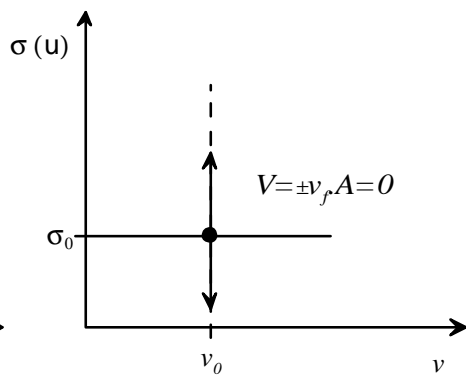

(c) $\sigma(\mathrm{u})$ versus $v$

Figura 2.21 - Curvas de interpretação do atrito em interfaces submetido ao cisalhamento com deslocamento normal constante.

A Equação (2.63) aplicada ao caso de deslocamento normal constante (DNC) se torna-se igual a:

$\sigma(u)=\frac{\tau(u)}{\operatorname{tg} \delta}+\eta \frac{d \tau(u)}{d u}$

A solução da Equação (2.64) é possível conhecendo-se uma função que represente a a tensão normal em função do deslocamento $u$ (Figura 2.21a) e aplicandose as condições de contorno específicas.

b) Ensaio de cisalhamento direto com rigidez normal constante (RNC)

A rigidez normal de uma interface é definida pela relação entre a variação da tensão normal e a variação do deslocamento normal provocado pelo cisalhamento. 


$$
K=\frac{\Delta \sigma(u)}{\Delta v}
$$

O ensaio de cisalhamento direto com rigidez normal constante se caracteriza por manter, durante toda a fase de cisalhamento, a relação constante entre a variação da tensão normal e a variação do deslocamento normal. Neste tipo de cisalhamento são impostos os deslocamentos tangenciais e normais. Dessa forma, a imposição de um deslocamento tangencial é seguida por uma correspondente variação da tensão (Figura 2.22a) e do deslocamento normal. No instante em que a variação de tensão normal começa a ocorrer, impõe-se um deslocamento vertical de modo a manter a relação mostrada na Equação (2.65). Esse modo de ensaio possibilita a utilização de infinitas trajetórias de carregamento de acordo com o valor de $K$ que se deseje utilizar (Figura $2.22 \mathrm{c})$.

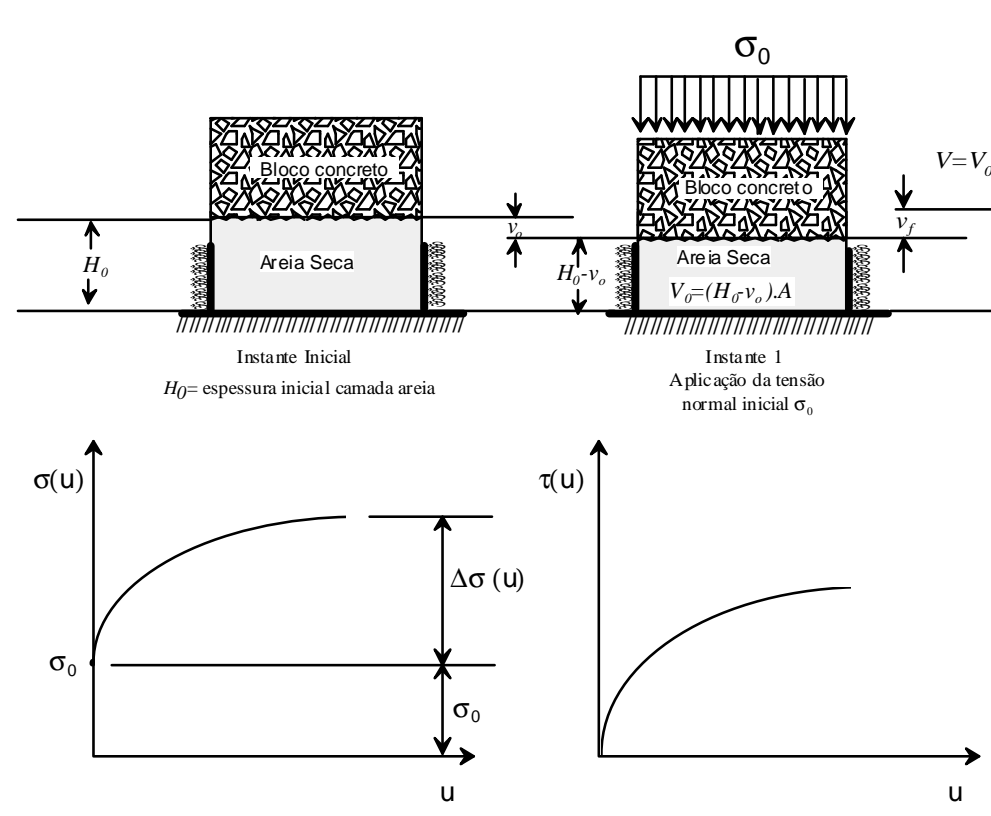

(a) $\sigma(\mathrm{u})$ versus $\mathrm{u}$

(b) $\tau(\mathrm{u})$ versus $\mathrm{u}$
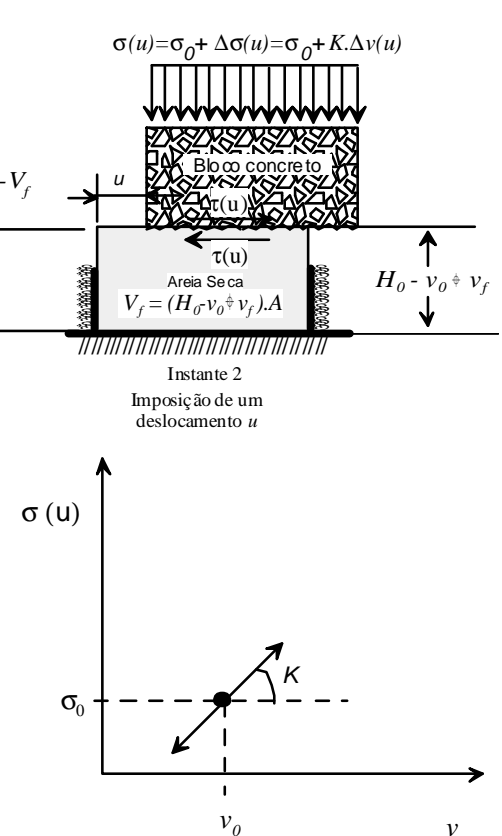

(c) $\sigma(\mathrm{u})$ versus $v$

Figura 2.22 - Curvas de interpretação do atrito em interfaces submetido ao cisalhamento com rigidez normal constante.

A Equação (2.63) aplicada ao caso de rigidez normal constante (RNC) pode ser apresentada de duas maneiras diferentes. Na primeira, assume-se uma condição geral onde o fenômeno de atrito mobilizado em interfaces é regido por uma equação diferencial parcial em função dos deslocamentos tangenciais $u$ e verticais $v$ :

$$
\sigma(u, v)=\frac{\tau(u, v)}{\operatorname{tg} \delta}+\eta \frac{\partial \tau(u, v)}{\partial u \partial v}+k \frac{\partial V(u, v)}{\partial u \partial v}
$$


$\mathrm{Na}$ segunda, adimite-se que o deslocamento vertical é imposto em função da variação de tensão normal devido à imposição deslocamento normal $\Delta \sigma(u)$. Assim, a variação de deslocamento normal também se torna função do deslocamento imposto $u$. Nessa abordagem, a varía vel independente continua sendo $u$ e a Equação (2.63), tornase:

$$
\sigma_{0}+K . v_{f}(u)=\frac{\tau(u)}{\operatorname{tg} \delta}+\eta \frac{d \tau(u)}{d u}+k \frac{d V(u)}{d u}
$$

Considerando válida a Equação (2.53), pode-se reescrever a Equação (2.67):

$$
\sigma_{0}+K . v_{f}(u)=\frac{\tau(u)}{\operatorname{tg} \delta}+\eta \frac{d \tau(u)}{d u}+k \cdot A \frac{v_{f}(u)}{d u}
$$

A solução da Equação (2.68) é possível conhecendo-se uma curva deslocamento normal $v_{f}$ em função do deslocamento tangencial $u$ e aplicando-se as condições de contorno específicas para cada coeficiente de rigidez $K$ adotado (Figura 2.22c).

c) Ensaio de cisalhamento direto com tensão normal constante (CNC)

O ensaio de cisalhamento direto com tensão normal constante se caracteriza por manter durante toda a fase de cisalhamente o mesmo valor da tensão normal atuante (Figura 2.23a). Neste tipo de cisalhamento é liberado o deslocamento normal que pode variar livremente de modo que a interface pode se contrair ou expandir (Figura 2.23c). Dessa forma, a imposição de um deslocamento tangencial $u$ é seguido por uma correspondente variação de volume provocada pela variação do deslocamento normal (Figura 2.23c).

A solução Equação (2.63) é possível conhecendo-se uma equação que relacione a variação de volume $V(\mathrm{u})$ com o deslocamento tangencial $u$ e aplicando-se as condições de contorno específicas.

No ítem que se segue será desenvolvida a solução da equação geral correspondente a este tipo de ensaio. 
2.3.2. Solução da equação de tensão tangencial mobilizada na interface em função do deslocamento $u$ para o caso de cisalhamento com tensão normal constante

Nesta tese propõe-se, apenas, a solução da Equação (2.63) para o caso de tensão normal constante.

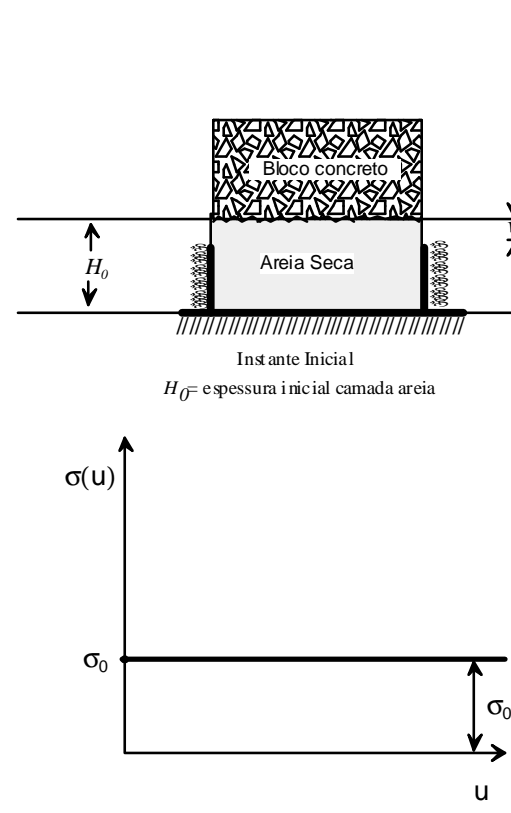

(a)

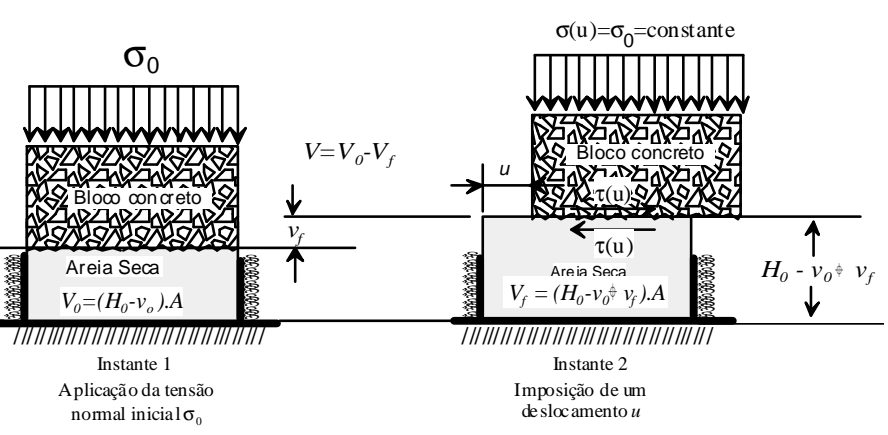

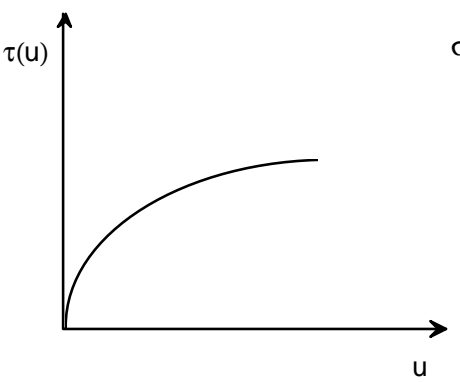

(b)

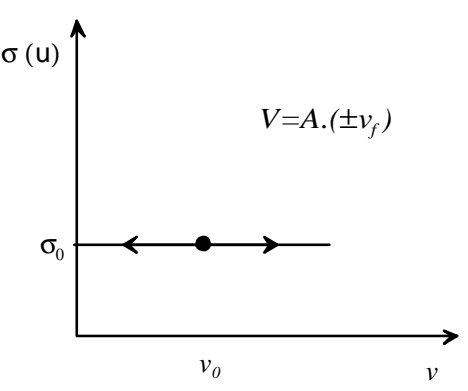

(c)

Figura 2.23 - Curvas de interpretação do atrito em interfaces submetido ao cisalhamento com tensão normal constante: a) $\sigma(u) x u$;b) $\tau(u) x u$; c) $\sigma(u) x v$.

Analisando o caso (c) do ítem anterior, nota-se que o fenômeno de cisalhamento com tensão normal constante pode ser modelado impondo-se a condição de contorno:

$$
\frac{d \sigma(u)}{d u}=0
$$

Logo:

$\frac{d}{d u} \frac{\tau(u)}{\operatorname{tg} \delta}+\eta \frac{d^{2} \tau(u)}{d u^{2}}+k \frac{d^{2} V(u)}{d u^{2}}=0$

ou ainda:

$$
\frac{d^{2} \tau(u)}{d u^{2}}+\frac{d \tau(u)}{\eta \operatorname{tg} \delta d u}=-k \frac{d^{2} V(u)}{\eta d u^{2}}
$$

A Equação (2.71) é uma equação diferencial não homogênea. Sua solução geral é obtida a partir de duas soluções do tipo: 
$\tau(u)=\tau_{c}(u)+\tau_{p}(u)$

Em que $\tau_{c}$ é a solução complementar com variável em $\mathrm{u} ; \tau_{p}$ é a solução particular, também com variável em $\mathrm{u}$.

A parcela homogênea da Equação:

$\frac{d^{2} \tau(u)}{d u^{2}}+\frac{d \tau(u)}{\eta \operatorname{tg} \delta \cdot d u}=0$

Possui solução complementar do tipo:

$\tau_{c}(u)=C_{1} e^{m_{1} u}+C_{2} e^{m_{2} u}$

Em que:

$$
m_{1}=0 \quad \text { ou } \quad m_{2}=-\frac{1}{\eta \operatorname{tg} \delta}
$$

Portanto:

$\tau_{c}(u)=C_{1}+C_{2} e^{\left(-\frac{1}{\operatorname{tg} \delta \eta}\right) u}$

A parcela não-homogênea da Equação (2.63) é:

$g(u)=-k \frac{d^{2} V(u)}{\eta d u^{2}}$

A variação de volume $V$, em função do deslocamento tangencial, é dada pela Equação (2.78), onde valores positivos significam contração e negativos significam dilatação e $a, J$ e $C$ são constantes da equação.

$V(u)=\frac{J}{a^{2}} u e^{a u}-\frac{2 J}{a^{3}} e^{a u}+C$

Diferenciando a Equação (2.78) em função de $u$, tem-se:

$$
\frac{d^{2} V(u)}{d u^{2}}=J u e^{a u}
$$

Substituindo a Equação (2.79) na Equação (2.77), tem-se: 
$g(u)=-\frac{k}{\eta} J u e^{a u}$

A solução particular da equação não homogênea é

$\tau_{p}(u)=A u e^{a u}$

Em que:

$\frac{d \tau_{p}(u)}{d u}=a u A e^{a u}+A e^{a u}$

$\frac{d^{2} \tau_{p}(u)}{d u^{2}}=a^{2} A u e^{a u}+2 A a e^{a u}$

Substituindo as Equações (2.72) e (2.74) na equação (2.61), encontra-se:

$a=-\frac{1}{2 \eta \operatorname{tg} \delta}$

e

$A=4 . k . J \cdot \operatorname{tg}^{2} \delta . \eta$

Portanto, solução da equação (2.57) para condição de tensão normal constante é

$\tau(u)=C_{1}+C_{2} e^{\left(-\frac{1}{\operatorname{tg} \delta . \eta}\right) u}+4 \cdot k \cdot J \cdot \operatorname{tg}^{2} \delta \eta \cdot u e^{\left(-\frac{1}{2 \operatorname{tg} \delta \eta}\right) u}$

As condições de contorno do problema são: $u=0 \rightarrow \tau=0 \quad \mathrm{e}$ $\lim _{u \rightarrow \infty} \tau=\sigma \operatorname{tg} \delta$; dessa forma, encontra-se que:

$C_{1}=\sigma_{0} \cdot \operatorname{tg} \delta$

e

$C_{2}=-\sigma_{0} \cdot \operatorname{tg} \delta$

Substituindo as Equações (2.87) e (2.88) na Equação (2.86), obtém-se a equação geral para cálculo da tensão tangencial mobilizada em interfaces de contato entre concreto e areia em função do deslocamento horizontal, mantida a tensão normal constante: 
$\tau(u)=\underbrace{\sigma_{0} . \operatorname{tg} \delta}_{(a)} \underbrace{-\sigma_{0} . \operatorname{tg} \delta e^{\left(-\frac{1}{\operatorname{tg} \delta \cdot \eta}\right)}}_{(b)} \underbrace{+4 . k . J \cdot \operatorname{tg}^{2} \delta . \eta \cdot u e^{\left(-\frac{1}{2 \operatorname{tg} \delta \cdot \eta}\right) u}}_{(c)}$

Nesta fórmula, a parcela (a) corresponde à componente de atrito verdadeiro, a parcela (b) corresponde à componente devido o rearranjo das partículas e aparcela (c) corresponde à componente devido a dilatância.

A equação geral (Equação 2.89) é formada pela superposição dos efeitos do atrito verdadeiro, do atrito rolamento e da variação volume. A influência de cada parcela da curva tensão tangencial mobilizada versus deslocamento tangencial é ilustrada nas Figuras 2.24a., 2.24b e 2.24c.

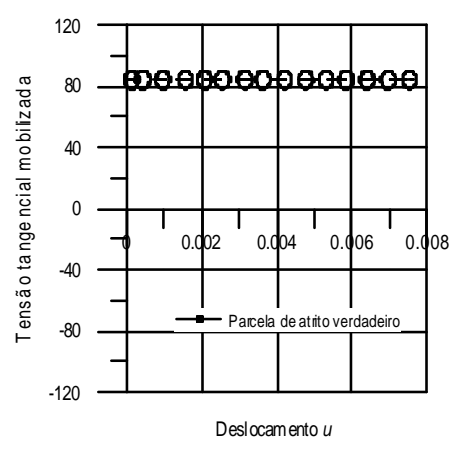

a) Parcela de atrito verdadeiro

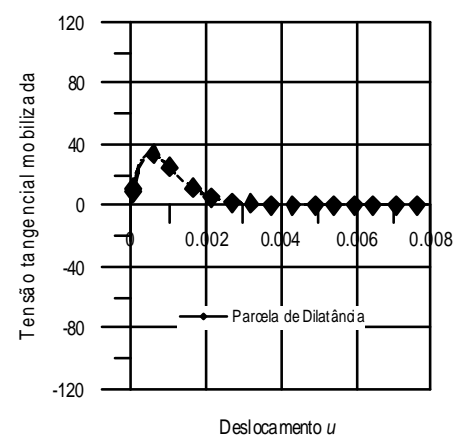

b) Parcela de dilatância

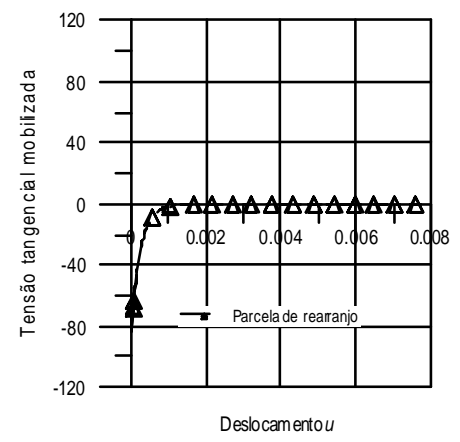

c) Parcela de rearranio partículas

Figura 2.24 - Curvas representativas das parcelas correspondentes.

A parcela (a) da Equação (2.89) correspondente ao atrito verdadeiro (atrito de deslizamento) é constante com o deslocamento. A parcela (b) da Equação (2.89) corresponde ao rearranjo das partículas. Nota-se que esta componente apresenta-se comé tende a se anular para grandes deslocamentos, o que também está de acordo com a realidade física do problema na qual se verifica, que após a ruptura, as partículas deslizam, perdendo, portanto, o atrito de rolamento. Nesse caso, a parcela de resistência mobilizada restante deve-se apenas ao atrito verdadeiro. A parcela (c) devido à dilatância é a responsável pelo pico de tensão tangencial quando essa parcela atinge seu valor máximo, a partir do qual começa a diminuir até se anular. Admitindo que o comportamento pós-ruptura de interfaces com material granular é definido pelo cisalhamento à volume constante, pode-se dizer, então, que o fato da componente de dilatância se anular para grande deslocamento está de acordo com a realidade física.

A Figura 2.25 mostra a curva tensão tangencial versus deslocamento $u$ resultante. 


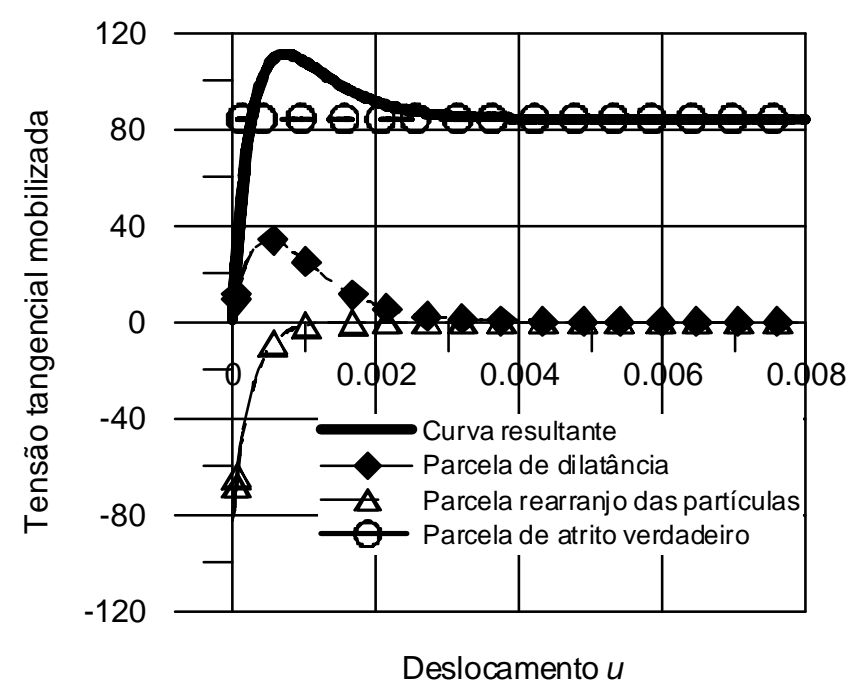

Figura 2.25 - Curva tensão tangencial mobilizada versus deslocamento $u$ (Equação 2.89).

A variação de volume em função do deslocamento horizontal é definida pela Equação (2.90):

$V(u)=4 . \operatorname{tg}^{2} \delta \eta^{2} . J \cdot u \cdot e^{\left(-\frac{1}{2 \operatorname{tg} \delta \eta}\right) u}+16 . J \cdot \operatorname{tg}^{3} \delta \cdot \eta^{3} \cdot e^{\left(-\frac{1}{2 \operatorname{tg} \delta . \eta}\right) u}+C$

Onde a condição de contorno para $u=0$ é $V=0$. Assim, a equação completa para cálculo da variação de volume é:

$V(\boldsymbol{u})=4 . \operatorname{tg}^{2} \delta \cdot \eta^{2} \cdot J \cdot u . e^{\left(-\frac{1}{2 \operatorname{tg} \delta . \eta}\right) u}+16 . J \cdot \operatorname{tg}^{3} \delta \cdot \eta^{3} \cdot e^{\left(-\frac{1}{2 \operatorname{tg} \delta . \eta}\right) u}-16 . J \cdot \operatorname{tg}^{3} \delta . \eta^{3}$

Em que $V(u)$ é positivo para contração e negativo para dilatação.

A constante $J$ é uma função empírica que depende da tensão normal atuante e da relação entre o índice de vazios inicial e o índice de vazios crítico.

$$
J=\left(\frac{E_{o e d}}{\sigma_{0}}\right)^{2} \cdot j
$$

Em que $j$ é uma função da linha de estado crítico.

$$
j=\frac{e_{\text {crítico }}-e_{o}}{e_{\text {crítico }}}
$$

Com: 


$$
\begin{aligned}
& e_{o}=\frac{\gamma_{\text {sólidos }}}{\left(\gamma_{\text {solo } \sec o}\right)_{0}}-1 \\
& \mathrm{e} \\
& e_{\text {crítico }}=\Gamma+\lambda \cdot \log \sigma_{0}
\end{aligned}
$$

sendo $\sigma_{0}$ a tensão normal inicial aplicada sobre o contato e $\lambda$ a inclinação da reta crítica (Figura 2.21) obtida pelo método de Casagrande descrito por Taylor (1948).

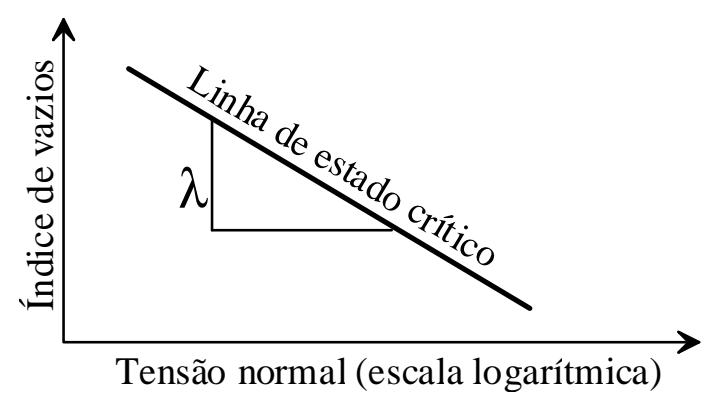

Figura 2.26 - Linha de estado crítico

O modelo físico-matemático para atrito estático demonstrado aqui possui simplificações inerentes à modelagem matemática adotada, tais como: a variação linear entre a variação de tensão normal e a taxa de variação da tensão tangencial em função do deslocamento horizontal; a variação linear entre a variação de tensão normal e a taxa variação de volume em função do deslocamento horizontal; e relação constante entre a tensão normal inicial e a resistência ao cisalhamento devido ao atrito verdadeiro.

Cabe ressaltar, ainda, que a equação geral foi deduzida para condições de contorno específicas, tendo como condição principal à manutenção da tensão normal constante durante todo o cisalhamento; no entanto, a equação diferencial proposta pode ser aplicada a qualquer trajetória de tensões idealizadas.

Nota-se que a Equação (2.63) é uma equação diferencial que por definição representa uma família de curvas. Isso significa dizer que essa equação diferencial possui um número infinito de soluções correspondentes ao número ilimitadode opções dos parâme tros.

Assim, para o caso de tensão normal constante durante o cisalhamento existe um número infinito de soluções que dependem das condições de contorno impostas ao problema.

Por exemplo, no caso de cisalhamento sem a consideração da componente devido a variação de volume tem-se: 
$\frac{d V(u)}{d u}=0$

A Equação (2.63) torna-se:

$\sigma(u)=\frac{\tau(u)}{\operatorname{tg} \delta}+\eta \frac{d \tau(u)}{d u}$

Aplicando-se a condição de tensão normal mobilizada na interface constante durante todo o ensaio $\left(\frac{d \sigma(u)}{d u}=0\right)$, tem-se:

$\frac{d \tau(u)}{\operatorname{tg} \delta d u}+\eta \frac{d^{2} \tau(u)}{d u^{2}}=0$

Integrando-se a Equação (2.98) considerando as mesmas condições de contorno descritas para a dedução da Equação (2.89), encontra-se que a tensão tangencial mobilizada durante o cisalhamento é dada por:

$\tau(u)=\sigma_{0} \cdot \operatorname{tg} \delta-\sigma_{0} \cdot \operatorname{tg} \delta e^{\left(-\frac{1}{\operatorname{tg} \delta \cdot \eta}\right) t}$

Ou ainda:

$\tau(u)=\sigma_{0} \cdot \operatorname{tg} \delta\left(1-e^{\left(-\frac{1}{\operatorname{tg} \delta \eta}\right) u}\right)$

Nota-se que a Equação (2.100) é uma equação exponencial semelhante a Equação (2.9) proposta por Potyondy (1961) para ajustar os seus resultados de ensaios de cisalhamento direto em interfaces. Segundo Potyondy (1961), essa mesma equação foi desenvolvida por Kezdi (1959).

A Equação (2.100) também se assemelha a Equação (2.10) desenvolvida experimentalmente por Teixeira (2003) a partir de ajustes de curvas tensão tangencial versus deslocamento tangencial obtidas em ensaios de arrancamento de geogrelhas embutidas em solos coesivos.

Comparando-se a Equação (2.100) com a Equação (2.89), percebe-se que a Equação (2.89) é uma generalização da Equação (2.100) de tal modo que pode-se reescrever a Equação (2.89) como a soma de duas parcelas:

$\tau(u)=\tau_{1}(u)+\tau_{2}(u)$

Onde $\tau_{1}(u)$ é a parcela (a) somada à parcela (b) da Equação (2.89): 
$\tau_{1}(u)=\sigma_{0} \cdot \operatorname{tg} \delta-\sigma_{0} \cdot \operatorname{tg} \delta e^{\left(\frac{1}{\operatorname{tg} \delta . \eta}\right) u}=\sigma_{0} \cdot \operatorname{tg} \delta\left(1-e^{\left(-\frac{1}{\operatorname{tg} \delta . \eta}\right) u}\right)$

e $\tau_{2}(u)$ corresponde a parcela (c) da Equação (2.89):

$\tau_{2}(u)=4 . k . J \cdot \operatorname{tg}^{2} \delta . \eta \cdot u e^{\left(-\frac{1}{2 \operatorname{tg} \delta . \eta}\right) u}$

A Equação (2.102) representa a influência do atrito de rolamento das partículas e do atrito verdadeiro (Equação de Potyondy), enquanto a Equação (2.103) representa a influência da dilatância. A Equação (2.103) mostra que a dilatância em material granular depende do rearranjo das partículas através do cavalgamento de uns grãos sobre os outros (observável através do $\eta$ ). Nota-se que esse fato também é comentado por Ortigão (1993).

Outro caso particular que vale ressaltar, é o caso de deslizamento em interfaces de contato entre duas superfícies rígidas sem a ocorrência de preenchimento com material granular. Nesse caso, a Equação (2.63), para condição de contorno de tensão normal constante durante todo o cisalhamento, resume-se na Equação (2.59) que representa um comportamento semelhante ao comportamento "rígido perfeitamente plástico“ conforme a Figura 2.1. 
CAPÍTULO III

\section{ESTUDO EXPERIMENTAL DE INTERFACES SOLO-ESTRUTURA}

Para dar suporte ao desenvolvimento desta tese, foi executado um programa experimental em interface de concreto-areia através de Ensaios de Cisalhamento Direto com Carga Normal Constante (CNC), considerando o efeito da rugosidade da superfície de contato, a granulometria da areia, sua densidade relativa inicial e o nível da tensão normal.

\subsection{Equipamento}

O equipamento utilizado consiste de um pórtico em estrutura metálica com suporte para dois atuadores MTS de $500 \mathrm{kN}$ de carga máxima de serviço, servo controlados para forças e deslocamentos, atuando na direção normal e tangencial à caixa de cisalhamento (Figura 3.1 e 3.2).

O sistema de aplicação dos esforços foi montado de modo que a caixa superior deslocava-se em relação à caixa inferior, mantida fixa no pórtico de reação e no piso através de parafusos. O sistema também possui articulação (rótulas) nos pontos de ancoragem dos atuadores de carga, permitindo a rotulagem do dispositivo, evitando, assim, o surgimento de esforços adicionais na interface de cisalhamento.

O equipamento faz parte do Laboratório de Mecânica das Rochas do Departamento de Geotecnia da Escola de Engenharia de São Carlos da Universidade de São Paulo. Esse equipamento foi montado para dar suporte à pesquisas realizadas utilizando corpos de prova de rocha intacta, rocha fratura ou modelos destes realizados em concreto.

O equipamento possui a capacidade de aplicar e monitorar várias trajetórias de carregamento, o que confere ao mesmo, grande versatilidade para o estudo de mecanismos de ruptura por cisalhamento direto. 


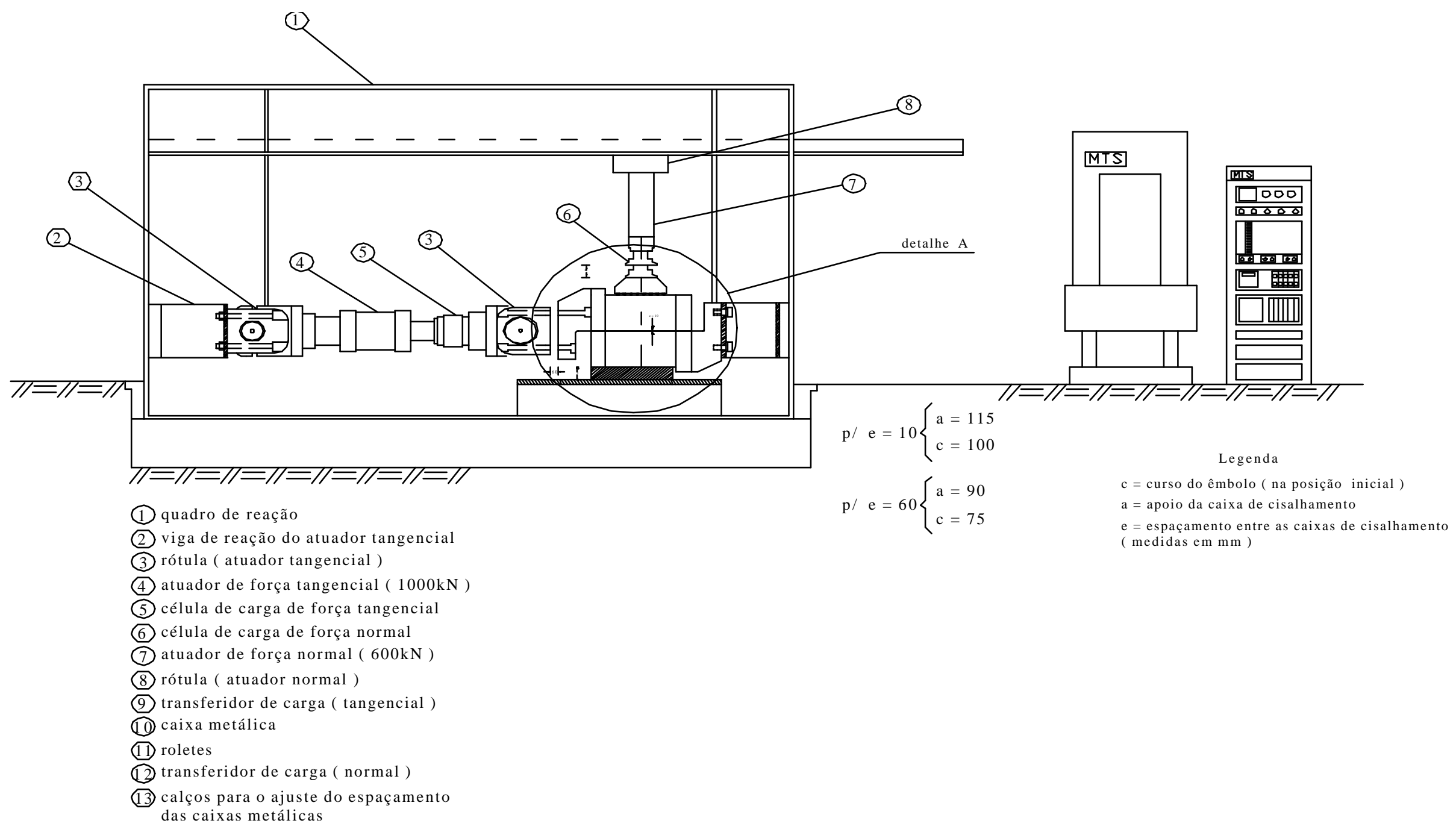

Figura 3.1 - Prensa de cisalhamento 


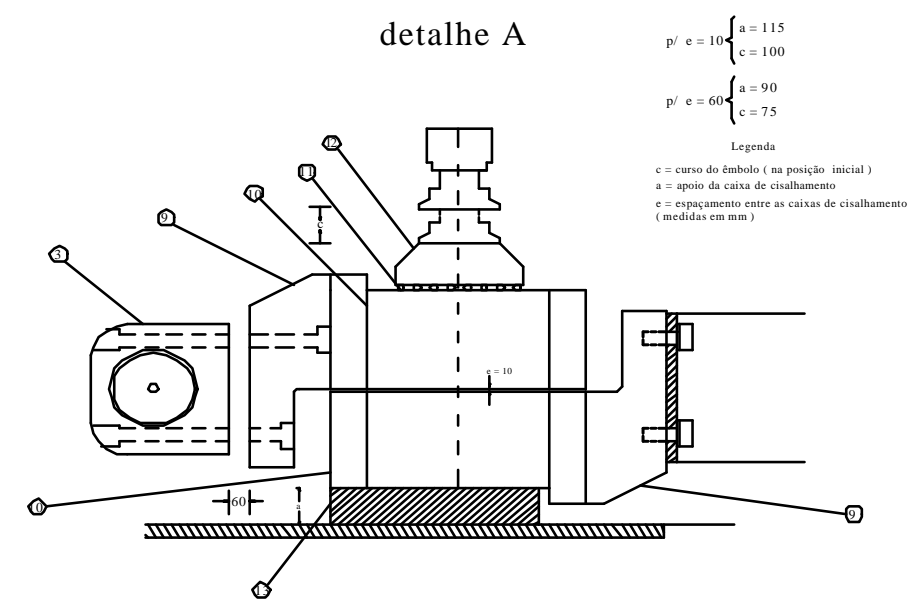

Figura 3.2 - Caixa de cisalhamento.

Utilizou-se como caixa de cisalhamento uma caixa de aço bipartida, de dimensões internas em planta de $500 \mathrm{~mm}$ x $500 \mathrm{~mm}$ e externa de $600 \mathrm{~mm}$ x $600 \mathrm{~mm}$. A altura interna e externa do seguimento inferior e superior da caixa são $240 \mathrm{~mm}$ e 240 $\mathrm{mm}$, respectivamente. A abertura de interface variou em torno de $15 \mathrm{~mm}$ para o solo e $15 \mathrm{~mm}$ para o bloco de concreto. Desse modo, as dimensões resultantes do corpo de prova foram de $500 \mathrm{~mm}$ por $500 \mathrm{~mm}$ em planta por $500 \pm 10 \mathrm{~mm}$ de altura, resultando numa área de contato $A=0,25 \mathrm{~m}^{2}$ e uma espessura inicial da camada de areia de $\mathrm{H}_{0}=$ $0,250 \pm 0,010 \mathrm{~m}$.

\section{CONDIÇÕES DE MONTAGEM}

O ensaio foi montado de modo que um bloco de concreto de $500 \mathrm{~mm}$ x $500 \mathrm{~mm}$ x $250 \mathrm{~mm} \pm 10 \mathrm{~mm}$ foi instalado na caixa superior e na caixa inferior foi montado com processo de chuva de areia o corpo de prova de solo. A Figura 3.3 mostra detalhes da interface ensaiada.

A colocação do corpo da banda de concreto sobre a areia foi realizada por simples superposição do bloco de concreto sobre o de areia. Para manter o confinamento inicial e permitir a manutenção da abertura da interface foi utilizado um gabarito de madeira que, posteriormente, quando do início do carregamento horizontal, era retirado.

\subsection{Instrumentação}

A instrumentação utilizada nos testes foi basicamente de dois tipos:

Transdutores de deslocamentos: foram utilizados seis transdutores de deslocamento do tipo LVDT para medida dos deslocamento indicado na Figura 2.4. Dois com cursor de $\pm 50 \mathrm{~mm}$, para medida dos deslocamentos horizontais (Figura 3.4b); 
e quatro com cursor de $\pm 35 \mathrm{~mm}$, para medida dos deslocamentos verticais (Figura 3.4a).

Células de carga: foram utilizadas duas células de carga com capacidade nominal de $500 \mathrm{kN}$; uma fixa ao atuador de carga horizontal $(F)$ e outra fixa ao atuador de carga vertical $(N)$ (Figura 3.4c e 3.4d).

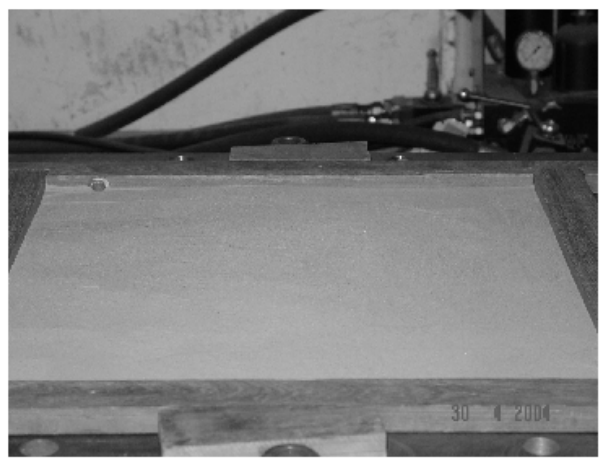

a) Superficie de areia

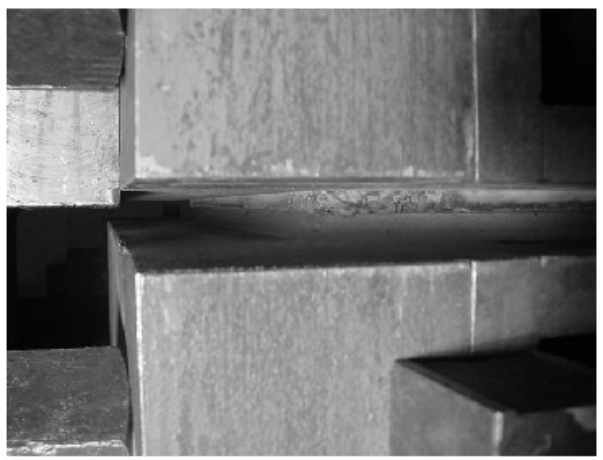

c) Vista anterior do contato antes do ens aio

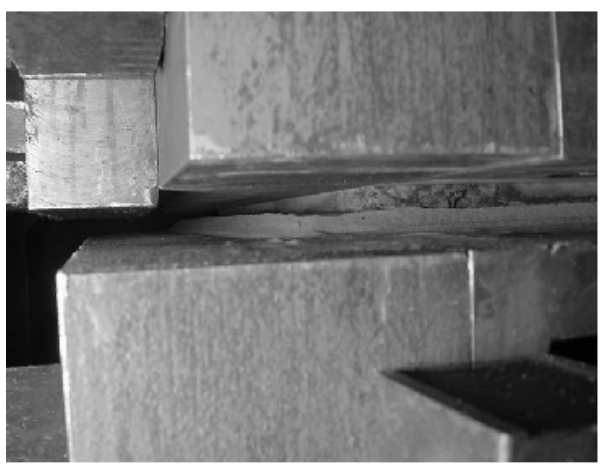

e) Vista anterior do contato depois da ruptura

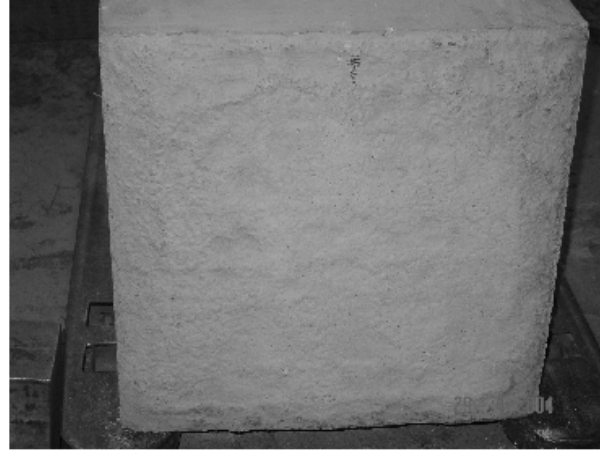

b) Superficie de concreto

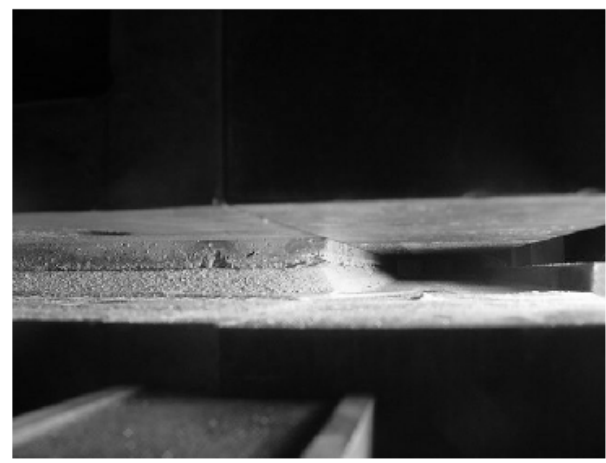

d) Vista posterior do contato antes do ensaio

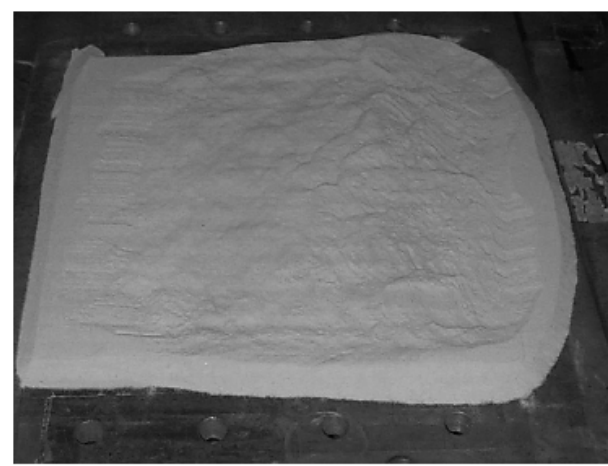

f) Superficie de areia após o ensaio

Figura 3.3 - a) Superfície de areia anterior à inserção do bloco de concreto na parte superior; b) bloco de concreto utilizado no ensaio; c) contato areia concreto antes do ensaio vista anterior; d) contato areia-concreto antes do ensaio: vista posterior; e) superfície de areia cisalhada após a retida do bloco de concreto; f) estado da superfície de areia após o cisalhamento.

Os transdutores de deslocamento vertical foram colocados em posições diagonais, de modo que o deslocamento médio entre os quatro representasse o deslocamento vertical do corpo de prova $v_{f}$. A mesma coisa aconteceu com os transdutores horizontais, que foram dispostos paralelamente entre si e na direção do 
deslocamento tangencial, de modo que o deslocamento médio entre os dois foi considerado como deslocamento tangencial ( $u$ ) (veja Figura 2.4).

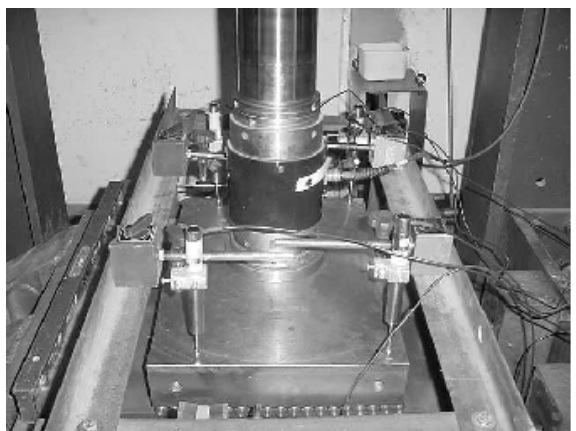

a) Transdutor de deslocamento vertical

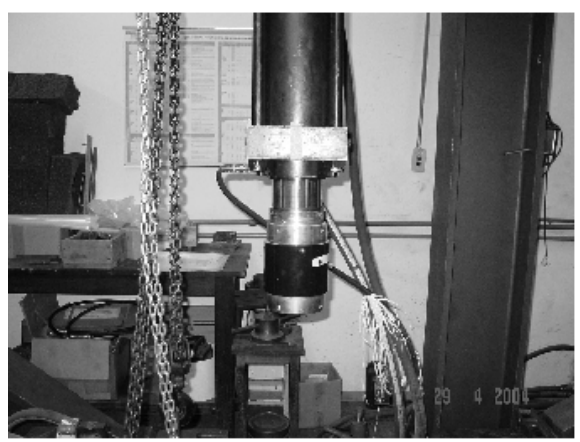

c) Atuador de carga vertical

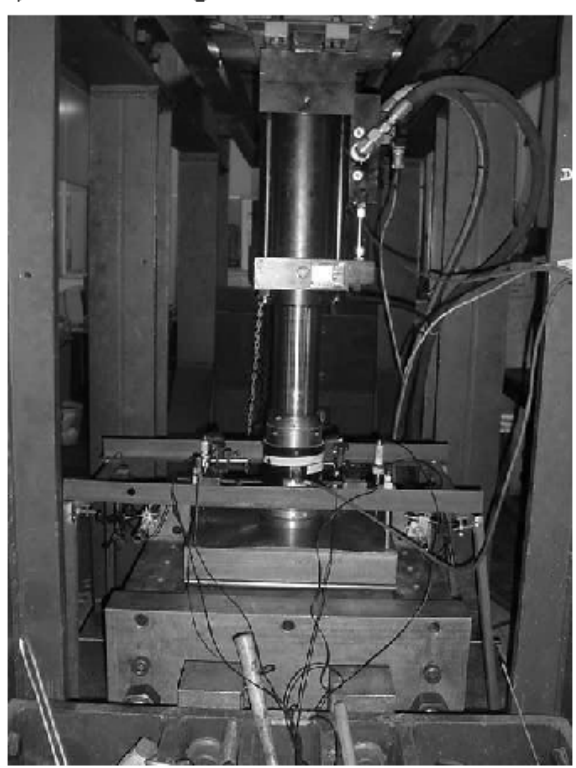

e) Vista frontal do ensaio

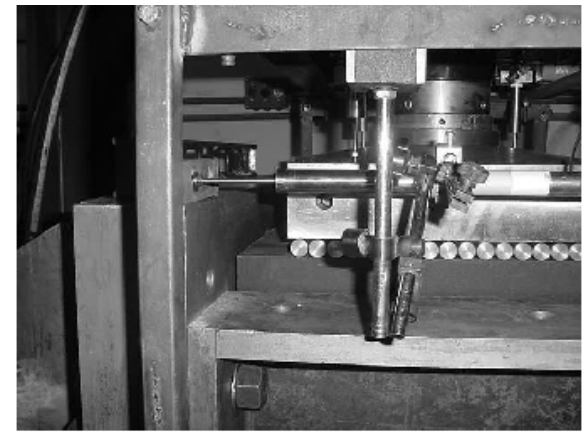

b) Transdutor de deslocamento horizontal

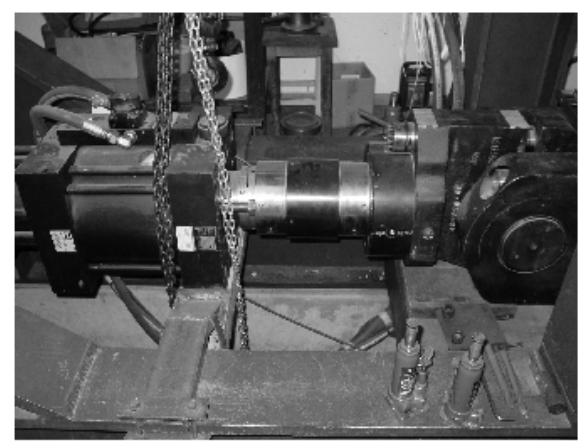

d) Atuador de carga horizontal

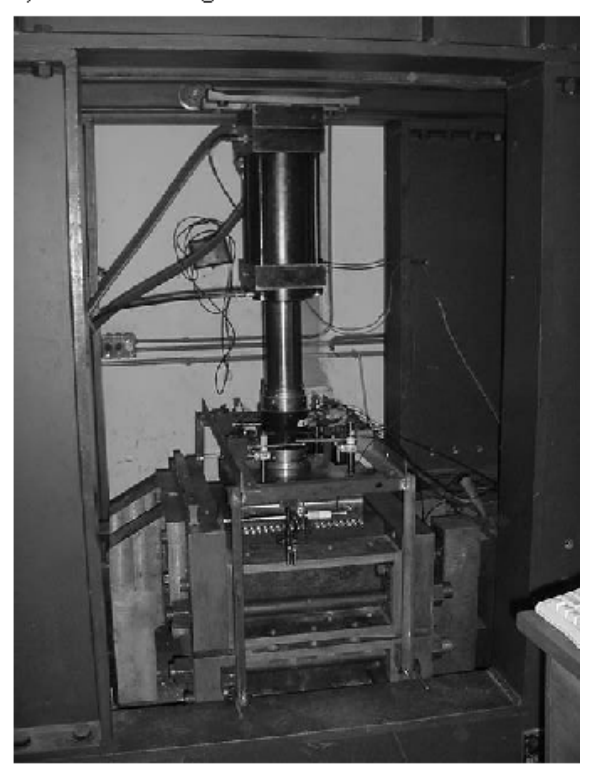

f) Vista lateral do ensaio

Figura 3.4 - a) Transdutor de deslocamento vertical com cursor de $\pm 35 \mathrm{~mm}$; b) transdutor de deslocamento horizontal com cursor de $\pm 10 \mathrm{~mm}$; c) atuador de carga vertical com capacidade de $500 \mathrm{kN}$; d) atuador de carga horizontal com capacidade de $500 \mathrm{kN}$; e) vista frontal do ensaio; f) vista lateral do ensaio.

\subsection{Materiais utilizados}

Neste estudo, procurou-se levantar a influência de cada parâmetro do sistema que provocasse uma modificação significativa no resultado e na sua interpretação 
(Potyondy, 1961; Duncan e Clough, 1971; Uesugi e Kishida, 1986a e 1986b; Uesugi e Kishida, 1987; Shallenberger e Filz, 1996; Gómez, 2000).

Fez-se necessária a simulação de cada parâmetro através de pelo menos duas condições diferentes. Dessa forma, o sistema estrutura-solo foi representado por um sistema bloco de concreto-areia.

A característica do concreto utilizado na confecção dos blocos está mostrada na Tabela 3.1. Para verificação de suas propriedades mecânicas foram retirados três corpos de prova cilíndricos, de $20 \mathrm{~cm}$ de altura e $10 \mathrm{~cm}$ de diâmetro para cada bloco. Estes foram rompidos à compressão simples, quando do término do ensaio de cisalhamento direto no respectivo bloco de ensaio. As propriedades mecânicas obtidas constam na Tabela 3.2.

Tabela 3.1 - Características do concreto fresco

\begin{tabular}{cc}
\hline Composição & Cimento Ari RS, Areia e Pedrisco \\
\hline Traço & $1: 1,5: 2,5$ \\
Fator a/c & 0,48 \\
Consumo de & $480 \mathrm{~kg} / \mathrm{m}^{3}$ \\
cimento & $4 \mathrm{~cm}$ \\
Abatimento & \\
\hline
\end{tabular}

Tabela 3.2 - Propriedades do concreto endurecido

\begin{tabular}{cccc}
\hline Propriedades & Médio & $\begin{array}{c}\text { Desvio } \\
\text { Padrão }\end{array}$ & \multirow{2}{*}{$\mathrm{F}_{\mathrm{ck}}$} \\
\hline Resistência $(\mathrm{MPa})$ & 44,7 & 4,1 & 37,9 \\
Módulo de elasticidade $(\mathrm{MPa})$ & 32425,3 & 1012 & \\
\hline
\end{tabular}

Foram utilizados dois tipos características de superfície de contato denominadas lisa e rugosa. A superfície lisa foi obtida utilizando-se como negativo uma chapa de aço lisa com rugosidade média de 0,010 $\mathrm{mm}$. A superfície rugosa foi obtida a partir de negativo representativo de uma estrutura moldada no local. Suas principais características constam da Tabela 3.3.

Tabela 3.3 - Propriedades da Superfície

\begin{tabular}{ccc}
\hline Superfície & $\begin{array}{c}\text { Rugosidade máxima } \\
(\mathrm{mm})\end{array}$ & \begin{tabular}{c} 
Largura média $(\mathrm{mm})$ \\
\hline Lisa SL
\end{tabular} \\
Rugosa RU & 21,028 & 0,08 \\
\hline
\end{tabular}

A forma e as propriedades das superfícies foram medidas através de rugosímetro eletrônico, disponível no Laboratório de Metrologia do Departamento de Engenharia da Escola de Engenharia de São Carlos (Figura 3.5a), em 1476 pontos, arranjados em uma malha retangular com espaçamento entre linhas de $10 \mathrm{~mm}$. Após o levantamento, foi traçado o modelo digital equivalente da superfície (Figura 3.5b). 


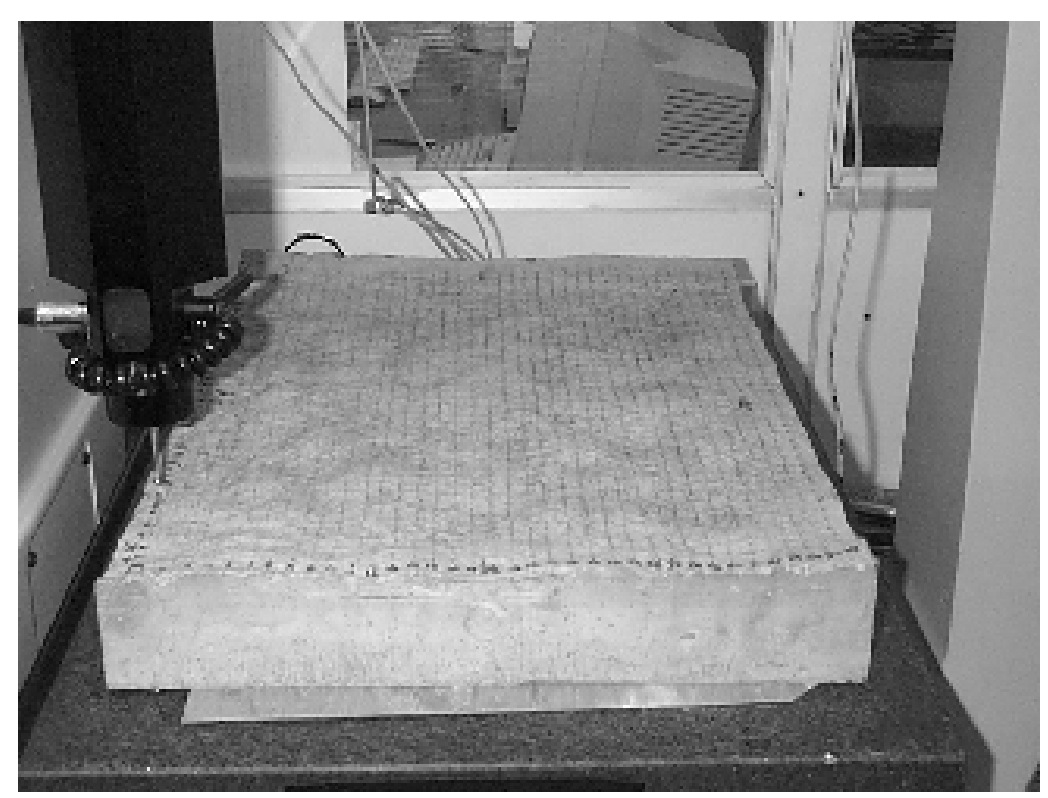

a) Negativo da superfície do bloco rugoso

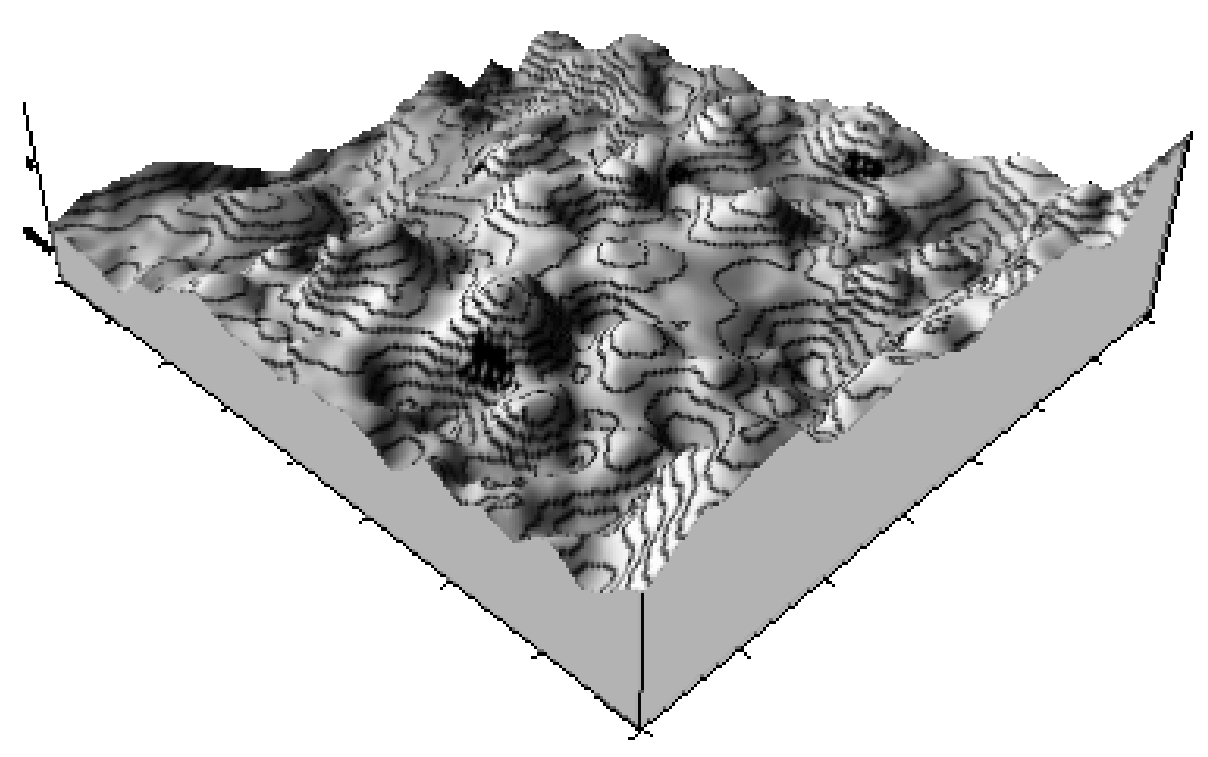

b) Modelo digital da superficie do bloco rugoso

Figura 3.5 a) Negativo da superfície rugosa utilizada no bloco de concreto utilizado; b) modelo digital da superfície rugosa utilizada no bloco de concreto utilizado 
Para modelagem do maciço de solos foram utilizados dois tipos de areia com granulometrias diferentes indicadas na Figura 3.6.

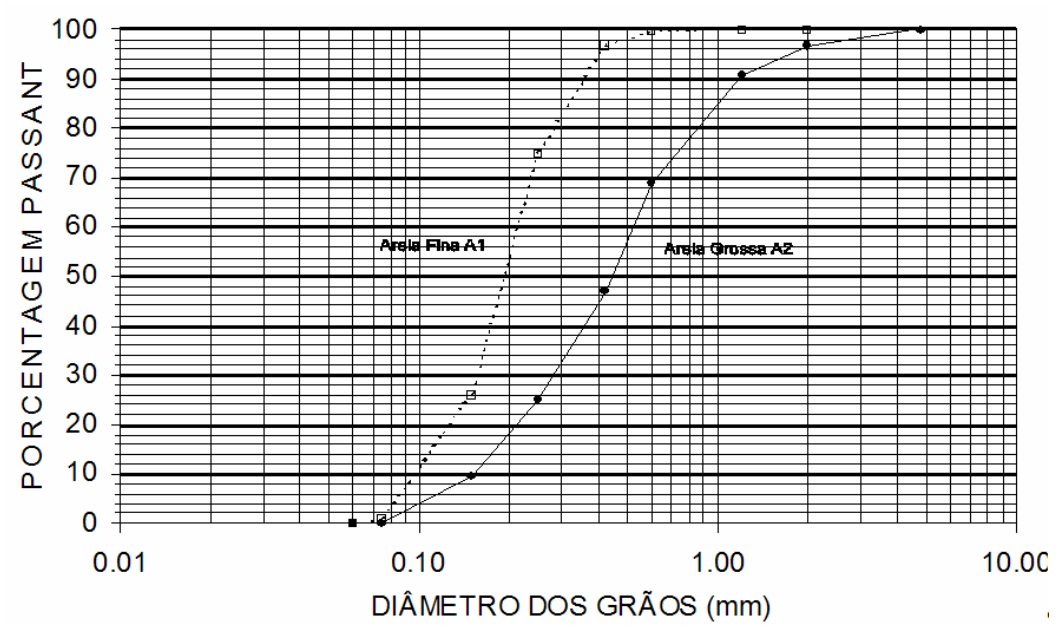

Figura 3.6 - Curva granulométrica

A areia fina, denominada de "A1", é proveniente de uma região localizada na Rodovia SP-215 (km154), próxima à cidade de São Carlos. É classificada como areia fina e possui grãos arredondados (Figura 3.7). Esta areia foi utilizada anteriormente por Costa (2005) em testes de comportamento geotécnico de condutos flexíveis enterrados.

A areia grossa, denominada de “A2", é proveniente da região de Mogi-Mirim e se classifica como uma areia média a grossa e possui grãos angulosos (Figura 3.8).

A densidade do material para cada ensaio foi obtida através da técnica de chuva de areia (Costa, 2005). Suas principais características podem ser vistas através da Tabela 3.4.

Tabela 3.4 - Índices Físicos

\begin{tabular}{ccccccc}
\hline Material & $\mathrm{D}_{10}(\mathrm{~mm})$ & $\mathrm{D}_{30}(\mathrm{~mm})$ & $\mathrm{D}_{60}(\mathrm{~mm})$ & $\begin{array}{c}\gamma \mathrm{max} \\
\left(\mathrm{kN} / \mathrm{m}^{3}\right)\end{array}$ & $\begin{array}{c}\gamma_{\min } \\
\left(\mathrm{kN} / \mathrm{m}^{3}\right)\end{array}$ & $\begin{array}{c}\gamma_{\mathrm{s}} \\
\left(\mathrm{kN} / \mathrm{m}^{3}\right)\end{array}$ \\
\hline Areia A1 & 0,10 & 0,15 & 0,20 & 17,93 & 15,04 & 26,50 \\
Areia A2 & 0,15 & 0,28 & 0,51 & 17,60 & 14,65 & 26,65 \\
\hline
\end{tabular}

A Figura 3.7 mostra que areia fina A1 possui grãos arredondados. Na Figura 3.8 percebe-se que os grãos da areia grossa A2 são ângulosos.

Os testes foram realizados com dois valores de compacidade para cada tipo de areia. As propriedades mecânicas foram determinadas a partir de ensaios de cisalhamento direto em amostras representativas dos dois materiais. Isto foi feito para que se pudesse analisar a variação de volume em função da densidade relativa inicial (índice de vazios inicial). Os resultados desses testes (curvas tensão tangencial 
deslocamento, curvas de variação de volume-deslocamento) são mostrados na Figura 3.9 .
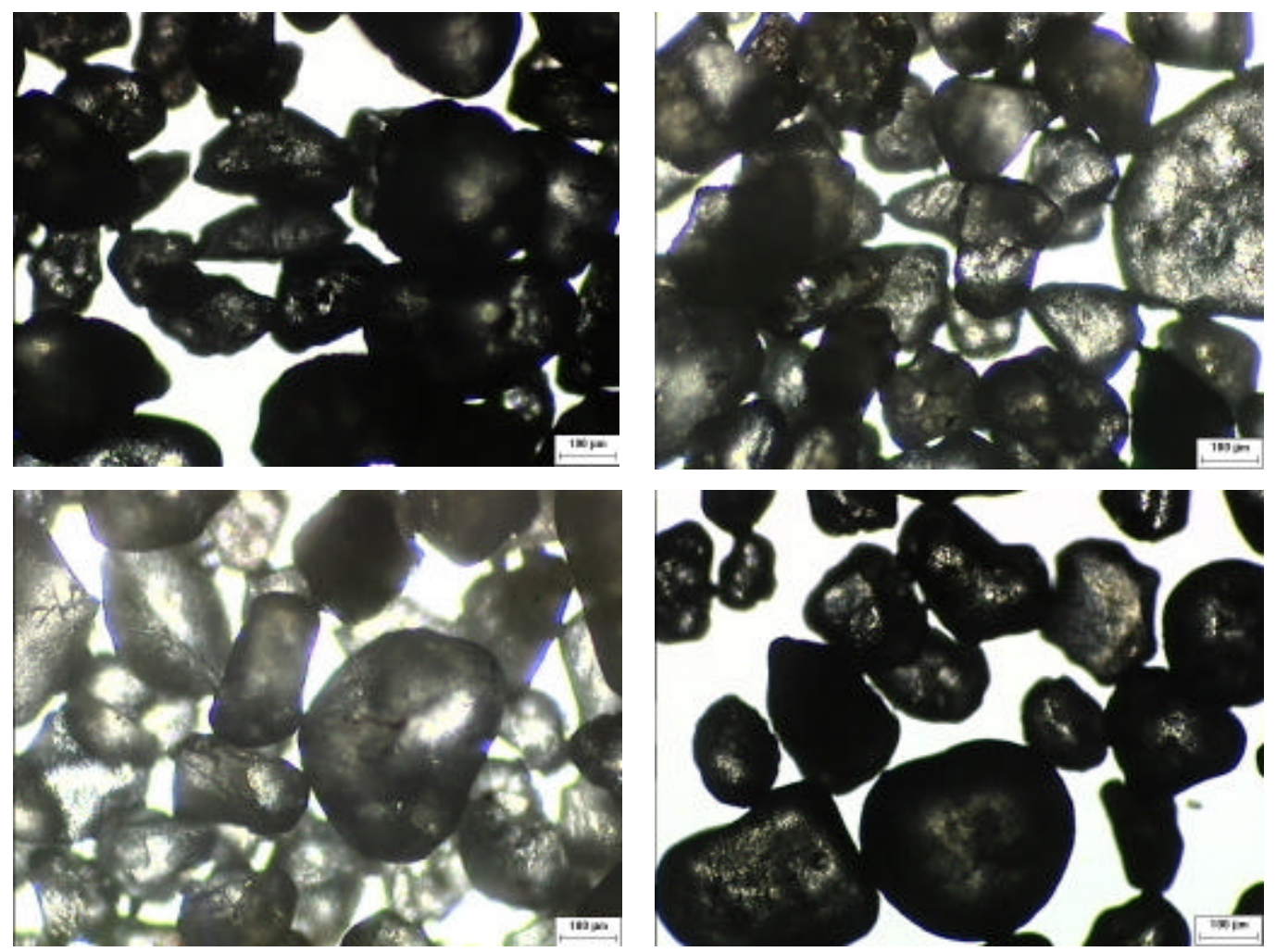

Figura 3.7 - Imagens microscópicas da areia A1
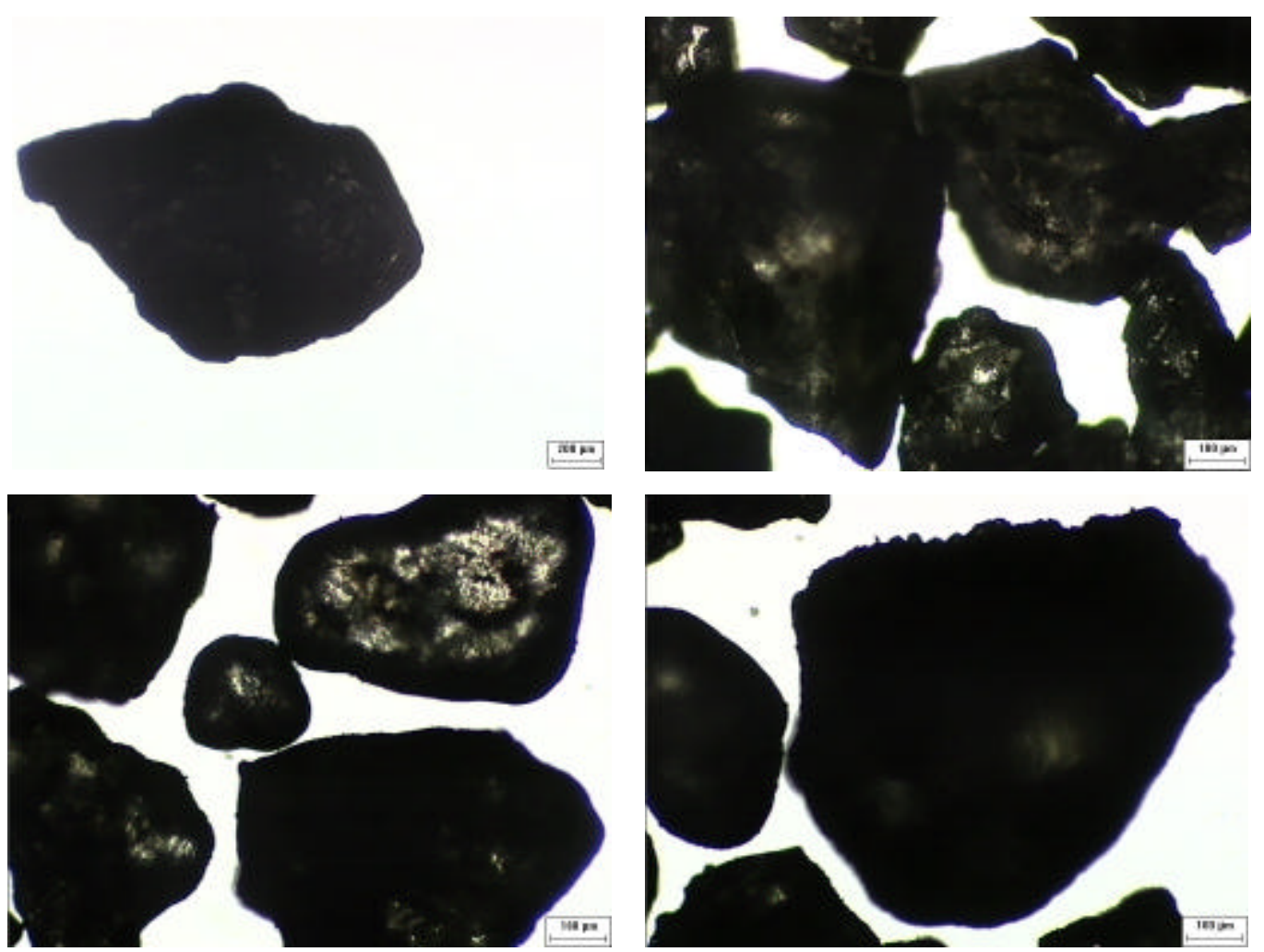

Figura 3.8 - Imagens microscópicas da areia A2 

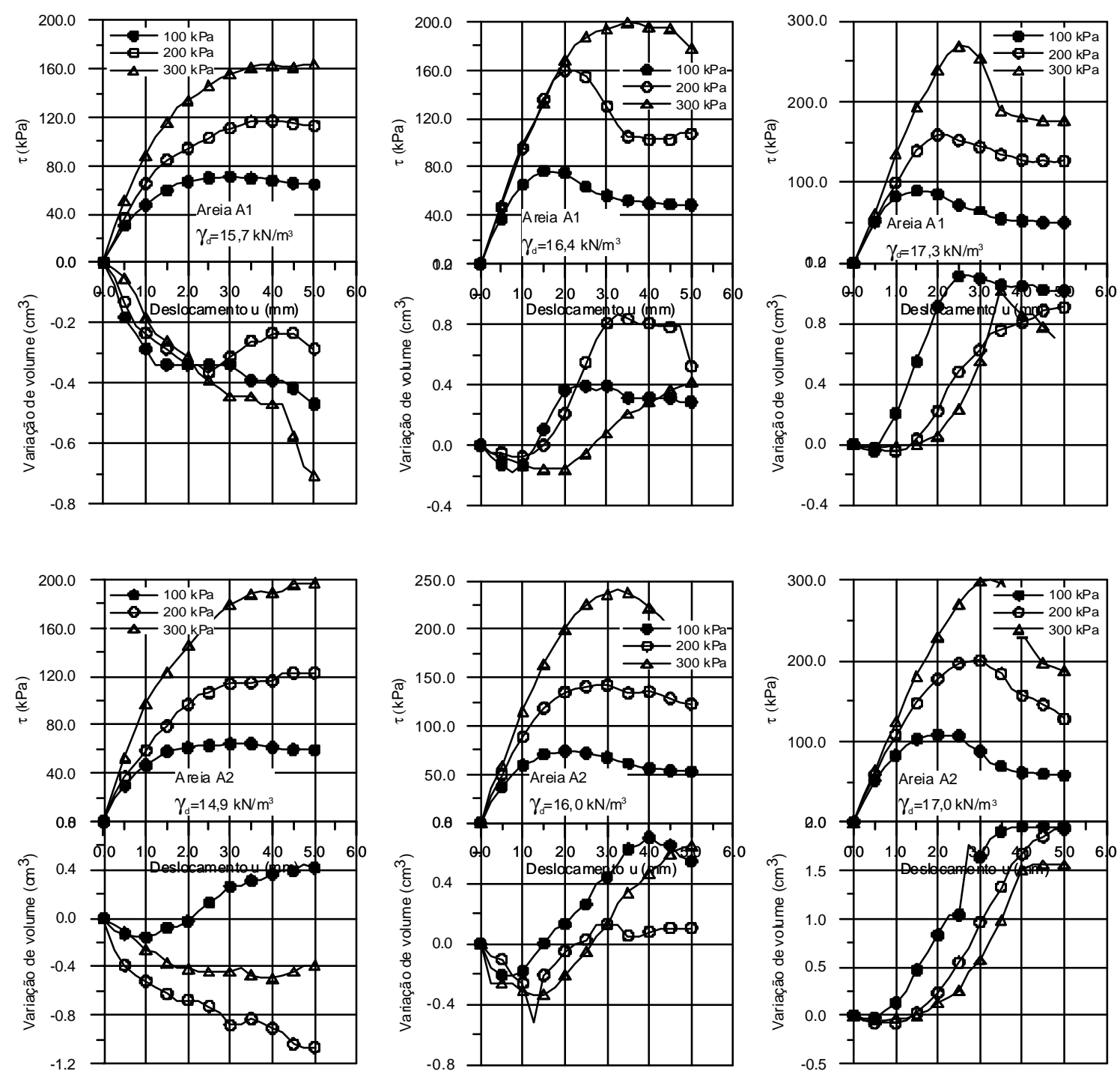

Figura 3.9 - Resultados de ensaios de cisalhamento direto em amostras de areia.

A partir dos resultados mostrados na Figura 3.9 foram traçadas curvas de índice de vazios iniciais e variação de volume do tipo de Casagrande que permitiu definir o índice de vazios crítico de cada caso. As curvas de Casagrande para a Areia A1 e Areia A2 são mostradas na Figura 3.10 e os valores correspondentes mostrados na Tabela 3.5, respectivamente. $\mathrm{O}$ índice de vazios crítico corresponde ao ponto onde a variação de volume é igual a zero.

Na Tabela 3.6 são mostrados os valores de índice de vazios (índice de vazios crítico) correspondentes a variação de volume nula para cada nível de tensão normal aplicada. Plotando-se os valores de índice de vazios crítico (corresponde a variação de volume nula) em função do logarítmo tensão normal aplicada define-se os pontos pertencentes à linha de estado crítico e indicados na Figura 3.11 para as areias A1 e A2, respectivamente. 
Tabela 3.5 - Valores de peso específico seco, índice de vazios inicial e variação de volume na ruptura para as areias A1 e A2.

\begin{tabular}{cccccccccc}
\hline $\begin{array}{c}\text { Tipo } \\
\text { de }\end{array}$ & \multicolumn{2}{c}{ Tensão normal 100 kPa } & \multicolumn{3}{c}{ Tensão normal 200 kPa } & \multicolumn{2}{c}{ Tensão normal 300 kPa } \\
\cline { 2 - 10 } Areia & $\begin{array}{c}\gamma_{\mathrm{d}} \\
\left(\mathrm{kN} / \mathrm{m}^{3}\right)\end{array}$ & $\mathrm{e}_{\mathrm{o}}$ & $\Delta \mathrm{V}(\mathrm{mm})$ & $\begin{array}{c}\gamma_{\mathrm{d}} \\
\left(\mathrm{kN} / \mathrm{m}^{3}\right)\end{array}$ & $\mathrm{e}_{\mathrm{o}}$ & $\Delta \mathrm{V}(\mathrm{mm})$ & $\begin{array}{c}\gamma_{\mathrm{d}} \\
\left(\mathrm{kN} / \mathrm{m}^{3}\right)\end{array}$ & $\mathrm{e}_{\mathrm{o}}$ & $\Delta \mathrm{V}(\mathrm{mm})$ \\
\hline \multirow{3}{*}{$\mathrm{A} 1$} & 15,9 & 0.74 & -0.25 & 15,9 & 0.74 & -0.4 & 1,59 & 0.74 & -0.4 \\
& 16,7 & 0.66 & 0.4 & 16,7 & 0.65 & 0.15 & 16,7 & 0.65 & -0.2 \\
& 17,5 & 0.58 & 0.6 & 17,5 & 0.58 & 0.25 & 17,5 & 0.57 & 0.05 \\
\hline \multirow{2}{*}{$\mathrm{A} 2$} & 14,8 & 0.79 & -0.10 & 14,8 & 0.79 & -0.50 & 14,9 & 0.78 & -0.90 \\
& 15,8 & 0.68 & 0.15 & 15,9 & 0.67 & 0.05 & 16,0 & 0.66 & -0.10 \\
\hline
\end{tabular}
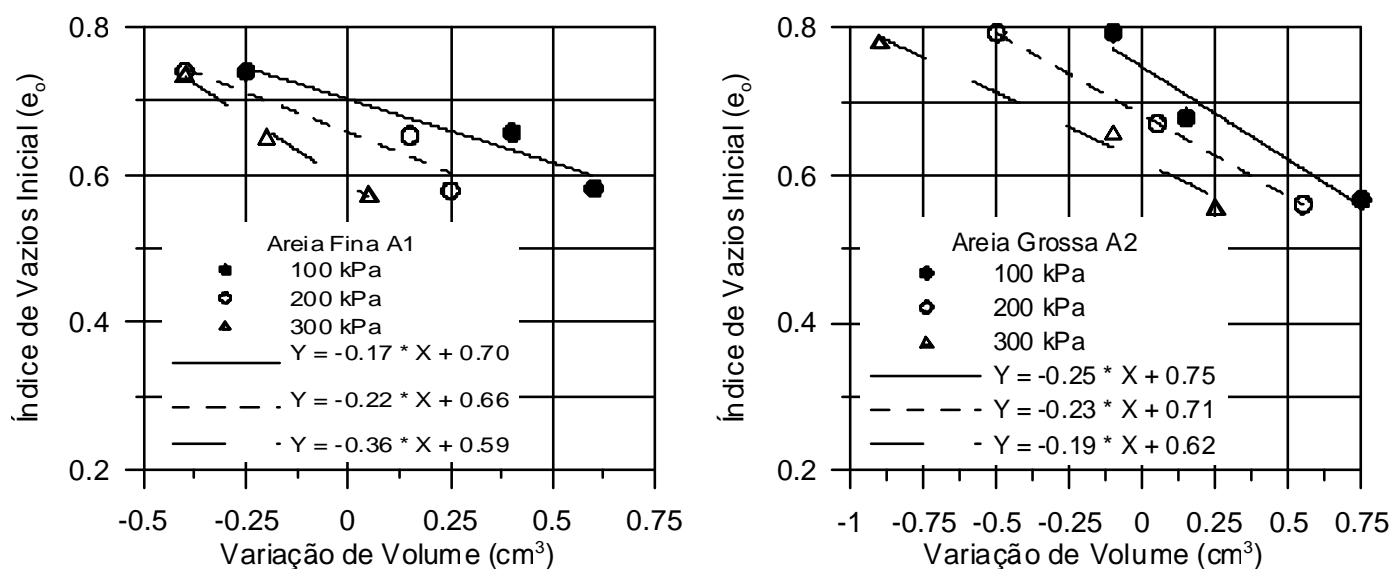

Figura 3.10 - Curva de índice de vazios inicial versus variação de volume na ruptura.

Tabela 3.6 - Valores de índice de vazios crítico das areias A1 e A2 para cada nível tensão normal.

\begin{tabular}{ccc}
\hline$\sigma_{\text {normal }}(\mathrm{kPa})$ & Areia A1 & Areia A2 \\
\cline { 2 - 3 } & $\mathrm{e}_{\text {crítico }}$ & $\mathrm{e}_{\text {crítico }}$ \\
\hline 100 & 0.70 & 0.75 \\
200 & 0.66 & 0.71 \\
300 & 0.59 & 0.62 \\
\hline
\end{tabular}

A resistência ao cisalhamento das areias A1 e A2 é mostrada também através da envoltória de Mohr-Coulomb nas Figuras 3.12 e 3.13, respectivamente.

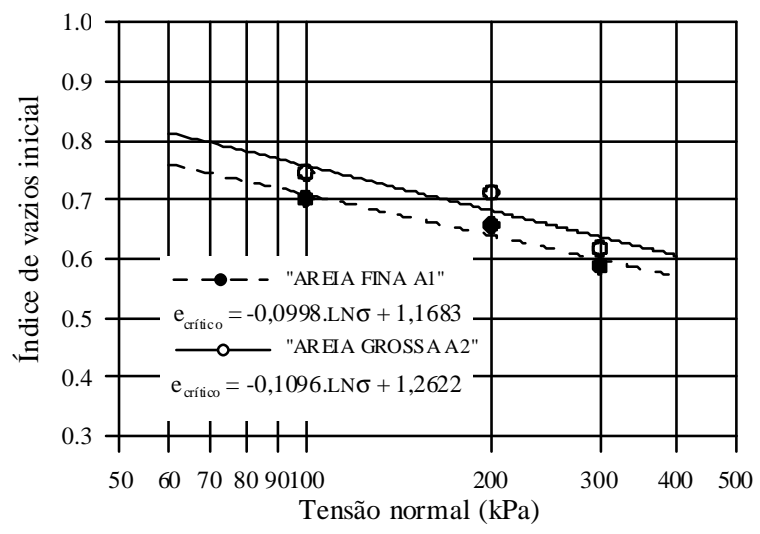

Figura 3.11 - Linha de estado crítico pelo método de Casagrande. 
Uma outra maneira de representar a variação da resistência ao cisalhamento em função do índice de vazios inicial é através do gráfico de ângulo de atrito por índice de vazios inicial. A grande vantagem deste tipo de apresentação consiste na possibilidade da determinação do ângulo de dilatância para cada índice de vazios inicial através da Equação (2.35). A Tabela 3.7 mostra os valores dos ângulos de atrito das areias A1 e A2 obtidos apartir das relações $\frac{\tau_{\text {pico }}}{\sigma}$ e $\frac{\tau_{\text {residual }}}{\sigma}$ e seus correpondentes índice de vazios inicial. As Figuras 3.14a e 3.14b mostram todos ângulos obtidos a partir da relação $\frac{\tau_{\text {pico }}}{\sigma}$ e $\frac{\tau_{\text {residual }}}{\sigma}$ plotados em função do índice de vazios inicial para as areias A1 e A2, respectivamente.

Cabe ressaltar, ainda, que o grafico da Figura 3.14 é comumente usado para determinação do índice de vazios críticos, de modo que deve ser traçado com valores submetidos à mesma tensão confinante. No entanto, como neste trabalho optourse por obter esses valores pelo diagrama de Casagrande, na Figura 3.14 estão lançados todos os valores obtidos, independentemente da tensão normal atuante.

Tabela 3.7 - Valores dos ângulos de atrito das areias A1 e A2 obtidos apartir das relações $\frac{\tau_{\text {pico }}}{\sigma}$ e $\frac{\tau_{\text {residual }}}{\sigma}$ e seus correpondentes índice de vazios inicial, para cada nível de tensão normal

\begin{tabular}{|c|c|c|c|c|c|c|c|c|}
\hline Areia & $e_{o}$ & $\sigma_{\text {normal }}(k P a)$ & $\tau_{\text {pico }}(k P a)$ & $\tau_{\text {residual }}(\mathrm{kPa})$ & $\tau_{\text {pico }} / \sigma$ & $\tau_{\text {residual }} \sigma$ & $\phi_{\text {pico }}\left({ }^{0}\right)$ & $\phi_{\text {residual }}\left({ }^{0}\right)$ \\
\hline \multirow{9}{*}{ 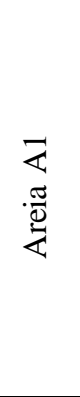 } & 0,74 & 100 & 70,9 & 64,4 & 0,7 & 0,6 & 35,3 & 32,8 \\
\hline & 0,74 & 200 & 117,1 & 113,1 & 0,6 & 0,6 & 30,4 & 29,5 \\
\hline & 0,74 & 300 & 164,2 & 164,2 & 0,5 & 0,5 & 28,7 & 28,7 \\
\hline & 0,66 & 100 & 76,6 & 48,6 & 0,8 & 0,5 & 37,4 & 25,9 \\
\hline & 0,65 & 200 & 160,1 & 107,4 & 0,8 & 0,5 & 38,7 & 28,2 \\
\hline & 0,65 & 300 & 199,9 & 178.0 & 0,7 & 0,6 & 33,7 & 30,7 \\
\hline & 0,58 & 100 & 89,5 & 49,8 & 0,9 & 0,5 & 41,8 & 26,5 \\
\hline & 0,58 & 200 & 158,5 & 126,2 & 0,8 & 0,6 & 38,4 & 32,3 \\
\hline & 0,57 & 300 & 268,8 & 176,3 & 0,9 & 0,6 & 41,9 & 30,4 \\
\hline \multirow{9}{*}{$\begin{array}{l}\frac{1}{2} \\
\frac{\pi}{2} \\
\frac{2}{2}\end{array}$} & 0,79 & 100 & 64,4 & 59.0 & 0,6 & 0,6 & 32,8 & 30,6 \\
\hline & 0,79 & 200 & 123,3 & 122,8 & 0,6 & 0,6 & 31,6 & 31,5 \\
\hline & 0,78 & 300 & 197,4 & 197,4 & 0,7 & 0,7 & 33,3 & 33,3 \\
\hline & 0,68 & 100 & 74,1 & 53.0 & 0,7 & 0,5 & 36,5 & 27,9 \\
\hline & 0,67 & 200 & 143,1 & 122,8 & 0,7 & 0,6 & 35,6 & 31,5 \\
\hline & 0,66 & 300 & 241,6 & 181,2 & 0,8 & 0,6 & 38,8 & 31,1 \\
\hline & 0,57 & 100 & 108,2 & 57,9 & 1,1 & 0,6 & 47,3 & 30,1 \\
\hline & 0,56 & 200 & 200,2 & 127,7 & 1.0 & 0,6 & 45.0 & 32,5 \\
\hline & 0,56 & 300 & 301,3 & 187,7 & 1.0 & 0,6 & 45,1 & 32,0 \\
\hline
\end{tabular}


Peso específico 15,7 kN/m³

Envoltória de pico

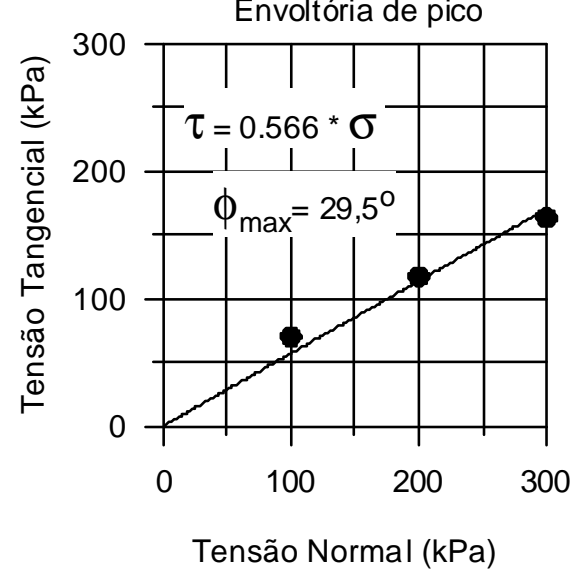

Tensão Normal (kPa)
Peso específico $16,5 \mathrm{kN} / \mathrm{m}^{3}$ Envoltória de pico
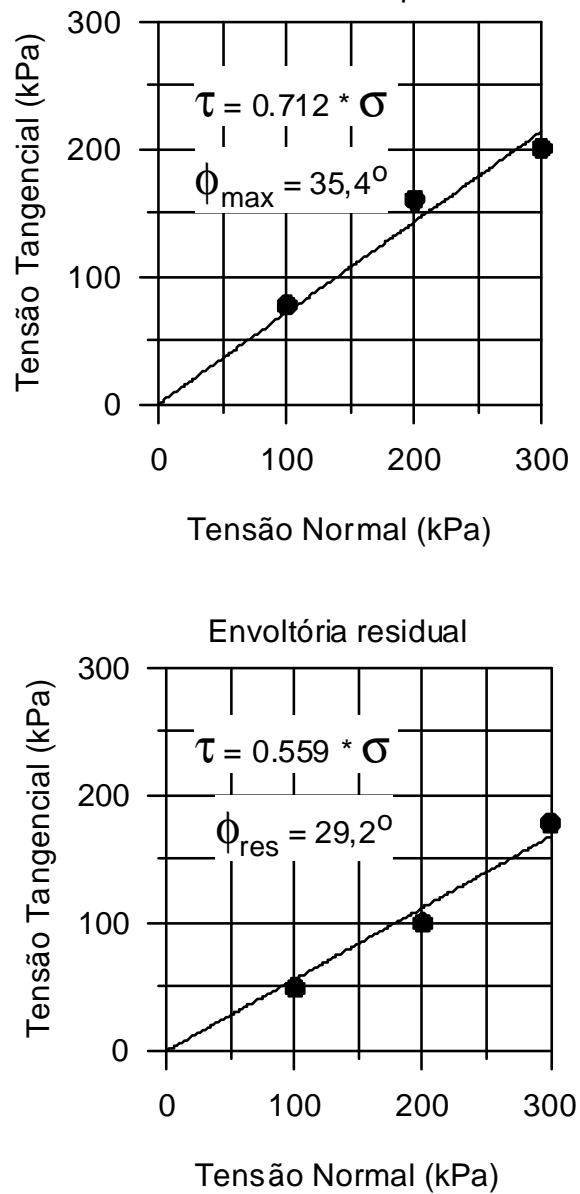

Peso específico $17,3 \mathrm{kN} / \mathrm{m}^{3}$ Envoltória de pico
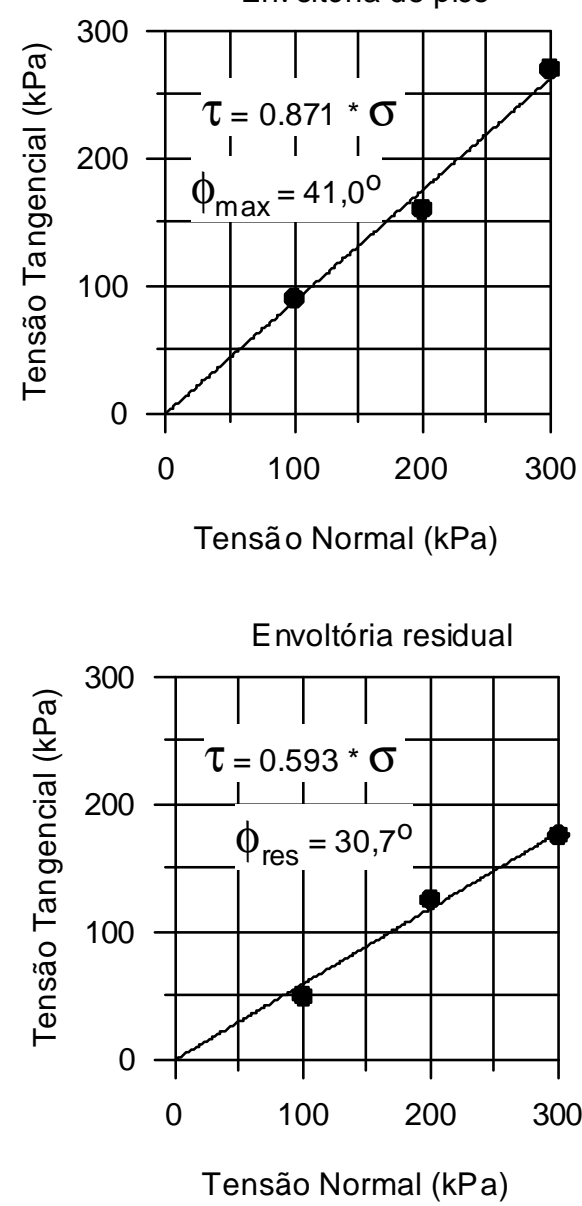

Figura 3.12 - Envoltórias de resistência de Mohr-Coulomb para areia A1 
Peso específico 14,9 kN/m³

Envoltória de pico

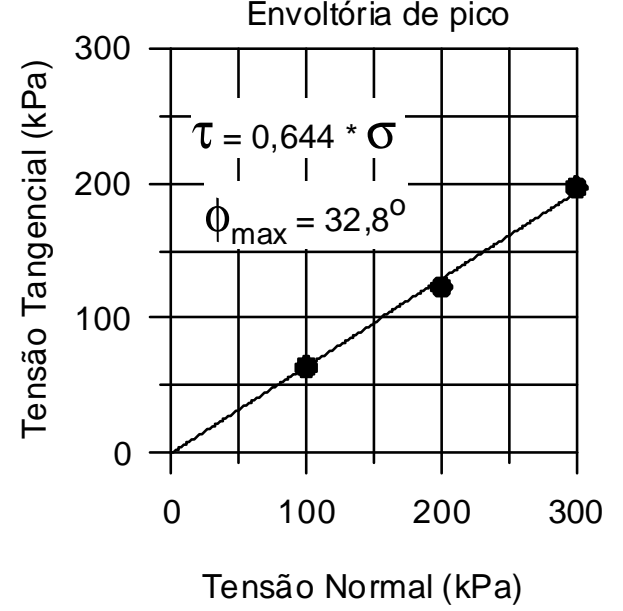

Tensão Normal (kPa)

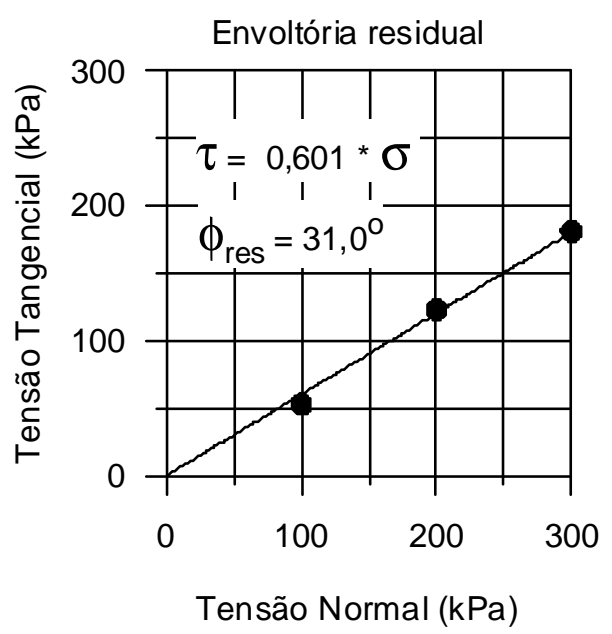

Peso específico $16,0 \mathrm{kN} / \mathrm{m}^{3}$

Envoltória de pico

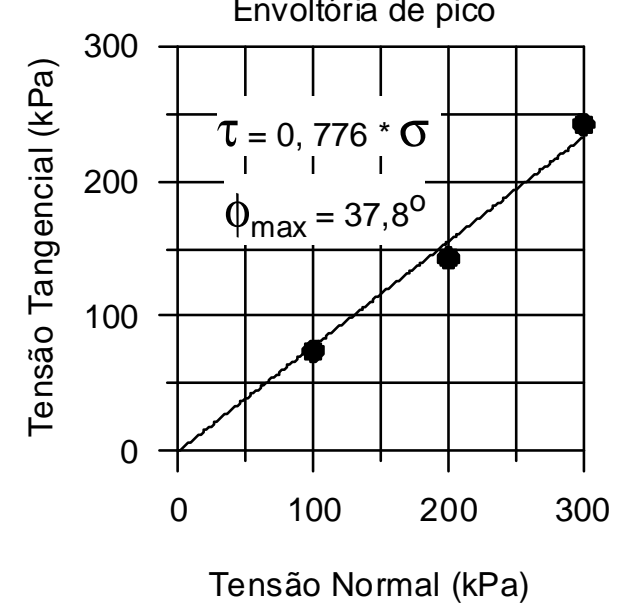

Figura 3.13 - Envoltórias de resistência de Mohr-Coulomb para areia A2

Peso específico $17,2 \mathrm{kN} / \mathrm{m}^{3}$

Envoltória de pico
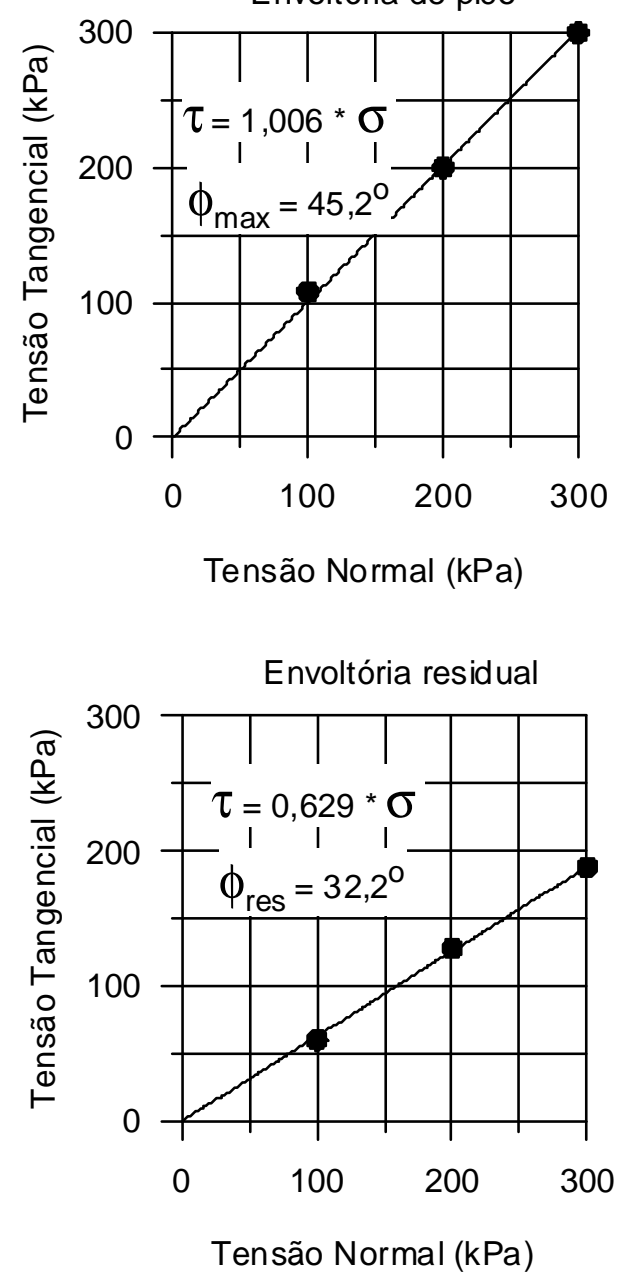


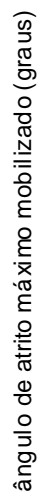

a)

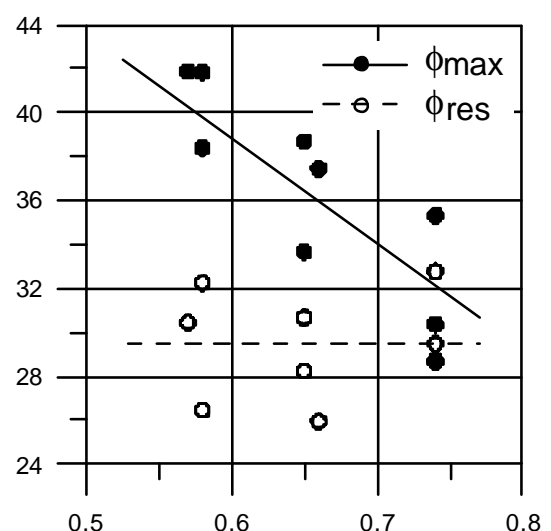

índice de vazios inicial $\left(e_{0}\right)$

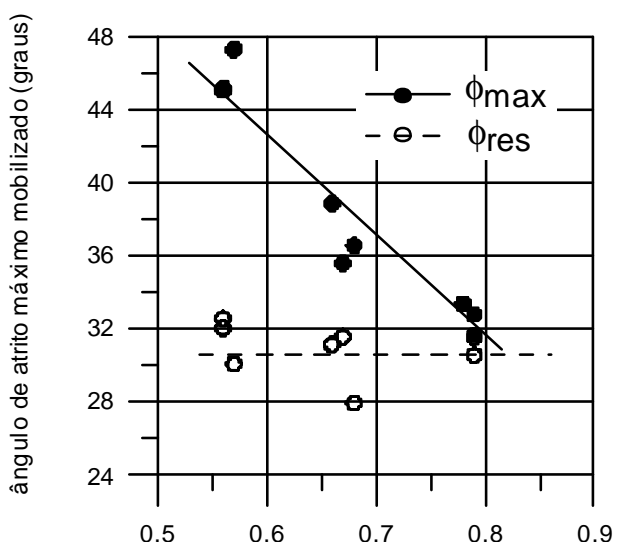

b)

índice de vazios inicial $\left(e_{0}\right)$

Figura 3.14 - Valores do ângulo de atrito máximo mobilizado (de pico e residual) obtidos em ensaios de cisalhamento direto: a) areia A1; b) areia A2

A deformabilidade das areias A1 e A2 foram avaliadas a partir de ensaios de compressão oedométrica. Dessa maneira, foi possível avaliar a relação entre o Módulo de deformabilidade oedométrico e a tensão normal aplicada (Figuras 3.15 e 3.16).

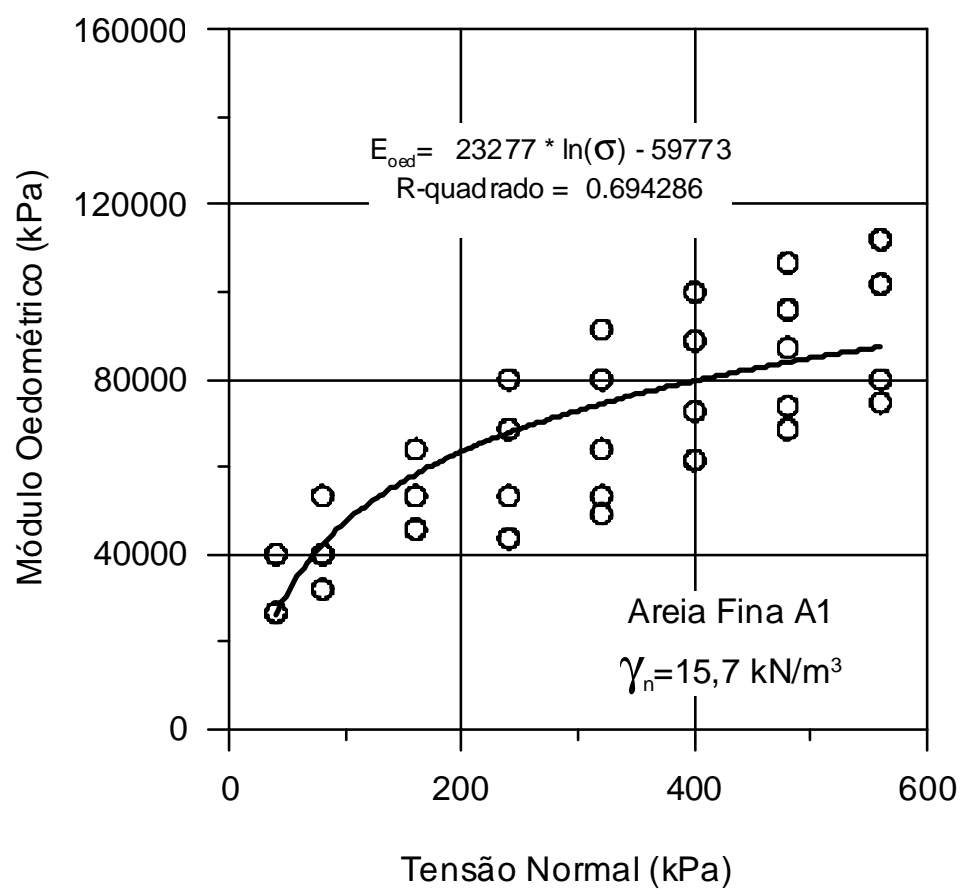

Figura 3.15 - Variação do módulo eodométrico secante da areia A1 em função da tensão normal aplicada. 


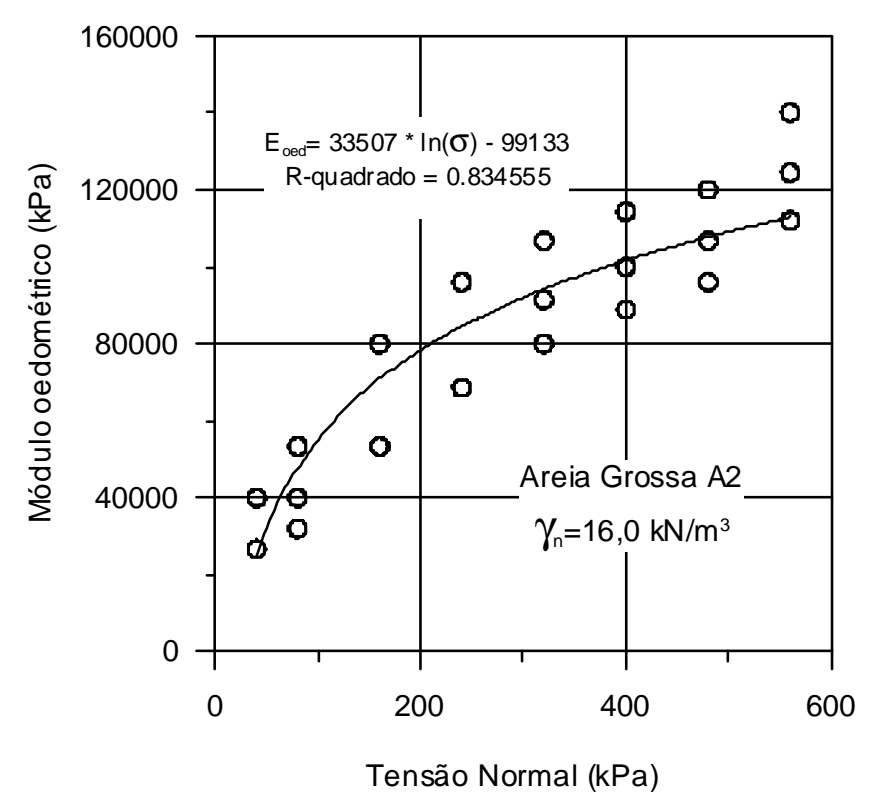

Figura 3.16 - Variação do módulo oedométrico secante da areia A1 em função da tensão normal aplicada.

3.4. Procedimento de ensaio dos ensaios em interface

Os ensaios em interface realizados foram do tipo carga normal constante de acordo com o ítem 2.2.3c, para os quais são válidas as Equações (2.80) e (2.83).

O deslocamento horizontal $u$ foi imposto com velocidade de $0,25 \mathrm{~mm} / \mathrm{min}$. Para minimizar erros induzidos por desconfinamento durante a instalação foi aplicada uma pré-carga de assentamento correspondente à uma força tangencial de $1 / 3$ da carga prevista para ruptura com força normal aplicada $N$ igual a $200 \mathrm{kN}$, seguida de descarregamento até zero.

A partir do ajuste inicial, as cargas normais $N$ foram aplicadas no início de cada ensaio e mantidas constantes durante toda a fase de imposição do deslocamento $u$. As cargas tangenciais $F$ foram medidas de modo contínuo até o limite de $15 \mathrm{~mm}$ de deslocamento, após o qual foi realizado o descarregamento.

Com a finalidade de minimizar os efeitos tridimensionais do ensaio (rotação do bloco de concreto no plano horizontal), de modo que os resultados representassem apenas os deslocamentos $u$ e $v$, fixou-se o atuador horizontal na caixa de cisalhamento de modo a impedir sua rotação. 
3.5. Resultados experimentais dos ensaios de cisalhamento direto com carga normal constante em interface concreto-areia

Os resultados são mostrados separadamente para cada ensaio através de curva tensão tangencial-deslocamento horizontal e variação de volume - deslocamento horizontal, nas Figuras 3.17 a 3.25.

A tensão tangencial foi obtida dividindo a força tangencial medida para cada deslocamento $u$ pela área da seção transversal do contato $A$.

Os deslocamentos tangenciais são considerados como a média dos valores medidos pelos dois transdutores de deslocamento horizontais. Os deslocamentos normais foram considerados como a média de quatro transdutores de deslocamento vertical.

Os resultados demonstram que o pico de resistência obtido nos ensaios realizados ocorreu para pequenos deslocamentos, da ordem de $3 \mathrm{~mm}$, para ensaios realizados em contatos realizados com areia compacta e superfície rugosa, e $1 \mathrm{~mm}$, para os realizados em contatos com areia compacta e superfície lisa.

Para os casos com menor compacidade relativa do solo, percebe-se que a resistência total foi mobilizada antes que os deslocamentos atingissem 10,0 mm.

A partir da curva de descarregamento, percebe-se, também, que os deslocamentos desenvolvidos durante o cisalhamento são todos irreversíveis ou permanentes.

As curvas tensão cisalhante-deslocamento horizontal demonstram que nos ensaios realizados com areia compacta aconteceu pico de resistência com correspondente aumento de volume, caracterizando a ocorrência de dilatância. Nota-se ainda que, para muitos casos, após o pico de resistência, ocorre a estabilização das resistências em um patamar menor, chamado de tensão residual, caracterizando a resistência devida ao atrito verdadeiro entre partículas na interface.

Para os casos com menor compacidade relativa do solo, percebe-se que a resistência total foi mobilizada antes que os deslocamentos atingissem 10,0 mm. Percebe-se que a resistência final obtida nesses ensaios foi maior que a resistência devida ao atrito verdadeiro do solo, sugerindo assim que existe uma terceira parcela contribuindo para mobilização das resistências no contato. Essa terceira parcela é o rearranjo das partículas.

Como era de se esperar, os contatos com superfícies rugosas e areia grossa compactas mobilizaram maior resistência, seguidos pelos contatos de areia fina compacta com superfície rugosa. Os resultados de resistência dos contatos entre areia fina compacta e areia grossa compacta com superfície lisa são equivalentes. 

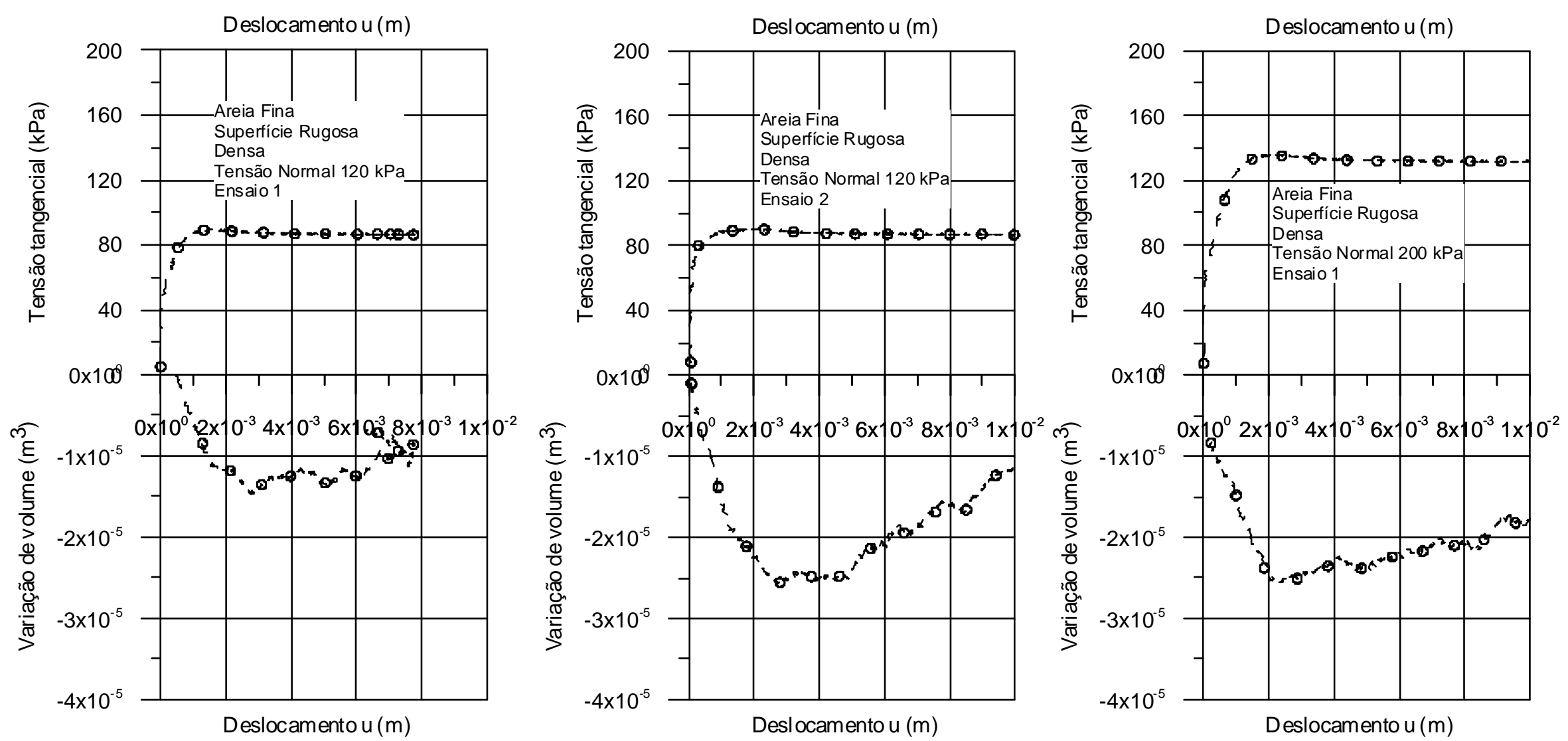

Figura 3.17 - Curvas tensão tangencial versus deslocamento tangencial e variação de volume versus deslocamento tangencial para a areia A1 compacta em contato com superfície rugosa de concreto. 

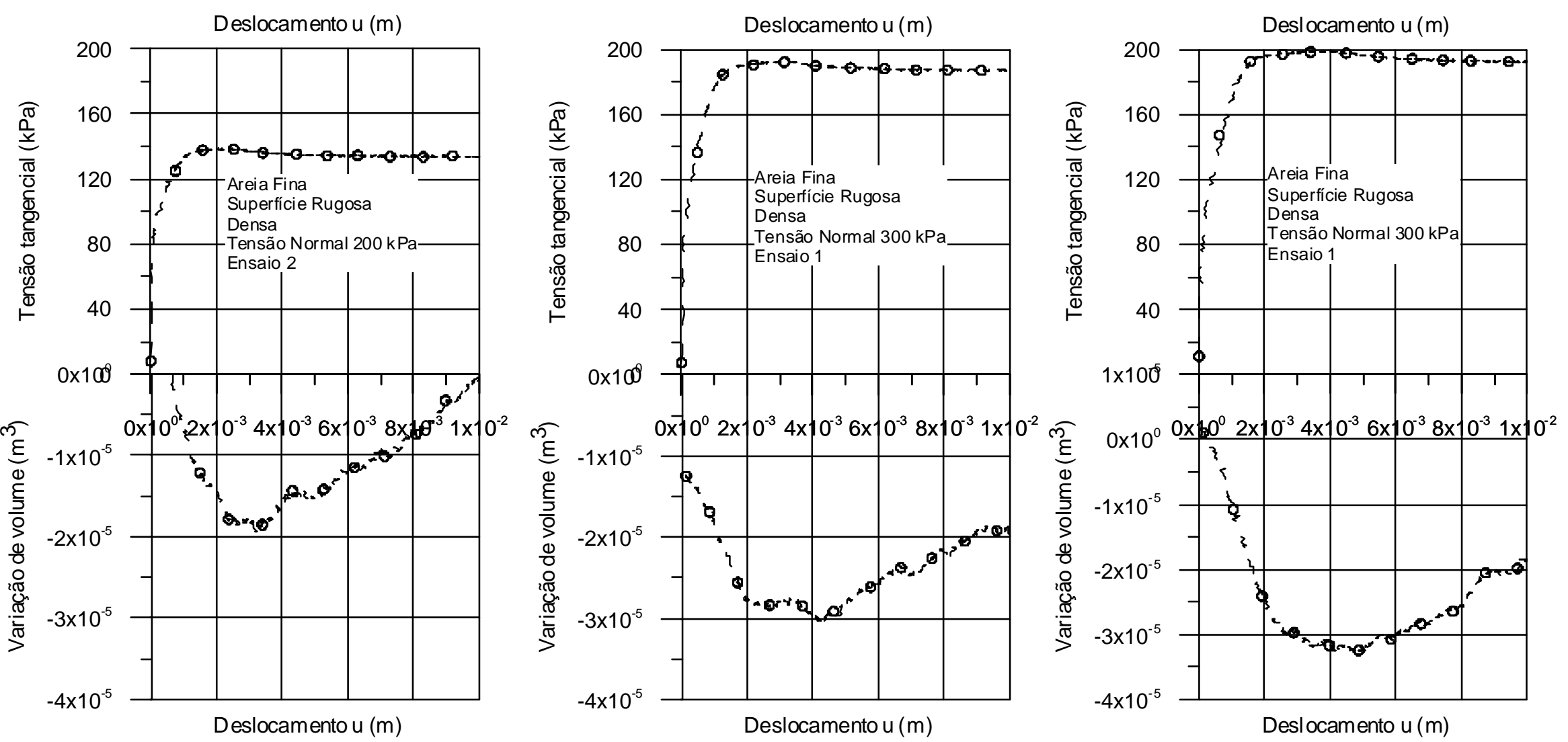

Figura 3.18 - Curvas tensão tangencial versus deslocamento tangencial e variação de volume versus deslocamento tangencial para a areia A1 compacta em contato com superfície rugosa de concreto. 

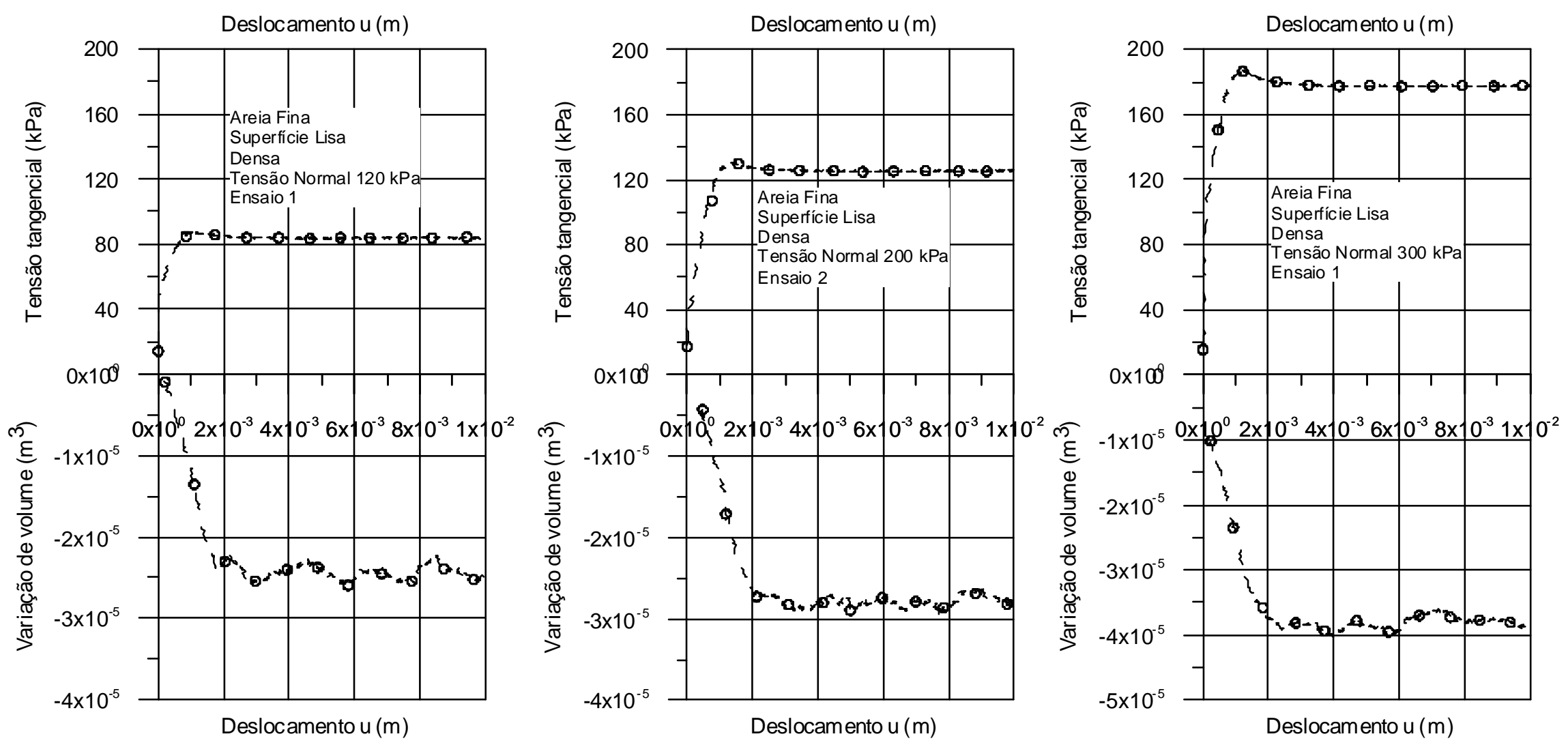

Figura 3.19 - Curvas tensão tangencial versus deslocamento tangencial e variação de volume versus deslocamento tangencial para a areia A1 compacta em contato com superfície lisa de concreto. 

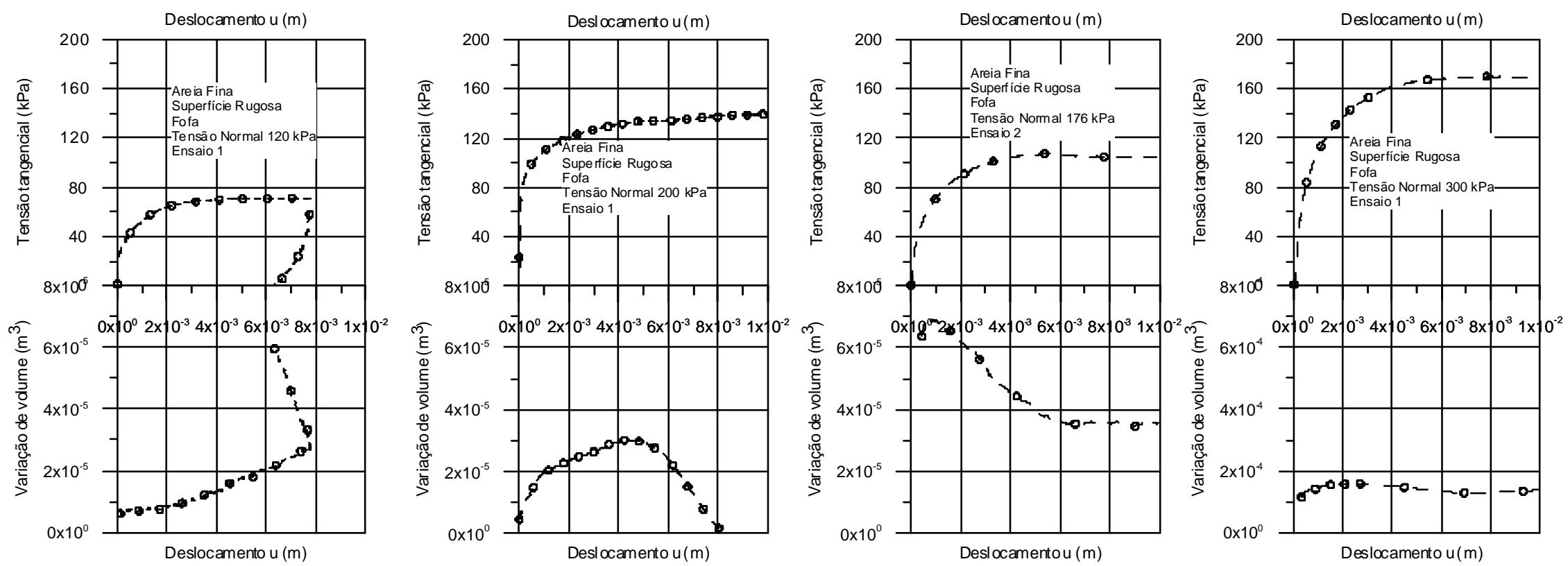

Figura 3.20 - Curvas tensão tangencial versus deslocamento tangencial e variação de volume versus deslocamento tangencial para a areia A1 fofa em contato com superfície rugosa de concreto. 

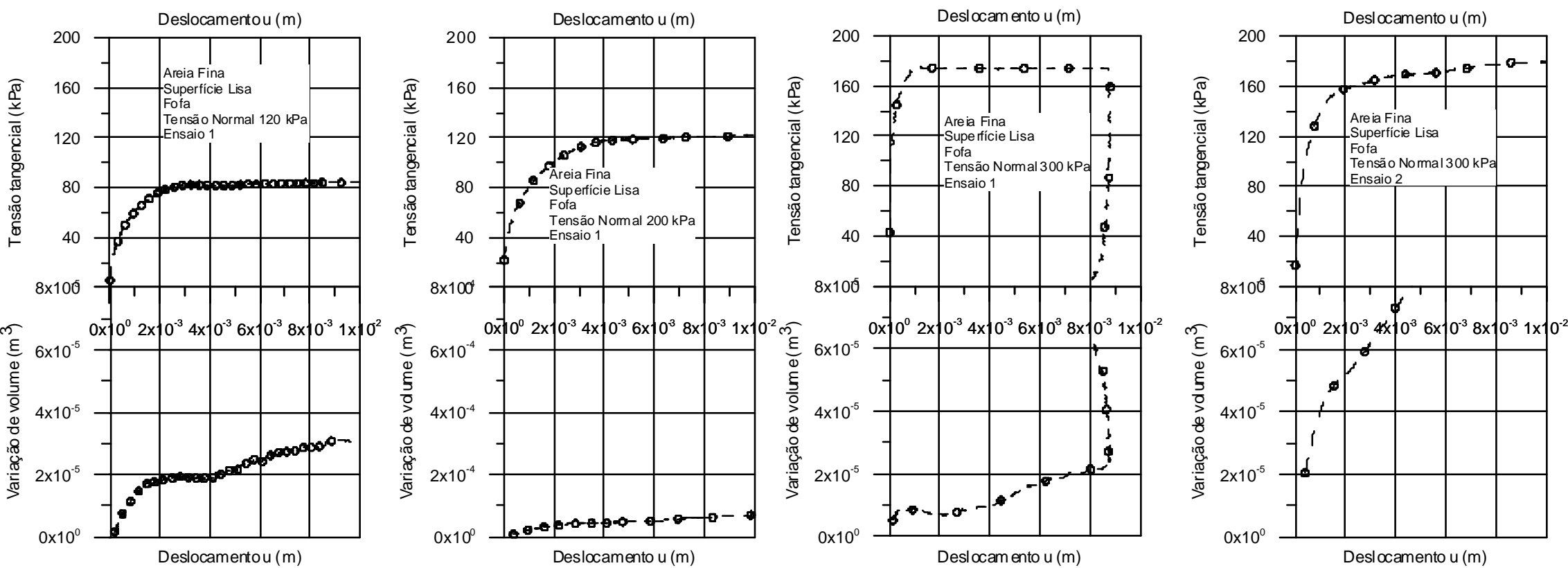

Figura 3.21 - Curvas tensão tangencial versus deslocamento tangencial e variação de volume versus deslocamento tangencial para a areia A1 fofa em contato com superfície lisa de concreto. 

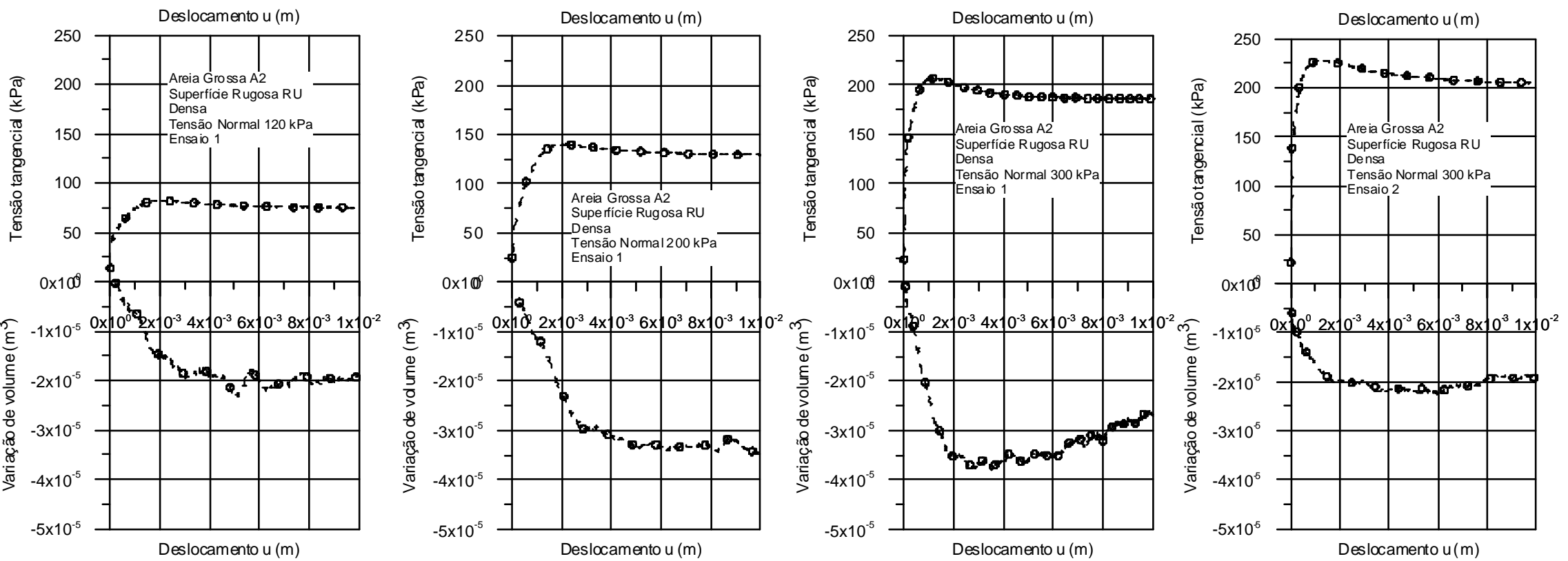

Figura 3.22 - Curvas tensão tangencial versus deslocamento tangencial e variação de volume versus deslocamento tangencial para a areia A2 compacta em contato com superfície rugosa de concreto. 

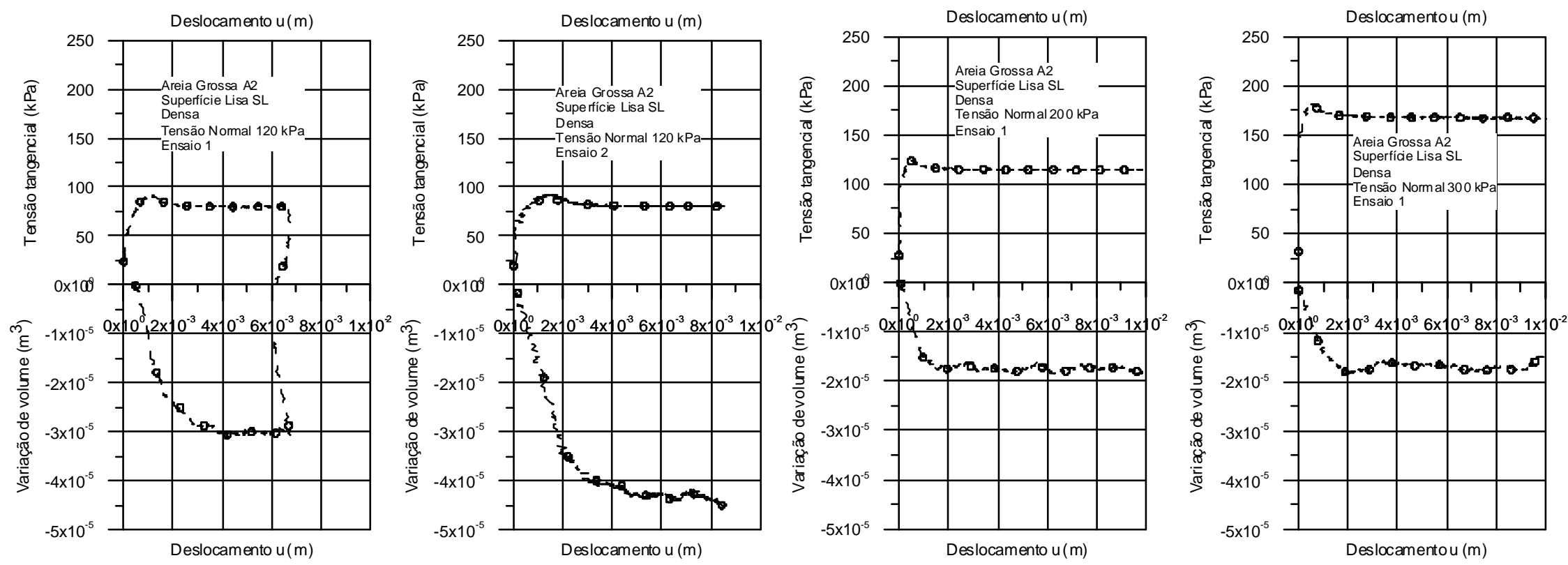

Figura 3.23 - Curvas tensão tangencial versus deslocamento tangencial e variação de volume versus deslocamento tangencial para a areia A2 compacta em contato com superfície lisa de concreto. 

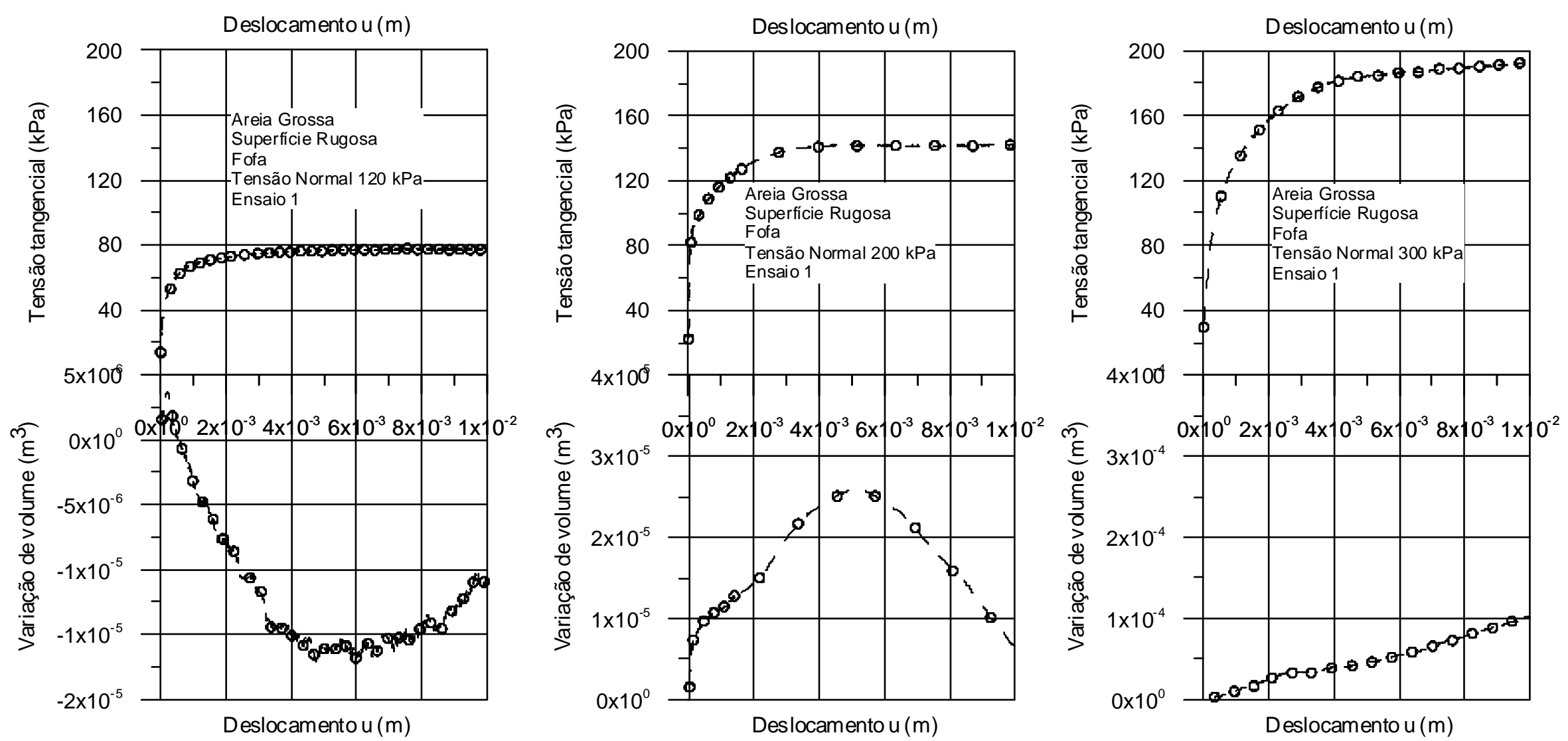

Figura 3.24 - Curvas tensão tangencial versus deslocamento tangencial e variação de volume versus deslocamento tangencial para a areia A2 fofa em contato com superfície rugosa de concreto. 

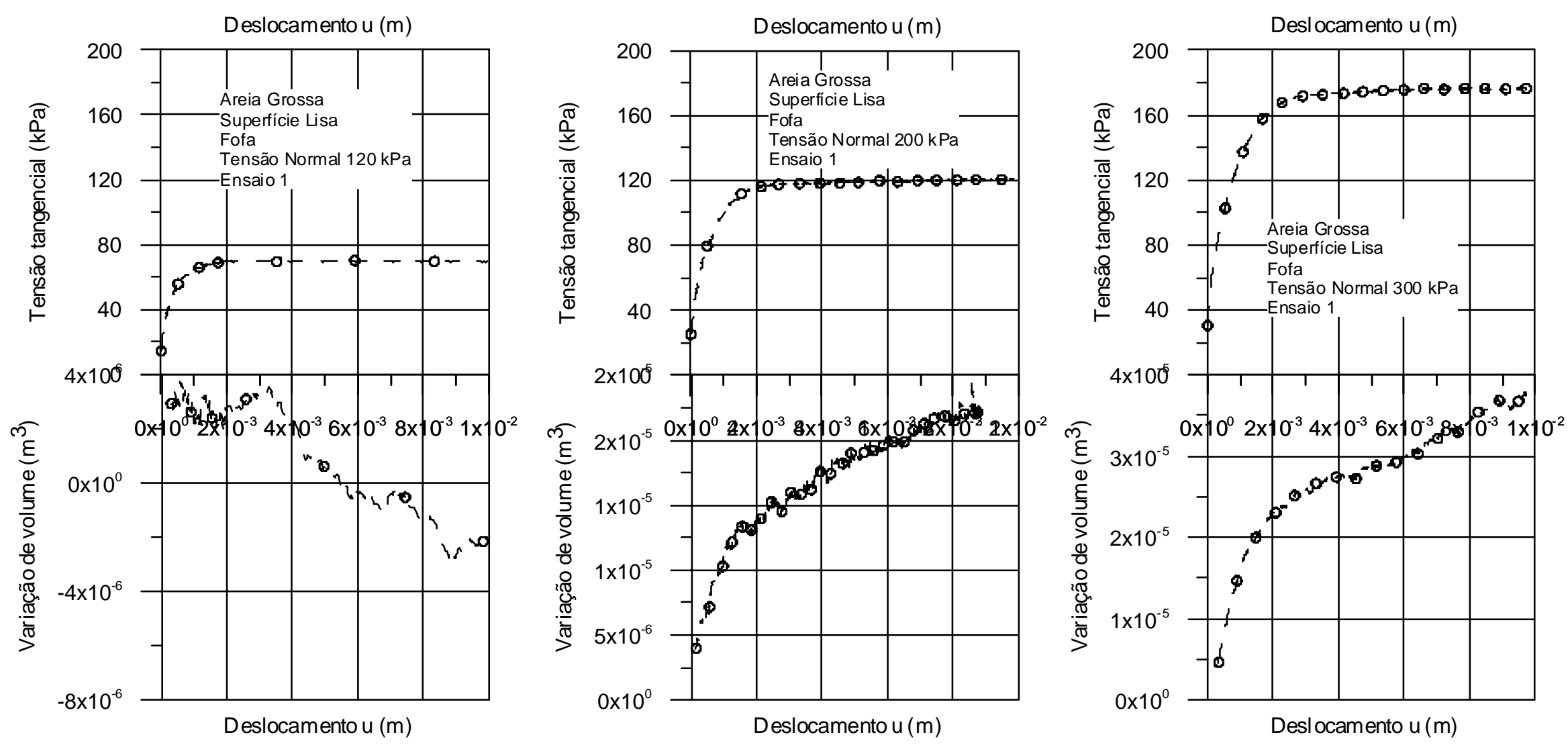

Figura 3.25 - Curvas tensão tangencial versus deslocamento tangencial e variação de volume versus deslocamento tangencial para a areia A2 fofa em contato com superfície lisa de concreto. 
Os resultados aqui apresentados apontam para a ocorrência de ângulos de atrito de pico na interface concreto-areia, variando entre $27,6^{\circ}$ e $34,9^{\circ}$ e ângulos de atrito residuais na interface concreto-areia da ordem de 29,2 ${ }^{\circ}$ (Figura 3.28). Esses resultados coincidem com os apresentados por Boulon at al. (1986), que, em ensaios de interfaces de areia-aço encontrou angulos de atrito variando entre $29^{\circ}$ e $33^{\circ}$. O mesmo pode-se dizer dos resultados de Gomez (2000), que encontrou ângulos de atrito de máximos mobilizados em interfaces de concreto areia variando de $29,5^{\circ}$ a $33,7^{\circ}$.

Tabela 3.8 - Valores dos ângulos de atrito nas interfaces estudadas obtidos a partir das relações $\frac{\tau_{\text {pico }}}{\sigma}$ e $\frac{\tau_{\text {residual }}}{\sigma}$ e os correpondentes índice de vazios inicial da areia que formou a interface para cada nível de tensão normal

\begin{tabular}{|c|c|c|c|c|c|c|c|c|}
\hline Interface & $\overline{\sigma_{0}(k P a)}$ & $\overline{e_{0}}$ & $\overline{\tau_{\text {pico }}(k P a)}$ & $\overline{\tau_{\text {residual }}(k P a)}$ & $\overline{\delta_{\text {pico }}\left({ }^{0}\right)}$ & $\overline{\delta_{\text {residual }}\left({ }^{0}\right)}$ & $\overline{\delta_{p i c o} / \phi_{p i c o}}$ & $\overline{\delta_{\text {residual }} / \phi}$ \\
\hline \multirow{4}{*}{$\begin{array}{l}\text { A1 FOFA } \\
\text { RU }\end{array}$} & 145,0 & 0,68 & & 71,0 & & 26,1 & & $\begin{array}{c}\text { esidual } \\
0.88\end{array}$ \\
\hline & 201,0 & 0,67 & & 107,2 & & 28,1 & & 0.95 \\
\hline & 225,0 & 0,65 & & 129,2 & & 29,9 & & 1.01 \\
\hline & 325,0 & 0,80 & & 169,4 & & 27,5 & & 0.93 \\
\hline \multirow{6}{*}{$\begin{array}{l}\text { A1 DENSA } \\
\text { RU }\end{array}$} & 145,0 & 0,51 & 88,4 & 86,8 & 31,4 & 30,9 & 0.77 & 1.01 \\
\hline & 145,0 & 0,47 & 89,1 & 86,7 & 31,6 & 30,9 & 0.77 & 1.01 \\
\hline & 225,0 & 0,45 & 136,6 & 131,6 & 31,3 & 30,3 & 0.76 & 0.99 \\
\hline & 225,0 & 0,46 & 137,8 & 134,4 & 31,5 & 30,9 & 0.77 & 1.01 \\
\hline & 325,0 & 0,45 & 193,1 & 187,5 & 30,7 & 30,0 & 0.75 & 0.98 \\
\hline & 325,0 & 0,45 & 197,1 & 192,3 & 31,2 & 30,6 & 0.76 & 1.00 \\
\hline \multirow{4}{*}{$\begin{array}{c}\text { A1 FOFA } \\
\text { SL }\end{array}$} & 145,0 & 0,72 & & 84,4 & & 30,2 & & 1.02 \\
\hline & 225,0 & 0,72 & & 123,7 & & 28,8 & & 0.98 \\
\hline & 325,0 & 0,70 & & 174,2 & & 28,2 & & 0.96 \\
\hline & 325,0 & 0,67 & & 180,1 & & 29,0 & & 0.98 \\
\hline \multirow{3}{*}{$\begin{array}{l}\text { A1 DENSA } \\
\text { SL }\end{array}$} & 145,0 & 0,53 & 88,3 & 84,8 & 31,3 & 30,3 & 0.76 & 0.99 \\
\hline & 225,0 & 0,53 & 128,7 & 125,7 & 29,8 & 29,2 & 0.73 & 0.95 \\
\hline & 325,0 & 0,52 & 186,8 & 177,7 & 29,9 & 28,7 & 0.73 & 0.93 \\
\hline \multirow{3}{*}{$\begin{array}{c}\text { A2 } \\
\text { FOFA RU }\end{array}$} & 145,0 & 0,70 & & 74,4 & & 27,2 & & 0.85 \\
\hline & 225,0 & 0,70 & & 142,6 & & 32,4 & & 1.01 \\
\hline & 325,0 & 0,67 & & 196,2 & & 31,1 & & 0.97 \\
\hline \multirow{4}{*}{$\begin{array}{c}\text { A2 DENSA } \\
\text { RU }\end{array}$} & 145,0 & 0,56 & 81,4 & 75,8 & 29,3 & 27,6 & 0.65 & 0.86 \\
\hline & 225,0 & 0,54 & 139,8 & 129,9 & 31,9 & 30,0 & 0.71 & 0.94 \\
\hline & 325,0 & 0,45 & 205,7 & 185,7 & 32,3 & 29,7 & 0.71 & 0.93 \\
\hline & 325,0 & 0,47 & 227,0 & 202,0 & 34,9 & 31,9 & 0.77 & 1.00 \\
\hline \multirow{3}{*}{$\begin{array}{c}\text { A2 FOFA } \\
\text { SL }\end{array}$} & 145,0 & 0,670 & & 70,2 & & 25,8 & & 0.81 \\
\hline & 225,0 & 0,710 & & 122,5 & & 28,6 & & 0.89 \\
\hline & 325,0 & 0,690 & & 178,7 & & 28,8 & & 0.90 \\
\hline \multirow{4}{*}{$\begin{array}{c}\text { A2 DENSA } \\
\text { SL }\end{array}$} & 145,0 & 0,530 & 90,7 & 80,4 & 32,0 & 29,0 & 0.71 & 0.91 \\
\hline & 145,0 & 0,490 & 91,3 & 80,7 & 32,2 & 29,1 & 0.71 & 0.91 \\
\hline & 225,0 & 0,480 & 120,5 & 115,0 & 28,2 & 27,1 & 0.62 & 0.85 \\
\hline & 325,0 & 0,480 & 170,2 & 166,7 & 27,6 & 27,2 & 0.61 & 0.85 \\
\hline
\end{tabular}

Para ângulos de atrito residuais Gómez, (2000) encontrou valores em torno de $28,5^{\circ}$. 
Lehane et al. (1993) também relatam resultados de ângulos de atrito na interface variando de $29^{\circ}$ a $33^{\circ}$, com ângulos residuais em torno de $28^{\circ}$, independentemente da densidade relativa.
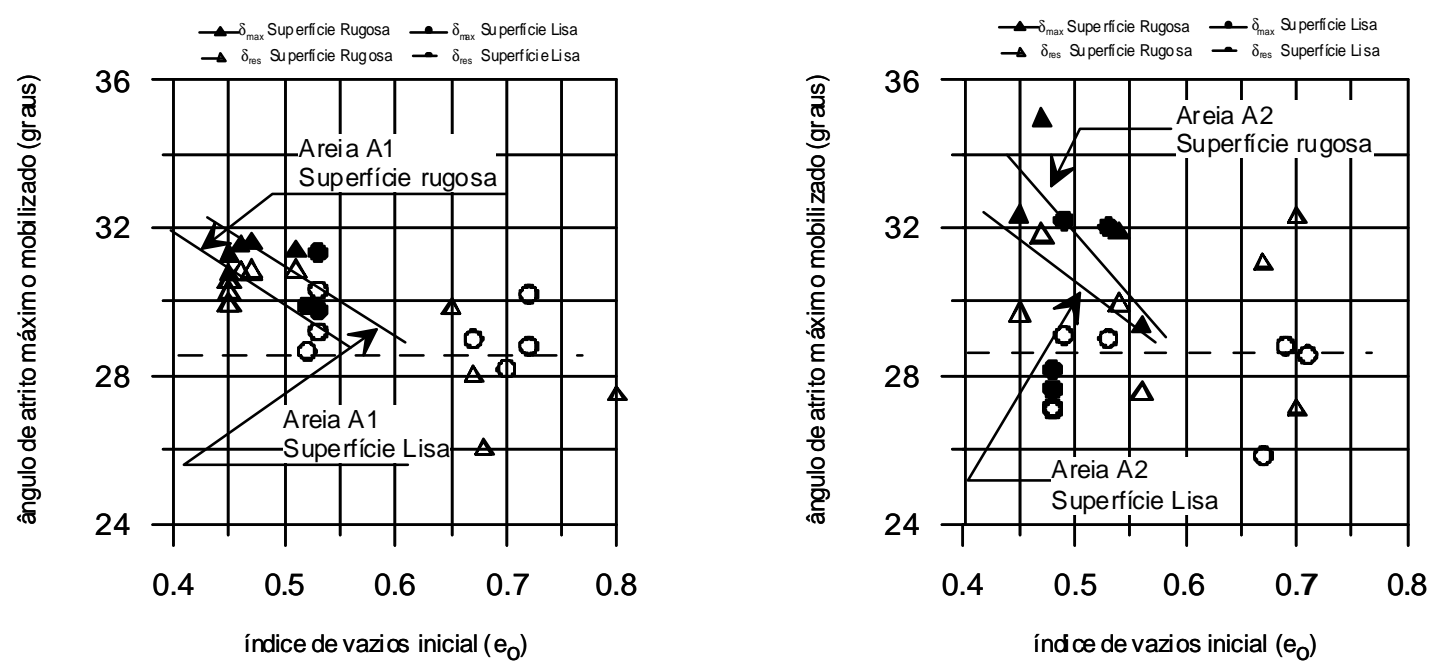

Figura 3.26 - Ângulos de atrito em superficie de contato areia concreto.

Quando comparados os resultados de ensaios realizados em contato solo-solo todos os autores encontram relações variando de $60 \%$ a $80 \%$. Esses valores também foram obeservados nesse programa experimental quando comparados com os ângulos de atrito de pico na interface com os ângulos de arito de pico no contato solo-solo. Esses valores também estão de acordo com os primeiros resultados publicados por Potyondy (1961). Quando comparados os resultados dos ângulos residuais percebe-se que oncorre uma razão variando de 0,8 a 1,0 .

Com relação à variação de volume ocorrida nos ensaios em interfaces, verificase que o valor máximo é muito menor que o que ocorreria em contato solo-solo.

Em todos os trabalhos consultados também se confirma que os deslocamentos necessários para mobilização total da resistência de pico em solos compactos varia entre $1 \mathrm{~mm}$ a $3 \mathrm{~mm}$, enquanto que, para solos fofos, a resistência é mobilizada com deslocamento de $10 \mathrm{~mm}$.

Após o primeiro carregamento, alguns corpos de prova foram reensaiados com diferentes tensões normais. Os reensaios também foram do tipo CNC (carga normal constante).

Os resultados dos ensaios de recarregamento são mostrados nas Figuras 3.27 a 3.30 e os valores de ruptura resumidos na Tabela 3.9. 

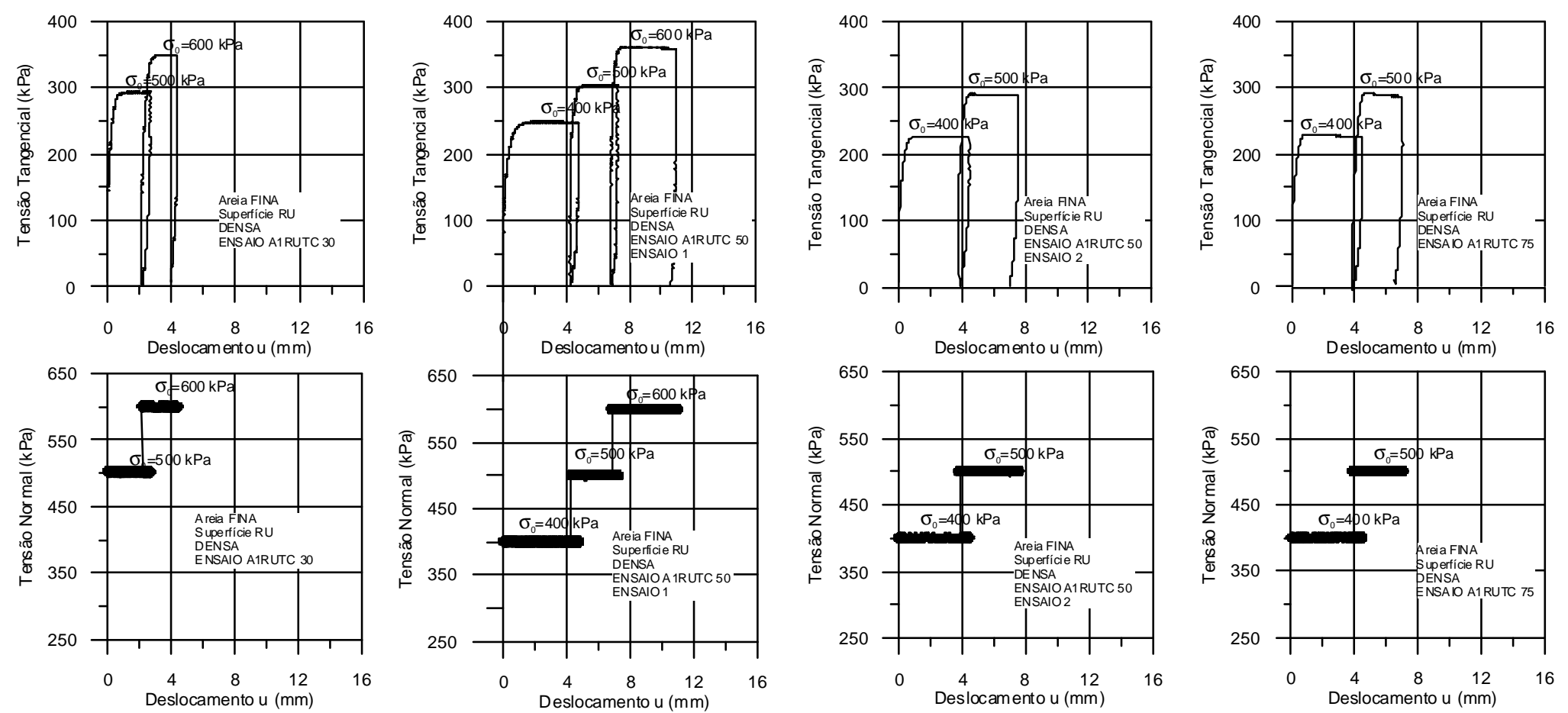

Figura 3.27 - Resultados de recarregamento em interfaces de contato entre a areia grossa A1 e Superfície RU. 

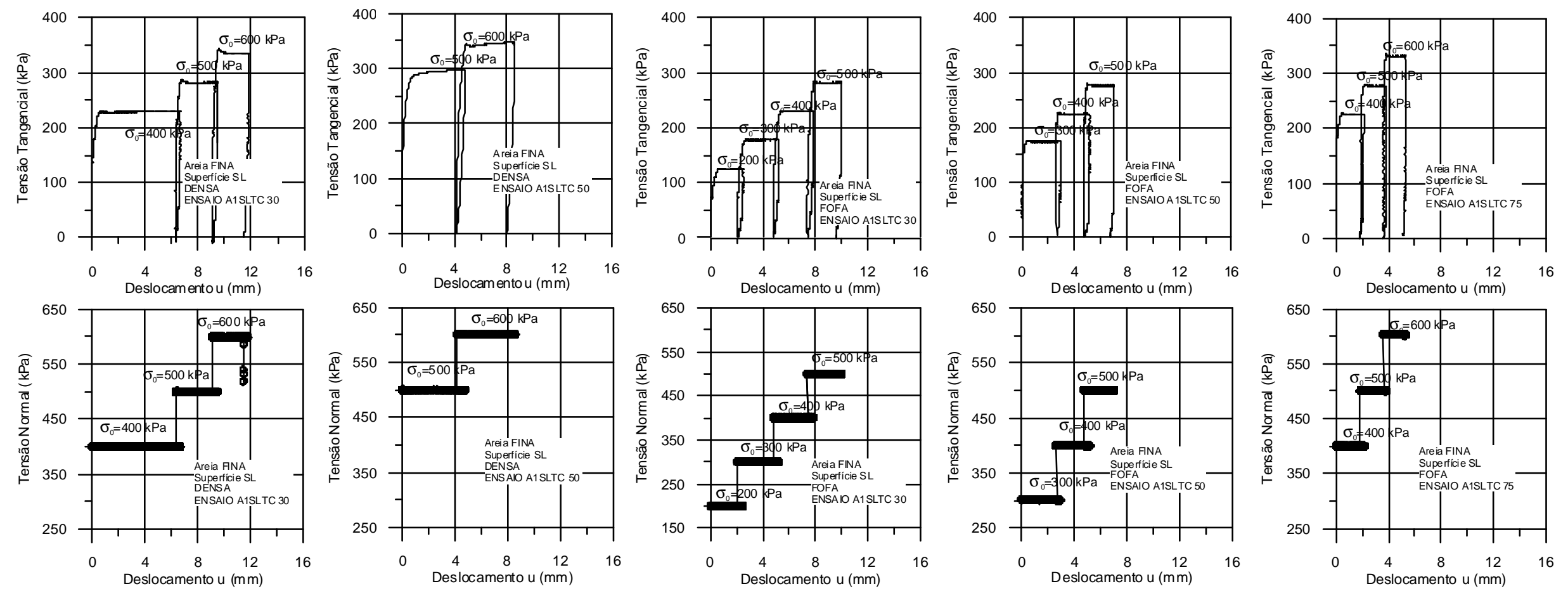

Figura 3.28 - Resultados de recarregamento em interfaces de contato entre a areia grossa A1 e Superfície SL. 

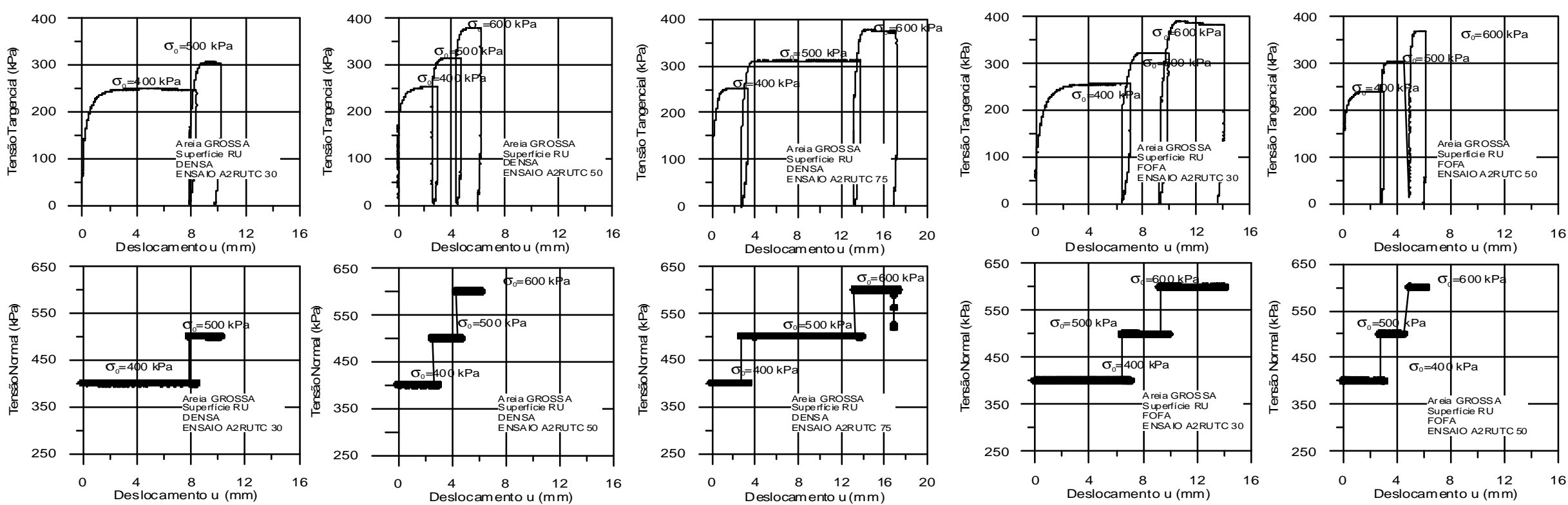

Figura 3.29 - Resultados de recarregamento em interfaces de contato entre a areia grossa A2 e Superfície RU. 

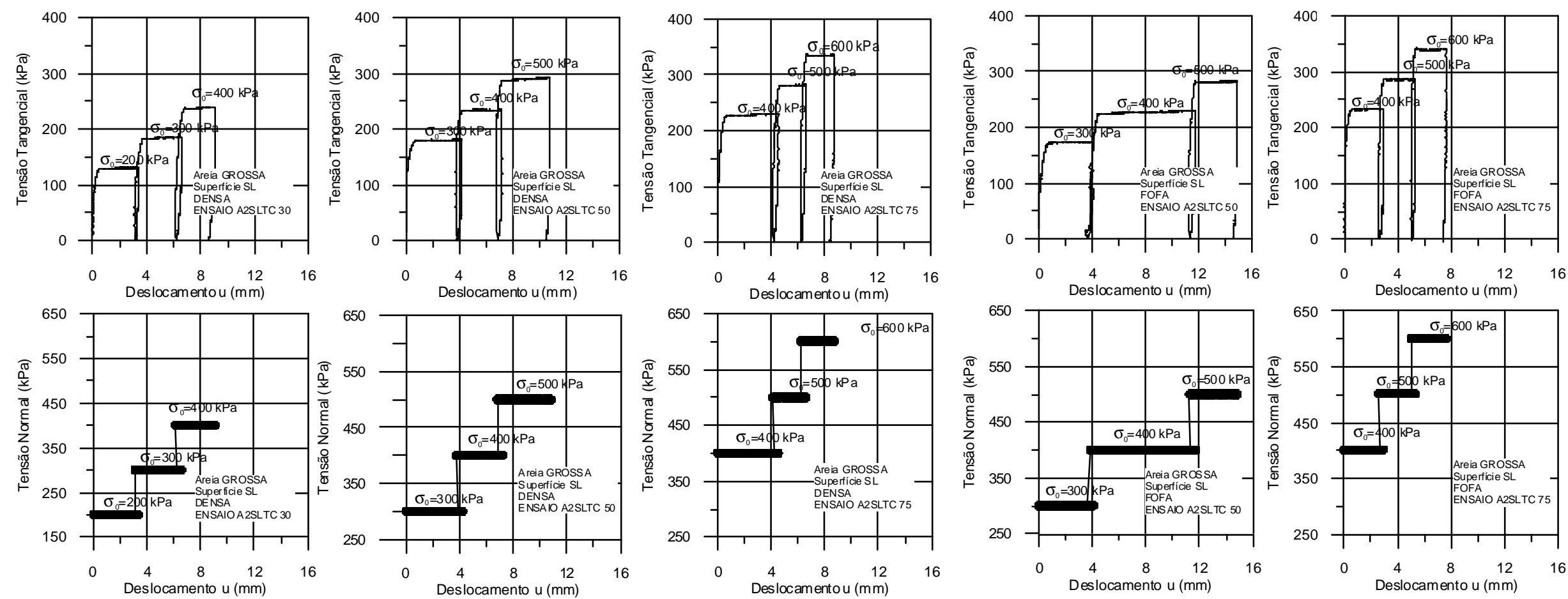

Figura 3.30 - Resultados de recarregamento em interfaces de contato entre a areia grossa A2 e Superfície SL. 
Tabela 3.9 - Valores dos ângulos de atrito nas interfaces estudadas obtidos apartir das relações $\frac{\tau_{\max }}{\sigma}$.

\begin{tabular}{|c|c|c|c|c|c|}
\hline Ensaio & Estado inicial & $\sigma_{0}(k P a)$ & $\tau_{\max }(k P a)$ & $\tau_{\max } / \sigma_{0}$ & $8\left(^{0}\right)$ \\
\hline \multirow{2}{*}{ A1 RUTC 30} & \multirow{2}{*}{ Densa } & 500 & 292 & 0,58 & 30,3 \\
\hline & & 600 & 349 & 0,58 & 30,2 \\
\hline \multirow{3}{*}{ A1 RUTC 50} & \multirow{3}{*}{ Densa } & 400 & 248 & 0,62 & 31,8 \\
\hline & & 500 & 304 & 0,61 & 31,3 \\
\hline & & 600 & 360 & 0,60 & 31,0 \\
\hline \multirow{2}{*}{ A1 RUTC 50} & \multirow{2}{*}{ Densa } & 400 & 227 & 0,57 & 29,6 \\
\hline & & 500 & 289 & 0,58 & 30,0 \\
\hline \multirow{2}{*}{ A1 RUTC 75} & \multirow{2}{*}{ Densa } & 400 & 229 & 0,57 & 29,8 \\
\hline & & 500 & 292 & 0,58 & 30,3 \\
\hline \multirow{3}{*}{ A1SLTC 30} & \multirow{3}{*}{ Densa } & 400 & 228 & 0,57 & 29,7 \\
\hline & & 500 & 281 & 0,56 & 29,3 \\
\hline & & 600 & 335 & 0,56 & 29,2 \\
\hline \multirow{2}{*}{ A1 SLTC 50} & \multirow{2}{*}{ Densa } & 500 & 297 & 0,59 & 30,7 \\
\hline & & 600 & 347 & 0,58 & 30,0 \\
\hline \multirow{4}{*}{ A1SLTC 30} & \multirow{4}{*}{ Fofa } & 200 & 125 & 0,63 & 32,0 \\
\hline & & 300 & 177 & 0,59 & 30,5 \\
\hline & & 400 & 229 & 0,57 & 29,8 \\
\hline & & 500 & 283 & 0,57 & 29,5 \\
\hline \multirow{3}{*}{ A1 SLTC 50} & \multirow{3}{*}{ Fofa } & 300 & 173 & 0,58 & 30,0 \\
\hline & & 400 & 225 & 0,56 & 29,4 \\
\hline & & 500 & 278 & 0,56 & 29,1 \\
\hline \multirow{3}{*}{ A1 SLTC 75} & \multirow{3}{*}{ Fofa } & 400 & 224 & 0,56 & 29,2 \\
\hline & & 500 & 277 & 0,55 & 29,0 \\
\hline & & 600 & 330 & 0,55 & 28,8 \\
\hline \multirow{2}{*}{ A2 RUTC 30} & Denca & 400 & 248 & 0,62 & 31,8 \\
\hline & Dentisa & 500 & 305 & 0,61 & 31,4 \\
\hline & & 400 & 253 & 0,63 & 32,3 \\
\hline A2 RUTC 50 & Densa & 500 & 314 & 0,63 & 32,1 \\
\hline & & 600 & 377 & 0,63 & 32,1 \\
\hline & & 400 & 252 & 0.63 & 32.2 \\
\hline A2 RUTC 75 & Densa & 500 & 311 & 0.622 & 31.9 \\
\hline & & 600 & 372 & 0.62 & 31.8 \\
\hline & & 400 & 256 & 0,64 & 32,6 \\
\hline A2 RUTC 30 & Fofo & 500 & 322 & 0,64 & 32,8 \\
\hline & & 600 & 382 & 0,64 & 32,5 \\
\hline & & 400 & 241 & 0.60 & 31.1 \\
\hline A2 RUTC 50 & Fofo & 500 & 304 & 0.61 & 31.3 \\
\hline & & 600 & 370 & 0.62 & 31.7 \\
\hline & & 200 & 130 & 0,65 & 33,0 \\
\hline A2 SLTC 30 & Densa & 300 & 183 & 0,61 & 31,4 \\
\hline & & 400 & 238 & 0,60 & 30,8 \\
\hline & & 400 & 229 & 0,57 & 29,8 \\
\hline A2 SLTC 50 & Densa & 500 & 281 & 0,56 & 29,3 \\
\hline & & 600 & 334 & 0,56 & 29,1 \\
\hline & & 300 & 180 & 0,60 & 31,0 \\
\hline A2 SLTC75 & Densa & 400 & 234 & 0,59 & 30,3 \\
\hline & & 500 & 292 & 0,58 & 30,3 \\
\hline & & 300 & 173 & 0,58 & 30,0 \\
\hline A2 SLTC 50 & Fofa & 400 & 228 & 0,57 & 29,7 \\
\hline & & 500 & 281 & 0,56 & 29,3 \\
\hline & & 400 & 233 & 0,58 & 30,2 \\
\hline A2 SLTC 75 & Fofa & 500 & 286 & 0,57 & 29,8 \\
\hline & & 600 & 340 & 0,57 & 29,5 \\
\hline
\end{tabular}




\section{CAPÍTULO IV \\ CALIBRAÇÃO E INTERPRETAÇÃO DA NATUREZA DOS PARÂMETROS FÍSICOS}

A calibração do modelo foi feita através dos resultados dos ensaios de cisalhamento direto com tensão normal constante em interfaces de contato entre superfícies de concreto-areia descritos no capítulo anterior.

O modelo constitutivo descrito nesse trabalho possui basicamente três propriedades da interface de acordo com a Equação (2.63): o ângulo de atrito verdadeiro na interface $\delta$; o módulo de dilatância $k$ e o coeficiente de rearranjo $\eta$.

Para calibração do modelo, foi feito um ajuste matemático das equações de tensão tangencial (Equação 2.89) e variação de volume (Equação 2.91) em função do deslocamento tangencial, aos resultados experimentais obtidos nos ensaios de cisalhamento direto em interfaces com tensão normal constante.

A calibração foi obtida de modo a se obter o melhor ajuste para a curva de tensão tangencial em função do deslocamento tangencial (Equação 2.89), enquanto que a curva de variação de volume em função do deslocamento tangencial foi traçada em decorrência dos parâmetros obtidos no melhor ajuste da Equação (2.89).

A comparação entre as curvas tensão tangencial e variação de volume em função do deslocamento tangencial medidas nos ensaios de cisalhamento direto com tensão normal constante em interface concreto-areia e calculadas pelas Equações (2.89) e (2.91), respectivamente, são mostradas nas Figuras 4.1 a 4.4, Os valores dos parâmetros do modelo (ângulo de atrito verdadeiro na interface $\delta$; módulo de dilatância $k$ e o coeficiente de rearranjo $\eta$ ) resultantes dos ajustes são mostrados na Tabela 4.1. 
Tabela 4.1 - Valores do ângulo de atrito verdadeiro na interface $\delta$; módulo de dilatância $k$ e o coeficiente de rearranjo $\eta$

\begin{tabular}{|c|c|c|c|c|c|c|c|}
\hline Ensaio & $\begin{array}{c}\sigma_{0} \\
(\mathrm{kPa})\end{array}$ & Material & Superfície & $\begin{array}{c}\delta \\
\text { (Graus) }\end{array}$ & $\begin{array}{c}k \\
\left(\mathrm{kPa} / \mathrm{m}^{2}\right)\end{array}$ & $\begin{array}{r}\eta \\
(\mathrm{m})\end{array}$ & $e_{o}$ \\
\hline A1_DENSA_RU_145_kPa_1 & 145 & Areia Fina A1 & Rugosa RC & 30.6 & 3000 & 0.00045 & 0.49 \\
\hline A1_DENSA_RU_145_kPa_2 & 145 & Areia Fina A1 & Rugosa RC & 30.6 & 3000 & 0.00045 & 0.48 \\
\hline A1_DENSA_RU_225_kPa_1 & 225 & Areia Fina A1 & Rugosa RC & 30.2 & 6000 & 0.00060 & 0.49 \\
\hline A1_DENSA_RU_225_kPa_2 & 225 & Areia Fina A1 & Rugosa RC & 30.6 & 6000 & 0.00055 & 0.49 \\
\hline A1_DENSA_RU_325_kPa_1 & 325 & Areia Fina A1 & Rugosa RC & 30.0 & 7000 & 0.00080 & 0.47 \\
\hline A1_DENSA_RU_325_kPa_2 & 325 & Areia Fina A1 & Rugosa RC & 30.5 & 8000 & 0.00095 & 0.48 \\
\hline A1_DENSA_SL_145_kPa_1 & 145 & Areia Fina A1 & Lisa SC & 30.0 & 4000 & 0.00055 & 0.49 \\
\hline A1_DENSA_SL_225_kPa_1 & 225 & Areia Fina A1 & Lisa SC & 29.0 & 5000 & 0.00070 & 0.49 \\
\hline A1_DENSA_SL_325_kPa_1 & 325 & Areia Fina A1 & Lisa SC & 28.8 & 9000 & 0.00090 & 0.48 \\
\hline A1_FOFA_RU_145_kPa_1 & 145 & Areia Fina A1 & Rugosa RC & 26.0 & 7000 & 0.00190 & 0.68 \\
\hline A1_FOFA_RU_225_kPa_1 & 225 & Areia Fina A1 & Rugosa RC & 31.0 & 8000 & 0.00130 & 0.65 \\
\hline A1_FOFA_RU_201_kPa_2 & 201 & Areia Fina A1 & Rugosa RC & 28.0 & 10000 & 0.00160 & 0.67 \\
\hline A1_FOFA_RU_325_kPa_4 & 325 & Areia Fina A1 & Rugosa RC & 28.7 & 6000 & 0.00190 & 0.67 \\
\hline A1_FOFA_SL_145_kPa_1 & 145 & Areia Fina A1 & Lisa SC & 30.0 & 7000 & 0.00180 & 0.68 \\
\hline A1_FOFA_SL_225_kPa_1 & 225 & Areia Fina A1 & Lisa SC & 29.0 & 7000 & 0.00140 & 0.67 \\
\hline A1_FOFA_SL_225_kPa_2 & 325 & Areia Fina A1 & Lisa SC & 29.0 & 6000 & 0.00180 & 0.72 \\
\hline A1_FOFA_SL_325_kPa_4 & 325 & Areia Fina A1 & Lisa SC & 28.5 & 10000 & 0.00100 & 0.64 \\
\hline A2_DENSA_RU_145_kPa_1 & 145 & Areia Grossa A2 & Rugosa RC & 28.0 & 7000 & 0.00050 & 0.55 \\
\hline A2_DENSA_RU_225_kPa_1 & 225 & Areia Grossa A2 & Rugosa RC & 30.0 & 12000 & 0.00070 & 0.54 \\
\hline A2_DENSA_RU_325_kPa_1 & 325 & Areia Grossa A2 & Rugosa RC & 32.0 & 12000 & 0.00060 & 0.49 \\
\hline A2_DENSA_RU_325_kPa_2 & 325 & Areia Grossa A2 & Rugosa RC & 30.0 & 12000 & 0.00080 & 0.49 \\
\hline A2_DENSA_SL_145_kPa_1 & 145 & Areia Grossa A2 & Lisa SC & 29.0 & 5000 & 0.00060 & 0.49 \\
\hline A2_DENSA_SL_145_kPa_2 & 145 & Areia Grossa A2 & Lisa SC & 29.0 & 7000 & 0.00057 & 0.53 \\
\hline A2_DENSA_SL_225_kPa_1 & 225 & Areia Grossa A2 & Lisa SC & 27.0 & 11000 & 0.00063 & 0.51 \\
\hline A2_DENSA_SL_325_kPa_1 & 325 & Areia Grossa A2 & Lisa SC & 27.5 & 12000 & 0.00070 & 0.50 \\
\hline A2_FOFA_RU_145_kPa_1 & 145 & Areia Grossa A2 & Rugosa RC & 27.5 & 4000 & 0.00080 & 0.67 \\
\hline A2_FOFA_RU_225_kPa_1 & 225 & Areia Grossa A2 & Rugosa RC & 32.5 & 8000 & 0.00130 & 0.70 \\
\hline A2_FOFA_RU_320_kPa_1 & 325 & Areia Grossa A2 & Rugosa RC & 30.5 & 10000 & 0.00200 & 0.67 \\
\hline A2_FOFA_SL_145_kPa_1 & 145 & Areia Grossa A2 & Lisa SC & 30.1 & 3000 & 0.00065 & 0.67 \\
\hline A2_FOFA_SL_225_kPa_1 & 225 & Areia Grossa A2 & Lisa SC & 28.0 & 7000 & 0.00130 & 0.71 \\
\hline A2_FOFA_SL_320_kPa_1 & 325 & Areia Grossa A2 & Lisa SC & 28.5 & 10000 & 0.00130 & 0.69 \\
\hline
\end{tabular}



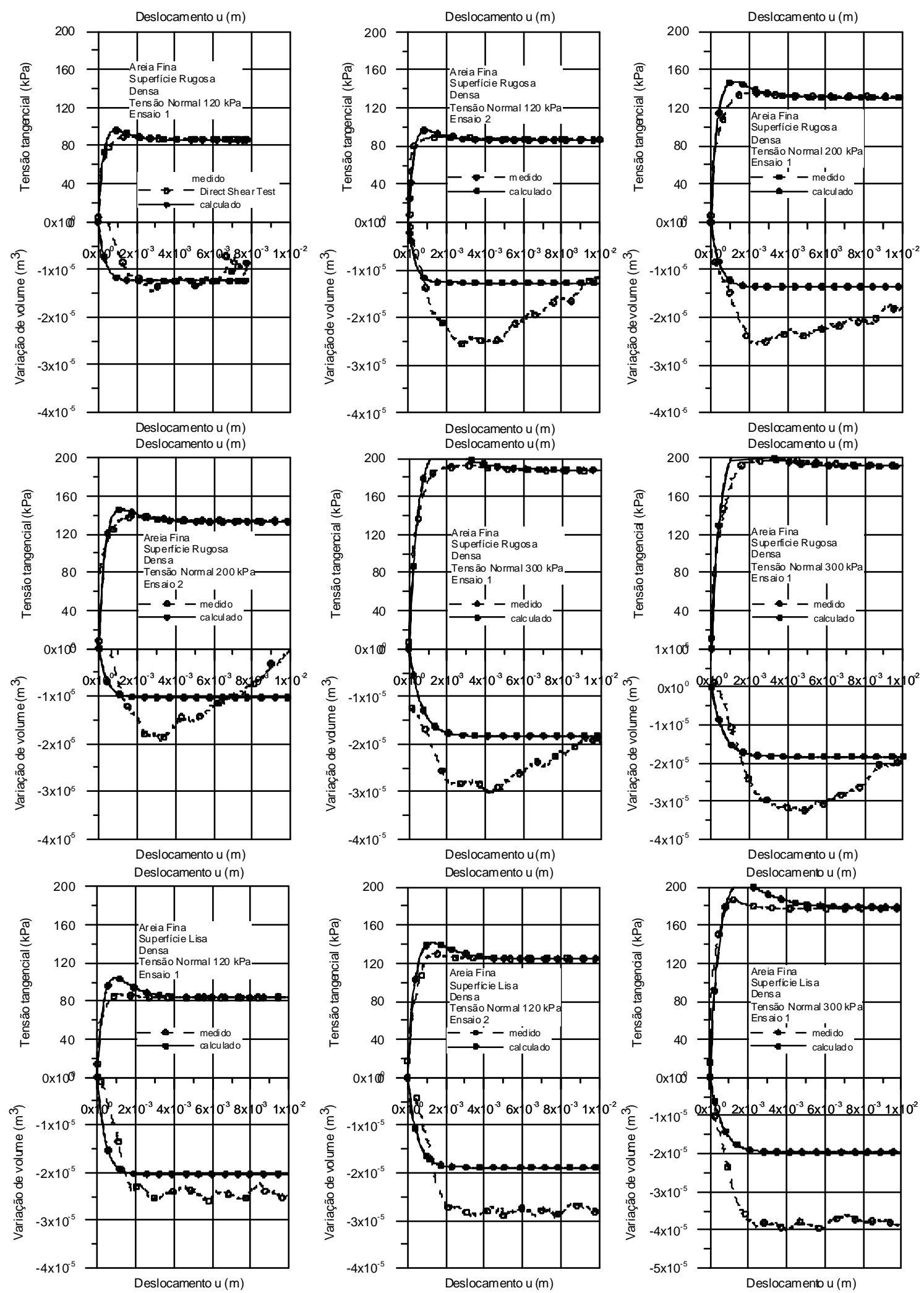

Figura 4.1 - Comparação entre resultados experimentais e os do modelo calibrado para areia fina A1 compacta. 

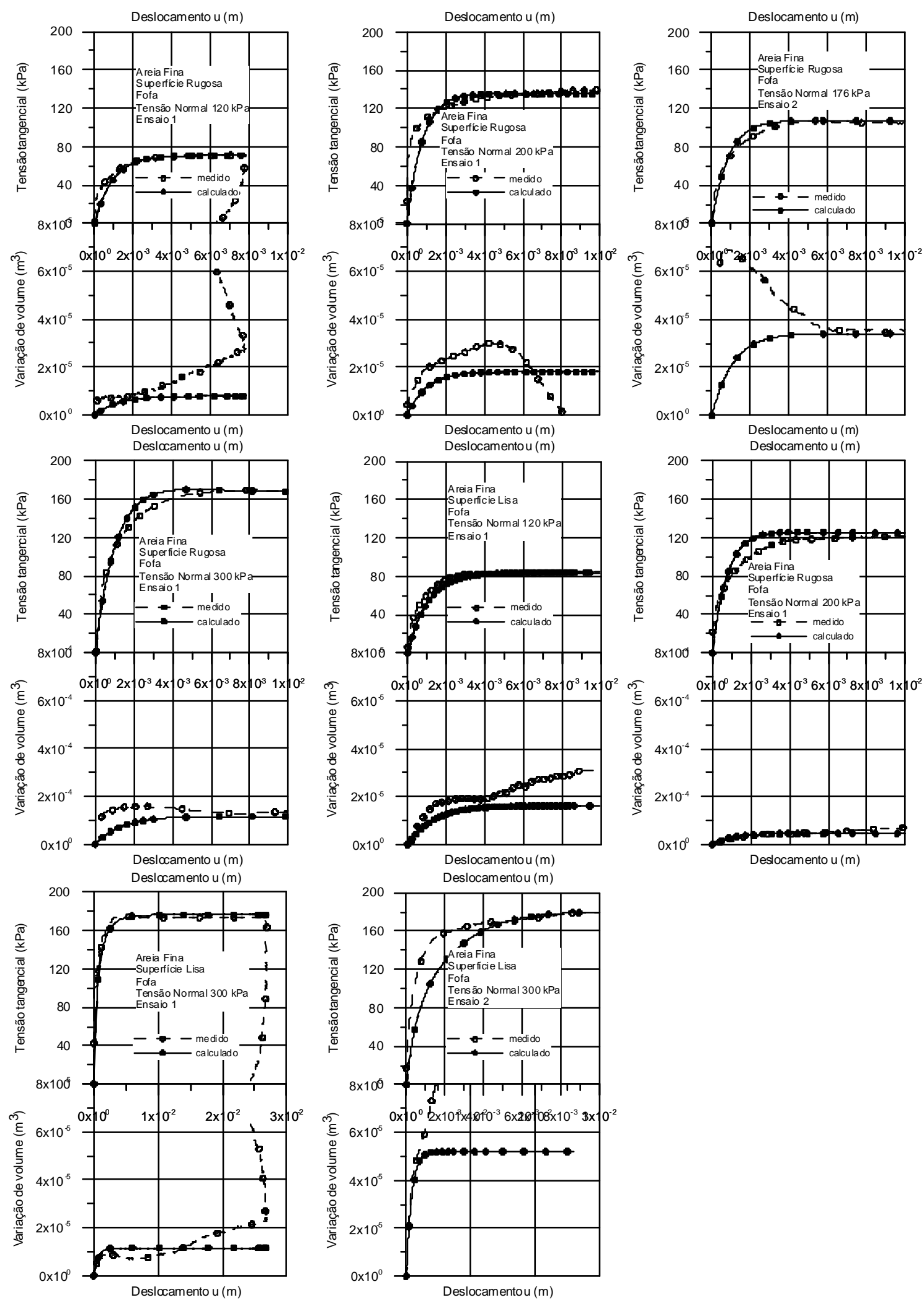

Figura 4.2 - Comparação entre resultados experimentais e os do modelo calibrado para areia fina A1 fofa. 

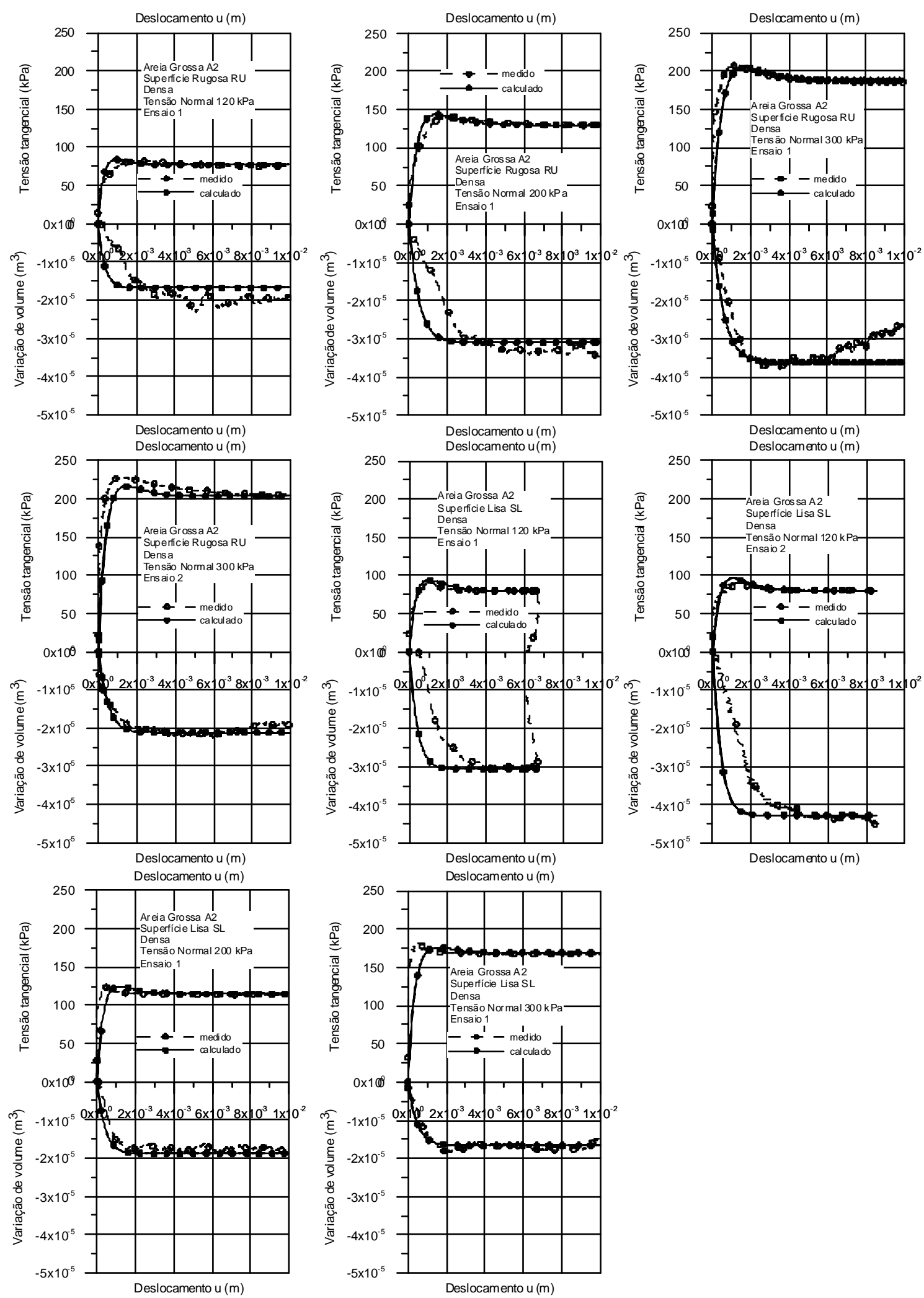

Figura 4.3 - Comparação entre resultados experimentais e os do modelo calibrado para areia grossa $\mathrm{A} 2$ compacta. 

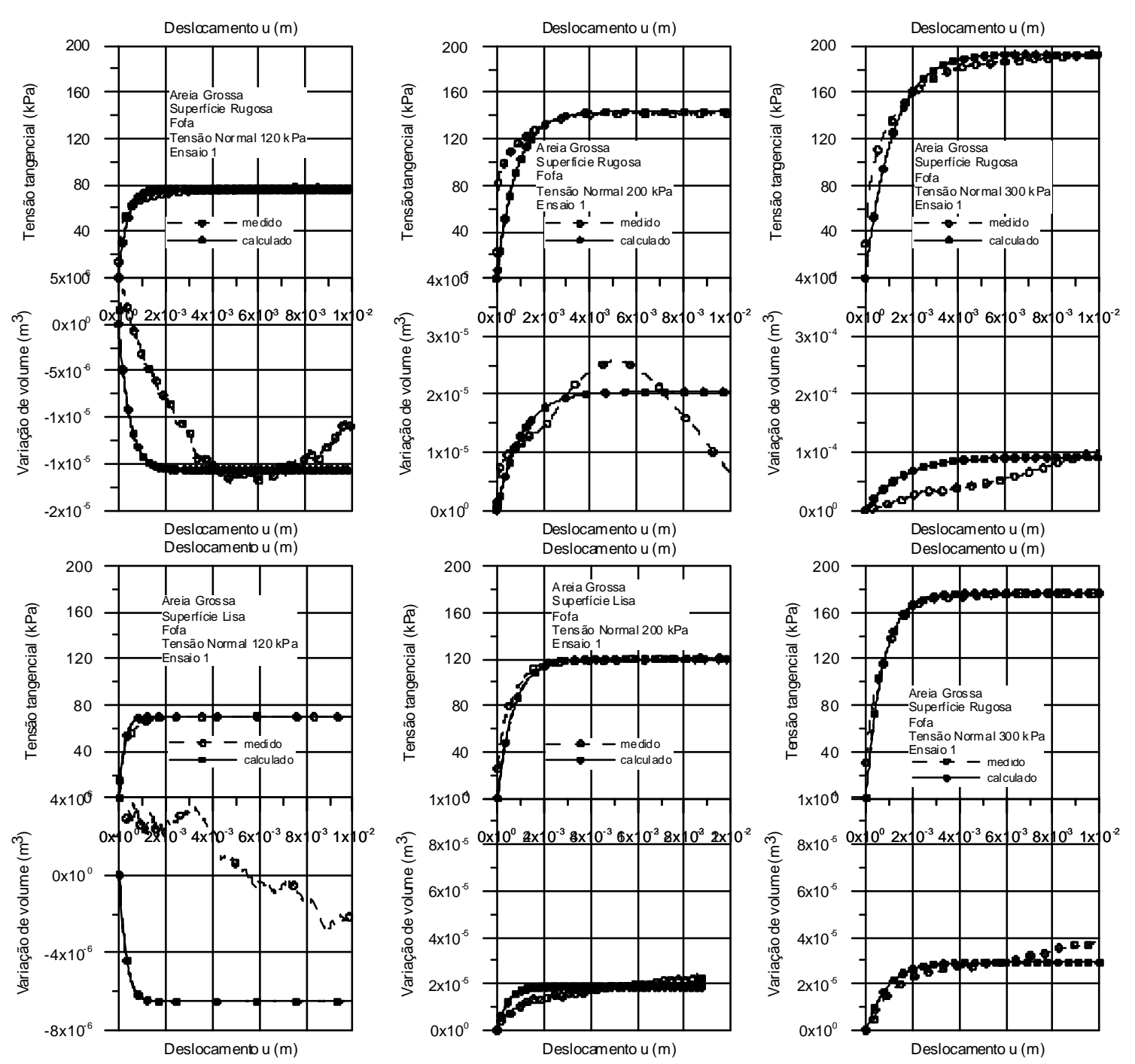

Figura 4.4 - Comparação entre resultados experimentais e os do modelo calibrado para areia grossa A2 fofa.

\subsection{Avaliação da natureza do módulo de dilatância $k$}

O módulo de dilatância tem afinidade direta com o módulo de elasticidade transversal. Segundo Lambe e Whitman (1969), o valor do módulo de elasticidade transversal $G$ é condicionado pela tensão normal aplicada, pelo índice de vazios inicial e pelo tipo de material.

O módulo de elasticidade transversal $G$ é, juntamente com o coeficiente de Poisson, a propriedade do material que relaciona deformações transversais e deformações longitudinais.

Em problemas de contato entre dois ou mais materiais, a transferência dessas deformações entre superfícies com geometria e materiais diferentes tem grande influência das propriedades físicas e geométricas da superfície de contato. 
Para se interpretar o valor de $k$ em problemas de contato concreto-solo, é necessário identificar o efeito da rugosidade e do diâmetro da partícula.

Define-se, então, o conceito de rugosidade máxima $R_{\max }$ como sendo a maior deflexão na superfície do contato.

Define-se, também, a largura média da bacia de rugosidade $L_{\text {médio }}$ como o comprimento médio da bacia de rugosidade na direção do deslocamento (Figura 4.5).

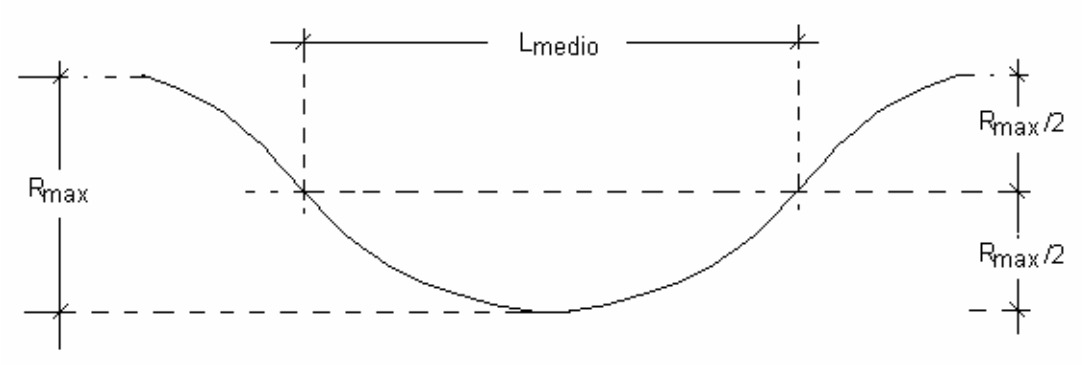

Figura 4.5 - Modelo de rugosidade.

A rugosidade de uma superfície é caracterizada pelo seu índice de rugosidade ou simplesmente pela rugosidade da superfície sólida.

Em estudos de interface, os pioneiros no uso desse conceito foram Uesugi e Kishida (1986a), que definiram o índice de rugosidade como a razão entre a rugosidade máxima e o diâmetro médio das partículas $\mathrm{D}_{50}$.

Esse conceito foi utilizado em vários trabalhos subseqüentes como os de Paikowsky et al. (1995), Ghionna e Mortara (2002), Fioravante (2002) e Porcino et. al. (2003).

A desvantagem desse número para caracterizar o contato é a não consideração da largura da bacia de cada rugosidade. Sua importância pode ser ilustrada se considerarmos uma superfície com uma deflexão Rmax de $10 \mathrm{~mm}$, quando comparada com o diametro de uma partícula de $0,1 \mathrm{~mm}$. Segundo esse conceito (Fioravante, 2002), essa interface seria uma interface altamente rugosa, independentemente da largura da rugosidade. No entanto, se a largura for muito grande ou muito pequena em relação ao pico de deflexão, a superfície pode ser considerada até como lisa, uma vez que as partículas de solo irão se mover sem dificuldades.

Dessa maneira, neste trabalho propõe-se que a rugosidade seja caracterizada pela relação entre a $R_{\text {max }}$ e $L_{\text {medio }}$ :

$R_{n}=\frac{R_{\max }}{L_{\text {medio }}}$

Para caracterizar a forma da distribuição da curva granulométrica, utilizamos a definição de coeficiente de uniformidade (ASTM D2487-00): 


$$
C u=\frac{D_{60}}{D_{10}}
$$

E coeficiente de curvatura:

$$
C c=\frac{D_{30}^{2}}{D_{10} \cdot D_{60}}
$$

As propriedades de cada superfície e do solo listadas no ítem anterior são mostradas nas Tabelas 4.2 e 4.3 .

Tabela 4.2 - Propriedades da superfície

\begin{tabular}{cccc}
\hline Superfície & $\begin{array}{c}\text { Rugosidade máxima } \\
R_{\max }(\mathrm{mm})\end{array}$ & $\begin{array}{c}\text { Largura média } \\
L_{\text {media }}(\mathrm{mm})\end{array}$ & $R_{n}=R_{\text {max }} / L_{\text {médio }}$ \\
\hline Lisa SL & 0,028 & 0,08 & 0.350 \\
Rugosa RU & 21,36 & 83,55 & 0.256 \\
\hline
\end{tabular}

Tabela 4.3 - Índices físicos

\begin{tabular}{ccccccc}
\cline { 1 - 3 } Material & $\mathrm{D}_{10}$ & $\mathrm{D}_{30}$ & $\mathrm{D}_{50}$ & $\mathrm{D}_{60}$ & $\mathrm{Cu}$ & $\mathrm{Cc}$ \\
& $(\mathrm{mm})$ & $(\mathrm{mm})$ & $(\mathrm{mm})$ & $(\mathrm{mm})$ & & \\
\hline Areia A1 & 0,10 & 0,15 & 0,19 & 0,20 & 2,0 & 1,125 \\
Areia A2 & 0,15 & 0,28 & 0,42 & 0,51 & 3,4 & 1,025 \\
\hline
\end{tabular}

Muitos autores, estudando problemas de capacidade de carga através da teoria de expansão de cavidade (Boulon et al., 1986; Oii e Carter, 1987; Housby, 1991), deduziram que a rigidez normal na interface, definida como.

$$
K=\frac{\Delta \sigma(u)}{\Delta u}
$$

é calculada através do módulo de deformabilidade transversal para expansão de uma cavidade cilíndrica de raio $R$, em meio elástico, homogêneo e isotrópico:

$$
K=\frac{2 G}{R}
$$

Jardine et al. (1998), a partir de resultados em ensaios de campo, sugerem que o coeficiente de rigidez dado pela Equação (4.5) seja corrigida de acordo com a rugosidade média da estaca.

$$
K=\frac{4 G R_{c i a}}{R}
$$


Onde $R_{\text {cia }}$ é a rugosidade média da superfície de uma estaca. Para estacas de aço, o autor recomenda usar $10^{-5}$.

Dessa forma, fica caracterizada que a rigidez normal de uma interface estacasolo é diretamente proporciosal ao módulo de elasticidade transversal do solo $(G)$, à rugosidade $\left(R_{c i a}\right)$ e inversamente proporcional à dimensão da interface refletida no raio da estaca $(R)$.

Jardine et al. (1998) também admitem que a influência da dilatância é menor quanto maior for o aumento do raio da estaca. Admitindo que o perímetro da estaca é diretamente proporcional ao seu raio e que a área de contato na interface é, também, diretamente proporcional ao perímetro, conclui-se que o módulo de dilatância também é inversamente proporcional à área de contato.

Em ensaios de juntas de maciços rochosos, Barton et. al. (1985) verificaram que o pico de resistência ao cisalhamento é menor quanto maior forem as dimensões do corpo de prova testado em ensaios de cisalhamento direto (Figura 4.6).

Levantando a hipótese de que o módulo de dilatância tem de ser função da rugosidade, da forma da curva granulométrica, do efeito do tamanho e do módulo de deformabilidade transversal, percebe-se que o mesmo deve ser:

- linearmente proporcional ao módulo de deformabilidade transversal;

- linearmente proporcional à rugosidade da superfície de contato;

- inversamente proporcional a área de contato;

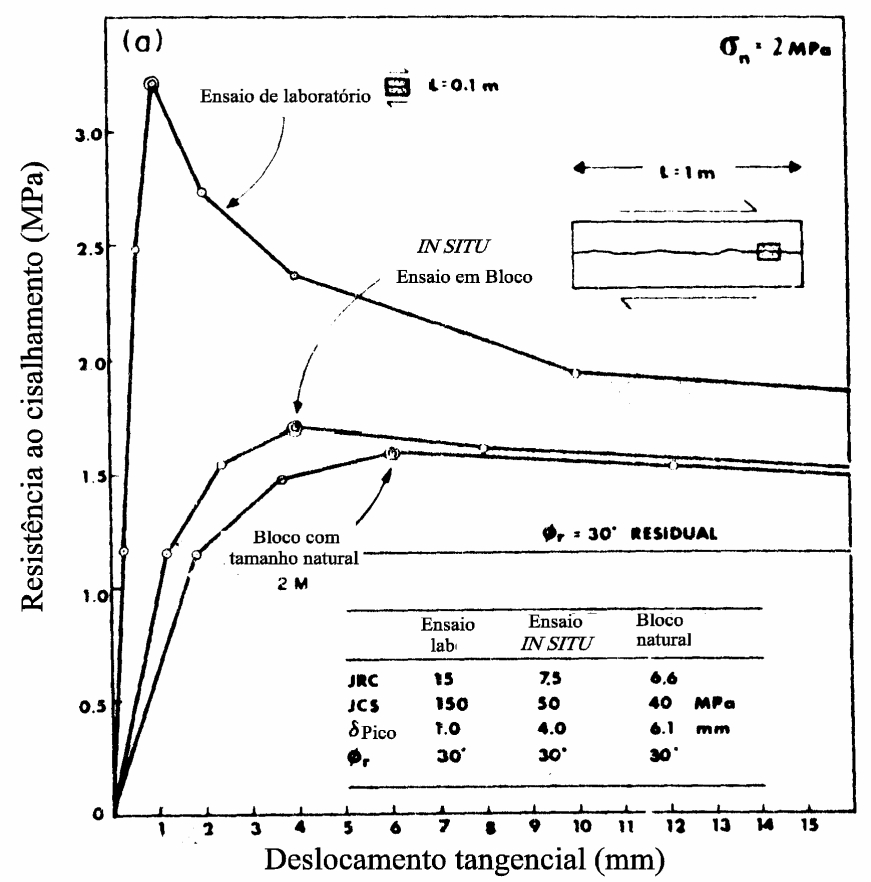

Figura 4.6 - Curvas de tensão tangencial versus deslocamento de blocos com diferentes tamanhos, submetidos à tensão normal de $2 \mathrm{MPa}$.

Dessa forma, através de semelhança à Equação (4.6), propõe-se neste trabalho uma equação para o módulo de dilatância $k$ que resume todas essas premissas e que é 
proporcional a rugosidade da superfície de contado dada por $R_{n}$, ao módulo de cisalhamento transversal $G$ e inversamento proporcional a área de contato $A$. Para fazer uma correção para consideração da forma da curva granulométrica, foi ainda introduzida na equação o coeficiente de uniformidade $C_{u}$ e o coeficiente de curvatura $C_{c}$, de modo que para granulometria formada por partículas esféricas e do mesmo tamanho os valores de $C_{u}$ e $C_{c}$ seriam unitários. A equação para cálculo do módulo de dilatância $k$ é:

$k=\frac{R_{n} \cdot G}{A \cdot C_{u} \cdot C_{c}}$

$R_{n}$ é a rugosidade da superfície dada pela Equação 4.6 (propriedade da superfície de contato);

$G$ é o módulo de deformabilidade transversal do solo (propriedade do solo);

$A$ é a área do plano de contato (propriedade geométrica do contato);

$C_{u}$ é o coeficiente de uniformidade do solo (propriedade do solo);

$C_{c}$ é o coeficiente de curvatura da curva do solo (propriedade do solo).

4.2. Avaliação da natureza do coeficiente de rearranjo $\eta$.

O coeficiente de rearranjo $\eta$ é um número que reflete a dificuldade ou a facilidade que uma partícula tem para se mover mobilizando o atrito de rolamento.

Esse número pode ser definido comparando-se as Equações (2.49) e (2.55). A análise direta destas duas equações impõe, por ordem física, que o coeficiente de rearranjo seja igual ao raio das partículas.

No entanto, cabe ressaltar que a Equação (2.49) foi deduzida a partir de um cilindro deslizando sobre uma superfície livre o que raramente vai acontecer com o solo.

Jiang et al. (2005) desenvolveram um modelo para resistência ao rolamento de material granular, onde a principal característica para ser definida é a largura de contato entre duas esferas. Para isso, os autores criaram um fator de forma, que é uma propriedade geométrica do grão e é proporcional ao tamanho da partícula e sua determinação deve ser feita através de uma investigação da microscopia do grão.

Um modelo semelhante é proposto por Liu et al. (2005), cujos parâmetros dos modelos de contato ao rolamento também são definidos em função de estudos de microscopia. No entanto, nesse trabalho, os autores discutem a influência da densidade relativa inicial e demonstram através de ensaios de cisalhamento direto que o atrito em interfaces é significativamente modificado em função desta densidade.

De ordem prática, pode-se citar o trabalho de Paikowsky et al. (1995), que faz uma descrição sobre o deslizamento de uma esfera sobre uma superfície rugosa. Nesse estudo, os autores propõem a avaliação do ângulo de rugosidade, como o parâmetro 
para se levar em consideração à forma da partícula de solo e sua influência sobre o atrito. Em todos os casos estudados ficou comprovada a ação do tamanho do grão, conjutamente com a densidade inicial do solo para a mobilização de atrito.

Outro fator importante, já discutido nos itens anteriores, é a rugosidade da superfície de contato (Uesugi e Kishida, 1986a; Paikowsky et al,1995; Ghionna e Mortara, 2002; Fioravante, 2002; Porcino et al., 2003).

Nesta tese, partindo da hipótese de que a resistência devido ao rearranjo das partículas é ocasionada pelo atrito de rolamento, considera-se o coeficiente de rearranjo é igual ao raio da esfera.

Desse modo, comparando-se as Equações (2.49) e (2.55), tem-se que:

$r \frac{d \tau}{d u}=\eta \frac{d \tau}{d u}$

Ou simplesmente:

$\eta=r$

A aplicação direta desse conceito esbarra na determinação do raio característico de um solo, com uma distribuição granulométrica qualquer. De forma empírica, nessa tese propõe-se o uso do raio médio dos grãos $\frac{D_{50}}{2}$ corrigido pelo coeficiente de uniformidade $C_{u}$ e pela rugosidade da superfície $R_{n}$ para cálculo do raio característico. $r=\frac{D_{50}}{2} \cdot \frac{C_{u}}{R_{n}}$

Ao levar em conta a influência da superfície de contato e do estado em que o maciço de solos se encontra, propõe-se ainda que o coeficiente de rearranjo seja calculado como o raio característico dividido pela Densidade Relativa $(D R)$ do solo e pelo índice de rugosidade. Assim, a equação de cálculo do coeficiente de rearranjo $\eta$ é:

$\eta=\frac{D_{50}}{2} \frac{C_{u}}{D R \cdot R_{n}}$

$D_{50}$ é o diâmetro médio das partículas;

$D R$ é a densidade relativa do solo

$R_{n}$ é a rugosidade da superfície de contato (Equação 2.6)

$C_{u}$ é o coeficiente de uniformidade (Equação 2.7). 
4.3. Previsão do ângulo de atrito verdadeiro na interface $\delta$; módulo de dilatância $k$ e o coeficiente de rearranjo $\eta$.

Para a previsão das curvas tensão tangencial deslocamento versus deslocamento tangencial e variação de volume versus deslocamento tangencial é necessário que se faça o cálculo do ângulo de atrito verdadeiro na interface $\delta$; módulo de dilatância $k$ e o coeficiente de rearranjo $\eta$, considerando as propriedades das areias A1 e A2 e das superfícies de contato RU e SL.

O ângulo de atrito verdadeiro na interface $\delta$ foi calculado através da observação da Tabela 3.10, na qual percebe-se que o ângulo de atrito verdadeiro $\delta$ é aproximadamente igual à 0,75 do ângulo de atrito máximo do solo $\phi_{\text {pico }}$ para os casos onde a areia é mais compacta e 0,90 do ângulo de atrito máximo para os casos onde a areia se encontrava no estado menos compacto.

$\delta \cong 0,75 . \phi_{\text {pico }}$

ou

$\delta \cong 0,9 . \phi_{\max }$

Para a previsão do módulo de dilatância $k$ foi utilizada a Equação (4.7) onde as as propriedades de rugosidade e da curva granulométrica de cada solo são mostradas nas Tabelas 4.2 e 4.3. O modúlo de deformabilidade transversal $G$ foi calculado através do módulo de elasticidade oedométrico $E_{o e d}$, utilizando-se coeficiente de Poisson $v$ igual 0,3. O módulo de elasticidade oedométrico $E_{\text {oed }}$ foi obtido em função da tensão normal atuante na interface através dos ensaios oedométricos realizados nas areiais A1 e A2 e mostrados nas Figuras 3.15 e 3.16, respectivamente.

A previsão do coeficiente de rearranjo foi realizada usando a Equação (4.11) utilizando as propriedades de rugosidade da granulometria constantes nas Tabelas $4.2 \mathrm{e}$ 4.3 .

Um resumo dos valores ângulo de atrito verdadeiro na interface $\delta$; módulo de dilatância $k$ e o coeficiente de rearranjo $\eta$ é mostrado na Tabela 4.4. A comparação entre as curvas tensão tangencial deslocamento versus deslocamento tangencial e variação de volume versus deslocamento tangencial previstas e medidas é mostrada no ANEXO B.

A Figura 4.7 mostra a comparação entre os resultados do módulo de dilatância, obtidos a partir do ajuste dos resultados experimentais e os resultados calculados segundo a Equação 4.7. 


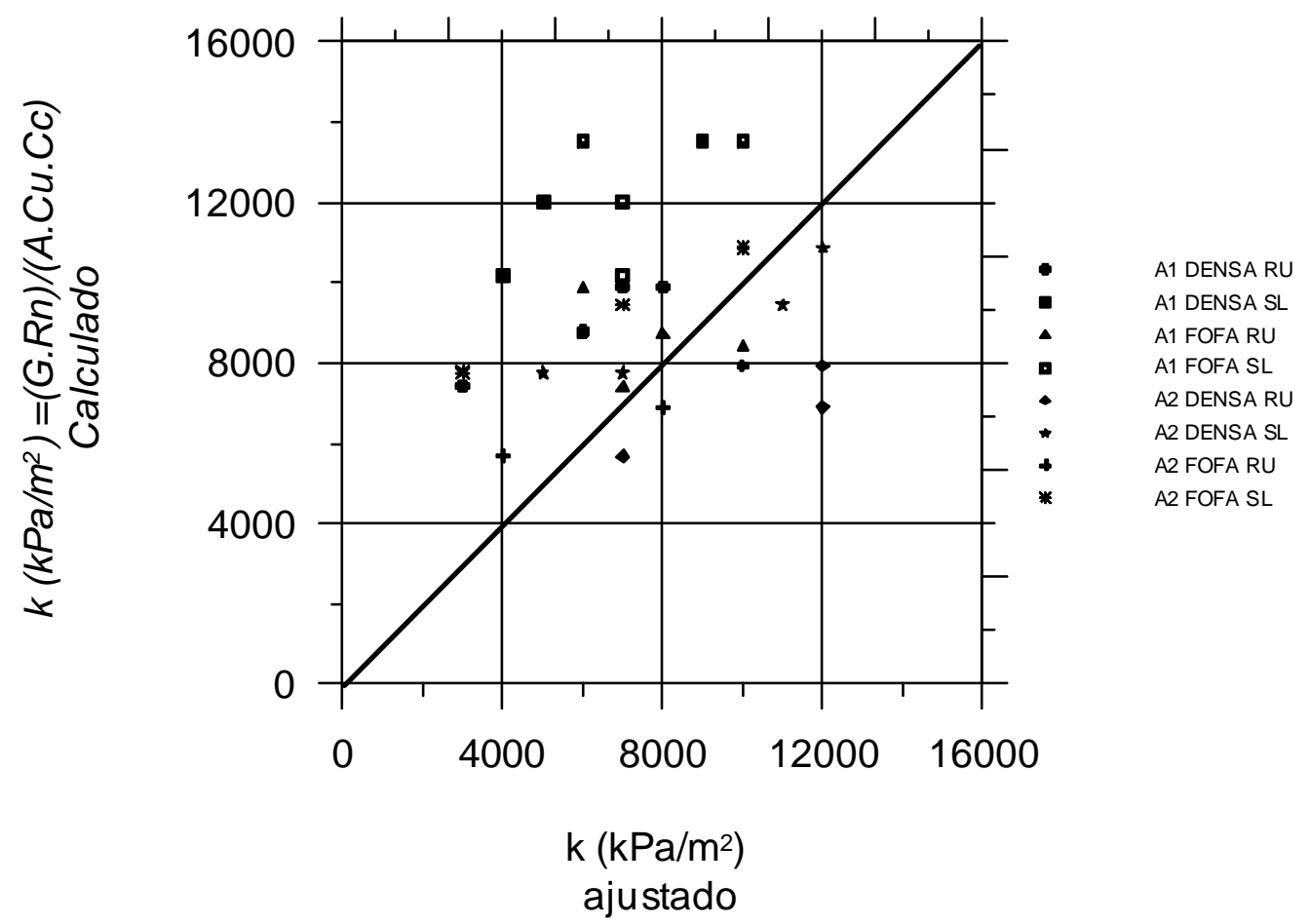

Figura 4.7 - Comparação entre o Módulo de Dilatância teórico e experimental

A Figura 4.8 mostra a comparação entre os resultados do coeficiente de rearranjo obtidos no ajuste das curvas tensão tangencial versus deslocamento tangencial e os resultados calculados pela Equação 4.11 .

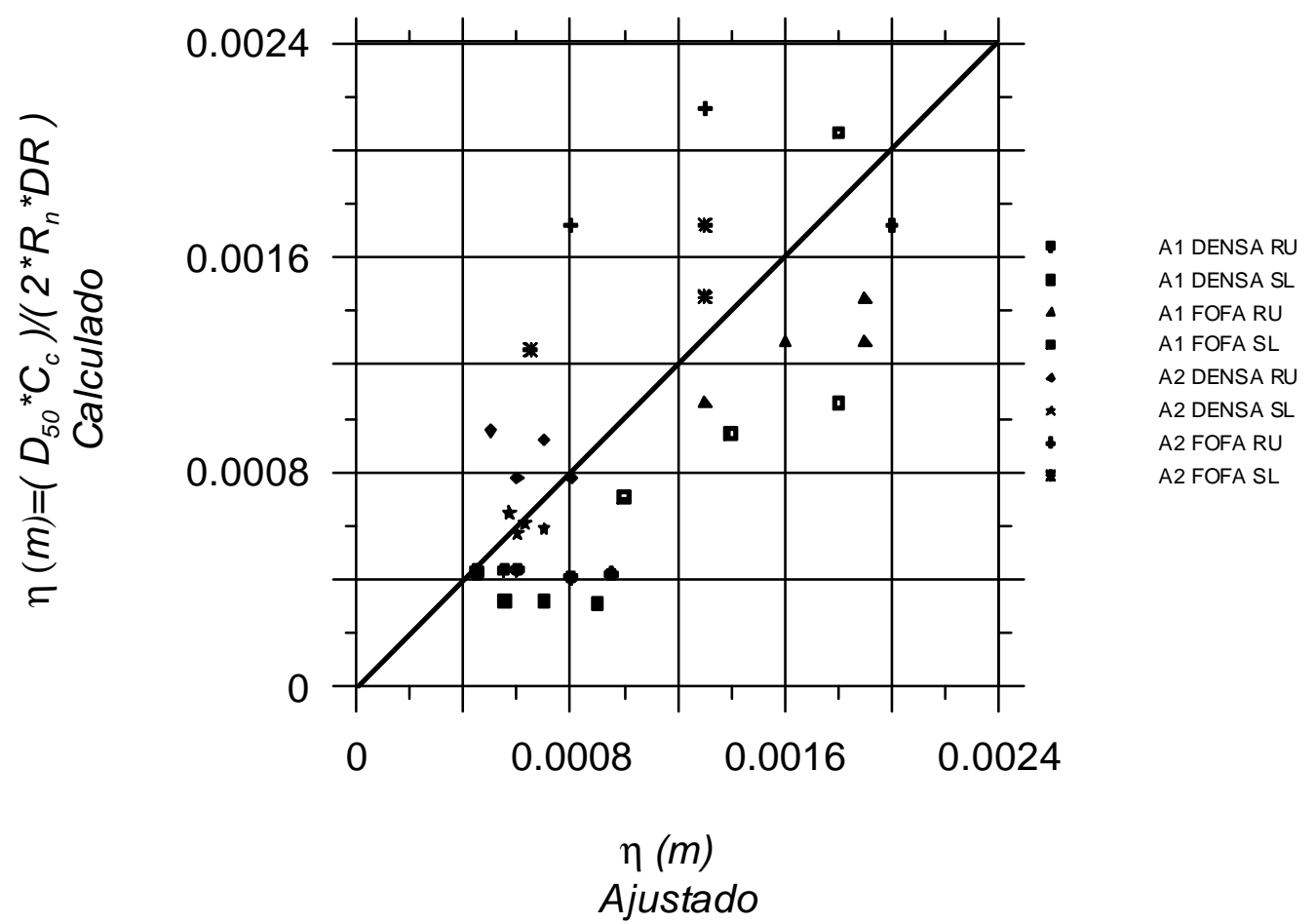

Figura 4.8 - Comparação entre o coeficiente de rearranjo teórico e experimental. 
Tabela 4.4 - Valores do ângulo de atrito verdadeiro na interface $\delta$; módulo de dilatância $k$ e o coeficiente de rearranjo $\eta$

\begin{tabular}{|c|c|c|c|c|c|c|c|c|c|c|c|c|c|c|c|c|c|c|c|c|}
\hline \multirow[b]{2}{*}{ ensaio } & \multirow{2}{*}{$\begin{array}{c}D_{10} \\
(\mathrm{~mm})\end{array}$} & \multirow{2}{*}{$\begin{array}{c}D_{30} \\
(\mathrm{~mm})\end{array}$} & \multirow{2}{*}{$\begin{array}{c}D_{50} \\
(\mathrm{~mm})\end{array}$} & \multirow{2}{*}{$\begin{array}{c}D_{60} \\
(\mathrm{~mm})\end{array}$} & \multirow[b]{2}{*}{$\mathrm{Cu}$} & \multirow[b]{2}{*}{$C c$} & \multirow{2}{*}{$\begin{array}{l}R_{\max } \\
(\mathrm{mm})\end{array}$} & \multirow{2}{*}{$\begin{array}{l}L_{\text {média }} \\
(\mathrm{mm})\end{array}$} & \multirow[b]{2}{*}{$R n$} & \multirow[b]{2}{*}{$\begin{array}{c}\sigma_{0} \\
(k P a)\end{array}$} & \multirow[b]{2}{*}{$e_{o}$} & \multirow[b]{2}{*}{$D R$} & \multirow[b]{2}{*}{$E_{\text {oed }}(\mathrm{kPa})$} & \multirow[b]{2}{*}{$G(k P a)$} & \multicolumn{3}{|c|}{ Medido } & \multicolumn{3}{|c|}{ Calculado } \\
\hline & & & & & & & & & & & & & & & $\begin{array}{c}\delta \\
\text { (Graus) }\end{array}$ & $\begin{array}{c}k \\
\left(k P a / m^{2}\right) \\
\end{array}$ & $\begin{array}{c}\eta \\
(m)\end{array}$ & $\begin{array}{c}\delta \\
\text { (Graus) }\end{array}$ & $\begin{array}{c}k \\
\left(\mathrm{kPa} / \mathrm{m}^{2}\right)\end{array}$ & $\prod_{(m)}$ \\
\hline & 0,1 & 0,15 & 0,19 & 0,2 & 2 & 1,125 & 21,36 & 83,55 & 0,256 & 145 & 0,49 & 1,0 & 57215 & 16347 & 30,6 & 3000 & 0,00045 & 31 & 7430 & 0,00044 \\
\hline & 0,1 & 0,15 & 0,19 & 0,2 & 2 & 1,125 & 21,36 & 83,55 & 0,256 & 145 & 0,48 & 1,0 & 57215 & 16347 & 30,6 & 3000 & 0,00045 & 31 & 7430 & 0,00042 \\
\hline & 0,1 & 0,15 & 0,19 & 0,2 & 2 & 1,125 & 21,36 & 83,55 & 0,256 & 225 & 0,49 & 1,0 & 67543 & 19298 & 30,2 & 6000 & 0,00060 & 31 & 8771 & 0,00044 \\
\hline & 0,1 & 0,15 & 0,19 & 0,2 & 2 & 1,125 & 21,36 & 83,55 & 0,256 & 225 & 0,49 & 1,0 & 67543 & 19298 & 30,6 & 6000 & 0,00055 & 31 & 8771 & 0,00044 \\
\hline & 0,1 & 0,15 & 0,19 & 0,2 & 2 & 1,125 & 21,36 & 83,55 & 0,256 & 325 & 0,47 & 1,0 & 76187 & 21768 & 30,0 & 7000 & 0,00080 & 31 & 9893 & 0,00041 \\
\hline & 0,1 & 0,15 & 0,19 & 0,2 & 2 & 1,125 & 21,36 & 83,55 & 0,256 & 325 & 0,48 & 1,0 & 76187 & 21768 & 30,5 & 8000 & 0,00095 & 31 & 9893 & 0,00042 \\
\hline & 0,1 & 0,15 & 0,19 & 0,2 & 2 & 1,125 & 0,028 & 0,08 & 0,350 & 145 & 0,49 & 1,0 & 57215 & 16347 & 30,0 & 4000 & 0,00055 & 31 & 10172 & 0,00032 \\
\hline & 0,1 & 0,15 & 0,19 & 0,2 & 2 & 1,125 & 0,028 & 0,08 & 0,350 & 225 & 0,49 & 1,0 & 67543 & 19298 & 29,0 & 5000 & 0,00070 & 31 & 12008 & 0,00032 \\
\hline & 0,1 & 0,15 & 0,19 & 0,2 & 2 & 1,125 & 0,028 & 0,08 & 0,350 & 325 & 0,48 & 1,0 & 76187 & 21768 & 28,8 & 9000 & 0,00090 & 31 & 13544 & 0,00031 \\
\hline & 0,1 & 0,15 & 0,19 & 0,2 & 2 & 1,125 & 21,36 & 83,55 & 0,256 & 145 & 0,68 & 0,3 & 57215 & 16347 & 26,0 & 7000 & 0,00190 & 27 & 7430 & 0,00145 \\
\hline & 0,1 & 0,15 & 0,19 & 0,2 & 2 & 1,125 & 21,36 & 83,55 & 0,256 & 225 & 0,65 & 0,4 & 67543 & 19298 & 31,0 & 8000 & 0,00130 & 27 & 8771 & 0,00106 \\
\hline & 0,1 & 0,15 & 0,19 & 0,2 & 2 & 1,125 & 21,36 & 83,55 & 0,256 & 201 & 0,67 & 0,3 & 64892 & 18541 & 28,0 & 10000 & 0,00160 & 27 & 8427 & 0,00129 \\
\hline & 0,1 & 0,15 & 0,19 & 0,2 & 2 & 1,125 & 21,36 & 83,55 & 0,256 & 325 & 0,67 & 0,3 & 76187 & 21768 & 28,7 & 6000 & 0,00190 & 27 & 9893 & 0,00129 \\
\hline & 0,1 & 0,15 & 0,19 & 0,2 & 2 & 1,125 & 0,028 & 0,08 & 0,350 & 145 & 0,68 & 0,3 & 57215 & 16347 & 30,0 & 7000 & 0,00180 & 27 & 10172 & 0,00106 \\
\hline & 0,1 & 0,15 & 0,19 & 0,2 & 2 & 1,125 & 0,028 & 0,08 & 0,350 & 225 & 0,67 & 0,3 & 67543 & 19298 & 29,0 & 7000 & 0,00140 & 27 & 12008 & 0,00094 \\
\hline & 0,1 & 0,15 & 0,19 & 0,2 & 2 & 1,125 & 0,028 & 0,08 & 0,350 & 325 & 0,72 & 0,1 & 76187 & 21768 & 29,0 & 6000 & 0,00180 & 27 & 13544 & 0,00207 \\
\hline & 0,1 & 0,15 & 0,19 & 0,2 & 2 & 1,125 & 0,028 & 0,08 & 0,350 & 325 & 0,64 & 0,4 & 76187 & 21768 & 28,5 & 10000 & 0,00100 & 27 & 13544 & 0,00071 \\
\hline & 0,15 & 0,28 & 0,42 & 0,51 & 3,4 & 1,025 & 21,36 & 83,55 & 0,256 & 145 & 0,55 & 0,9 & 67622 & 19321 & 28,0 & 7000 & 0,00050 & 34 & 5670 & 0,00095 \\
\hline & 0,15 & 0,28 & 0,42 & 0,51 & 3,4 & 1,025 & 21,36 & 83,55 & 0,256 & 225 & 0,54 & 0,9 & 82344 & 23527 & 30,0 & 12000 & 0,00070 & 34 & 6905 & 0,00092 \\
\hline & 0,15 & 0,28 & 0,42 & 0,51 & 3,4 & 1,025 & 21,36 & 83,55 & 0,256 & 325 & 0,49 & 1,1 & 94666 & 27047 & 32,0 & 12000 & 0,00060 & 34 & 7938 & 0,00078 \\
\hline & 0,15 & 0,28 & 0,42 & 0,51 & 3,4 & 1,025 & 21,36 & 83,55 & 0,256 & 325 & 0,49 & 1,1 & 94666 & 27047 & 30,0 & 12000 & 0,00080 & 34 & 7938 & 0,00078 \\
\hline & 0,15 & 0,28 & 0,42 & 0,51 & 3,4 & 1,025 & 0,028 & 0,08 & 0,350 & 145 & 0,49 & 1,1 & 67622 & 19321 & 29,0 & 5000 & 0,00060 & 34 & $\begin{array}{l}7763 \\
\end{array}$ & 0,00057 \\
\hline & 0,15 & 0,28 & 0,42 & 0,51 & 3,4 & 1,025 & 0,028 & 0,08 & 0,350 & 145 & 0,53 & 0,9 & 67622 & 19321 & 29,0 & 7000 & 0,00057 & 34 & 7763 & 0,00065 \\
\hline & 0,15 & 0,28 & 0,42 & 0,51 & 3,4 & 1,025 & 0,028 & 0,08 & 0,350 & 225 & 0,51 & 1,0 & 82344 & 23527 & 27,0 & 11000 & 0,00063 & 34 & 9453 & 0,00061 \\
\hline & 0,15 & 0,28 & 0,42 & 0,51 & 3,4 & 1,025 & 0,028 & 0,08 & 0,350 & 325 & 0,50 & 1,0 & 94666 & 27047 & 27,5 & 12000 & 0,00070 & 34 & 10867 & 0,00059 \\
\hline & 0,15 & 0,28 & 0,42 & 0,51 & 3,4 & 1,025 & 21,36 & 83,55 & 0,256 & 145 & 0,67 & 0,5 & 67622 & 19321 & 27,5 & 4000 & 0,00080 & 24 & 5670 & 0,00172 \\
\hline & 0,15 & 0,28 & 0,42 & 0,51 & 3,4 & 1,025 & 21,36 & 83,55 & 0,256 & 225 & 0,70 & 0,4 & 82344 & 23527 & 32,5 & 8000 & 0,00130 & 24 & 6905 & 0,00215 \\
\hline & 0,15 & 0,28 & 0,42 & 0,51 & 3,4 & 1,025 & 21,36 & 83,55 & 0,256 & 325 & 0,67 & 0,5 & 94666 & 27047 & 30,5 & 10000 & 0,00200 & 24 & 7938 & 0,00172 \\
\hline & 0,15 & 0,28 & 0,42 & 0,51 & 3,4 & 1,025 & 0,028 & 0,08 & 0,350 & 145 & 0,67 & 0,5 & 67622 & 19321 & 30,1 & 3000 & 0,00065 & 24 & 7763 & 0,00126 \\
\hline & 0,15 & 0,28 & 0,42 & 0,51 & 3,4 & 1,025 & 0,028 & 0,08 & 0,350 & 225 & 0,71 & 0,4 & 82344 & 23527 & 28,0 & 7000 & 0,00130 & 24 & 9453 & 0,00172 \\
\hline & 0,15 & 0,28 & 0,42 & 0,51 & 3,4 & 1,025 & 0,028 & 0,08 & 0,350 & 325 & 0,69 & 0,4 & 94669 & 27048 & 28,5 & 10000 & 0,00130 & 24 & 10868 & 0,00145 \\
\hline
\end{tabular}




\section{CAPÍTULO $\mathrm{V}$ \\ INTERAÇÃO SOLO-ESTRUTURA}

Muitos dos problemas geotécnicos envolvem a compatibilização de deslocamentos entre estruturas e o maciço de solos. O correto entendimento desses deslocamentos é fundamental para análises e projetos de estruturas com fundações em solos ou rocha mais realistas e com aproximações aceitáveis dentro da engenharia.

Dentro desse contexto, o método dos elementos finitos tem sido largamente utilizado nas previsões de obras geotécnicas, sejam elas submetidas a cargas estáticas ou dinâmicas.

Em grande parte dos problemas e carregamentos não ocorre deslizamento ou descolamento entre a estrutura e o solo, de modo que é perfeitamente aceitável que se considerem essas duas partes como um meio contínuo com os pontos pertencentes a interface, apresentando os mesmos deslocamentos.

No entanto, em casos como o de juntas de maciços rochosos, e fundações em estacas ou de muros de solo reforçado, onde a mobilização de resistência e a distribuição de tensões dependem fundamentalmente do deslizamento entre a estrutura e solo, é necessário que se utilizem elementos especiais para representar esse deslizamento. Esses elementos são chamados de maneira geral de elementos de interface e, em casos particulares, de elementos de junta.

Quando se trabalha com um elemento de interface é necessário que se tenha em mente que o seu estudo compreende duas partes distintas: a formulação do elemento em si e a formulação do comportamento constitutivo da interface. Assim, um mesmo elemento de interface pode ter vários comportamentos constitutivos ou, uma mesma lei constitutiva, pode ser utilizada em diversos elementos de interface. 
5.1. Revisão bibliográfica sobre elementos de interface

A modelagem de interfaces geralmente é feita com o uso do método dos elementos finitos. Diversas pesquisas na área de interação solo-estrutura em interfaces procuram desenvolver elementos de interface que melhor representem fisicamente um determinado problema quando submetido a uma determinada condição de carregamento.

Na literatura, encontram-se diversos trabalhos demonstrando uma evolução na utilização de elementos de interface.

Os elementos de interfaces foram introduzidos por Goodman et al. (1968) para análise numérica via elementos finitos de juntas de maciços rochosos. Esse elemento de interface teve sua utilização posteriormente estendida para análise de interação soloestrutura em interfaces de muros de contenção por Clough e Duncan (1971).

O elemento de interface de Goodman et al. (1968) recebe o nome de elemento de junta. Esse elemento, que possui espessura nula, é formado por quatro pontos nodais, com deslocamentos na direção normal e tangencial à direção da interface (Figura 5.1). O comprimento do elemento é L e os nós 1,4 e 2,3 possuem inicialmente as mesmas coordenadas e, como mostra a Figura 5.1, a origem do sistema de coordenadas situa-se no centro do elemento.

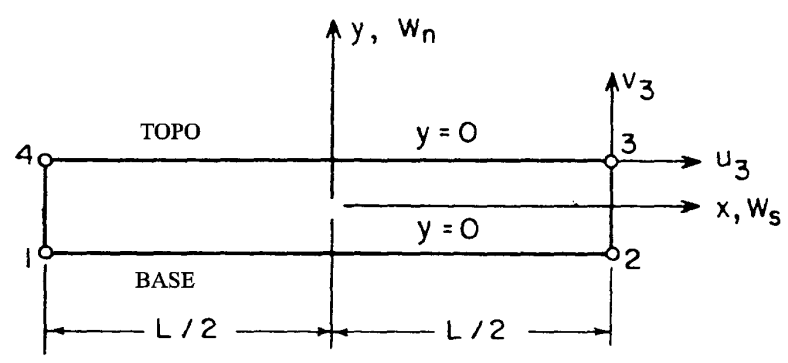

Figura 5.1 - Elemento de junta em coordenadas locais (Goodman et al. 1968)

Sua relação constitutiva consiste em uma lei linear, com valores constantes de rigidez ao cisalhamento e para a rigidez normal.

$$
\begin{gathered}
\sigma=k_{N} v \\
\tau=k_{T} u
\end{gathered}
$$

Sua equação constitutiva torna-se então:

$$
\left\{\begin{array}{l}
\tau \\
\sigma
\end{array}\right\}=\left[\begin{array}{cc}
k_{T} & 0 \\
0 & k_{N}
\end{array}\right] \cdot\left\{\begin{array}{l}
u \\
v
\end{array}\right\}
$$

Onde $k_{N}$ é a rigidez normal da interface; $v$ é o deslocamento normal na interface; $\sigma$ é a tensão normal atuante na interface; $k_{T}$ é a rigidez cisalhante da interface; $u$ é o deslocamento tangencial na interface; $\tau$ é a tensão tangencial atuante na interface. 
A variação dos deslocamentos na junta é considerada como linear. Dessa forma, os deslocamentos da base são:

$$
\left\{\begin{array}{l}
u_{B A S E} \\
v_{B A S E}
\end{array}\right\}=\frac{1}{2}\left[\begin{array}{cccc}
1-\frac{2 x}{L} & 0 & 1+\frac{2 x}{L} & 0 \\
0 & 1-\frac{2 x}{L} & 1+\frac{2 x}{L}
\end{array}\right]\left\{\begin{array}{l}
u_{1} \\
v_{1} \\
u_{2} \\
v_{2}
\end{array}\right\}
$$

e os deslocamentos do topo são:

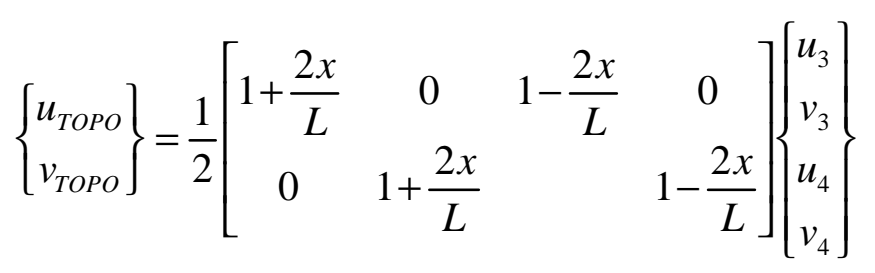

Os deslocamentos relativos no elemento de junta são:

$$
\left\{\begin{array}{l}
u \\
v
\end{array}\right\}=\left\{\begin{array}{l}
u_{T O P O}-u_{B A S E} \\
v_{T O P O}-v_{B A S E}
\end{array}\right\}
$$

Desse modo:

$$
\left\{\begin{array}{l}
u_{T O P O}-u_{B A S E} \\
v_{T O P O}-v_{B A S E}
\end{array}\right\}=-\frac{1}{2}\left[\begin{array}{cccccccc}
-A & 0 & B & 0 & B & 0 & A & 0 \\
0 & -A & 0 & -B & 0 & B & 0 & A
\end{array}\right] \cdot\left\{\begin{array}{l}
u_{1} \\
v_{1} \\
u_{2} \\
v_{2} \\
u_{3} \\
v_{3} \\
u_{4} \\
v_{4}
\end{array}\right\}
$$

Onde:

$$
\begin{aligned}
& A=1-\frac{2 x}{L} \\
& B=1+\frac{2 x}{L}
\end{aligned}
$$

Considerando o comportamento mecânico linear (Figura 5.2) calculado pela Equação (5.3), a matriz de rigidez local do elemento de junta de Goodman et al. (1968) é: 


$$
K=\frac{1}{6}\left[\begin{array}{cccccccc}
2 k_{T} & 0 & k_{T} & 0 & -k_{T} & 0 & -2 k_{T} & 0 \\
0 & 2 k_{N} & 0 & k_{N} & 0 & -k_{N} & 0 & -2 k_{N} \\
k_{T} & 0 & 2 k_{T} & 0 & -2 k_{T} & 0 & -k_{T} & 0 \\
0 & k_{N} & 0 & 2 k_{N} & 0 & -2 k_{N} & 0 & -k_{N} \\
-k_{T} & 0 & -2 k_{T} & 0 & 2 k_{T} & 0 & k_{T} & 0 \\
0 & -k_{N} & 0 & -2 k_{N} & 0 & 2 k_{N} & 0 & k_{N} \\
-2 k_{T} & 0 & -k_{T} & 0 & k_{T} & 0 & 2 k_{T} & 0 \\
0 & -2 k_{N} & 0 & -k_{N} & 0 & k_{N} & 0 & 2 k_{N}
\end{array}\right]
$$

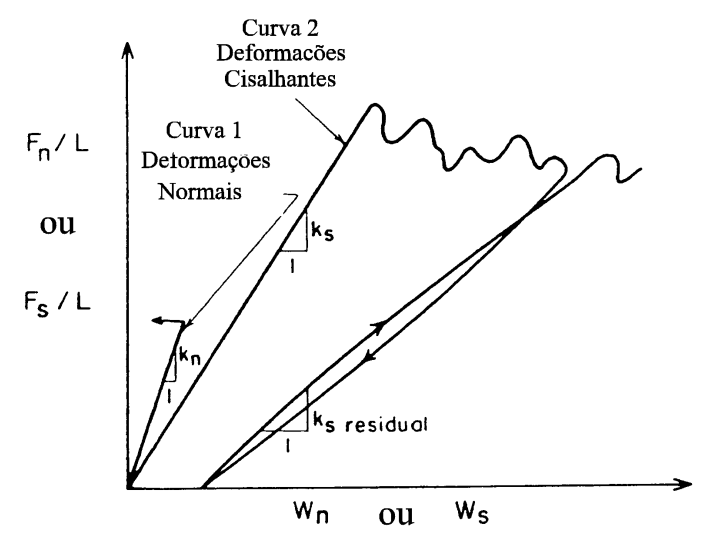

Figura 5.2 - Modelo hipotético de comportamento mecânico em uma junta (Goodman et al., 1968).

Nessa formulação, não é considerada a relação entre os deslocamentos tangenciais e os deslocamentos normais na interface.

A primeira modificação nesse tipo de elemento foi realizada por Goodman (1976), quando introduziu no elemento, além dos deslocamentos longitudinais e transversais na junta, deformações de rotação (Figura 5.3).

Nessa formulação, Goodman (1977) define o vertor de deslocamentos relativos do centro da junta, como:

$\left\{\varepsilon^{T}\right\}=\left[\begin{array}{lll}\Delta u_{o} & \Delta v_{o} & \omega_{o}\end{array}\right]$

Esses deslocamentos podem ser relacionados com os deslocamentos nodais por:

$\left\{\begin{array}{l}\Delta u_{o} \\ \Delta v_{o} \\ \Delta \omega_{o}\end{array}\right\}=-\left[\begin{array}{cccccccc}-\frac{1}{2} & 0 & -\frac{1}{2} & 0 & \frac{1}{2} & 0 & \frac{1}{2} & 0 \\ 0 & -\frac{1}{2} & 0 & -\frac{1}{2} & 0 & -\frac{1}{2} & 0 & -\frac{1}{2} \\ 0 & \frac{1}{L} & 0 & -\frac{1}{L} & 0 & \frac{1}{L} & 0 & -\frac{1}{L}\end{array}\right] \cdot\left\{\begin{array}{l}u_{1} \\ v_{1} \\ u_{2} \\ v_{2} \\ u_{3} \\ v_{3} \\ u_{4} \\ v_{4}\end{array}\right\}$ 


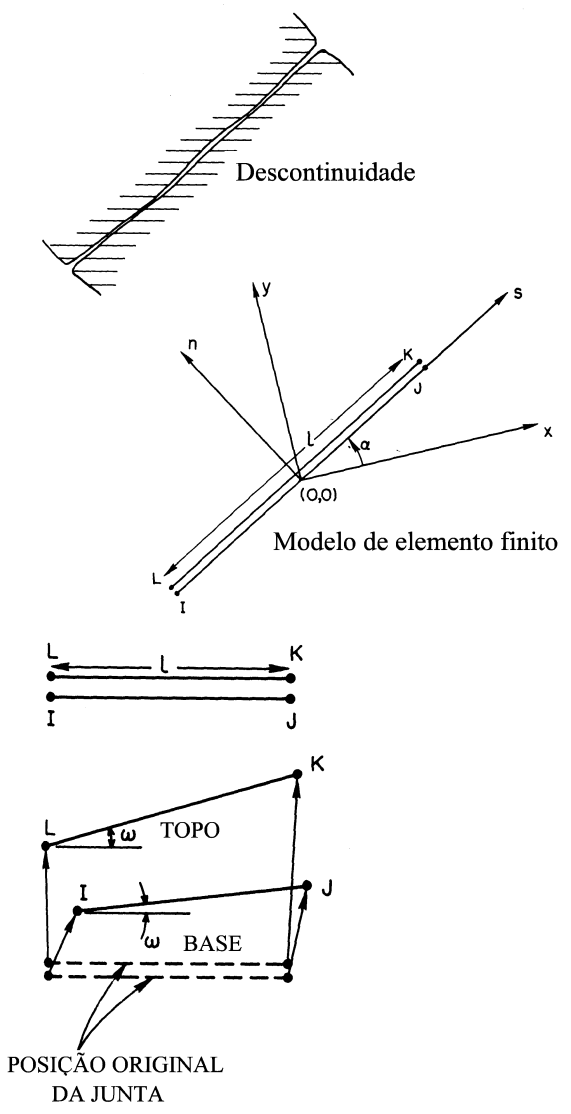

Figura 5.3 - Elemento de junta com rotação (Goodman, 1977)

A equação constitutiva desse elemento é:

$$
\left\{\begin{array}{l}
\tau \\
\sigma \\
M o
\end{array}\right\}=\left[\begin{array}{ccc}
k_{T} & 0 & 0 \\
0 & k_{N} & 0 \\
0 & 0 & k_{\omega}
\end{array}\right] \cdot\left\{\begin{array}{l}
\Delta u \\
\Delta v \\
\Delta \omega
\end{array}\right\}
$$

Onde $\tau$ é a tensão tangencial na interface; $\sigma$ é a tensão normal na interface; $M o$ é o momento em torno do centro da interface; $k_{T}$ é a rigidez ao cisalhamento na interface; $k_{N}$ é a rigidez normal na interface.

A rigidez de rotação é avaliada em função do movimento de rotação da junta devido a uma força aplicada no nó 4 (Figura 5.1), enquanto os nós 1 e 2 são fixos. Para isto, considera-se que os deslocamentos possuem variação linear ao longo da junta, Figura 5.4.

\section{Considerando-se que}

$k_{\omega}=\frac{k_{n} \cdot L^{3}}{4}$

A matriz de rigidez do elemento em coordenadas locais torna-se: 


$$
K=\frac{1}{4}\left[\begin{array}{cccccccc}
k_{T} & 0 & k_{T} & 0 & -k_{T} & 0 & -k_{T} & 0 \\
0 & 2 k_{N} & 0 & 0 & 0 & 0 & 0 & -2 k_{N} \\
k_{T} & 0 & k_{T} & 0 & -k_{T} & 0 & -k_{T} & 0 \\
0 & 0 & 0 & 2 k_{N} & 0 & -2 k_{N} & 0 & 0 \\
-k_{T} & 0 & -k_{T} & 0 & k_{T} & 0 & k_{T} & 0 \\
0 & 0 & 0 & -2 k_{N} & 0 & 2 k_{N} & 0 & 0 \\
-k_{T} & 0 & -k_{T} & 0 & k_{T} & 0 & k_{T} & 0 \\
0 & -2 k_{N} & 0 & 0 & 0 & 0 & 0 & 2 k_{N}
\end{array}\right]
$$

Outra mudança significativa foi introduzida por Desai (1981), ao deduzir a matriz de rigidez de um elemento de interface tridimensional.

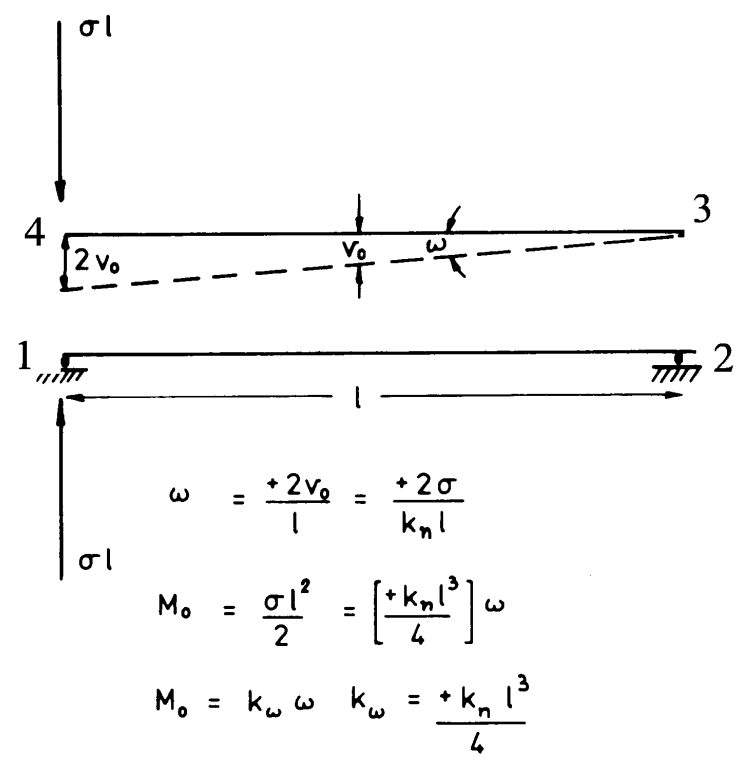

Figura 5.4 - Determinação da rigidez rotacional (Goodman, 1977)

Wilson (1977) desenvolveu um elemento de interface bidimensional considerando a espessura da junta ou interface. Essa mudança foi uma das mais significativas, por proporcionar à junta comportamento de corpo sólido, o qual está passível de sofrer deformações (Figura 5.5).

Garrido et al. (1994) discutem a aplicação de um procedimento incremental para solução de problemas tridimensionais com interfaces de atrito. A rigidez da interface é considerada linear, no entanto o critério de ruptura de Morh-Coulomb é utilizado para definir a ocorrência ou não do deslizamento.

Baseados no conceito de interface de espessura nula, Bouzid et al. (2004) apresentam uma formulação para um elemento de interface para problemas axissimétricos. A formulação é apresentada para sólidos de revolução submetidos a carregamentos não simétricos com carregamento. O comportameno mecânico da interface é considerado linear com seus coeficie ntes de rigidez na direção normal e na direção tangencial, calculados em função do módulo de deformabilidade transversal e do coeficiente de Poisson. 


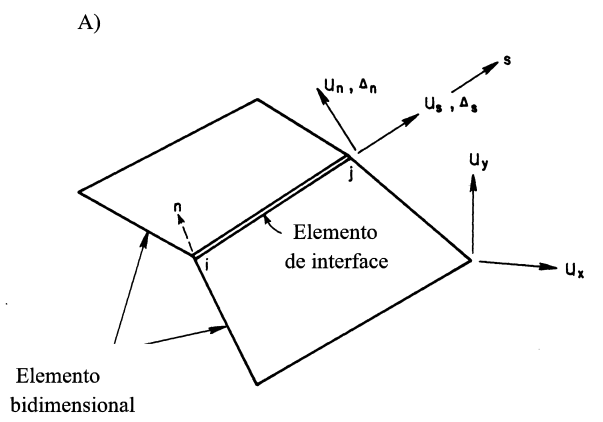

C)

$$
\begin{aligned}
& u_{n i}^{T}=u_{n i}+\Delta_{n i} \\
& u_{s i}^{T}=u_{s i}+\Delta_{s i} \\
& u_{n j}^{T}=u_{n j}+\Delta_{n j} \\
& u_{j i}^{T}=u_{s i}+\Delta_{s j} \\
& \varepsilon_{s s}=\frac{u_{s j}-u_{s i}}{L} \\
& \varepsilon_{n n}=\frac{1}{h}\left[\Delta_{n i}+\frac{s}{L}\left(\Delta_{n j}-\Delta_{n i}\right)\right] \\
& \varepsilon_{n s}=\frac{1}{h}\left[\Delta_{s i}+\frac{s}{L}\left(\Delta_{s j}-\Delta_{s i}\right]+\frac{1}{L}\left(u_{n j}-u_{n i}\right)\right.
\end{aligned}
$$

B)

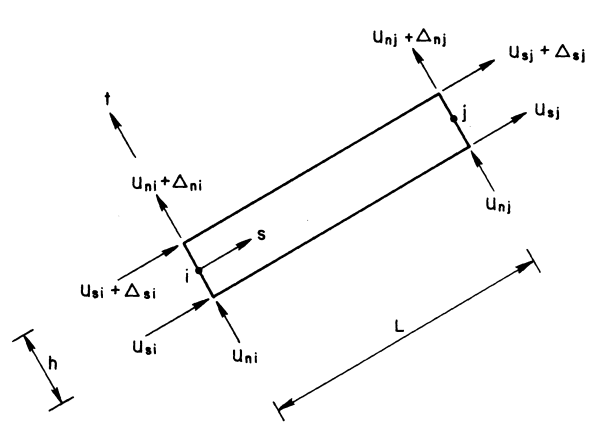

D)

$\left\{\begin{array}{l}\varepsilon_{s s} \\ \varepsilon_{n n} \\ \varepsilon_{n s}\end{array}\right\}=(1 / h)\left[\begin{array}{llllllll}(h / L) & (h / L) & 0 & 0 & 0 & 0 & 0 & 0 \\ 0 & 0 & 0 & 0 & 1-(s / L) & (s / L) & 0 & 0 \\ 0 & 0 & -(h / L) & (h / L) & 0 & 0 & 1-(s / L) & (s / L)\end{array}\right]\left\{\begin{array}{l}u_{s i} \\ u_{s j} \\ u_{n i} \\ u_{n j} \\ \Delta_{n i} \\ \Delta_{n j} \\ \Delta_{s i} \\ \Delta_{s j}\end{array}\right\}$

Figura 5.5 - Formulação de elemento de interface considerando a espessura da junta (Wilson, 1977): A) elemento bidimensional; B) elemento de interface e seus deslocamentos nodais correspondentes; C) deslocamentos nodais da banda superior e deformações do elemento; D) deformações do elemento em função dos deslocamentos nodais.

\subsection{Modelos constitutivos utilizados em elementos de interfaces}

A maior parte dos programas que utilizam elementos de interface difere entre si pelo modelo constitutivo. Esses modelos constitutivos se classificam em dois tipos básicos, os lineares e os não lineares. Os modelos lineares consideram constantes os coeficientes de rigidez aos deslocamentos normais e tangenciais, limitando a uma faixa de valores de acordo com um critério de ruptura. Já os modelos não lineares adotam uma função matemática de alto grau qualquer para cálculo dos coeficientes de rigidez, de forma a representar uma relação constitutiva da interface; assim a tensão cisalhante e a tensão normal são obtidas em função dos deslocamentos tangenciais e normais.

O comportamento mecânico na interface solo-estrutura depende da composição entre tensões cisalhantes e tensões normais ( $\mathrm{Ng}$ et al. 1997). O comportamento tensãodeformação no contato é geralmente considerado elástico linear para a tensão normal e elasto-perfeitamente plástico para a tensão de cisalhamento (Figura 5.6). 

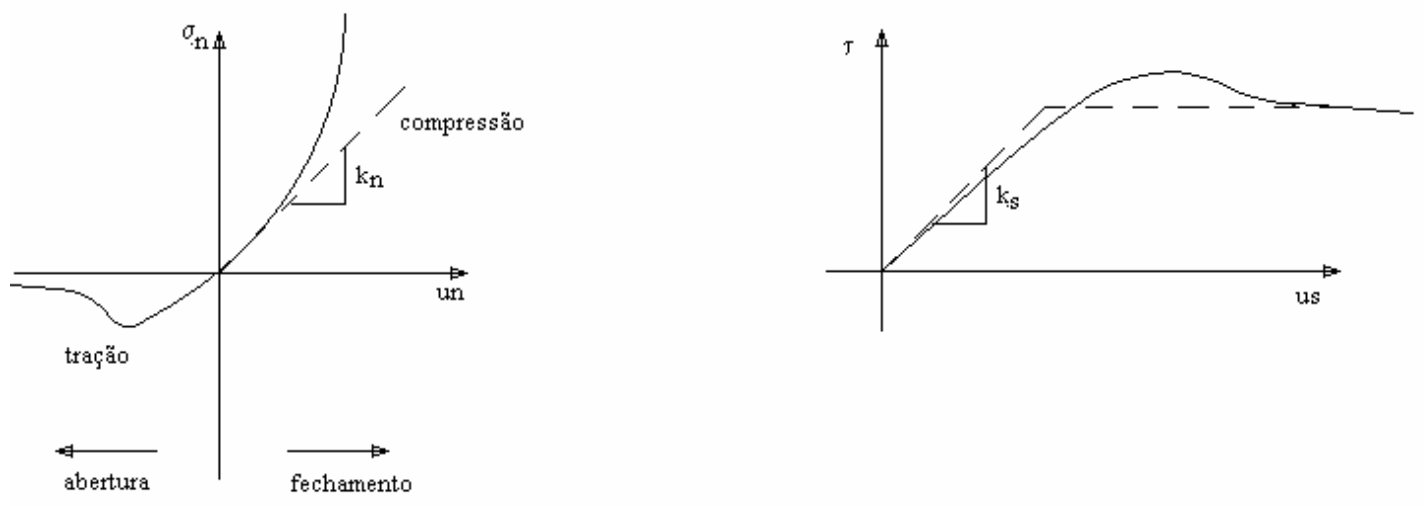

Figura 5.6 - relações tensão-deslocamento em interface solo-estrutura (Desai e Nagaraj, 1988): (a) tensões normais; (b) tensões cisalhantes.

$\mathrm{Ng}$ et al. (1997) desenvolveram um modelo constitutivo para elementos de interface, com comportamento dividido em:

1. Sem deslizamento: o comportamento é elástico linear tanto para rigidez norma $\mathrm{k}_{\mathrm{n}}$, quanto para a de cisalhamento $\mathrm{k}_{\mathrm{s}}$.

2. Deslizamento: a resistência ao cisalhamento é governada pelo critério de MohrCoulomb, onde para grandes deslocamentos a tensão cisalhante atinge um valor máximo, ocorrendo deslizamento. Para valores abaixo desse limite, a compressibilidade é governada pela rigidez $\mathrm{k}_{\mathrm{s}}$.

3. Descarregamento: descarregamento, a resistência ao cisalhamento é restaurada.

4. Separação: na tração normal, ocorre separação entre as partes.

5. recuperação: se durante o deslizamento ocorrer uma separação, pode ocorrer a recuperação do contato; caso se inverta o valor da tensão normal, restaura-se a rigidez normal e cisalhante.

A Figura 5.7 mostra esquematicamente os modelos de deformações possíveis de acontecer segundo o modelo de $\mathrm{Ng}$ et al. (1997).

A grande vantagem dessa abordagem é que os modelos são lineares, de modo que sua solução é obtida a partir das equações de equilíbrio e do critério de ruptura, no caso, o de Mohr-Coulomb, para resistência ao cisalhamento.

$F_{T} \leq c . A+F_{N} \tan \delta$

O segundo critério é de resistência à tração

$F_{N} \geq r_{t} A$

Onde: $r_{t}$ é uma resistência à tração (propriedade do tipo de material que para solos é considerada zero).

Um terceiro critério necessário é o de abertura da fenda:

$v_{1}-v_{2} \leq e$ 
Onde $\boldsymbol{e}$ é a abertura inicial do contato.

As relações entre forças e deslocamentos no contato podem ser estabelecidas independentemente do modelo de solução a ser empregado no sistema. Basicamente são duas relações: uma com relação à rigidez tangencial e outra com relação à rigidez normal (Figura 5.8).

Para sistemas trabalhando na região do primeiro critério, tem-se:

$k_{T} \neq 0 \quad e \quad k_{N} \neq 0$

Para casos de separação:

$k_{T}=0 \quad e \quad k_{N}=0$

Clough e Duncan (1971) desenvolveram um modelo constitutivo não linear para interfaces baseado numa função hiperbólica para representar o comportamento tensão cisalhante versus deslocamento tangencial, onde a rigidez ao cisalhamento é obtida pela função:

$k_{s t}=k_{s i} \cdot\left(1-\frac{R_{f} \tau}{\sigma_{n} \operatorname{tg} \delta}\right)^{2}$

Onde:

$k_{s i}=K_{I} \gamma_{w}\left(\frac{\sigma_{n}}{p_{a}}\right)^{n_{j}}$

Desse modo, a rigidez tangente é:

$k_{s t}=K_{I} \gamma_{w}\left(\frac{\sigma_{n}}{p_{a}}\right)^{n_{j}} \cdot\left(1-\frac{R_{f} \tau}{\sigma_{n} t g \delta}\right)^{2}$

Sendo $k_{s i}$ a rigidez inicial da interface; $K_{I}$ um número de rigidez adimensional (definido em função do ajuste da curva); $n_{j}$ um expoente de rigidez adimensional (definido em função do ajuste da curva); $R_{f}$ a razão de ruptura; $\sigma_{n}$ a tensão normal atuante na interface; $\delta$ o ângulo de atrito máximo mobilizado na interface; $\Delta u$ é o deslocamento tangencial a interface.

Desai (1981) utilizou o modelo não linear hiperbólico para análise de estacas via elementos finitos onde a rigidez ao cisalhamento tangente é:

$k_{s t}=k_{s i}\left(1-\lambda_{2}\right)^{2}$

Onde a $k_{s i}$ é obtido pela Equação (5.23) e

$$
\lambda_{2}=\frac{R_{f} \tau}{\sigma_{n} \operatorname{tg} \delta+c}
$$



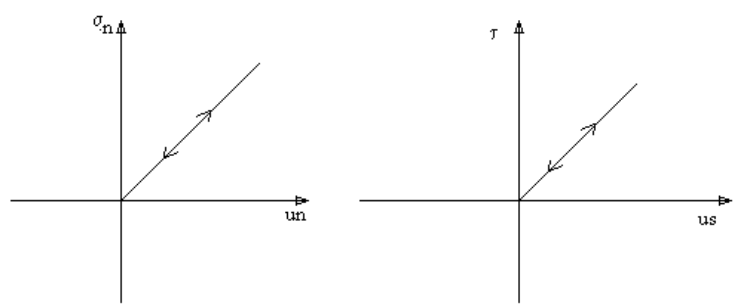

sem deslizamento
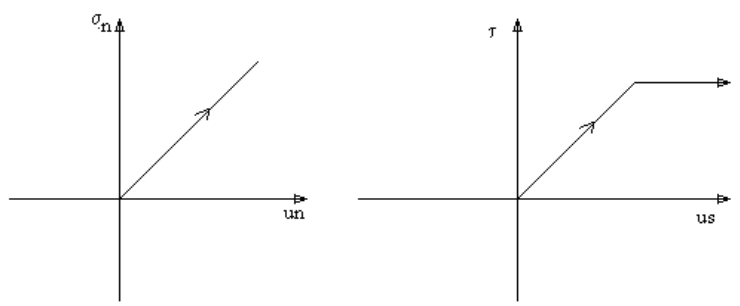

deslizamento
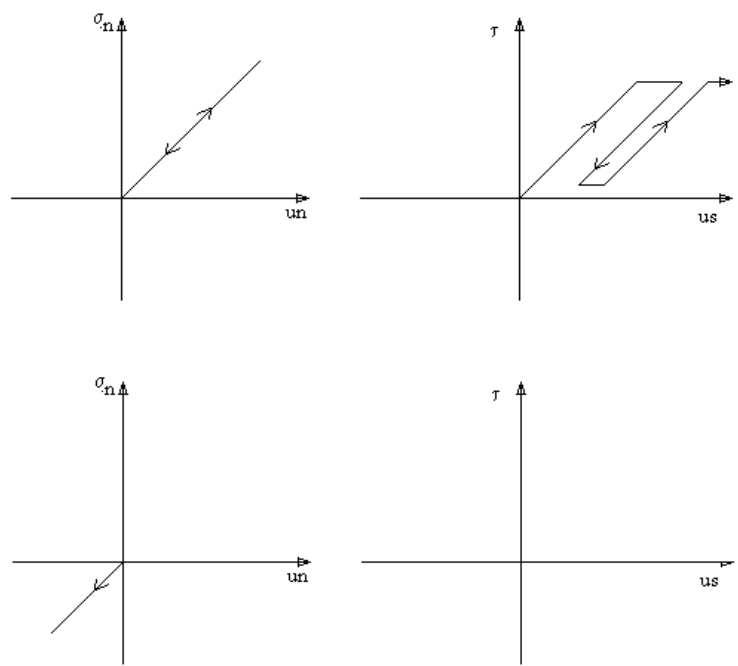

separação
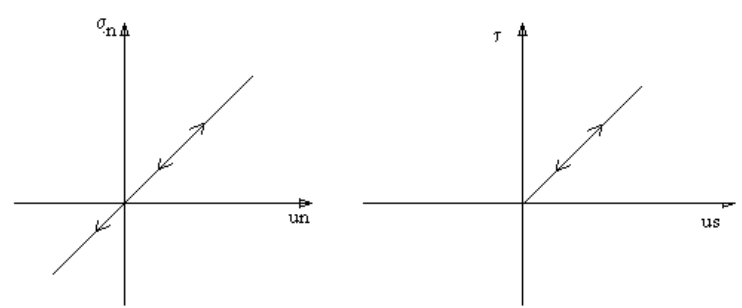

recuperą̧ão

Figura 5.7 - Modos de deformação na interface (Ng et al. 1997)
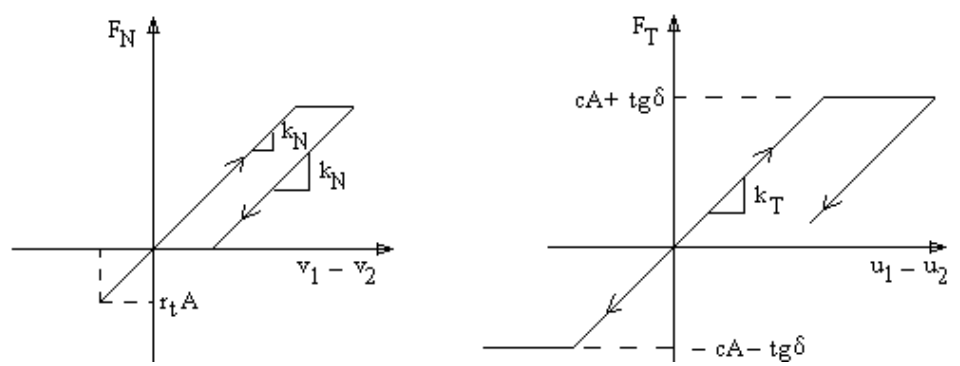

Figura 5.8 - Modelo de comportamento mecânico na interface (Frank et al., 1982) 
Em análise de resultados de ensaios de campo, Desai (1981) sugere ainda que o coeficiente de rigidez normal seja adotado arbitrariamente a partir do melhor ajuste dos resultados de campo.

Em casos onde ocorrem picos de resistência e posterior decaimento para um patarmar residual (softening behaviour) (Figura 5.9), Desai (1981), sugere o uso da equação:

$$
k_{s t}=\alpha_{p} k_{s i}-\frac{\alpha_{p} k_{i}-\alpha_{r} k_{i}}{u_{p}-u_{r}}\left(u-u_{r}\right)
$$

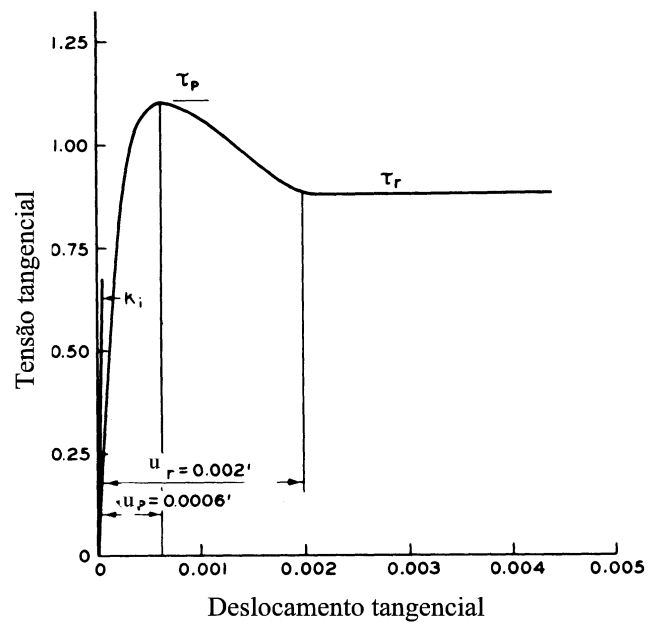

Figura 5.9 - Curva tensão versus deslocamento para "softening behaviour" (Desai, 1977).

Goodman (1976) também apresenta um modelo não linear para o comportamento de juntas de maciços rochosos. Nesse trabalho, o autor apresenta um modelo de variação hiperbólica para a tensão normal em função da abertura da junta:

$\frac{\sigma-\sigma_{0}}{\sigma_{0}}=A\left(\frac{\Delta v}{v_{m c}-\Delta v}\right)^{t}$

Onde $v_{m c}$ é o deslocamento máximo de fechamento da junta; $A$ e $t$ são propriedades da junta.

A variação da tensão cisalhante em função do deslocamento tangencial é determinada em função de um coeficiente de rigidez ao cisalhamento $k_{s}$ constante (Figura 5.10).

A resistência ao cisalhamento de pico é calculada pela equação de Ladanyi e Archambault (1970), em função da dilatância e da aspereza da superfície de contato da junta.

$\tau_{p}=\frac{\sigma\left(1-a_{s}\right) \cdot\left(\dot{v}+\operatorname{tg} \phi_{\mu}\right)+a_{s} \cdot S_{r}}{1-\left(1-d_{s}\right) \cdot \dot{v} \cdot \operatorname{tg} \phi_{\mu}}$

Onde $\tau_{p}$ é a tensão cisalhante de pico mobilizada; $\sigma$ é a tensão normal atuante; $\phi_{\mu}$ é o ângulo de atrito da junta lisa; $S_{r}$ é a resistência ao cisalhamento da parede da junta 
intacta; $\dot{v}$ é a variação da dilatância em função do deslocamento tangencial secante no pico de tensão cisalhante (Figura 5.10); $a_{s}$ é a percentagem da área de contato efetiva durante o cisalhamento calculada em função da tensão normal aplicada (Figura 5.11).

$$
\begin{aligned}
& \dot{v}=\left(1-\frac{\sigma}{q_{u}}\right)^{4} \cdot \operatorname{tg} i_{0} \\
& a_{s}=1-\left(1-\frac{\sigma}{q_{u}}\right)^{1,5} \\
& \text { I } \quad r=-\tau_{r} ; \quad \Delta u \leq u_{r(-)} \\
& \text { II } \quad \tau=-\tau_{p}+\frac{\tau_{p}-\tau_{r}}{u_{p}-u_{r}}\left(\Delta u-u_{p(-)}\right) ; \quad u_{r(-)} \leq \Delta u \leq u_{p(-)} \\
& \text { III } \tau=k_{s} \Delta u+\tau_{0} ; \quad u_{p(-)} \leq \Delta u \leq u_{p(+)} \\
& \text { IV } \tau=\tau_{p}+\frac{\tau_{p}-\tau_{r}}{u_{p}-u_{r}}\left(\Delta u-u_{p(+)}\right) ; \quad u_{p(+)} \leq \Delta u \leq u_{r(+)} \\
& v \quad \tau=\tau_{r} ; \quad \Delta u \geq u_{r(+)}
\end{aligned}
$$

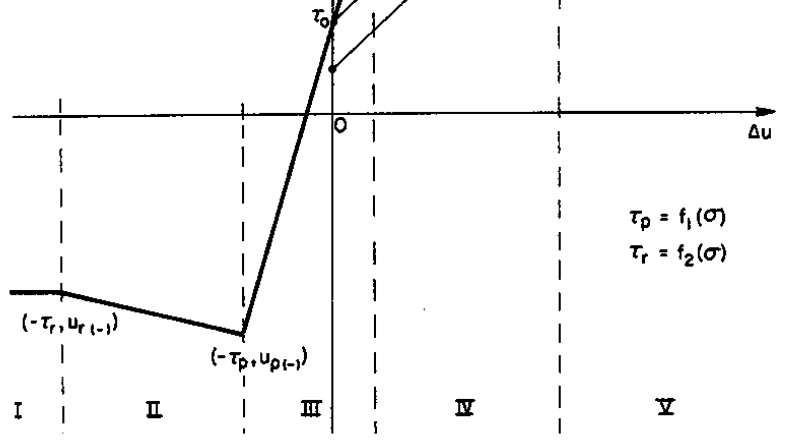

Figura 5.10 - Modelo constitutivo para o comportamento da tensão cisalhante em função do deslocamento (Goodman, 1977).
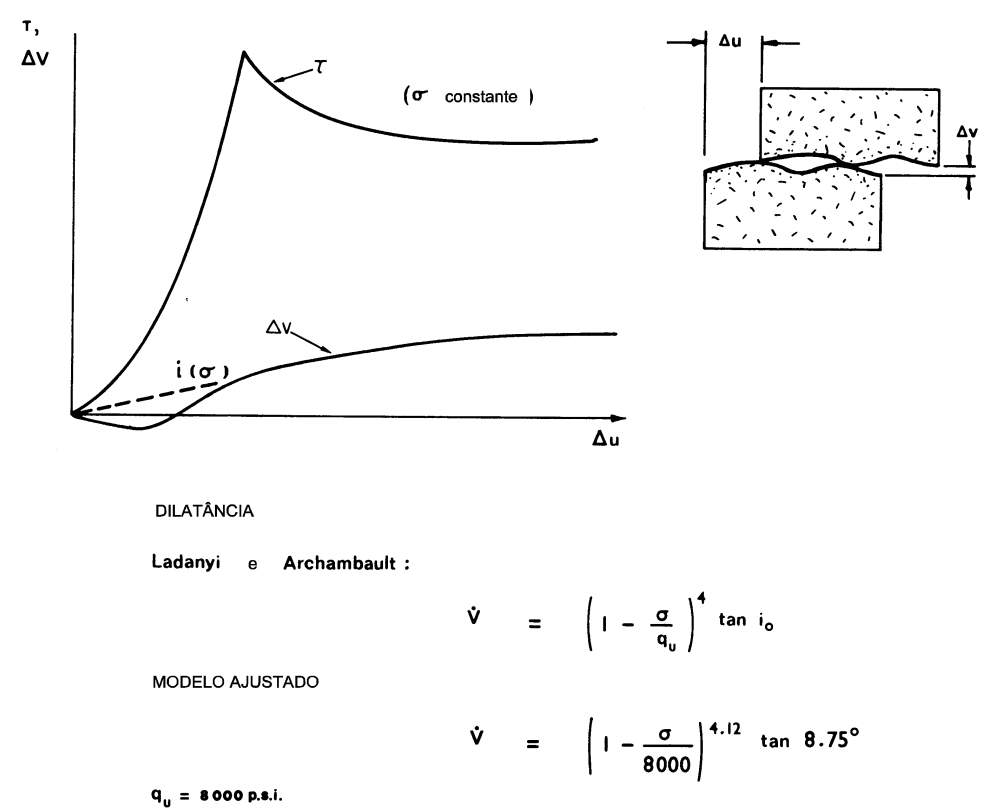

Figura 5.11 - Dilatância no cisalhamento de rochas mantida a tensão normal constante (Goodman, 1977). 
Zaman et al. (1984) desenvolveram um modelo constitutivo, baseado numa equação polinomial, para representar o comportamento da interface quando submetidas a carregamentos cíclicos. Nesse modelo, são considerados os comportamentos de carga e descarga e uma relação constitutiva para o comportamento mecânico na direção normal à interface.

Outros modelos não lineares de contato podem ser vistos em Guo (2001), Reddy et al. (1997) e Gens et al. (1990).

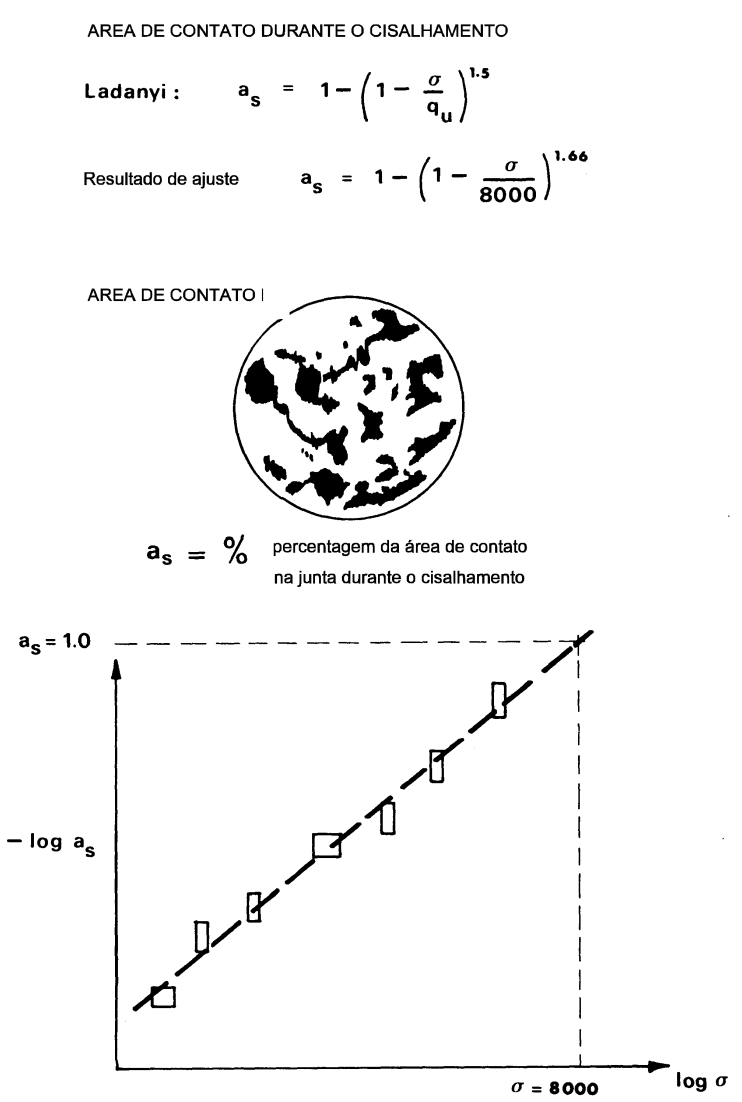

Figura 5.12 - Proporção da área de contato na parede da junta durante o cisalhamento (Goodman, 1977).

5.3. Aplicação do modelo proposto em análises numéricas pelo método dos elementos finitos

A previsão do comportamento de interfaces torna-se importante quando se deseja efetuar uma análise de problemas geotécnicos considerando o efeito da interação solo-estrutura, principalmente quando se tratar de estruturas cujo mecanismo de estabilidade mobiliza resistência de atrito.

O princípio de análise de interação solo-estrutura consiste no fato de a maioria das obras se constituírem em sistemas, cujo comportamento global é definido mais pelas relações entre suas partes do que pelo comportamento de cada parte individualmente.

Como exemplo de um desses sistemas construtivos tem-se uma fundação profunda equilibrada por atrito lateral, que pode ser definida como um sistema formado 
por um elemento estrutural (aço, concreto, madeira) e pelo maciço de solos (pedregulho, areia, silte, argila) cujo comportamento é fortemente condicionado pela interface entre o solo e o concreto, de maneira que a interface também deve ser considerada como parte integrante do sistema e seu comportamento mecânico incorporado na análise, ficando, portanto, o sistema de fundação profunda, constituído pelo elemento estrutural de fundação, pelo maciço de solos e pela interface entre eles.

Dessa maneira, uma análise completa de interação solo-estrutura em fundações profundas requer a compatibilização dos deslocamentos de meios sólidos contínuos diferentes (estaca e maciço de solos), considerando ainda um modelo constitutivo para interface. Uma ferramenta capaz de resolver este sistema consiste no Método dos Elementos Finitos (MEF).

Como visto no ítem anterior, a maioria dos estudos realizados através de elementos de interface se utilizam da formulação de Goodman et al. (1968). A consideração da não linearidade fisica de uma interface se dá através do cálculo iterativo e a conseqüente atualização do coeficiente de rigidez tangente ou secante, de acordo com o nível de carregamento.

Todos os modelos constitutivos pesquisados foram incorporados ao elemento de Goodman et al. (1968), através da compatibilização entre os coeficientes de rigidez e as equações correspondentes a cada modelo.

Também é fato que a maior parte das análises feitas se resumem a elementos de contatos com comportamento linear e, portanto, com coeficientes de rigidez normal e tangencial constantes para qualquer nível de carregamento.

Os que apresentam comportamentos não lineares lançam mão de equações de alta ordem, o que invariavelmente correspondem a um grande número de parâmetros para serem determinados. Parâmetros esses que, na maioria dos casos, são determinados através de ajustes matemáticos dos resultados de ensaios de cisalhamento direto e que, sem dúvida, acabam inviabilizando o uso desses modelos para previsão de estruturas em serviço.

Por outro lado, o uso de alguns modelos não lineares fica restrito à alguns tipos característicos de curvas devido ao fato da maior parte deles ser originada do ajuste de linhas de tendência, preservando assim o caracter empírico e, portanto, restritivo quanto ao uso generalizado.

Nesse contexto, o modelo aqui proposto encontra um vasto campo de aplicação, uma vez que se trata de um modelo teórico cujos parâmetros são de conhecimento geral e já largamente discutidos e tratados na mecânica dos solos.

Além disto, trata-se de uma única função matemática com a pretensão de atender a todos os tipos de curvas tensão versus deslocamentos tangenciais.

Para incorporar esse modelo constitutivo para o comportamento mecânico de elementos de interfaces, basta compatibilizar os deslocamentos calculados através da função matemática com os calculados numericamente a partir de coeficientes de rigidez. 
A proposta aqui apresentada é para utilização no elemento de Goodman et al. (1968)', que consiste em um elemento plano de quatro nós com espessura nula e matriz constitutiva formados por dois coeficientes segundo a Equação (5.3).

A compatibilização dos deslocamentos tangenciais da interface de acordo com a equações aqui proposta (Equação (2.89) e Equação (2.91)) é feita através de um processo iterativo considerando os coeficientes de rigidez variáveis, em função do deslocamento através de processo incremental na forma:

$\left(k_{T}\right)_{i}=\left(k_{T}\right)_{i-1}+\left(\Delta k_{T}\right)_{i}$

Onde:

$\left(\Delta k_{T}\right)_{i}=\frac{\Delta \tau_{i}}{\Delta u_{i}} \cdot \frac{u_{i}-u_{0}}{u_{0}}$

$\frac{\Delta \tau_{i}}{\Delta u_{i}}=\frac{\tau_{i}-\tau_{i-1}}{u_{i}-u_{i-1}}$

O processo iterativo começa com o valor do coeficiente de rigidez tangencial inical $\left(k_{T}\right)_{0}$, na forma:

$\left(k_{T}\right)_{0}=\frac{\tau\left(u_{0}\right)}{u_{0}}$

Onde $u_{0}$ é o deslocamento inicial obtido em função da força tangencial atuante na interface.

Substituindo a Equação (2.89) na equação (5.35), tem-se:

$\left(k_{T}\right)_{0}=\frac{\left(\sigma_{0} \cdot \operatorname{tg} \delta-\sigma_{0} \cdot \operatorname{tg} \delta e^{\left(\frac{1}{\operatorname{tg} \delta \cdot \eta}\right)_{0}}+4 . k . J \cdot \operatorname{tg}^{2} \delta \cdot \eta \cdot u_{0} e^{\left(\frac{1}{2 \operatorname{tg} \delta}\right) u_{0}}\right)}{u_{0}}$

$\left(k_{T}\right)_{i}=\frac{\left(\sigma_{0} \cdot \operatorname{tg} \delta-\sigma_{0} \cdot \operatorname{tg} \delta e^{\left(-\frac{1}{\operatorname{tg} \delta \cdot \eta}\right) u_{i}}+4 \cdot k \cdot J \cdot \operatorname{tg}^{2} \delta \cdot \eta \cdot u_{i} e^{\left(-\frac{1}{2 \operatorname{tg} \delta \cdot \eta}\right) u_{i}}\right)}{u_{i}}$

A determinação do coeficiente de rigidez normal é feita através de processo iterativo de modo que:

$$
\left(k_{N}\right)_{i}=-\frac{\sigma_{0} \cdot A}{\left(4 . \operatorname{tg}^{2} \cdot \eta^{2} \cdot J \cdot u_{i} \cdot e^{\left(\frac{1}{2 \operatorname{tg} \phi \eta}\right) u_{i}}+16 \cdot J \cdot \operatorname{tg}^{3} \delta \cdot \eta^{3} \cdot e^{\left(-\frac{1}{2 \operatorname{tg} \phi \eta}\right)^{u_{i}}}-16 \cdot J \cdot \operatorname{tg}^{3} \delta \eta^{3}\right)}
$$

Onde $\sigma_{0}$ é a tensão normal aplicada e mantida constante durante todo o cisalhamento. 


\section{CAPÍTULO VI \\ TRANSFERÊNCIA DE CARGA EM ESTACAS POR ATRITO LATERAL}

O modo como ocorre a transferência de esforços de uma estaca para o solo em uma fundação submetida a um carregamento vertical é um dos assuntos mais discutidos em engenharia de fundações. Sua determinação depende principalmente do tipo da estaca, do processo executivo, do tipo de solo no qual a estaca está embutida, da superfície de contato estaca-solo e da rigidez do sistema.

Em todos os casos, a rigidez do sistema apresenta papel preponderante por ela influenciar diretamente na grandeza dos deslocamentos.

O modo como uma carga vertical atuante em uma estaca se distribui ao longo da mesma em função dos deslocamentos dos pontos na superfície de contato entre o elemento estrutural e o maciço de solos recebe o nome de mecanismo de transferência de carga. No mecanismo de transferência de carga, deve-se destacar a importância da ponta que em muitos casos comanda seu comportamento mecânico.

No entanto, o esforço sobre uma estaca é, nos casos mais comuns, aplicada sobre o topo e segue do topo no sentido da ponta passando necessariamente pelo fuste e gerando em cada uma de suas seções um dado esforço normal. Esse esforço é proporcional aos deslocamentos sofridos em cada ponto da estaca e esses deslocamentos proporcionais ao quinhões de carga transferida para o solo em cada seção.

Se o elemento estrutural da estaca for infinitamente rígido, todos os pontos da estaca terão os mesmos deslocamentos de forma que os quinhões de carga transferidos em cada seção serão iguais para toda a estaca.

Caso a ponta da estaca estiver sobre material com rigidez muito elevada (rocha) toda a carga será transferida pela ponta. Porém, se a ponta estiver assentada sobre material altamente compressível, toda a carga será transferida pela lateral da estaca. 
Para a maioria dos problemas, esse mecanismo é resolvido através de funções de transferência de carga. Estas funções são adotadas, de modo a permitir que se tenha a relação entre o deslocamento de uma seção da estaca e o valor da carga naquela seção. Dessa maneira, o esforço passa a agir sobre a interface de maneira a mobilizar uma reação para equilibrar o sistema.

Como o sistema é admitido estático, tem-se que a carga transferida em cada seção é numericamente igual à resistência lateral local mobilizada nesta mesma seção. Cabe salientar que a resistência mobilizada pode não ser a máxima possível e que sua mobilização irá depender do valor do deslocamento sofrido pela estaca.

O mecanismo de cisalhamento na interface solo-estrutura tem influência significativa no comportamento de estruturas que trabalham basicamente com resistência ao atrito, como estacas, ancoragens, estruturas de contenção e solo grampeado. A compreensão desse mecanismo resulta na adoção de modelos mais condizentes com comportamento da curva carga-deslocamento, com o valor da capacidade de carga e com a transferência de esforços da estrutura para o maciço de solos.

Os modelos utilizados para estudo desse mecanismo de tranferência de carga se classificam em modelos unidimensionais, bidimensionais e tridimensionais.

\subsection{Modelos unidimensionais}

A modelagem de interface entre estaca-solo através de modelos unidimensionais geralmente se baseia nas equações de equilíbrio estático de um elemento infinitesimal de estaca-solo com comprimento $d x$ (Figura 6.1).

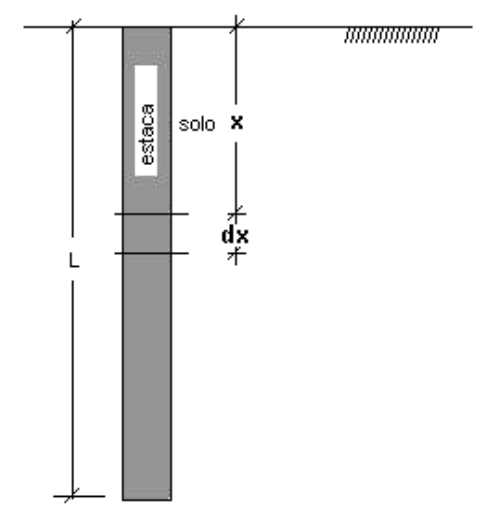

Figura 6.1 - Estaca de referência

Detalhando ainda mais esse elemento de estaca-solo, podem-se perceber as tensões que atuam para manter o seu equilíbrio (Figura 6.2). 


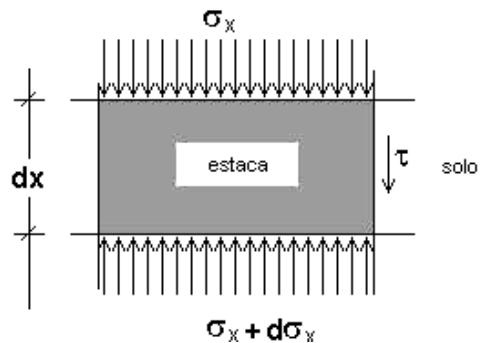

Figura 6.2 - Elemento de infinitesimal

Tomando-se como condição de equilíbrio o somatório da forças na direção vertical igual a zero:

$\sigma_{x}$. área $+\tau . d x$. perímetro $-\left(\sigma_{x}+d \sigma_{x}\right)$.área $=0$

Operando-se os termos semelhantes:

$\tau . d x$. perímetro $-d \sigma_{x}$.área $=0$

Ou ainda,

$\frac{d \sigma_{x}}{d x}=\frac{\tau . \text { perímetro }}{\text { área }}$

$\mathrm{Na}$ maior parte dos problemas de contato, considera-se a deformação do elemento estrutural composta apenas de deformações elásticas que na forma unidimensional é:

$\sigma_{x}=E_{c} \varepsilon_{x}$

Admitindo-se que o deslocamento longitudinal é função apenas da posição $x$ :

$\varepsilon_{x}=\frac{d u}{d x}$

Substituindo a Equação (6.5) na Equação (6.4):

$\sigma_{x}=E_{c} \frac{d u}{d x}$

Que, aplicada na Equação (6.3), resulta:

$\frac{d\left(E_{c} \frac{d u}{d x}\right)}{d x}-\frac{\tau \cdot \text { perímetro }}{\text { área }}=0$ 
Rearranjando os termos, a equação unidimensional para cálculo de transferência de esforços em estacas submetidas a esforços axiais é:

$$
E_{c} \frac{d^{2} u}{d x^{2}}-\frac{\tau . \text { perímetro }}{\text { área }}=0
$$

A Equação (6.8) também é escrita na forma:

$$
\frac{d^{2} u}{d x^{2}}-\frac{\tau \cdot \text { perímetro }}{E_{c} \cdot \text { área }}=0
$$

Chamando-se $R E$ de rigidez axial da estaca:

$$
R E=\frac{\text { perímetro }}{E_{c} \cdot \text { área }}
$$

E substituindo na Equação (6.9):

$$
\frac{d^{2} u}{d x^{2}}-\tau \cdot R E=0
$$

Observando-se a Equação (6.11), sua aplicação pode ser imediata. Para isso, basta que se considere uma relação constitutiva entre $\tau$ e $u$.

A maior parte dos trabalhos que seguiram o tratamentamento matemático unidimensional considera uma função de $\tau(u)$ linear (Figura 6.3):

$$
\tau(u)=k_{s} \cdot u
$$

Onde $k_{s}$ é o coeficiente de rigidez do sistema estaca-solo; $\tau$ é a tensão tangencial mobilizada na interface estaca-solo; $u$ é o deslocamento longitudinal da estaca.

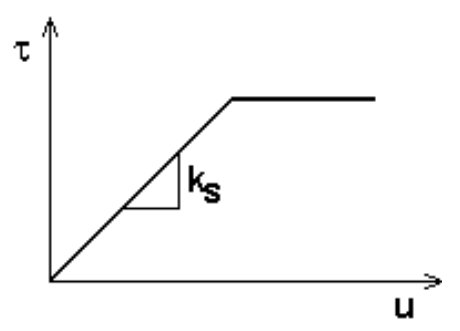

Figura 6.3 - Comportamento de cisalhamento na interface.

Substituindo a Equação (6.12) na Equação (6.11):

$$
\frac{d^{2} u}{d x^{2}}-k_{s} \cdot u \cdot R E=0
$$


Agrupando-se o coeficiente de rigidez da estaca com o coeficiente de rigidez ao cisalhamento no contato estaca-solo, obtém-se a rigidez do sistema estaca-solo $K_{E S}$ :

$K_{E S}=k_{s} \cdot R E$

Logo:

$\frac{d^{2} u}{d x^{2}}-K_{E S} u=0$

A Equação (6.15) é uma equação de diferencial de segunda ordem e homogênea. Sua solução pode ser obtida por processos analíticos ou numéricos, dependendo da necessidade e das condições de contorno exigidas.

Vários trabalhos tomaram essa linha de raciocínio onde se pode destacar Farmer (1975), que define a rigidez do sistema estaca-solo $K_{E S}$ em função do módulo de cisalhamento; Guo (2001), que também define a rigidez do sistema estaca-solo $K_{E S}$ em função do módulo de cisalhamento, que por sua vez varia com a profundidade. Mesra e Chen (2004) interpretam do sistema estaca-solo $K_{E S}$ como sendo uma função do deslocamento tangencial u. Fiorante (2002) adota também a rigidez do sistema estacasolo $K_{E S}$ em função do módulo de cisalhamento, estabelecendo uma relação deste com a rugosidade da superfície de contato e com a dimensão média da partícula do solo $\mathrm{D}_{50}$; Lee, Bolton e Al Tabbaa (2002) consideram a rigidez do sistema estaca-solo $K_{E S}$ uma função do módulo de elasticidade.

Verifica-se que a função entre $\tau$ e $u$ não é linear, de forma que a solução da equação (6.15), para esses casos de não-linearidade física, fica restrita. Em alguns casos, soma-se a esta conjuntura a não linearidade geométrica, que torna a solução desse tipo de problema praticamente impossível.

Observando o mecanismo de mobilização das deformações e das resistências laterais em estacas, verifica-se que as resistências são mobilizadas de acordo com os deslocamentos que ocorrem no fuste e que na maioria dos casos ocorre deslizamento entre o fuste e o maciço de solos. Dessa forma, a montagem de equações de compatibilidade de deslocamentos ao longo do fuste da estaca algumas vezes conduz a valores equivocados.

Observando-se a Figura 6.4, pode-se interpretar o mecanismo de deslocamentos e resistências mobilizadas. 
Nesse mecanismo, fica claro que as tensões tangenciais mobilizadas na interface são função direta do seu deslocamento e que uma abordagem alternativa seria a de levantar as equações constitutivas do contato estaca-solo considerando todas as variáveis intervenientes, estabelecendo-as em termos de curvas tensão tangencial deslocamento relativo na interface.

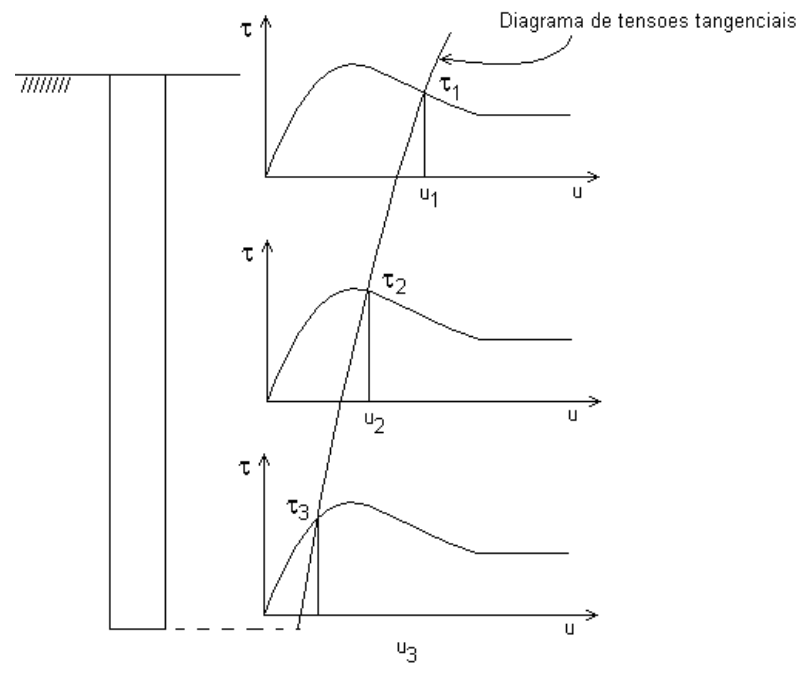

Figura 6.4 - Comportamento de cisalhamento na interface (Randolph, 1985).

Cabe ressaltar que o comportamento reológico do solo e do elemento estrutural pode ser linear e o comportamento da interface ser não linear, uma vez que na interface suas esquações constitutivas correspondentes são independentes e podem ser totalmente diferentes.

Para cálculo da resistência mobilizada na interface e, consequentemente, o diagrama de distribuição de tensões ao longo do comprimento da estaca, foram publicados diversos trabalhos onde se procura levantar algumas incógnitas e assim obter uma solução cujo resultado se aproxime da realidade física.

Os trabalhos que apresentam solução analítica baseada na teoria da elasticidade que merecem destaque aqui são os de Martins (1945) apud Grillo (1948)e de Geddes (1969).

Martins (1945) apud Grillo (1948), publicou a solução para distribuição de tensões verticais em um meio contínuo, elástico, homogêneo, isotrópico e semi-infinito devido à uma carga uniformimente de distribuída ao longo do fuste da estaca e a carga devido a carga de ponta (Figura 6.5)

Geddes (1969) apresentou um método para determinação das tensões baseado nas equações de Mindlin (1936), deduzidas a partir da teoria da elasticidade para meio contínuo elástico linear isotrópico semi-infinito.

Para obter o campo de tensão no maciço de solos, o autor supõe conhecida a forma do diagrama de distribuição de esforços ao longo da estaca. Dessa maneira, fica eliminada a hiperestaticidade do problema e facilitando o cálculo análitico das tensões 
em qualquer ponto interno ao meio. A solução é obtida através de coeficientes de tensão adimensionais.

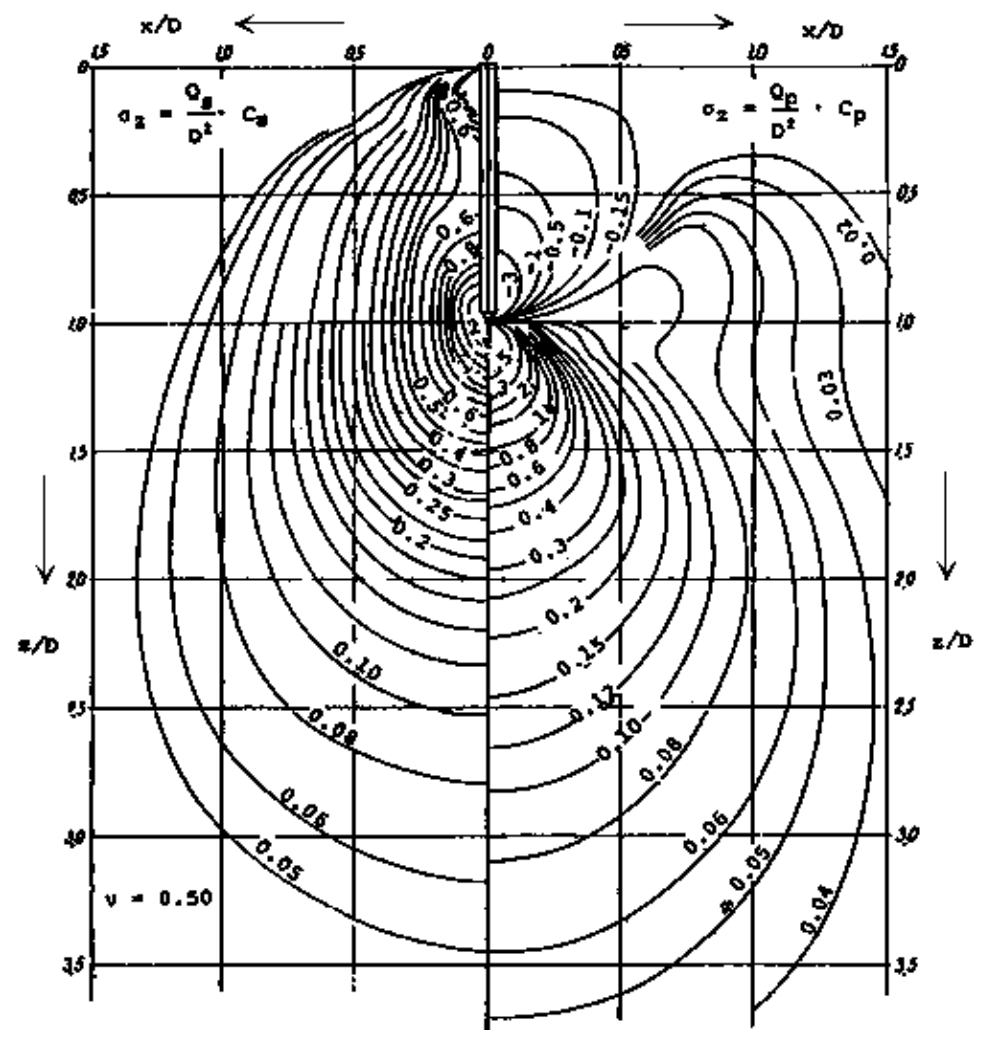

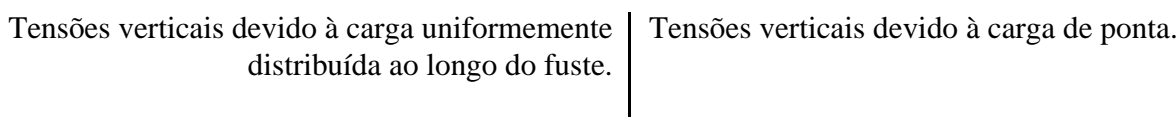

Figura 6.5 - Distribuíção de tensões verticais em torno de uma estaca imbutida em meio sólido elástico (Martins, 1945 apud Grillo,1948).

Geddes (1969) apresenta a solução para três casos característicos (Figura 6.6)

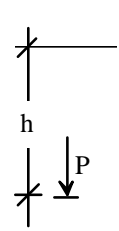

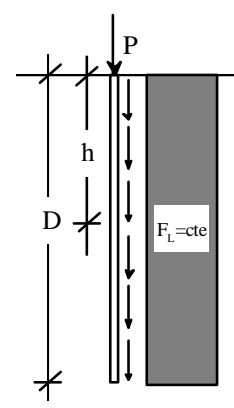

b) Caso B

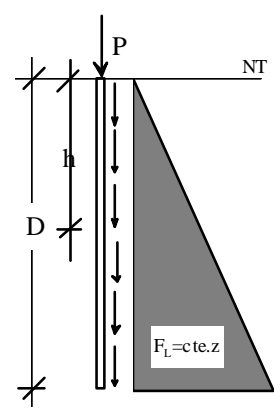

c) Caso C

Figura 6.6 - Diagramas de transferencia de carga considerados por Geddes (1969).

Caso A: Carga concentrada aplicada a uma profundidade qualquer $h$ no interior de um maciço homogêneo, isotrópico, elástico semi-infinito (Problema original de Mindlin, 1936); 
Caso B: O total da carga aplicada uniformemente ao longo de um eixo vertical a partir da superfície até uma profundidade $h$ (refere-se a caso de variação uniforme do atrito lateral).

Caso C: O total da carga aplicada varia linearmente ao longo de um eixo vertical de um valor nulo na superfície até um valor máximo a uma profundidade $h$ (refere-se a caso de variação linear do atrito lateral).

Para o caso de tensões devidas ao atrito lateral uniforme a carga distribuída, pode ser obtida por:

$\delta P=\left(\frac{P}{D}\right) \delta h$

Aplicando -se a Equação (6.16) nas expressões para calculo das tensões propostas por Mindlin (1936), têm-se:

$$
\begin{aligned}
& z z=\left(\frac{P}{D}\right) \frac{1}{8 \pi(1-v)} \int_{0}^{D}\left[-\frac{(1-2 v)(z-h)}{R_{1}^{3}}+\frac{(1-2 v)(z-h)}{R_{2}^{3}}-\frac{3(z-h)^{3}}{R_{1}^{5}} \ldots\right. \\
& \left.\ldots-\left\{\frac{3(3-4 v) z(z+h)^{2}-3 h(z+h)(5 z-h)}{R_{2}^{5}}\right\}-\frac{30 z h(z+h)^{3}}{R_{2}^{7}}\right] d h \\
& r r=\left(\frac{P}{D}\right) \frac{1}{8 \pi(1-v)} \int_{0}^{D}\left[\frac{(1-2 v)(z-h)}{R_{1}^{3}}-\frac{(1-2 v)(z-7 h)}{R_{2}^{3}}+\frac{4(1-v)(1-2 v)}{R_{2}\left(R_{2}+z+h\right)}-\frac{3 r^{2}(z-h)}{R_{1}^{5}} . .\right. \\
& \left.\ldots-\left\{\frac{6 h(1-2 v)(z+h)^{2}-3(3-4 v) r^{2}(z-h)-6 h^{2}(z+h)}{R_{2}^{5}}\right\}-\frac{30 r^{2} z h(z+h)}{R_{2}^{7}}\right] d h \\
& \theta \theta=\left(\frac{P}{D}\right) \frac{1}{8 \pi(1-v)} \int_{0}^{D}\left[\frac{(1-2 v)(z-h)}{R_{1}^{3}}+\frac{(1-2 v)(3-4 v)(z+h)-(1-2 v) 6 h}{R_{2}^{3}} \ldots\right. \\
& \left.\ldots-\frac{4(1-v)(1-2 v)}{R_{2}\left(R_{2}+z+h\right)}+\left\{\frac{6 h(1-2 v)(z+h)^{2}-6 h^{2}(z+h)}{R_{2}^{5}}\right\}\right] d h \\
& r z=\left(\frac{P}{D}\right) \frac{r}{8 \pi(1-v)} \int_{0}^{D}\left[-\frac{(1-2 v)}{R_{1}^{3}}+\frac{(1-2 v)}{R_{2}^{3}}-\frac{3(z-h)^{2}}{R_{1}^{5}} \ldots\right. \\
& \left.\ldots-\left\{\frac{3(3-4 v) z(z+h)-3 h(3 z+h)}{R_{2}^{5}}\right\}-\frac{30 z h(z+h)^{2}}{R_{2}^{7}}\right]
\end{aligned}
$$

Onde:

$$
\begin{aligned}
& R_{1}^{2}=r^{2}+(z-h)^{2} \\
& R_{2}^{2}=r^{2}+(z+h)^{2}
\end{aligned}
$$

De maneira semelhante, pode-se aplicar o mesmo procedimento para o caso de atrito lateral, variando linearmente com a profundidade. no valor de: 
$2 P \frac{h}{D^{2}}$

Onde a carga aplicada em cada profundidade é:

$\delta P=2 P \frac{h}{D^{2}} \delta h$

E as expressões para cálculo das tensões serão:

$$
\begin{aligned}
& z z=\frac{P}{4 \pi(1-v) D^{2}} \int_{0}^{D}\left[-\frac{(1-2 v)(z-h) h}{R_{1}^{3}}+\frac{(1-2 v)(z-h)}{R_{2}^{3}}-\frac{3 h(z-h)^{3}}{R_{1}^{5}} \ldots\right. \\
& \left.\ldots-\left\{\frac{3(3-4 v) z h(z+h)^{2}-3 h^{2}(z+h)(5 z-h)}{R_{2}^{5}}\right\}-\frac{30 z h^{2}(z+h)^{3}}{R_{2}^{7}}\right] d h \\
& r r=\frac{P}{4 \pi(1-v) D^{2}} \int_{0}^{D}\left[\frac{(1-2 v)(z-h) h}{R_{1}^{3}}-\frac{(1-2 v)(z-7 h) h}{R_{2}^{3}}+\frac{4(1-v)(1-2 v) h}{R_{2}\left(R_{2}+z+h\right)}-\frac{3 r^{2}(z-h) h}{R_{1}^{5}} \ldots\right. \\
& \left.\ldots-\left\{\frac{6 h(1-2 v) h(z+h)^{2}-3(3-4 v) h r^{2}(z-h)-6 h^{3}(z+h)}{R_{2}^{5}}\right\}-\frac{30 r^{2} z h^{2}(z+h)}{R_{2}^{7}}\right] d h \\
& \theta \theta=\frac{P}{4 \pi(1-v) D^{2}} \int_{0}^{D}\left[\frac{(1-2 v)(z-h) h}{R_{1}^{3}}+\frac{(1-2 v)(3-4 v) h(z+h)-(1-2 v) 6 h^{2}}{R_{2}^{3}} \ldots\right. \\
& \left.\ldots-\frac{4(1-v) h(1-2 v)}{R_{2}\left(R_{2}+z+h\right)}+\left\{\frac{6 h^{2}(1-2 v)(z+h)^{2}-6 h^{3}(z+h)}{R_{2}^{5}}\right\}\right] d h \\
& r z=\frac{P}{4 \pi(1-v) D^{2}} \int_{0}^{D}\left[-\frac{(1-2 v) h}{R_{1}^{3}}+\frac{(1-2 v) h}{R_{2}^{3}}-\frac{3(z-h)^{3}}{R_{1}^{5}} \ldots\right. \\
& \left.\ldots-\left\{\frac{3(3-4 v) z h(z+h)-3 h^{2}(3 z+h)}{R_{2}^{5}}\right\}-\frac{30 z h^{2}(z+h)^{2}}{R_{2}^{7}}\right]
\end{aligned}
$$

Onde:

$$
\begin{aligned}
& R_{1}^{2}=r^{2}+(z-h)^{2} \\
& R_{2}^{2}=r^{2}+(z+h)^{2}
\end{aligned}
$$

Apesar da simplicidade da solução, os modelos analíticos baseados na hipótese de meio homogêneo, isotrópico, elástico, linear e semi-infinito, possuem uma série de restrições quando comparados aos resultados de provas de cargas devido ao fato do diagrama de transferência de carga raramente seguir funções matemáticas bem definidas.

Vésic (1975) mostra vários casos possíveis de ocorrência de atrito lateral e o diagrama de resistência lateral acumulado (Figura 6.7).

A forma real do diagrama de atrito lateral é bastante discutível, uma vez que não existe uma função que possa ser generalizada para todos os casos. A forma do diagrama de atrito lateral depende das camadas de solo que compõem o maciço em estudo, da 
carga aplicada do tipo de el,emento estrutural, da execução e do tempo após a execução e do efeito de grupo entre estacas.

Com a finalidade de descobrir o diagrama de atrito, vários trabalhos relatam os resultados de instrumentação das deformações e dos deslocamentos que ocorrem no fuste de estacas em serviço. Como já comentado, os deslocamentos ao longo do fuste não são iguais em todos os seus pontos; variam de acordo com a profundidade, provocando uma mobilização de atrito lateral diferenciada ao longo da estaca (Figura $6.8)$.

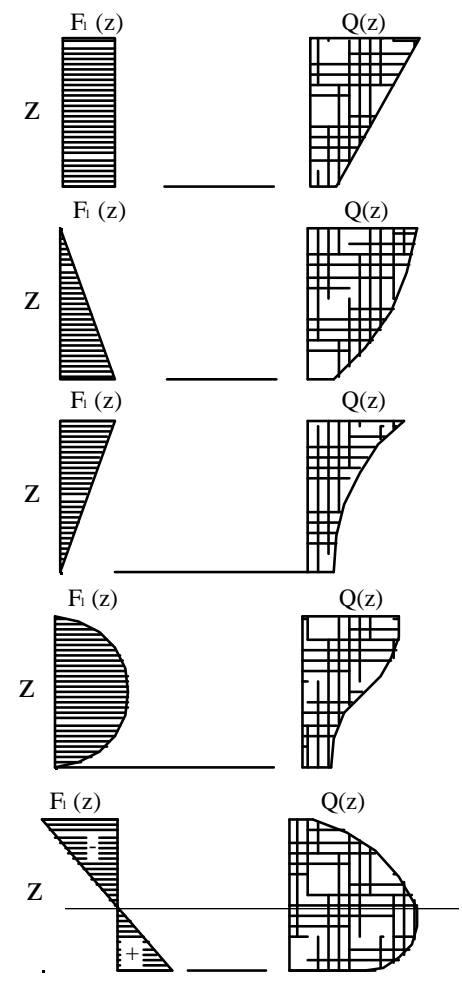

Figura 6.7 - Diagramas típicos de distribuição de atrito lateral local (Fl(z)) e esforço normal na estaca $(\mathrm{Q}(\mathrm{z}))$.

Em casos gerais, a forma do diagrama de atrito lateral não segue nenhum padrão definido. A Figura 6.9 mostra um caso diagrama de esforço normal e resistência lateral mobilizada. Na figura, percebe-se que os valores máximos ocorreram no topo e na base e o valor mínimo ocorre no centro da estaca (Lopes, 1986), provando que a resistência lateral mobilizada não possui uma função própria e deve ser avaliada caso a caso.

Vésic (1975) destaca que a maior complicação na determiação do mecanismo de transferência de carga acontece quando o elemento estrutural de fundações é deformável de modo que os deslocamentos do topo sejam elevados, enquanto os da base pequenos. Nesse caso, em alguns pontos os deslocamentos sofridos são suficientes para mobilizar toda a resistência lateral, enquantos outros pontos sequer foram carregados. 

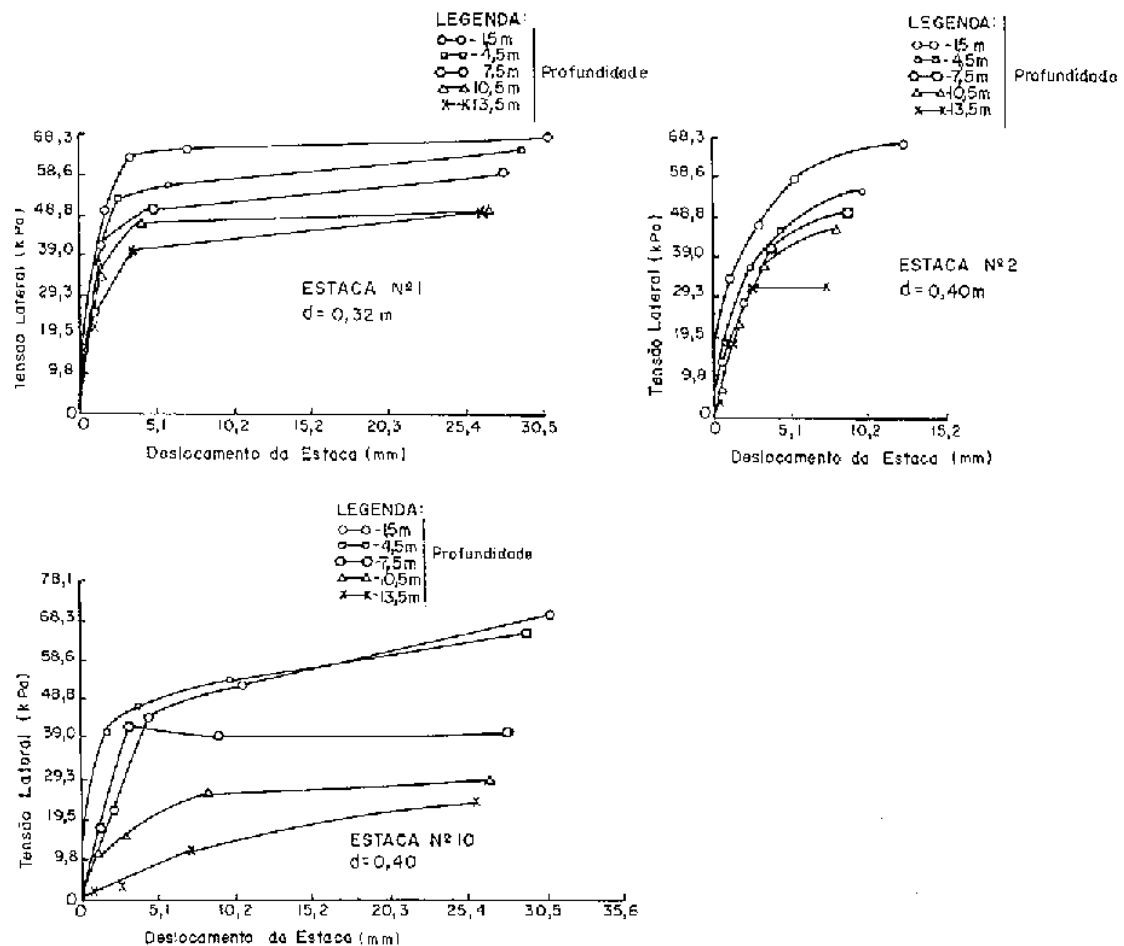

Figura 6.8 -Mobilização de tensão lateral em função do deslocamento que ocorreu em estacas cravadas em areia (Coyle e Sulaiman, 1967).

Aoki (1989) propõe um modelo simples de transferencia de carga. Neste modelo, a carga aplicada no topo da estaca mobiliza todo o atrito lateral necessário para equilibrá-la, até o valor máximo da resistência lateral, de modo que o valor da carga lateral é numericamente igual ao atrito lateral máximo de mobilizado. Se a carga aplicada no topo da estaca for maior que a resistência lateral total, o excedente será transferido para a ponta. A simplificação deste modelo consiste no fato dele eliminar o alto grau de hiperestaticidade do sistema de apoios ao longo do fuste. Nota-se que a carga lateral mobilizada depende apenas do tipo de solo, do tipo da estaca e do deslocamento necessário para mobilizar determinada resistência.

Coyle e Reese (1966) desenvolveram um processo numérico iterativo para solução da Equação (6.15). Nesse processo, se discretiza a estaca em vários elementos com as suas respectivas forças atuantes. A solução é obtida adotando-se um valor para o deslocamento da estaca, calculando-se as forças que atuam em cada um dos seus elementos, a começar pela ponta.

Poulos e Davis (1968) deduziram um método de transferência de carga baseado na compatibilidade entre os deslocamentos dos pontos da estaca e os pontos no solo adjacentes. Para solução do sistema hiperestático resultante, os autores propõem que a estaca seja discretizada em um número finito de elementos.A compressibilidade da estaca é obtida a partir da rigidez normal de cada elemento e os deslocamentos do solo através das equações de Mindlin (1936) para carregamento concentrado no interior de um meio elástico, isotrópico, semi-infinito. 

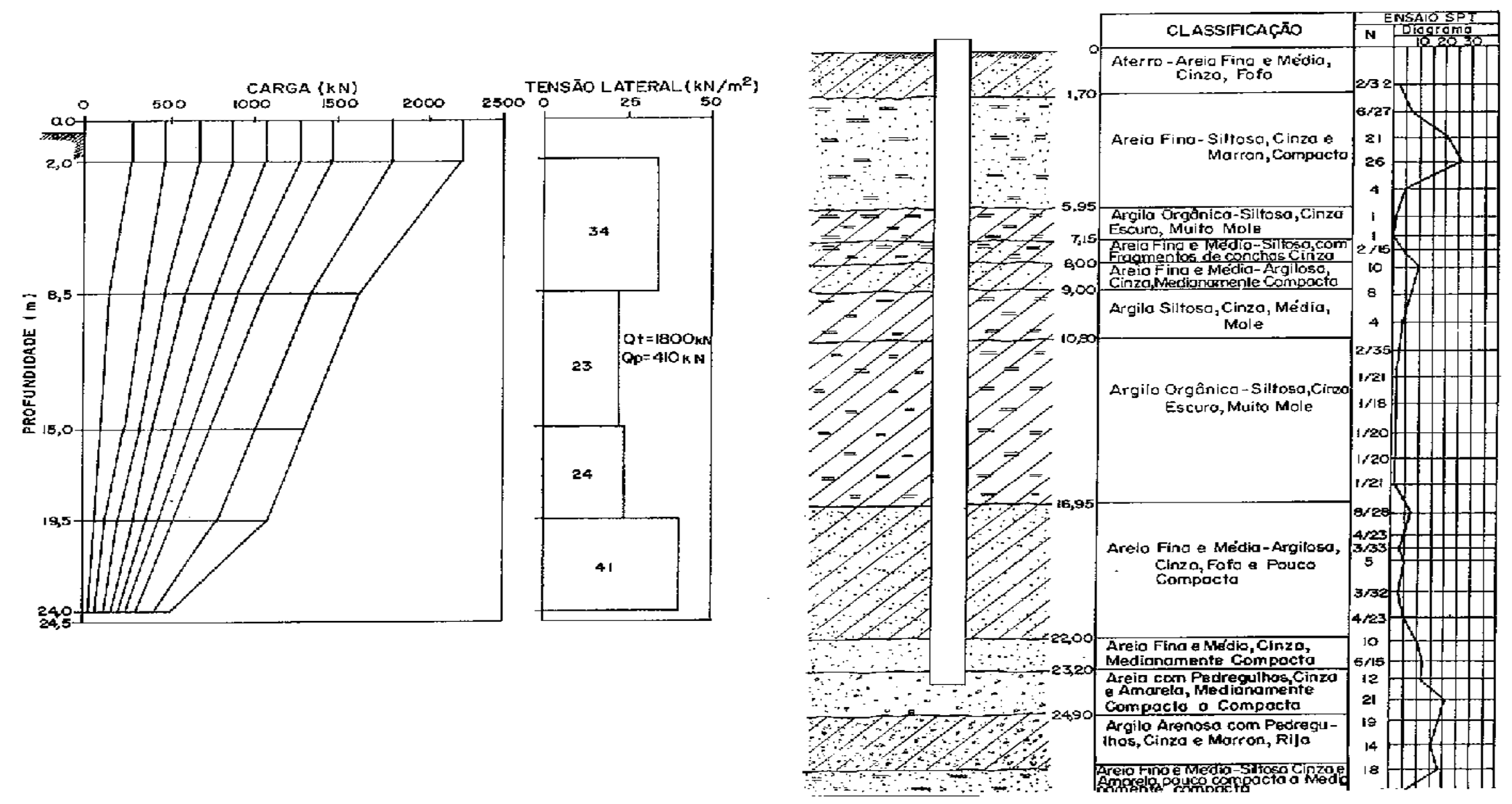

Figura 6.9 - Mobilização do atrito lateral (Lopes, 1986). 
Para ajustar melhor esses resultados, surgiram então métodos de cálculo de transferência de carga onde o mecanismo levasse em conta os deslocamentos na interface da estaca e a relação tensão tangencialdeslocamento.

Esse comportamento pode ser obtido através da hipótese de Winkler. Segundo essa hipótese, a estaca se constitui em uma barra sobre apoios elásticos e lineares (Figura 6.10).
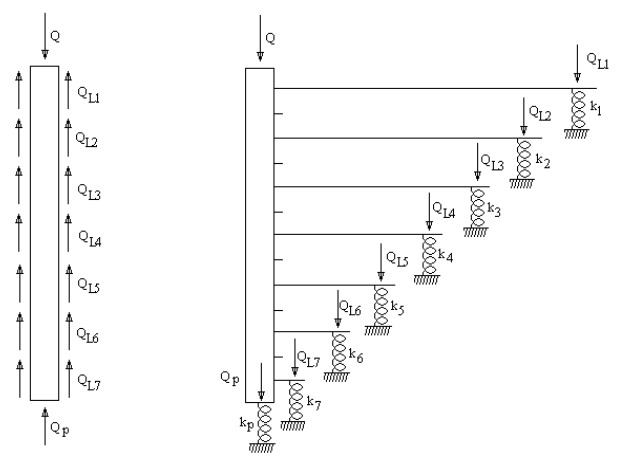

Figura 6.10 - Modelo mecânico de uma estaca carregada axialmente (Reese, 1978)

Nesse caso, ainda se considera que cada apoio elástico possui deformabilidade e carregamento independente dos demais, de modo que a carga atuante em um determinado ponto causa deslocamento apenas naquele ponto.

$p=k \cdot w(x, y)$

Onde $p$ é a pressão de contato em algum ponto; $w(x, y)$ é o deslocamento correspondente; $k$ é o coeficiente de reação vertical ou coeficiente de rigidez do sistema estaca-solo.

Uma evolução do modelo de estaca sobre apoios elásticos é a consideração de um critério de ruptura como limite para a resistência mobilizada, conferindo um comportamento elástico perfeitamente plástico para interface. Geralmente o critério utilizado é o critério de ruptura de Morh-Coulomb (Figura 6.11).

A máxima resistência ao atrito mobilizada na lateral estaca $\tau_{\max }$ é calculada com:

$\tau_{\max }=c^{\prime}+\beta_{f} \cdot \sigma_{v i}^{\prime}$

Onde:

$\beta_{f}=K \operatorname{tg} \delta_{a}$

Sendo que $K$ é o coeficiente de empuxo; $\delta_{a}$ é o ângulo de atrito efetivo entre a estaca e o solo; . $\sigma_{v i}^{\prime}$ é a tensão vertical efetiva no solo atuante. 


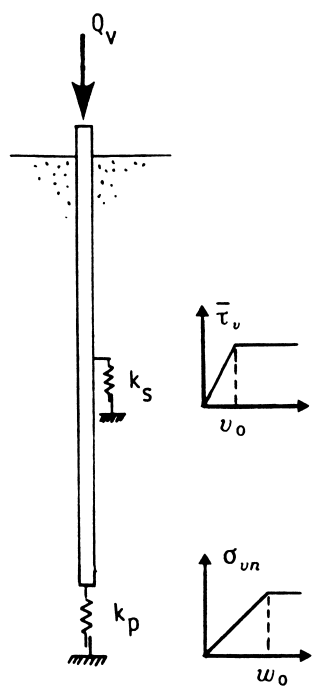

Figura 6.11 - Modelo de cálculo de recalques em estacas sobre apoios elasto-plástico perfeitos (Bernardes, 1989)

A carga lateral é calculada através da integral das tensões máximas mobilizadas ao longo da estaca.

$$
P_{L}=U \int_{0}^{L} \tau_{\max } d L
$$

Onde $L$ é o comprimento mobilizado da estaca.

Nesse modelo de estaca isolada, o comportamento reológico dos apoios elásticos pode ser definido de forma específica para cada material (estaca e solo), uma vez que a solução da hipótese de Winkler corresponde à solução da Equação (6.15).

Misra e Chen (2004) deduziram uma solução analítica para equação (6.15) com comportamento da tensão tangencial mobilizada na interface elasto-plastico perfeito (Figura 6.12). Os autores fizeram diversas aplicações da formulação para resultados de provas de carga em micro-estacas.

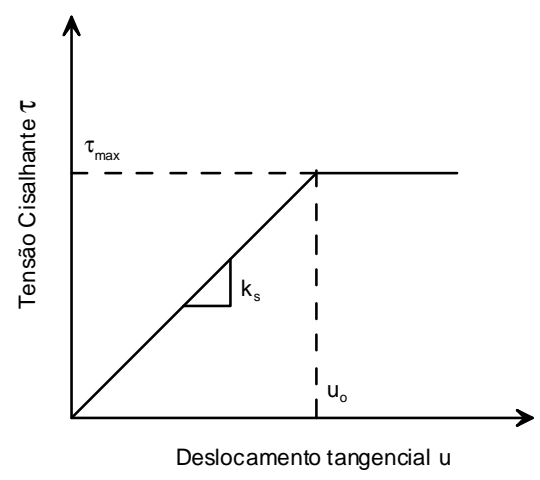

Figura 6.12 - Comportamento elástico linear perfeitamente plástico 
Hird e Russel (1990) também demonstram uma solução analítica para a Equação 6.15 e uma equação para cálculo da tensão mobilizada, em função do comprimento da inclusão.

Modelos de estacas sobre molas com comportamento não linear também podem ser utilizados para solução da Equação (6.15), bastando para isso que se tenha uma relação constitutiva não linear que permita avaliar o coeficiente de rigidez em função do deslocamento e da carga aplicada sobre a estaca (Figura 6.13).
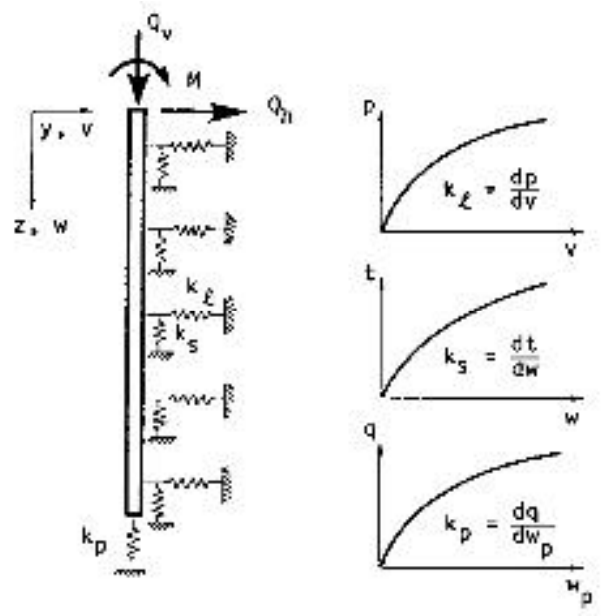

Figura 6.13 - Estacas sobre apoios elásticos não lineares (Bernardes, 1989)

Dentre os modelos de transferência de carga que usam funções de transferência de carga não lineares, podem ser citados o de Seed e Reese (1957) e Kraft et al.(1981), Kagawa (1981), que ficaram conhecidos como modelos de transferência (T-Z).

Estas funções de transferência de carga na realidade compreendem soluções da Equação 6.15, no entanto o método propõe que se façam modificações no valor do do coeficiente de reação, de forma a ajustar os resultados observados no campo, resultando, assim, numa função aproximadora de curvas carga-deslocamentos e diagramas de transferência de carga observados em campo.

Seed e Reese (1957) e Kraft et al.(1981) consideram que o coeficiente de rigidez de cada mola é uma função do módulo de elasticidade transversal, cuja variação é calculada por:

$$
G_{s}=G_{i}\left[1-\frac{\tau . R}{\tau_{\max }}\right]
$$

Onde $G_{s}$ é o módulo de cisalhamento, quando da aplicação da tensão $\tau$; $G_{i}$ é o módulo de cisalhamento inicial; $\tau$ é a tensão tangencial; $\tau_{\max }$ é a tensão de cisalhamento na 
ruptura, geralmente calculada através do critério de ruptura de Morh-Coulomb; $R$ é uma constante de ajuste da curva, é a inclinação da reta formada por $1-G d G$ versus

O módulo de elasticidade transversal $G_{s}$ é deduzido pela teoria da elasticidade, a partir do módulo de elasticidade $E_{s}$ longitudinal, na forma:

$$
G_{s}=\frac{E_{s}}{2\left(1+v_{s}\right)}
$$

Onde $v_{s}$ é o coeficiente de poisson.

Zhu e Chang (2002) propuseram um modelo não-linear análitico baseado nas curvas de degradação do modulo de deformabilidade transversal $G$, utilizando uma outra função para aproximação da relação entre as tensões cisalhantes na interface e a tensão máxima mobilizada (Figura 6.14)

$$
G_{s}=G_{i}\left[1-f\left(\frac{\tau .}{\tau_{\max }}\right)^{g}\right]
$$

Onde $f$ e $g$ são parâmetros de ajuste da curva tensão-deslocamento.

Outro modelo de transferência de carga entre estaca-solo foi proposto por Liu et al. (2004), no qual é proposto um modelo trilinear perfeitamente plástico com pico de resistência para representar o comportamento da tensão tangencial mobilizada em função do deslocamento (Figura 6.15). Nesse trabalho, os autores desenvolvem a formulação para aplicação em solos estratificados e propõem uma solução matricial para o sistema de equações resultante.

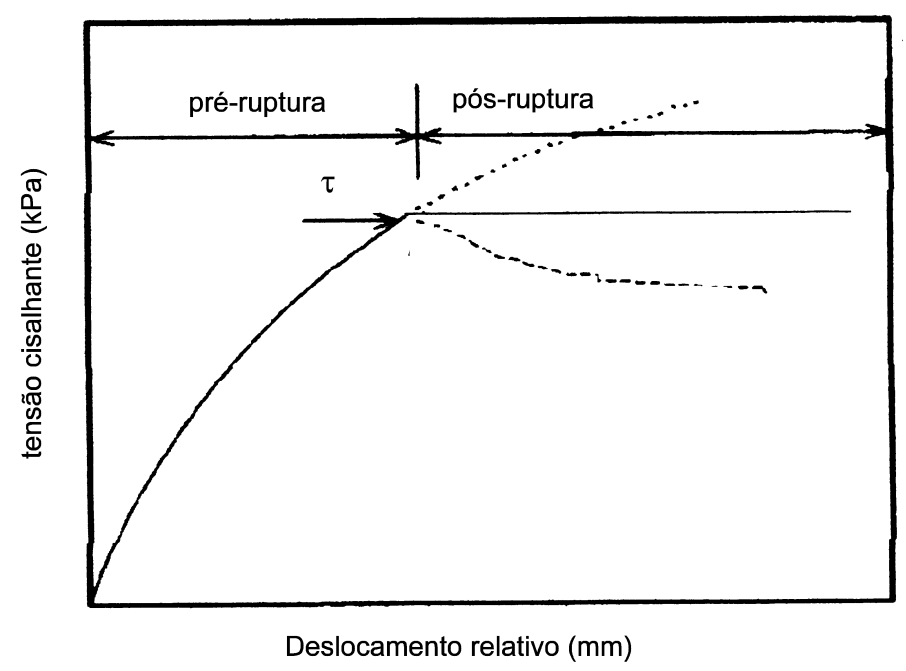

Figura 6.14 - Curva de variação de tensão cisalhamente na interface estaca-solo (Zhu e Chang, 2002) 


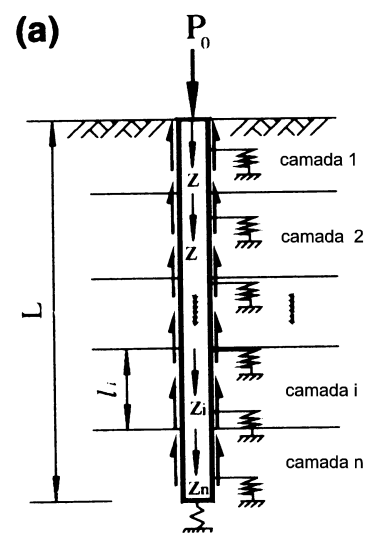

(b)

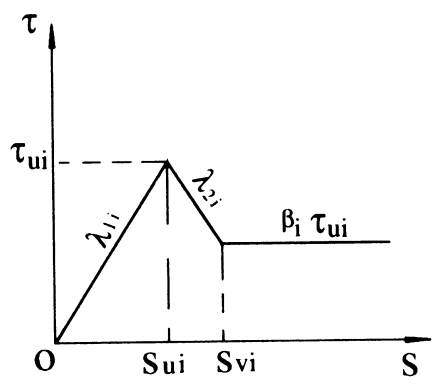

Figura 6.15 - Modelo simplificado de análise de interação estaca-solo: a) estaca sobre apoios elásticos; b) tensão tangencial mobilizada em função do deslocamento (Liu et al., 2004)

Guo (2001) também utiliza um modelo tri-linear elasto-plástico para interfaces estaca-solo em maciço não homogêneos com pico de tensão (Figura 6.16).

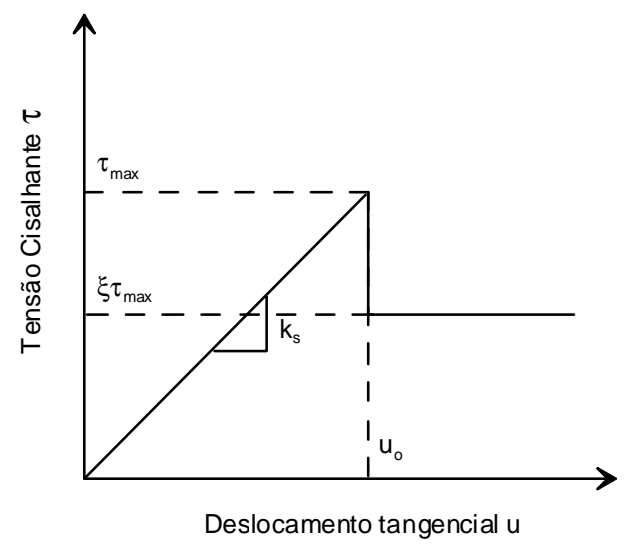

Figura 6.16 -Modelo tri-linear para tensão tangencial mobilizada em função do deslocamento (Guo, 2001)

Para interpretar resultados de ensaios de arrancamento de reforços de aço e geossintéticos executados em solo e em rocha, Gurung e Wao 2001) propõe uma equação hiperbólica, para melhor ajustar seus resultados experimentais.

$\tau=\frac{w}{\frac{1}{k_{s}}+\frac{w}{\tau_{\max }}}$

Uma outra relação não linear também baseada na equação hiperbólica (Modelo de Duncan e Chang (1970). foi utilizada por Xiao et al. (2002) para interpretar resultados de curvas carga-recalque de estacas de grande diâmetro. Nesse trabalho, os autores desenvolveram a formulação para maciço estratificado. 
No entanto, a solução analítica para problemas descritos com comportamento não-linear é quase que inexistente, devido ao elevado grau de hiperestaticidade e, principalmente, devido à maioria das análises não lineares serem iterativas.

Dessa maneira, os métodos numéricos se apresentam como uma ferramenta de grande eficiência. Destaca-se na solução da Equação (6.15), o Método dos Elementos Finitos (MEF), que em problemas unidimensionais consiste na utilização de elementos reticulares (elementos de barra) sobre apoios elásticos.

O cálculo dos coeficientes de reação de cada apoio é feito em função do comportamento imaginado para interface ou para a ponta.

Dessa maneira, é possível adotar um comportamento não linear através do cálculo dos coeficientes de reação, bastando para isso que se disponha de uma função que represente a variação desses coeficientes em função dos deslocamentos.

Como desmonstrado no Capítulo V desta dissetação, as Equações 4.37 e 4.38 podem fornecer os coeficientes $k_{T}$ e $k_{N}$ não-lineares para problemas de interfaces estacasolo submetidos a tensões de cisalhamento.

Essa equações foram utilizadas na análise dos resultados experimentais de carregamentos estáticos, em modelos de estacas publicados por Orlando (2000).

\subsubsection{Resultados Experimentais de Orlando (2000)}

Orlando (2000) divulgou os resultados de provas de carga realizadas à tração e à compressão realizadas em modelos de estacas metálicas executadas em areia.

Esses ensaios foram realizados em modelos reduzidos com relação comprimento/diâmetro de 10 vezes.

As estacas consistiam em tubos metálicos de 76,2 mm de diâmetro externo e espessura da parede $1,2 \mathrm{~mm}$, com peso nominal de $1,1 \mathrm{kN} / \mathrm{m}$ e $780 \mathrm{~mm}$ de comprimento. Sua superfície externa recebeu um tratamento com a colagem de grãos de areia para simular a rugosidade, tornando o diâmetro final de $78 \mathrm{~mm}$.

O solo utilizado é classificado com uma areia fina média (Figura 6.17) e suas propriedades mecânicas de resistência foram avaliadas em função do índice de vazios (Figura 6.18). 


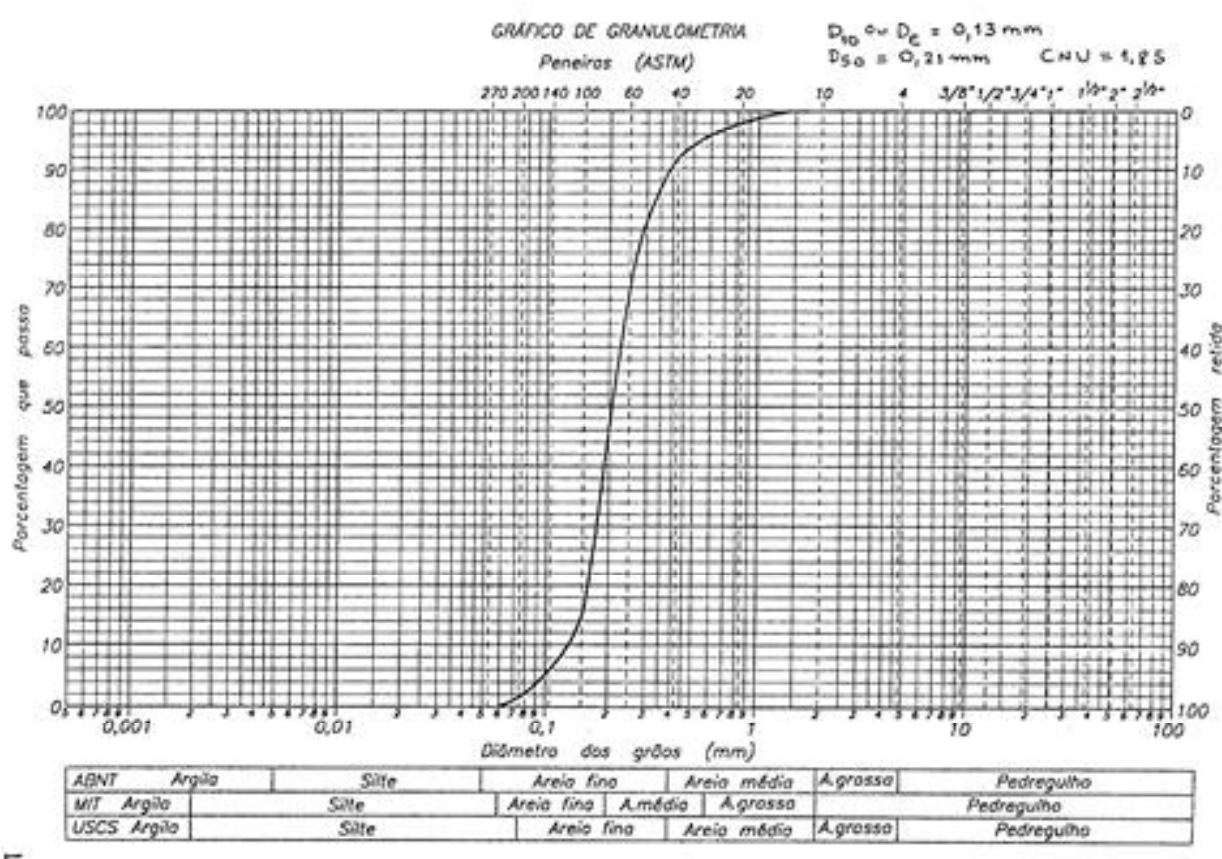

Figura 6.17 - Curva Granulométrica da areia utilizada por Orlando, 2000.

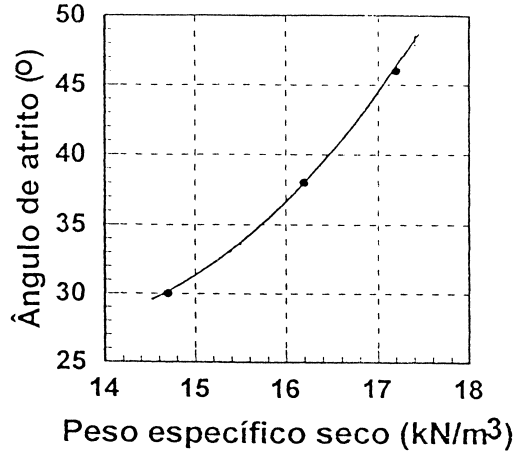

(a)

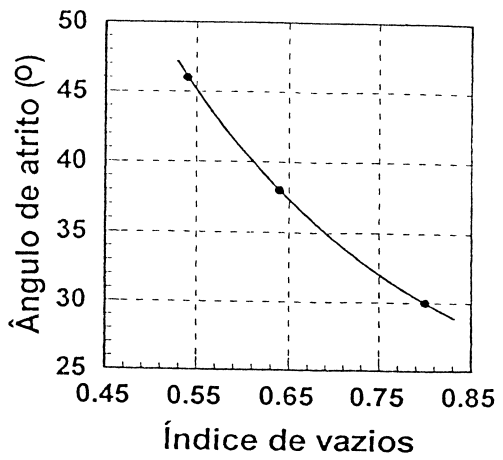

(b)

Figura 6.18 - Ângulo de atrito de pico: a) em função do peso específico; b) em função do índice de vazios (Orlando, 2000).

As envoltórias de Morh-Coulomb para resistência ao cisalhamento de pico e residual estão mostradas na Figura 6.19.

Os ensaios foram montados com areia no estado fofa e compacta e o carregamento realizado com deslocamento controlado na velocidade de 0,25 $\mathrm{mm} /$ minuto. Os modelos foram instalados sempre aos pares e ensaiados com pelo menos três carregamentos diferentes em cada modelo na sequência tração/compressão/tração e compressão/tração/compressão, respectivamente. 


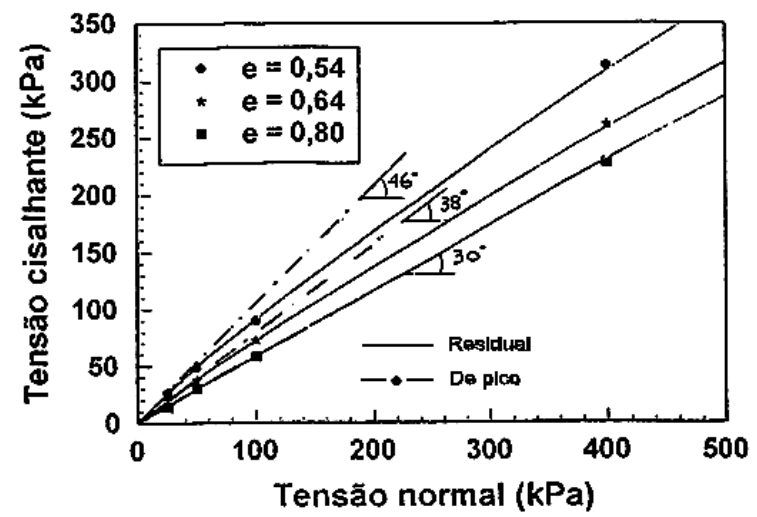

Figura 6.19 - Envoltoria de Morh-Coulomb para a resistência da areia (Orlando, 2000).

Os resultados dos experimentos de Orlando (2000) executados em modelos de estacas $\frac{L}{D}=10$ com carregamento vertical de tração e compressão são mostrados nas Figuras 6.20 e 6.21 para os casos de areia fofa e densa, respectivamente.

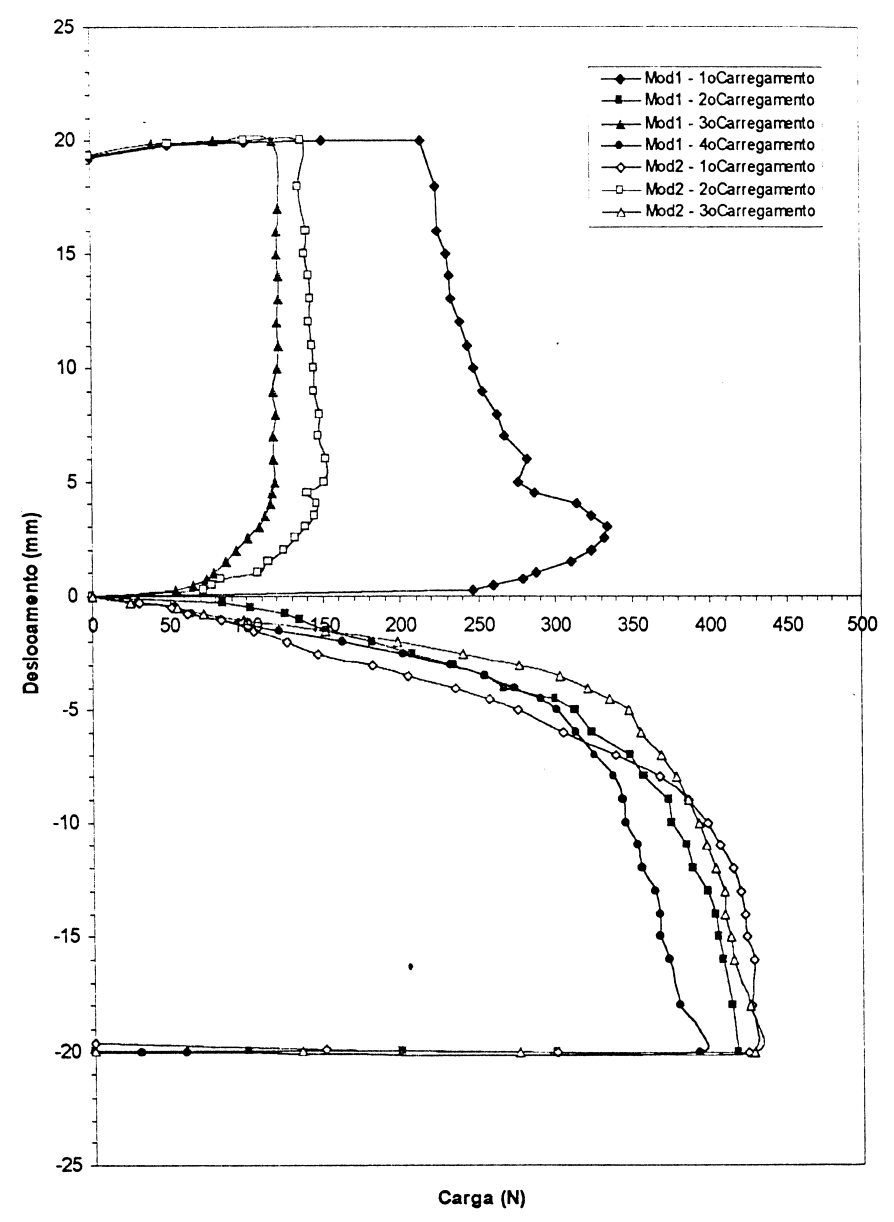

Figura 6.20 - Curva carga-deslocamento para os ensaios em modelo com areia fofa e $\frac{L}{D}=10$ (Orlando, 2000). 


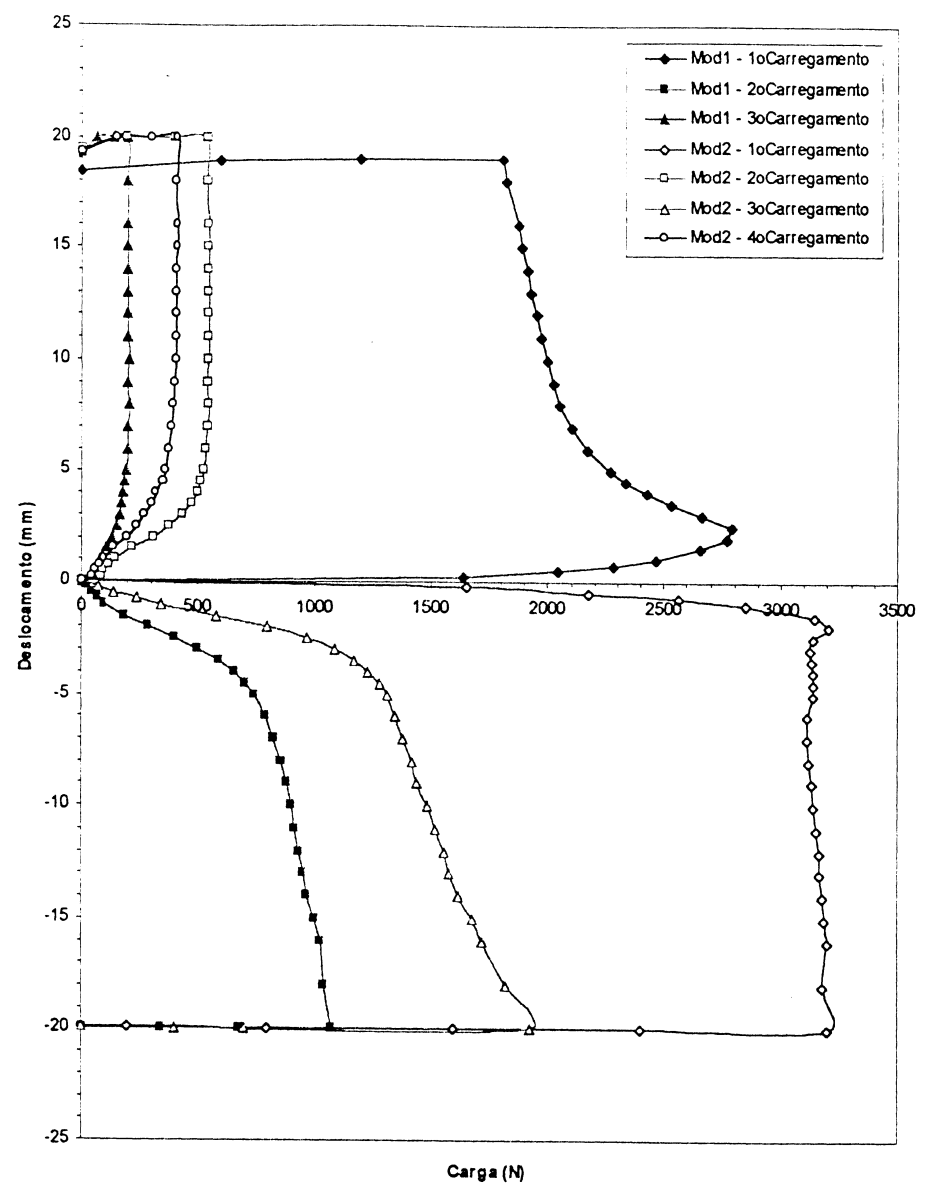

Figura 6.21 - Curva carga-deslocamento para os ensaios em modelo com areia compacta e $\frac{L}{D}=10$ (Orlando, 2000).

6.1.2. Análise numérica dos ensaios de Orlando (2000) através de modelos unidimensionais

A análise numérica dos ensaios de Orlando (2000) foi feita com o programa FTOOL versão 2.11, desenvolvido por Luiz Fernando Martha, da Pontíficia Universidade Católica do Rio de Janeiro. Esse programa resolve sistemas planos formados por elementos de barra sobre apoios fixos ou elásticos.

Para proceder à análise considerando o comportamento não-linear, foram calculados os coeficientes de rigidez equivalentes para cada deslocamento de maneira iterativa pelo procedimento descrito no Capítulo V, através das equações 5.32 a 5.38. 
Na simulação admitiu-se que a estaca é formada por 10 elementos de barra, apoiados sobre 5 linhas de apoios deformáveis na lateral e um apoio na ponta (Figura 6.22).

Na simulação dos resultados de Orlando (2000), consideroutse a rigidez da ponta nula, de forma a obter carga mobilizada na ponta igual a zero.

Foram selecionados dois casos para aplicação da formulação proposta nessa tese em análise unidimensional.

O primeiro caso simulado corresponde ao primeiro carregamento à compressão da estaca de relação $\frac{L}{D}=10$, executada no maciço de areia fofa. Nesse caso, a curva carga-deslocamento experimental não apresentou pico de resistência, sendo que a resistência máxima foi obtida para deslocamento da ordem de $11 \mathrm{~mm}$.

Os parâmetros utilizados para a simulação são mostrados na Tabela 6.1.

Tabela 6.1 - Parâmetros utilizados na simulação da Estaca de $\frac{L}{D}=10$, executados em maciço de areia no estado fofo.

\begin{tabular}{cc}
\hline DIÂMETRO DA ESTACA $(\mathrm{m})$ & 0.078 \\
PESO ESPECÍFICO $\left(\mathrm{kN} / \mathrm{m}^{3}\right)$ & 14.1 \\
COEFICIENTE DE EMPUXO $=$ & 0.8 \\
$\delta$ residual $\left({ }^{\circ}\right)$ & 27 \\
$k\left(\mathrm{kN} / \mathrm{m}^{4}\right)$ & 7000 \\
$\eta ? \mathrm{~m} ?$ & 0.002 \\
\hline
\end{tabular}

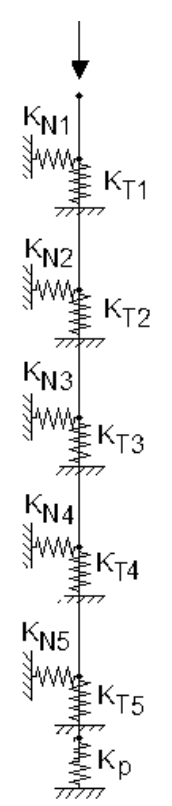

Figura 6.22 - Modelo numérico da estaca $\frac{L}{D}=10$ de Orlando (2000). 
Os resultados da simulação são mostrados em comparação com os resultados experimentais através da curva carga-deslocamento na Figura 6.23.

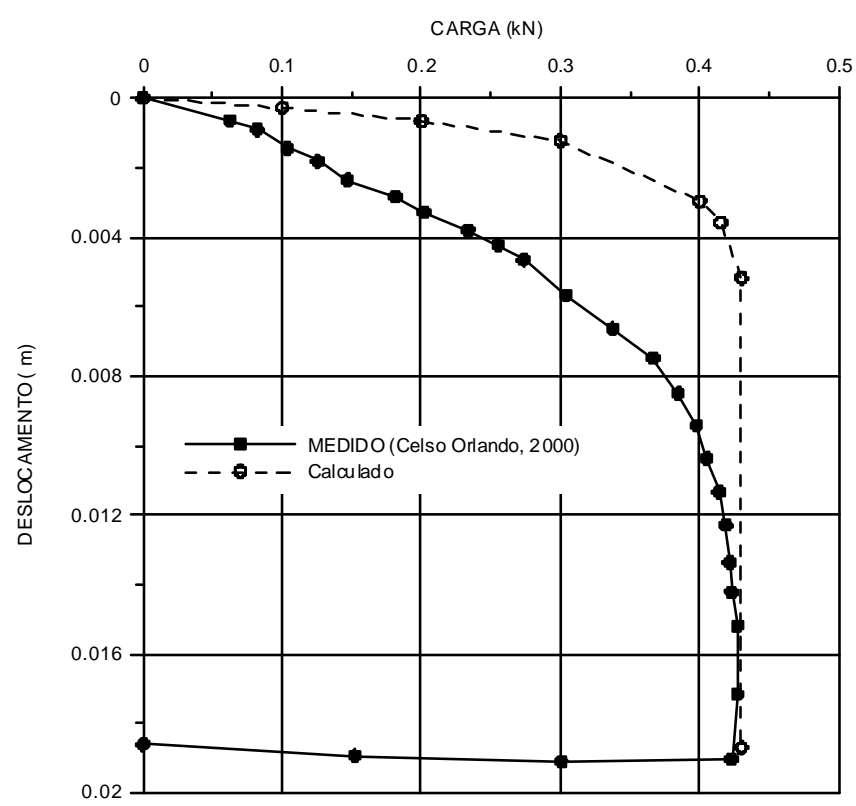

Figura 6.23 - Curva carga-recalque medida e calculada para a estaca de $\frac{L}{D}=10$, executada em areia fofa.

A análise efetuada pemitiu também o traçado do diagrama de esforço normal mobilizado ao longo da estaca para cada nível de carregamento analisado (Figura 6.24).

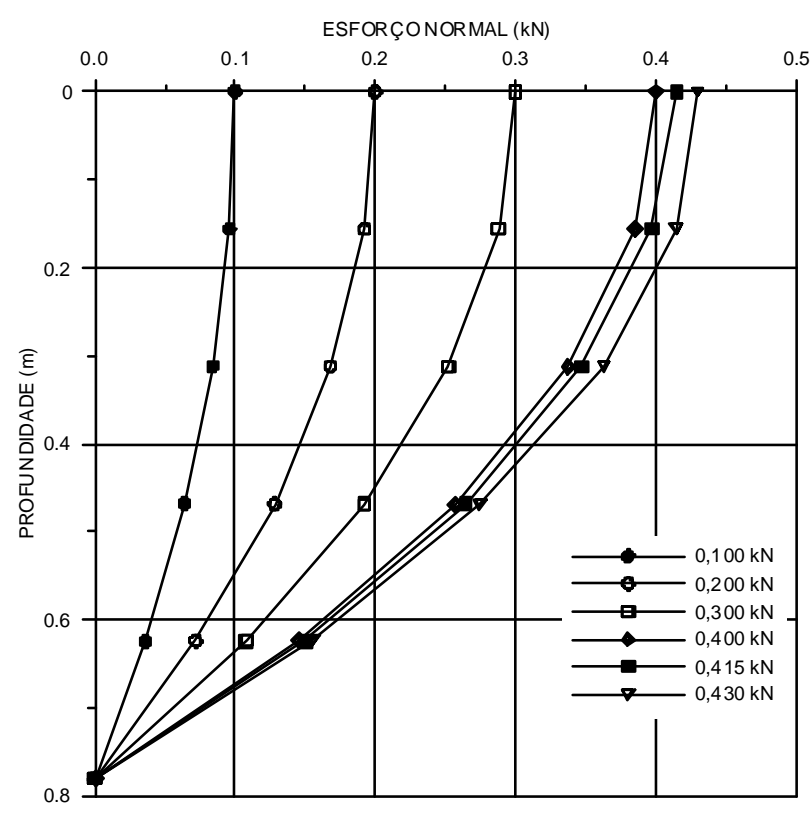

Figura 6.24 - Diagrama de esforço normal calculado na simulação da prova de carga no modelo $\frac{L}{D}=10$, executada em areia fofa. 
O segundo caso simulado corresponde ao primeiro carregamento do modelo 2 à compressão da estaca de relação $\frac{L}{D}=10$, executada no maciço de areia compacta. Nesse caso, a curva carga-deslocamento mostrou uma ruptura com pico de resistência atingido com deslocamento da ordem de $2 \mathrm{~mm}$. Os parâmetros utilizados para a simulação são mostrados na Tabela 6.2.

Tabela 6.2 - Parâmetros utilizados na simulação da Estaca de $\frac{L}{D}=10$, executados em maciço de areia no estado compacto.

\begin{tabular}{cc}
\hline DIÂMETRO DA ESTACA $(\mathrm{m})$ & 0.078 \\
PESO ESPECÍFICO $\left(\mathrm{kN} / \mathrm{m}^{3}\right)$ & 17.7 \\
COEFICIENTE DE EMPUXO $=$ & 4.0 \\
$\delta$ residual $\left({ }^{\circ}\right)$ & 33 \\
$k\left(\mathrm{kN} / \mathrm{m}^{4}\right)$ & 7000 \\
$\eta ? \mathrm{~m} ?$ & 0.0005 \\
\hline
\end{tabular}

A curva carga-deslocamento calculada é mostrada na Figura 6.25.

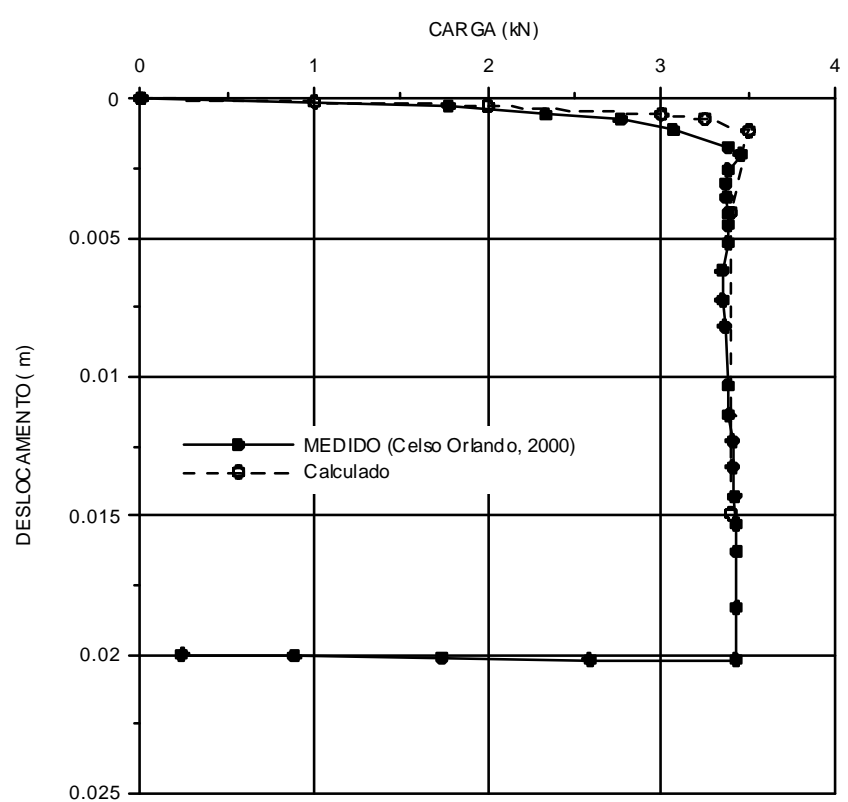

Figura 6.25 - Curva carga-recalque medida e calculada para a estaca de $\frac{L}{D}=10$, executada em areia compacta.

O diagrama de esforço normal calculado o longo da estaca está mostrado na Figura 6.26. 


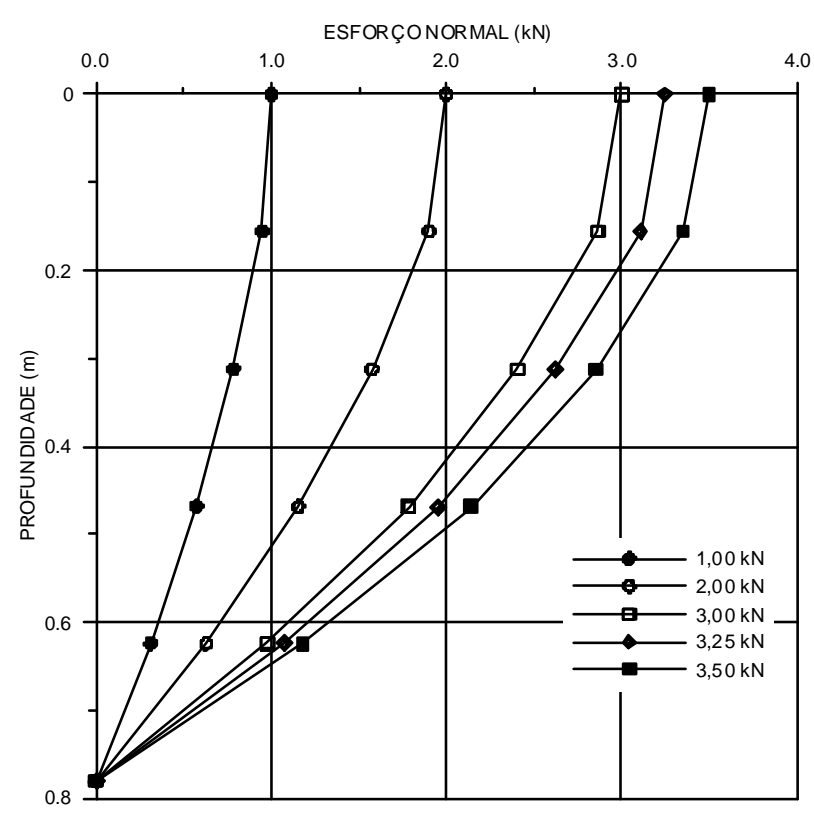

Figura 6.26 - Diagrama de esforço normal calculado na simulação da prova de carga no modelo $\frac{L}{D}=10$, executada em areia densa.

\subsection{Modelos bidimensionais}

Esta solução geralmente é conseguida com o uso de métodos numéricos, como o método dos elementos finitos e diferenças finitas.

Nesses casos, a ferramenta de cálculo mais utilizada é o método dos elementos finitos, cuja solução pode ser apresentada tanto para modelos planos, quanto para modelos tridimensionais.

Um dos trabalhos pioneiros na análise dos mecanismos de transferencia de carga de estacas escavadas usando o método dos elementos finitos com elementos de interface foi apresentado por Ellison et al. (1971). Nesse trabalho, é apresentada a modelagem de uma estaca isolada embutida em meio contínuo elástico, bidimensional axissimétrico. $\mathrm{O}$ modelo constitutivo utilizado para interface considera elementos de mola entre a lateral da estaca e o solo com os coeficientes de rigidez normal e vertical constantes até o limite da resistência ao atrito lateral.

Ellison et al.(1971) defendem que uma análise não linear de interfaces soloestrutura ao longo do contato lateral entre o solo e o fuste da estaca tem que possuir os seguintes requisitos básicos:

$>$ um mecanismo de ruptura entre a lateral da estaca e o solo; 
$>$ uma relação tensão-deformação constitutiva para o comportamento mecânico do solo adjacente ao fuste da estaca, no topo e na ponta;

relação tensão-deformação constitutiva para o comportamento mecânico do elemento estrutural;

a sequência de carregamento;

o procedimento de solução.

Os autores fizeram uma aplicação desse procedimento na análise de estacas escavadas embutidas num solo argiloso de Londres, cujo comportamento reológico foi considerado como uma função tri-linear, onde a resistência ao cisalhamento na interface foi obtida a partir da adesão entre a estaca e o solo.

O procedimento de cálculo utilizado teve a seguinte rotina:

> aplicação das propriedades constitutivas dos materiais envolvidos;

$>$ aplicação das tensões geostáticas, em função do peso específico de cada material;

$>$ aplicação das propriedades das molas normais e tangenciais (horizontal e vertical);

aplicação da sequência de carregamento;

$>$ solução do primeiro estágio de carregamento, de modo que as tensões e os deslocamentos obtidos fossem adicionados ao estado de tensão e deslocamento inicial;

$>$ levantamento de todas as forças verticais em cada elemento de mola ao longo da profundidade do fuste;

$>$ aplicação de novas propriedades dos materiais envolvidos;

$>$ verificação se o critério de ruptura de adesão esta atendido em cada elemento de mola;

> verificação do equilíbrio entre a carga total aplicada e as reações verticais em cada elemento de mola;

$>$ aplicação do novo incremento de carga e repetição do processo de cálculo.

Lopes (1979), com base em análises numéricas em elementos finitos, propõe um modelo de tensões em torno de uma estaca carregada axialmente (Figura 6.27). O modelo proposto representa a trajetória de tensões que ocorrem no entorno da estaca até sua ruptura. $\mathrm{O}$ autor também compara a trajetória de tensões na ruptura de uma estaca com as tensões de ruptura do solo, em um ensaio triaxial (Figura 6.28). 


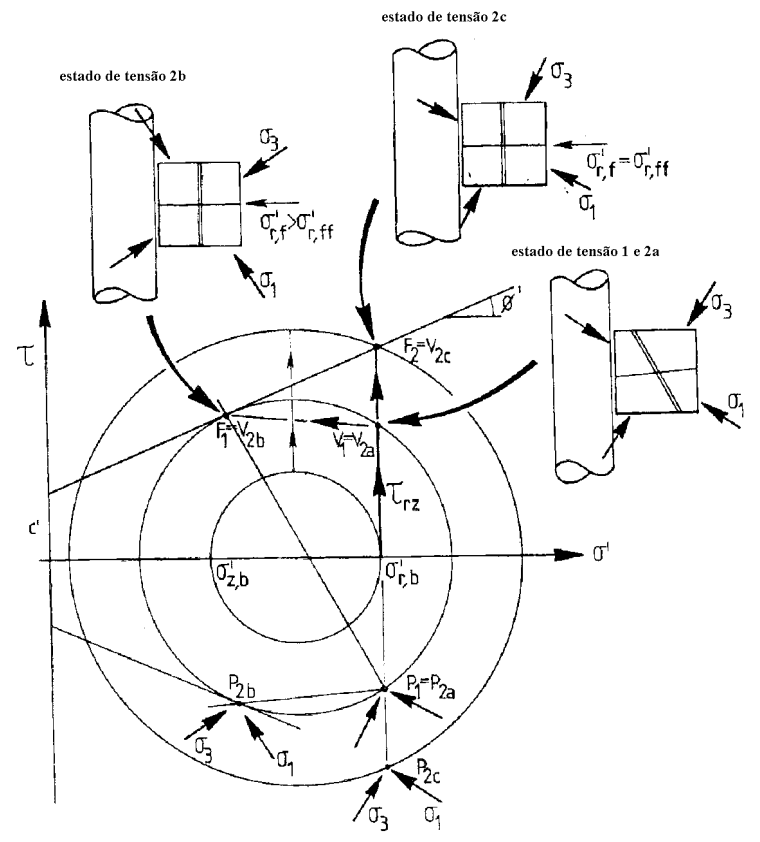

Figura 6.27 - Possibilidades de trajetória de tensões de uma estaca até a ruptura.

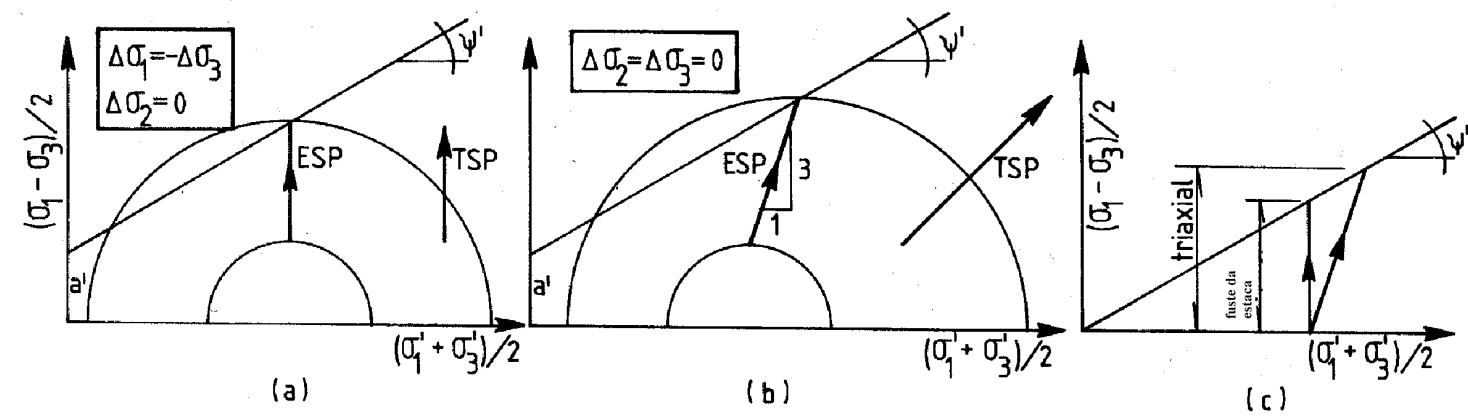

Figura 6.28 - Comparação entre as trajetórias de carregamento: (a) em torno de fuste de uma estaca, (b) em ensaio triaxial convencional em um solo não dilatante, (c) comparação entre eles.

Modelos mais complexos para determinação das tensões no entorno de uma estaca podem ser verificados nos trabalhos de Luk e Keer (1980) e de Liang e Feng (2002).

Potts e Martins (1982) realizam a simulação de carregamento axial de modelo reduzido de estaca executado em argila para determinação da resistência ao atrito lateral. O maciço de solos foi considerado com comportamento prescrito pelo modelo Cam-Clay modificado e o elemento estrutural considerado como elástico não-linear. Jardine et al. (1986) simularam a influência de modelos constitutivos não lineares na análise de interação solo-estrutura de estacas através de elementos finitos 
2D. Os autores utilizaram um modelo empírico de relação tensão-deformação, baseado em uma função de degradação logaritmica para o módulo de elasticidade. O modelo é utilizado para simular o carregamento de uma estaca de $30 \mathrm{~m}$ de comprimento executada em argila mole.

Neves (1993) apresenta a simulação de estacas escavadas utilizando elementos finitos axissimétricos. A interface foi modelada com comportamento elasto-plástico perfeito, com o uso do critério de ruptura de Morh-Coulomb. Nesse trabalho, a autora destaca, ainda, a influência da dilatânc ia e compara os resultados obtidos na simulação com os resultados de provas de carga em estacas escavadas instrumentadas executadas com carga de compressão e de tração.

Potts (2003) faz uma discussão sobre a aplicação de métodos numéricos para previsão do comportamento de obras geotécnicas, destacando a importância das equações de equilíbrio, de compatibilidade, de comportamento constitutivo dos materiais e das condições de contorno, para se obter uma análise confiável. Faz uma comparação entre as soluções numéricas no estado plano de deformação e no estado plano axissimétrico. No trabalho, o autor discute ainda o problema de convergência para os coefientes de rigidez em modelos não lineares. Destaca ainda a importância da dilatância na determinação da capacidade de carga lateral e na forma da curva carga recalque de estacas carregadas axialmente.

Bouzid et al. (2004) desenvolveram um elemento de interface para simular o contato estaca-solo, baseados no conceito de espessura nula para elementos de juntas introduzido por Goodman et al. (1968). A formulação desse elemento foi deduzida para análise plana de problemas aximétricos, com carregamentos simétricos ou não simétricos. Os elementos de interface podem ser facilmente implementados, acoplados a elementos triangulares de seis nós ou retangulares de oito nós. Sua matriz de rigidez possui solução fechada, cujos elementos são função apenas dos coeficientes de rigidez tangente e normal na interface.

Lee et al. (2002) realizaram uma simulação através de elementos finitos com modelos 2D axissimétricos para casos de estacas isoladas e 3D para grupos de estacas. Nesse estudo, os autores consideraram o aumento de carga provocado pelo atrito negativo em estacas. Adotaram para o elemento estrutural comportamento elástico linear e para o maciço de solos e interface foi considerado comportamento elásto plástico com o critério de ruptura de Morh-Coulomb. 
Mabsout et al. (1999) e Mabsout e Sadek (2003) utilizaram o método dos elemento finitos com análise 2D axissimétrica, para simular o efeito do deslizamento durante a cravação de estacas. O solo é representado com um modelo de estado crítico, com comportamento viscoso. Os resultados são mostrados através de diagramas de tensões em torno da estaca e curvas de deslocamento do topo em função do tempo. Também é feita uma interpretação da resistência lateral e total mobilizada em função do tempo.

Jeong et al. (2004) fazem uma comparação entre os resultados de análise bidimensional e tridimensional para cálculo de atrito negativo em estacas escavadas. A estaca foi considerada como elemento rígido elático linear, enquanto o maciço de argila foi representado por um modelo isotrópico elástico linear. A interface foi simulada com o modelo de ruptura de Morh-Coulomb e coeficientes de rigidez normal e de cisalhamento ajustados de acordo com os resultados.

No trabalho, os autores ainda fizeram uma análise paramétrica da influência do coeficiente de atrito na interface, da distribuição da carga ao longo da estaca e do efeito de grupo.

Sheng et al. (2005) realizaram uma análise da cravação de estacas através do método dos elementos finitos, usando elementos de interface. O elemento estrutural de fundação foi tratado como elemento rígido e o solo com comportamento prescrito pelo modelo Cam-Clay. Foram monitorados os deslocamentos e as tensões atuantes no topo e na base da estaca, e os resultados comparados com valores medidos em modelos de estacas submetidos a carregamentos axial em centrífuga.

Nesse trabalho, os autores utilizam uma formulação axissimétrica para grandes deslocamentos e simulam a cravação da estaca através de constantes cinéticas. Destacam, ainda, que em alguns casos, tiveram problemas de convergência.

Observando os trabalhos citados na bibliografia sobre a interpretação da transferência de esforços entre o elemento estrutural e o solo, percebe-se que, independentemente da forma que se aborde o problema (analítica ou numérica), os modelos necessitam de uma função que defina a curva tensão tangencial-deslocamentos. Na quase totalidade dos trabalhos, se admite que essa relação é linear, de modo que a solução geral fica condicionada apenas ao coeficiente de rigidez estaca-solo.

Observando o trabalho de Yu e Housby (1991) sobre a aplicação e o desenvolvimento de um modelo constitutivo de plasticidade para previsão do comportamento dos solos dilatantes, percebe-se facilmente que, em solos dilatantes, a 
determinação de uma função que aproxime os resultados experimentais é uma tarefa complexa e que na maioria das vezes tem-se que considerar duas funções diferentes: uma para o ramo da curva antes de se atingir o pico de resistência e outra para o ramo de caimento, até atingir o nível das tensões residuais.

A aplicação do modelo constitutivo aqui proposto e demonstrado para cálculo da tranferência de esforços torna-se um avanço devido ao fato de, através de uma única função matemática, ter a possibilidade concreta de se obter a curva tensão tangencialdeslocamento completa.

Esse modelo constitutivo para interfaces pode ser irrestritamente para solução de problemas de tranferências de esforços, bastando, para isso, apenas a substitituição dos coeficientes de rigidez normal e de cisalhamento originalmente propostos pelos seus autores pelos aqui sugeridos nas Equações 5.37 e 5.38 .

Como exemplos de aplicação e comprovação do potencial do modelo constitutivo aqui proposto, o mesmo foi utilizado na simulação de estacas trabalhando por atrito embutidas em solo arenoso, modelados pelo métodos dos elementos finitos aximétricos.

O elemento estrutural de fundação e o maciço de solos foram considerados como elásticos lineares, através de elementos triangulares de três nós. A interface foi considerada como elemento de quatro nós do tipo de Goodman et al. (1968), adaptados ao caso axissimétrico de acordo com a proposição de Bouzid et al. (2004).

A solução de problemas de transferência de esforços entre o elemento estrutural e o maciço de solos tem, na maioria dos casos reais, que utilizar modelos mais complexos e que permitam, não somente a determinação dos deslocamentos ao longo da estaca, mas o campo de tensões no maciços de solos no qual o elemento está embutido.

\subsubsection{Estaca submetida à compressão (Bernardes, 1989).}

Bernardes (1989) apresenta os resultados de provas de cargas instrumentadas em estacas modelo ensaiadas à compressão. As estacas foram construídas com tubos de alumínio do Tipo B-50 SWP de 3,5 m de comprimento, $75 \mathrm{~mm}$ de diâmetro externo e 4 mm de espessura da parede. Seu módulo de elasticidade foi de 70 GPa e sua tensão de escoamento $180 \mathrm{MPa}$ (Figura 6.29).

O maciço de solos foi executado em um tanque de concreto armado prismático medindo $3 \mathrm{~m}$ de profundidade, $4 \mathrm{~m}$ de largura e $4 \mathrm{~m}$ de comprimento. Utilizourse uma 
areia glaci-fluvial com coeficiente de uniformidade 2,04. Suas características fisicas se encontram na Figura 6.30. Sua deposição no interior do tanque foi feita com processo de chuva de areia, que conferiu ao maciço peso específico médio de $16,0 \mathrm{kN} / \mathrm{m}^{3}$ (valor mínimo de $15,8 \mathrm{kN} / \mathrm{m}^{3}$ e máximo de $16,6 \mathrm{kN} / \mathrm{m}^{3}$ ), utilizando-se de placa com abertura de $16 \mathrm{~mm}$.

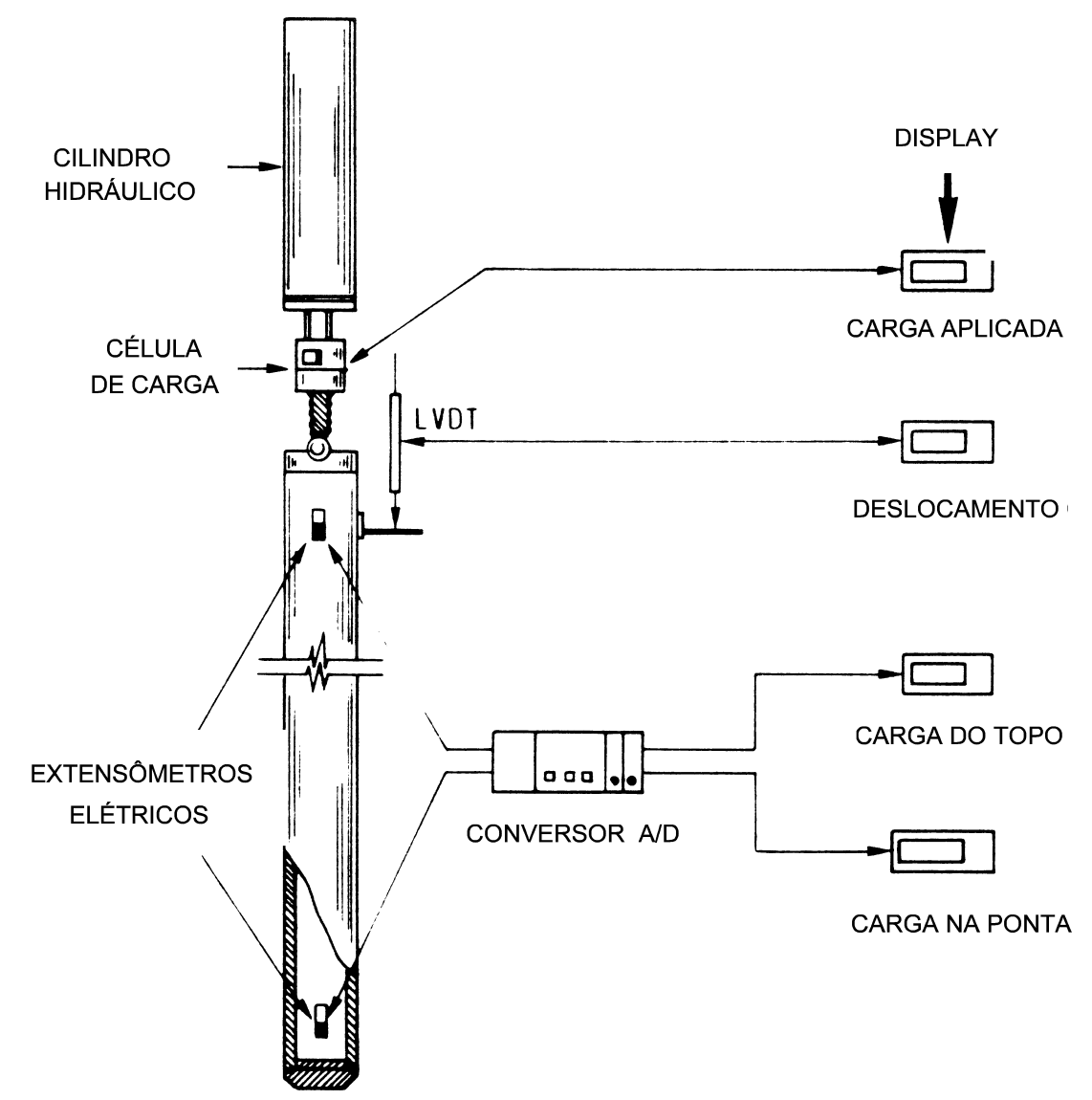

Figura 6.29 - Estaca instrumentada utilizada por Bernardes (1989).

As propriedades de resistência foram obtidas através de ensaios triaxiais em corpos de prova moldados em laboratório e conduzidos em condições secas e saturadas com várias porosidades diferentes. A Figura 6.31 reproduz o gráfico de ângulo de atrito em função da porosidade para este material.

Em seu trabalho, Bernardes (1989), utilizou o maciço de solos com porosidade inicial de 39,9\%, sendo o ângulo de atrito representativo por ele considerado como $38^{\circ}$. 


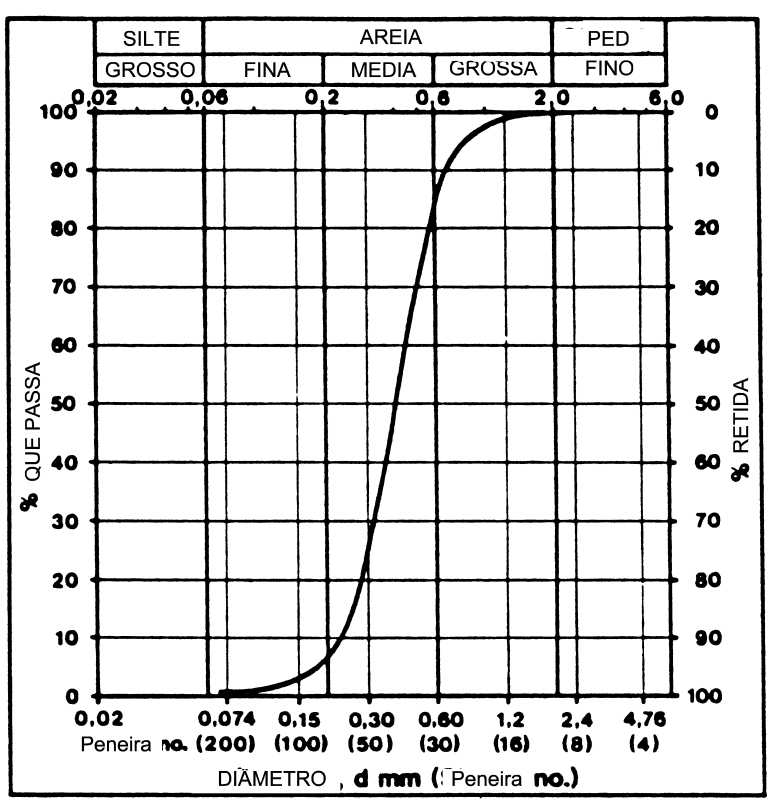

\begin{tabular}{|l|l|}
\hline MINERAL & 8 \\
\hline Quartzo & 35 \\
Na- Feldspato & 25 \\
K- Feldspato & 20 \\
Mica & 10 \\
Outros & 10 \\
& \\
\hline
\end{tabular}

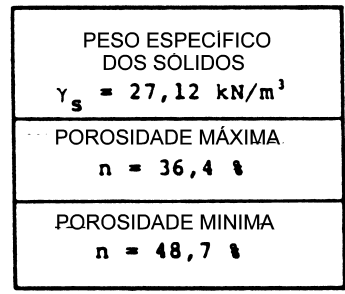

Figura 6.30 - Dados gerais da areia utilizada por Bernardes (1989)

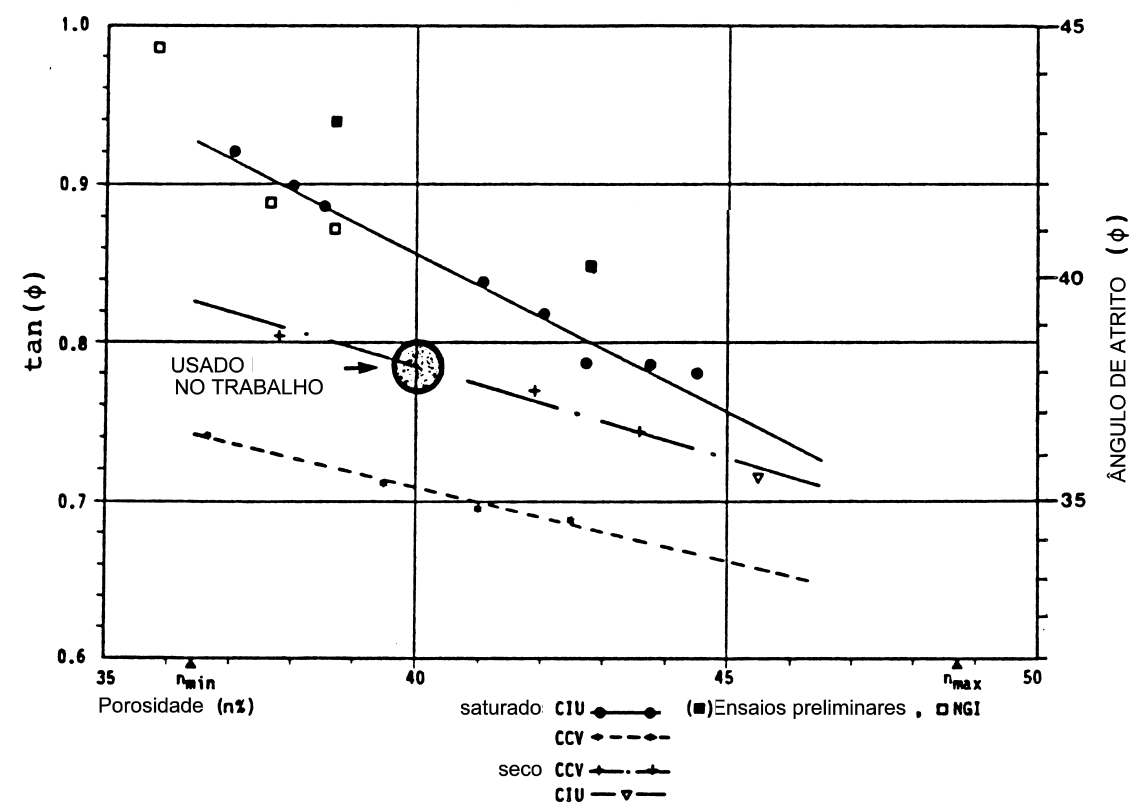

Figura 6.31 - Ângulo de atrito versus porosidade (Bernardes, 1989)

As provas de carga estáticas nos modelos foram realizadas em grupos de cinco estacas, com as seguintes caracteristicas: 
- Estaca 4 - Comprimento enterrado de $2,5 \mathrm{~m}$, com a lateral protegida com um tubo plástico, para eliminar o atrito lateral.

- Estaca 3 - Comprimento enterrado de 2,5 m com a ponta inserida em um tubo plástico, para evitar a resistência de ponta, medindo apenas o atrito lateral.

- Estaca 1 e 5 - Comprimento enterrado de 2,5 metros, sem nenhuma proteção.

- Estaca 2 - Estaca cravada no centro do tanque. Nela foram realizados ensaios estáticos e dinâmicos.

A Figura 6.32 mostra os resultados do ensaio na estaca 3, onde foram medidos carga lateral e os deslocamentos

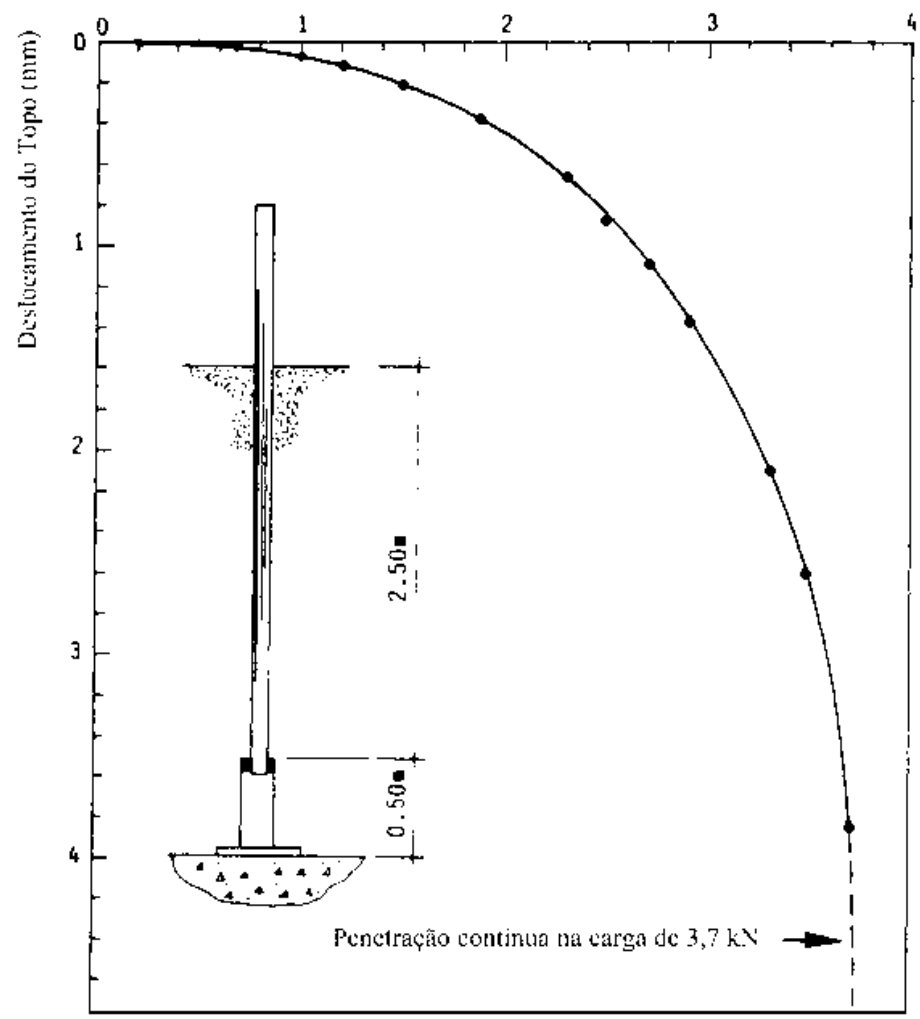

Figura 6.32 - Resultado dos ensaios de carregamento estático em modelo de estaca submetida apenas ao atrito lateral (Bernardes, 1989)

6.2.2. Simulação numérica dos resultados de Bernardes (1989) com elementos finitos bidimensionais.

A análise bidimensional dos ensaios de Bernardes (1989) foi feita com o programa JETTY, para análises de juntas de maciços rochosos, usando o método dos elementos finitos escrito por John e Goodman (Goodman, 1976). 
Uma adaptação foi feita para solução de problemas bidimensionais axissimétricos e para consideração de juntas com rigidezes variáveis a longo do comprimento da interface.

O ensaio 3 realizado por Bernardes (1989) foi simulado com elementos sólidos triangulares com comportamento elástico linear. O contato estaca solo representado por 5 elementos de interfaces, com rigidez calculada independentemente umas das outras, de acordo com as equações 5.36 e 5.37 .

Os parâmetros utilizados para a simulação são mostrados na Tabela 6.3.

Tabela 6.3 - Parâmetros utilizados na simulação dos resultados de Bernardes (1989)

\begin{tabular}{cc}
\hline DIÂMETRO DA ESTACA $(\mathrm{m})$ & 0.075 \\
PESO ESPECÍFICO $\left(\mathrm{kN} / \mathrm{m}^{3}\right)$ & 16.0 \\
COEFICIENTE DE EMPUXO $=$ & 0.65 \\
$\delta$ residual $\left({ }^{\circ}\right)$ & 27 \\
$k\left(\mathrm{kN} / \mathrm{m}^{4}\right)$ & 7000 \\
$\eta(\mathrm{m}) ?$ & 0.0025 \\
\hline
\end{tabular}

A Figura 6.33 mostra a malha de elementos finitos utilizada na simulação e a deformada correspondente ao carregamento de $3 \mathrm{kN}$.
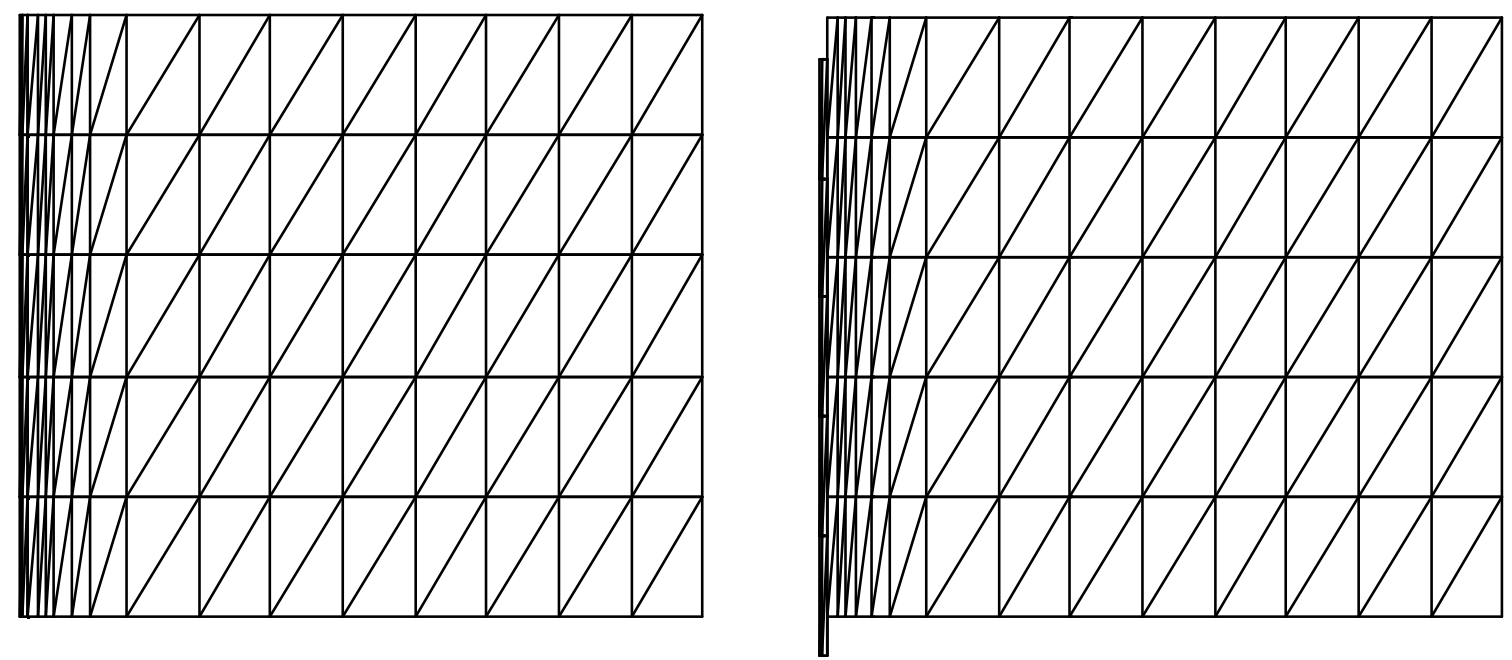

Figura 6.33 - Deformada obtida na simulação dos resultados de Bernardes (1989), pelo método dos elementos finitos.

Os resultados da simulação são mostrados em comparação com os resultados experimentais, através da curva carga-deslocamento na Figura 6.34. 


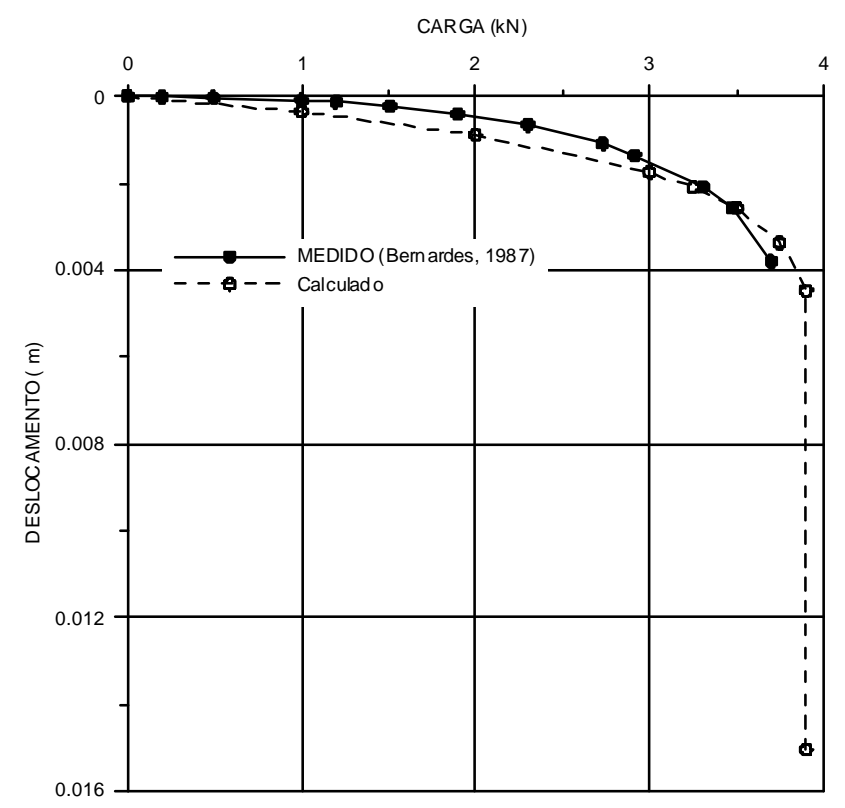

Figura 6.34 - Curva carga-recalque medida e calculada na simulação dos resultados de Bernardes (1989).

O diagrama de esforço normal mobilizado ao longo da estaca é mostrado na Figura 6.35.

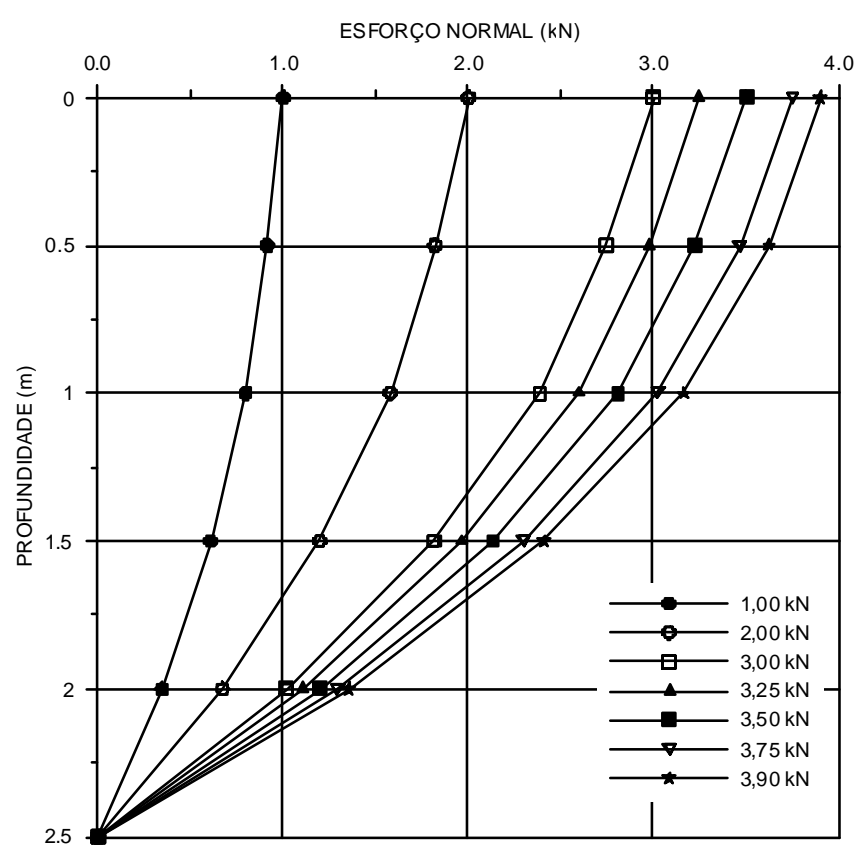

Figura 6.35 - Diagrama de esforço normal calculado para estaca 5 de Bernardes (1989).

A simulação permitiu também a avaliação da distribuição de tensões no meio contínuo. Esses diagramas estão mostrados nas Figuras 6.36 a 6.41 . 

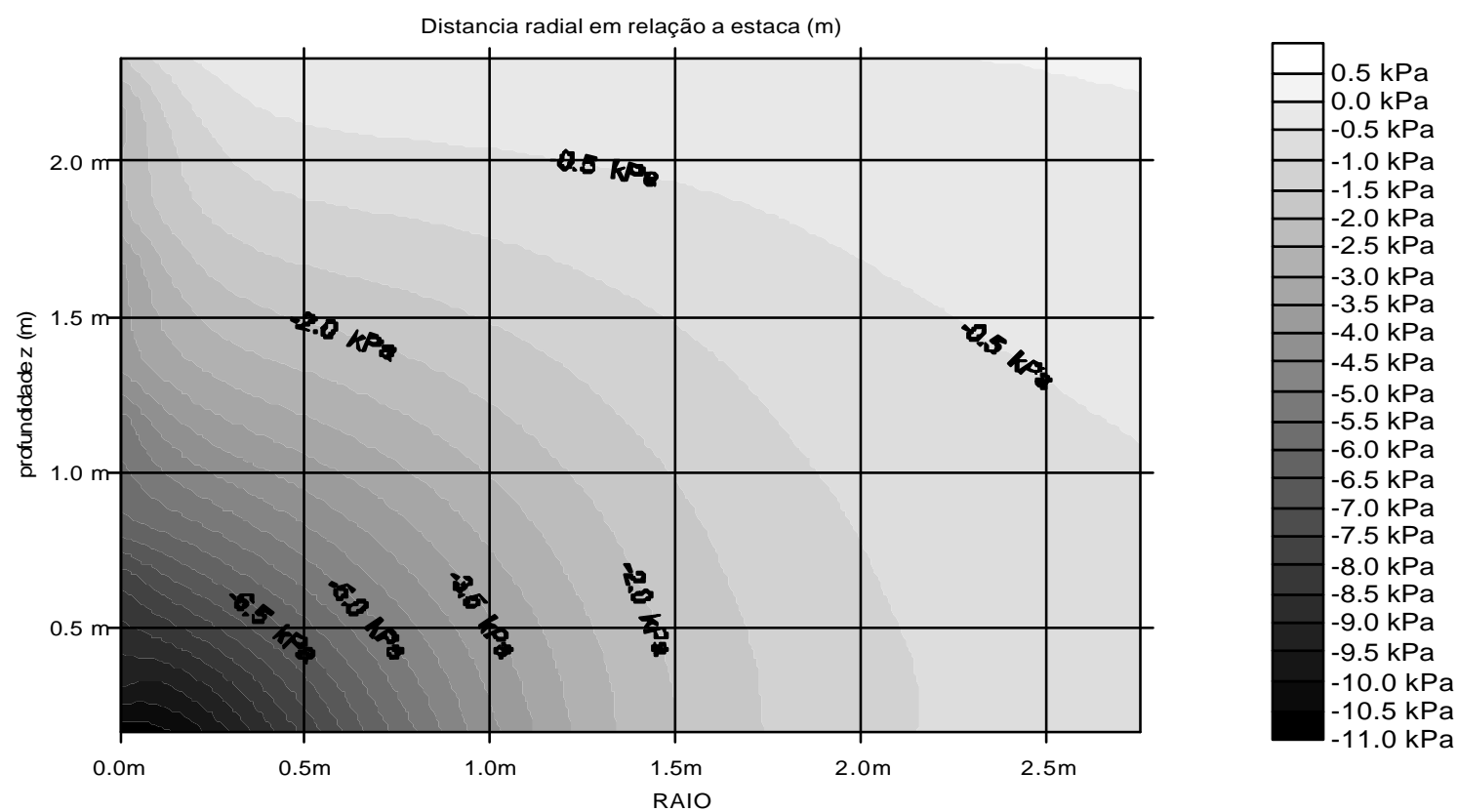

Figura 6.36 - Diagrama de distribuição das tensões principais menor

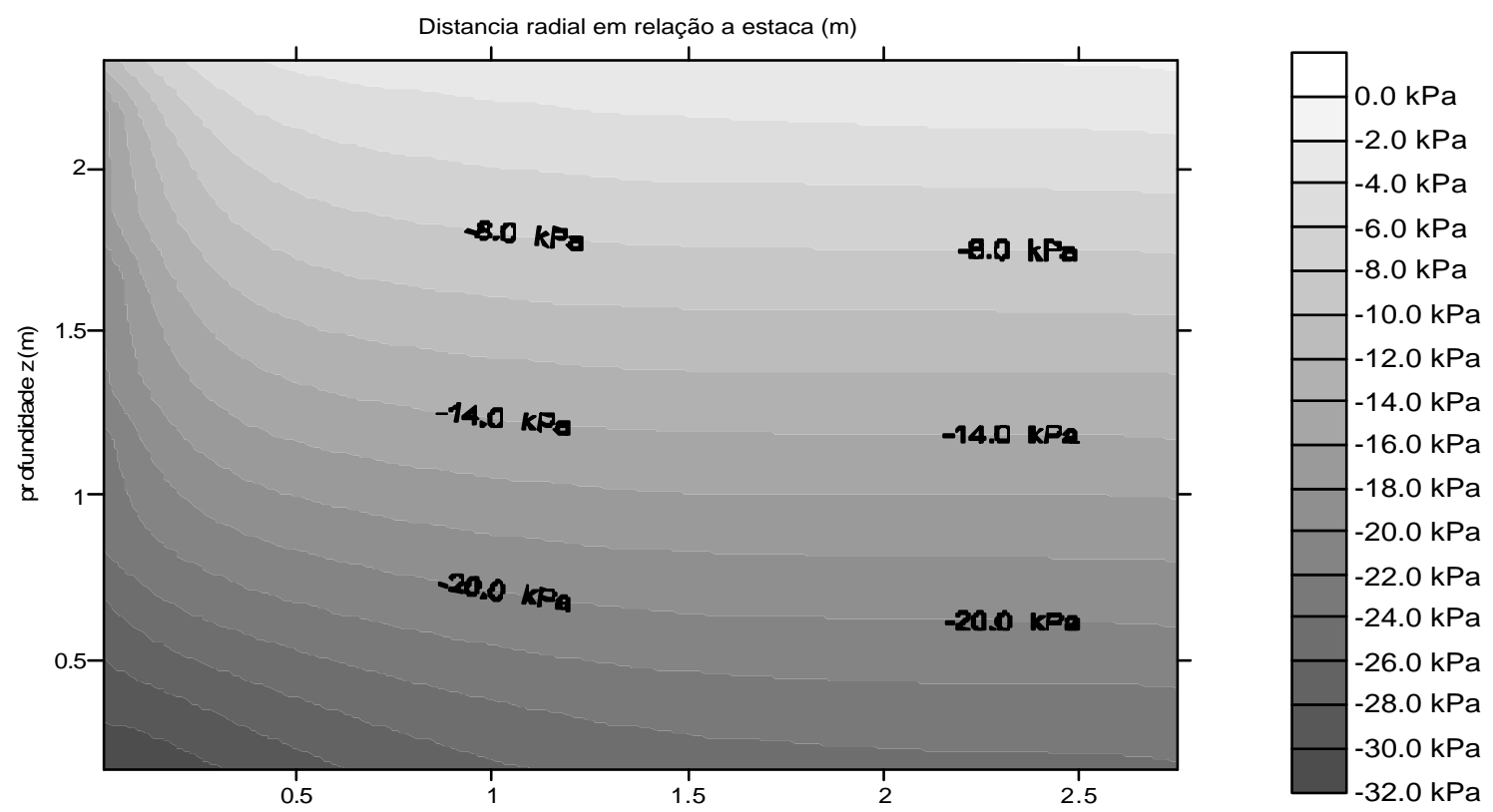

Figura 6.37 - Diagrama de distribuição das tensões principais maior 


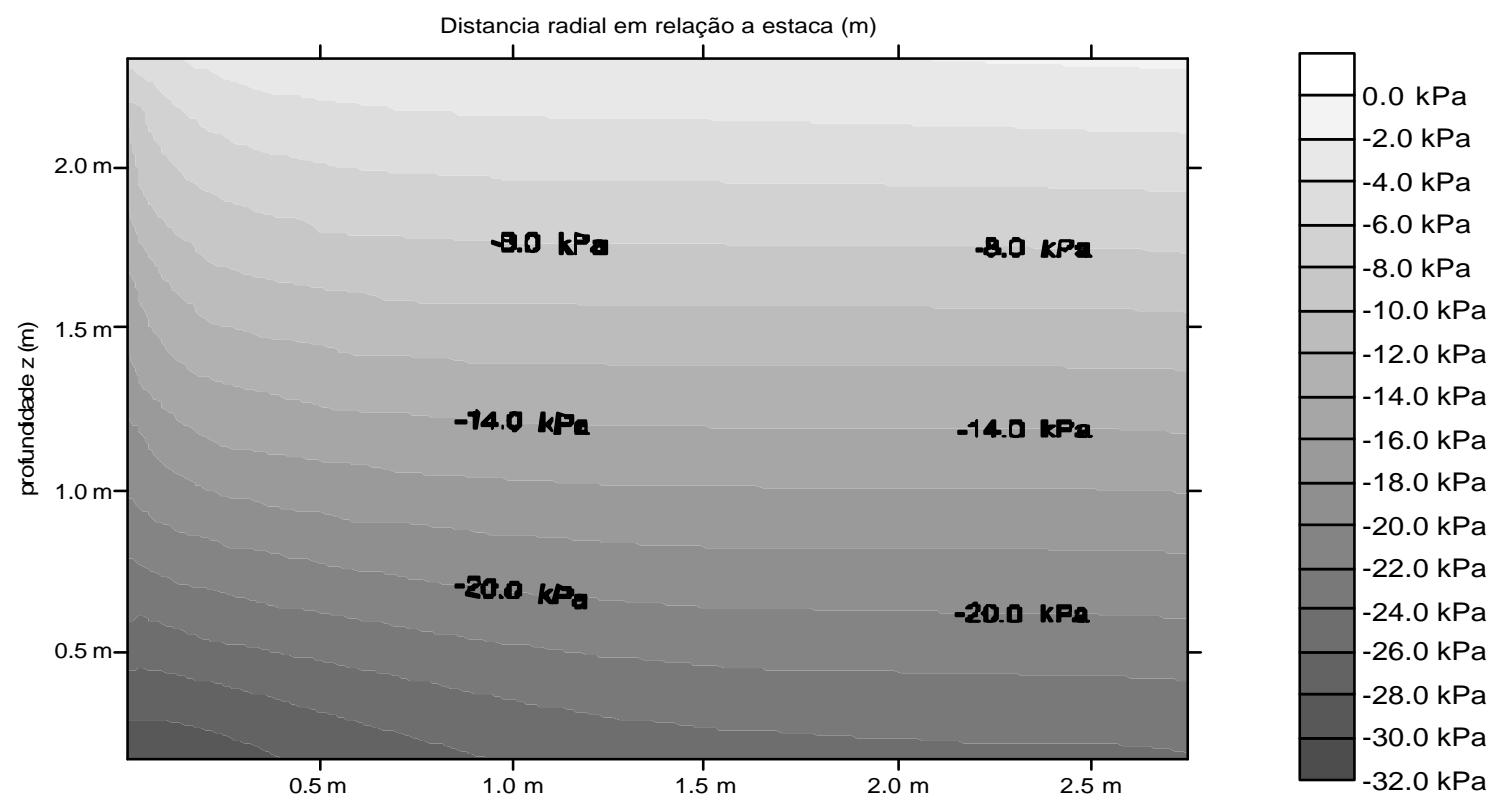

Figura 6.38 - Diagrama de distribuição das tensões na direção radial

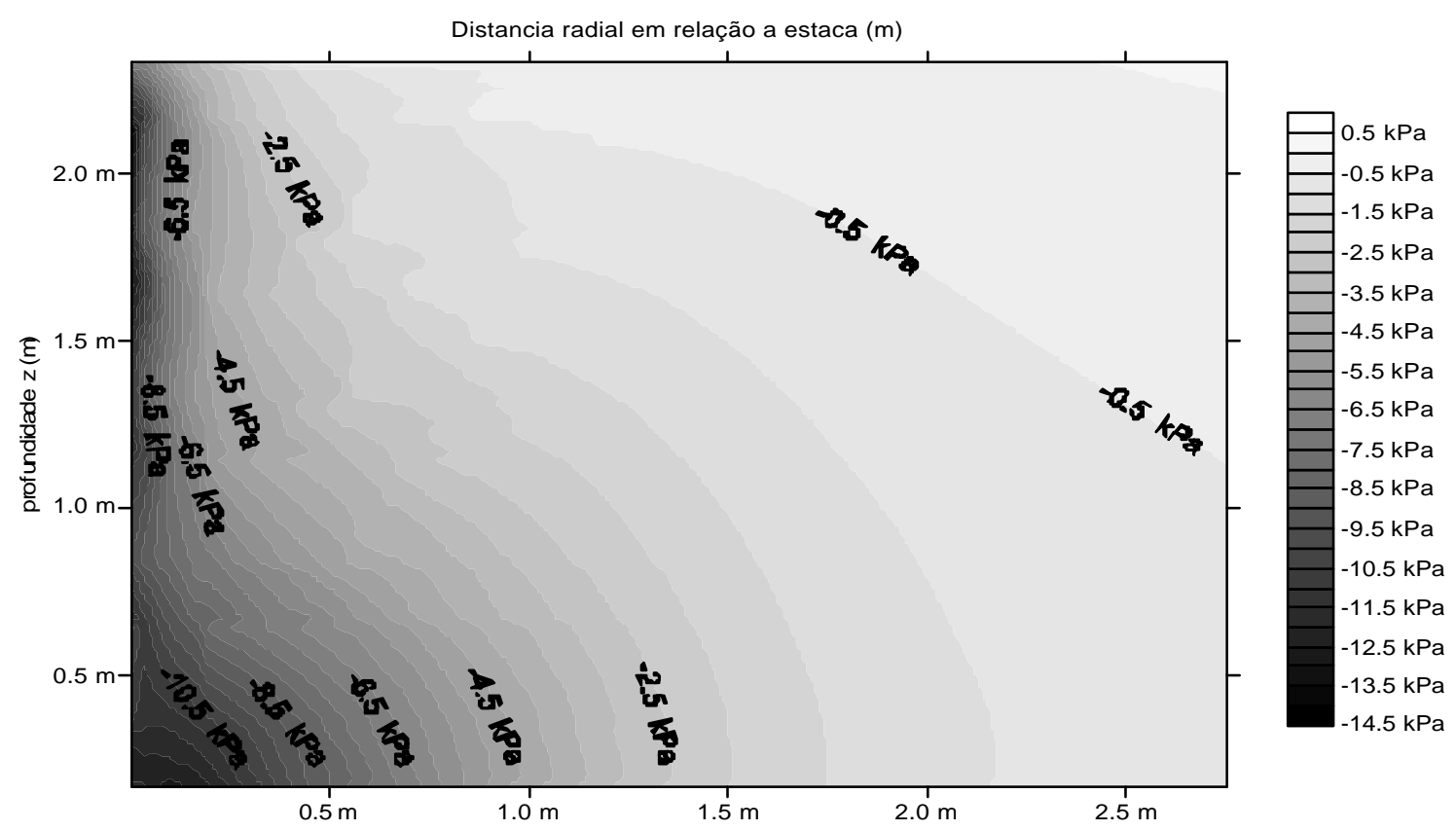

Figura 6.39 - Diagrama de distribuição das tensões cisalhantes 


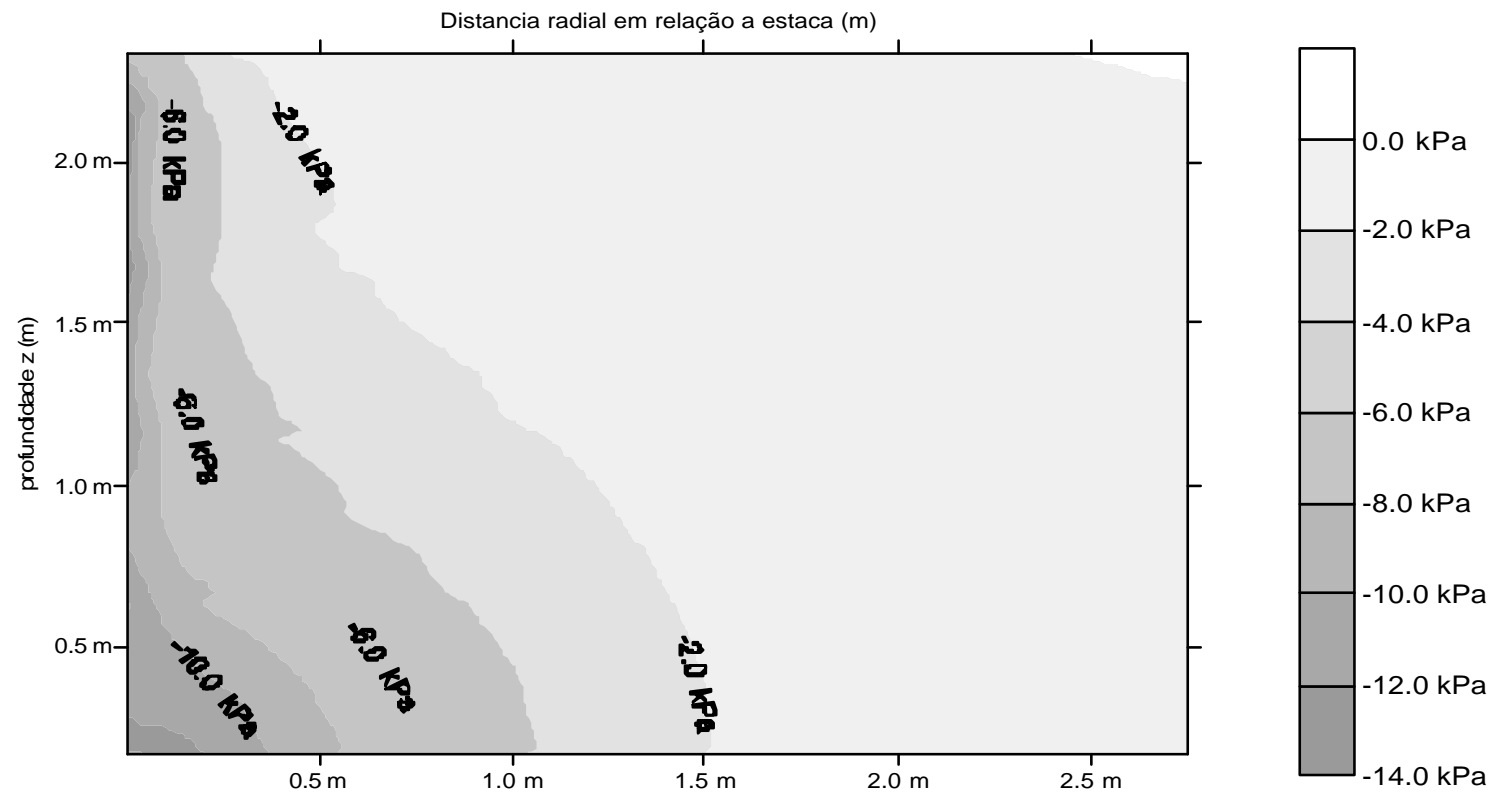

Figura 6.40 - Diagrama de distribuição das tensões na direção vertical

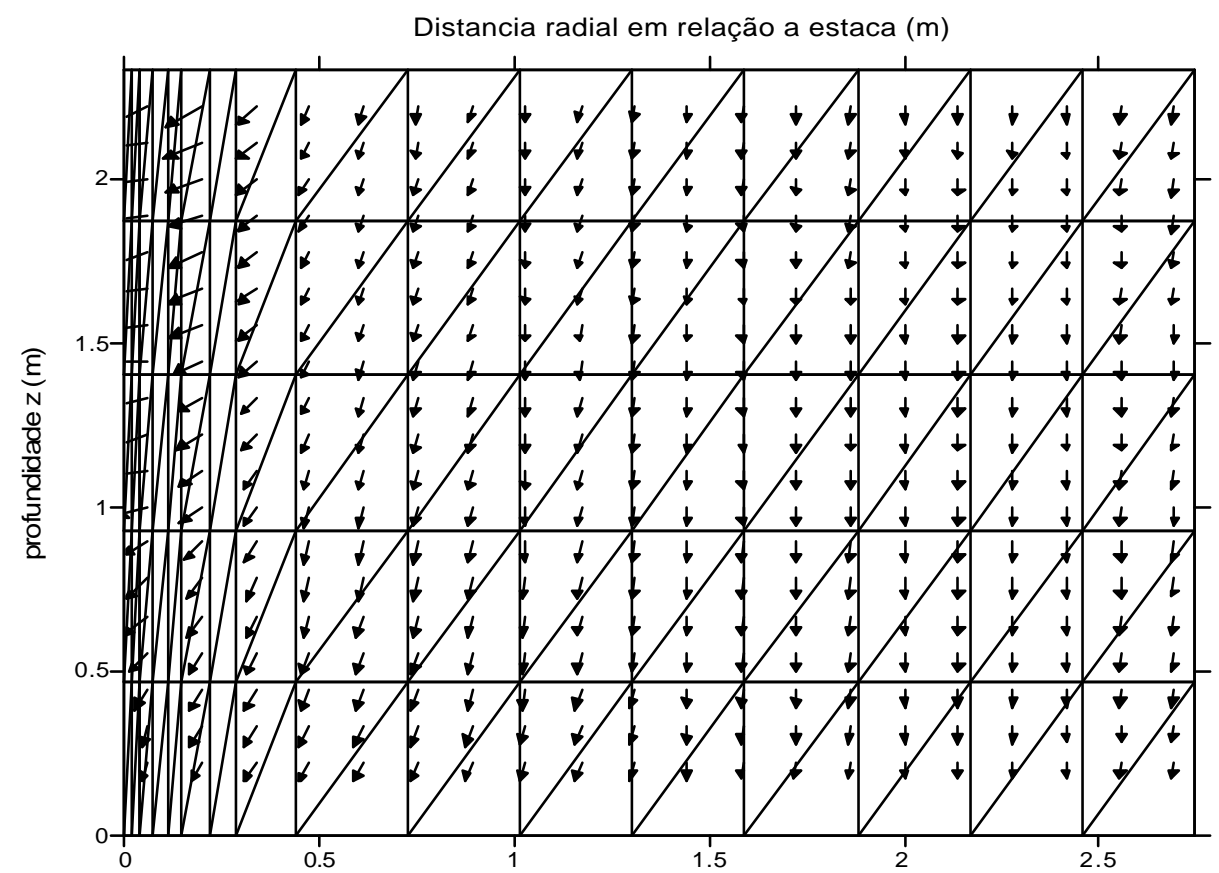

Figura 6.41 - Vetores da direção das tensões principais. 


\subsection{Análise dos resultados}

As simulações realizadas demonstram a possibilidade do cálculo das tensões tangenciais e normais em interaface estaca solo através do método dos elementos finitos, usando o modelo constitutivo aqui proposto para representar o comportamento reológico dos elementos de interface de espessura nula em análise 2D axissimétricas e também para representar o comportamento de apoios deformáveis em análises 1D sobre apoios deformáveis não linerares.

Os resultados obtidos nas simulações (tanto unidimensional, quanto bidimensional) são compatíveis com os resultados observados nos experimentos estudados, principalmente quando se refere aos resultados de capacidade de carga.

Com relação à forma da curva carga-recalque, percebe-se uma menor aproximação entre os resultados medidos e calculados. No entanto, as diferenças obtidas são função dos parâmetros adotados, de modo que é possível se ter uma melhor aproximação caso se retro-analisem as curvas carga versus deslocamento.

Apesar de não se ter referência de comparação para os diagramas de esforço normal, pode-se concluir que a análise numérica não linear é uma ferramenta poderosa para cálculo e previsão deste diagrama, em qualquer nível de carregamento.

O mesmo acontece para a previsão do campo de tensões radiais, verticais e tangenciais, na qual os valores obtidos possuem a mesma ordem dos valores fornecidos pelas demais análises discutidas.

Um fato importante que deve ser notado consiste na aplicação de coeficientes de rigidez normal e de cisalhamento diferentes para cada nível de tensão e em cada elemento, possibilitando uma análise de carregamento estático em estacas mais condizente com a realidade física, onde o nível de tensão normal varia em função da profundidade.

Cabe ainda ressaltar que a aplicação do modelo de atrito estático não linear aqui prosposto é extremamente simplificada, quando comparada com outros modelos não lineares, devido ao fato de necessitar da adoção de apenas três parâmetros reológicos para a interface.

O modelo aqui proposto apresentou ainda como vantagem na simulação o fato de possuir boa convergência para a maioria dos casos simulados. 


\section{CAPÍTULO VII \\ CONCLUSÕES E SUGESTÕES}

\subsection{Conclusões Gerais}

Este trabalho apresenta um novo modelo de previsão do comportamento mecânico em interfaces de contato entre areia e concreto. Este modelo é baseado na ocorrência do atrito verdadeiro entre as partículas granulares e a superfície de contato, no rearranjo das partículas e na dilatância. O modelo considera, ainda, que uma interface constitui-se em um problema bidimensional com espessura nula. Sua validação é feita através de ensaios convencionais de cisalhamento direto com carga normal constante (CNC). A equação resultante permite uma solução analítica para a resistência ao cisalhamento, mobilizada em função do deslocamento tangencial na interface. Permite, também, o equacionamento da variação de volume, em função do deslocamento tangencial que ocorre durante o cisalhamento. Considerando-se que o sistema é confinado lateralmente (deformações transversais nulas), pode-se obter a variação do deslocamento normal em função do deslocamento tangencial.

$\mathrm{O}$ uso deste modelo em problemas de interação solo-estrutura é facilitado com a aplicação do método dos elementos finitos, que permite a consideração de todas a partes que compõem o sistema (elemento estrutura, maciço de solos e interface). Aqui utilizamos modelos elásticos lineares para representar o comportamento do maciço de solos e do elemento estrutural de fundação, demonstrando assim que o fator que mais condiciona o comportamento de um sistema de fundação submetido ao cisalhamento é a interface.

Comparando-se os resultados experimentais de provas de carga em modelos de estacas submetidas à compressão com os resultados obtidos em simulações numéricas 
unidimensianais e bidimensionais, conclui-se que o modelo aqui demonstrado se aplica fortemente para a previsão da curva de resistência ao cisalhamento na interface estaca solo, servindo ainda para determinação de sua capacidade de carga.

De acordo com os resultados obtidos nos ensaios de cisalhamento direto em interfaces e na elaboração do modelo constitutivo de atrito estático em interfaces, podese concluir que o comportamento de sistema solo-estrututra é condicionado pelo comportamento reológico da estrutura, do solo e, principalamente, da interface entre os dois.

Conclui-se também que a formulação deduzida no Capítulo II desta dissertação é restrita às hipóteses de cálculo e às condições de contorno básicas utilizadas.

A formulação sugerida no Capítulo V para cálculo dos coefientes de rigidez normal e de cisalhamento necessários para utilização do modelo de Goodman et al. (1968) também se torna restrita às condições de contorno utilizadas para dedução das equações que a originaram.

Os modelos simulados no Capítulo VI se restringiram a casos de carregamentos estáticos de estaca de atrito submetidas à compressão. Isto ocorreu devido a necessidade de simular casos onde a ruptura acontece por deslizamento na interface.

Além disso, em todos os casos estudados no Capítulo VI, considerou-se a tensão normal aplicada na interface como sendo constante durante todo o cisalhamento, o que não corresponde à realidade fisica observada em diversos trabalhos disponíveis na literatura, onde a tensão atuante sofre um acréscimo devido à dilatância.

Como as simulações aqui realizadas tiveram por objetivo demonstrar a aplicação do modelo reológico de atrito estático proposto, essa consideração de tensão normal sempre constante na interface se deve ao fato da simulação seguir fielmente as condições de contorno e as hipóteses impostas no desenvolvimento da formulação. 
7.2. Sugestões para futuras pesquisas.

Este trabalho apresenta os fundamentos de um modelo constitutivo de atrito em interfaces, utilizando os conceitos de dilatância, de rearranjo das partículas e de atrito de deslizamento. A solução de sua equação diferencial básica é obtida considerando a tensão normal constante durante o cisalhamento como condição de contorno principal.

No contexto de desenvolvimento do modelo constitutivo, um primeiro melhoramento a ser feito é a dedução da solução da equação básica e a verificação de sua consistência para outras trajetórias de tensão.

Outra possibilidade de melhoramento na formulação consiste na consideração de deformações da interface ou, conseqüentemente, na dedução de uma formulação para interfaces de espessuras não nulas.

Ressalta-se ainda a necessidade da generalização das equações, aqui restritas para material granular, para qualquer tipo de solo.

No campo da aplicação do modelo, sugere-se sua aplicação para previsão de atrito em interfaces de muros de contenção e inclusões de reforços de solo.

Uma aplicação mais sofisticada pode ser feita para análise de provas de carga dinâmica, utilizando o modelo aqui proposto, em substituição ao modelo de SMITH (1960).

Do ponto de vista numérico, sugere-se o desenvolvimento de uma técnica consistente, que garanta a convergência do modelo em todos os casos.

Sugere-se, ainda, que se implemente o modelo constitutivo aqui proposto em formulações de elementos finitos com dependência de deslocamentos, nas quais esse modelo poderia retratar a relação de dependência entre nó o mestre e escravo. 


\section{REFERÊNCIAS}

AL-DOURI, R. H., POULOS, H. G., (1991), Static and cyclic direct shear tests on carbonate sands, Geotecnical Testing Journal, v. 15, n.. 2, p. 138 - 157.

AMERICAN SOCIETY FOR TESTING AND MATERIAL (2000). Standard practice for classification of soils for engineering purpose (Unified soil classification system. ASTM D 2487-00.

AOKI, N. (1989). A new dynamic load test concept. 12 $2^{\text {th }}$ International Conference of Soil Mechanics and Foundation Engeneering, Rio de Janeiro, v. 5, p $1-4$.

ASSOCIAÇÃO BRASILEIRA DE NORMAS TÉCNICAS (1996). Projeto e execução de fundações, NBR 6122/96.

BAKEER, R. M.; SAYED, M. S.; CATES, P.; SUBRAMANIAN, R. (1998). Pullout and shear tests on geogrid reinforced lightweight aggregate. Geotextiles and Geomembranes, v. 16, n.1, p. 119-133.

BARTON, N. (1976). The shear strenght of rock and rock joints. International Journal of Rock Mechanics Mining Sciences \& Geomechanics, v.13, p.255-279.

BARTON, N.; BANDIS, S.; BAKTAR, K. (1985). Strenght, deformation and conductivity coupling of rock joints. International Journal of Rock Mechanics Mining Sciences \& Geomechanics, v. 22, n. 3, p. 121-140.

BARTON, N.; CHOUBEY, V. (1977). The shear strength of rock joints in theory and practice. Rock Mechanics, v.10, n. 1, p.1-54.

BERNARDES, G. P., (1989), Dynamic and static testing of large model piles in sand. Universitetet I Trondheim, Institutt for Geoteknikk, Trondheim. Norwegian. Thesis of Doctor of Engineering.

BOLTON, M. D., (1986). The strength and dilatancy of sands. Geotechnique v.36, n. 1, p. 65-78.

BOULON, M. (1991). Le comportement d'interface sol-structure: aspects expérimentaux et numériques. Revue Française de Géotechnique, v. 16, p. 65-79.

BOULON, M.; (1989). Basic features of Soil-Structure Interaction Behavior.: Computer and Geotechnics, v. 7, p. $115-131$.

BOULON, M.; NOVA, R. (1990). Modelling of soil-structure interface behaviour a comparison between elastoplastic and rate type laws. Computers and Geotechnics, v.9, p.21-46.

BOULON, M.; PLYTAS, C.; FORAY, P. (1986). Comportement d'interface et prévision du frottement latéral le long des pieux et tirants d'ancrage. Revue Française de Géotechnique, v. 35, p. 31-48.

BOUZID, Dj. A.; TILIOUINE, B.; VERMEER, P. A. (2004). Exact formulation of interface stiffness matrix for axisymmetric bodies under non- axisymmetric loading. Computers and Geotechnics, v.31, p. 75-87.

BOWLES, J. E. (1988). Foundation Analysis and Design. McGraw-Hill. New York. b

CHAMPANEY, L. C. (2002). Contact unilateral entre solides élastiques. Notes du cours "Eléments Finis"du DESS Dynamique des Structures Modernes dans leur Environnement.

CHICATA, L. F. G. (2003). Boletin Cientifico de la Universidad Nacional de Ingenieria, Facultad de Ingenieria Civil y Instituto de Investigación, Lima Perú, Año 1, n.1, Agosto.

CLOUGH, G. W.; DUNCAN, J. M. (1971). Finite element analysis of retaining wall behaviour. Journal of the Soil Mechanics and Foundation Division, ASCE, 97, SM12. 
COSTA, Y. D. J. (2005). Modelagem física de condutos enterrados sujeitos a perda de apoio ou elevação localizada. Tese. Escola de Engenharia de São Carlos. USP. São Carlos.

COYLE, H. M.; REESE, L. C. (1966). Load transfer for axially loaded pile in clay. Journal of the Soil Mechanics and Foundation Division, ASCE, v. 92, n. SM2, march, 1966, p. 1-26.

DESAI, C. S., DRUMM, E. C., ZAMAN, M. M. (1985). Cyclic testing and modeling of interfaces, Journal of the Soil Mechanics and Foundation Division, ASCE, v.111, n. 6, p. $785-815$.

DESAI, C. S., (1977). Soil-structure interaction and simulation problems. Finite Elements in Geomechanics., Ed. By G. Gudehus, John Wiley \& Sons, New York, p. Chapter 7.

DESAI, C. S., (1981). Behavior of interfaces between structural and geologic media. State-of-the-art paper. International conference recent advance geotechnical earthquake engineering soil dynamic. St. Louis, Mo. April, 1981.

DESAI, C. S.; NAGARAJ, B. K., (1988). Modelling for cyclic normal and shear behavior of interfaces. Journal of engineer mechanics division. ASCE. v. 114. n. EM7, p. 1198-1217.

DOVE, J. E.; JARRETT, J. B. (2002). Behavior of dilative sand interfaces in a geotribology framework. Journal of Geotechnical and Geoenvironmental Engineering, v. 128, n.. 1, January 1, p. 25-37b.

DUNCAN, J. M.; CHANG, C. Y. (1970). Nonlinear analysis of stress and strain in soils. Journal of the Soil Mechanics and Foundation Division. ASCE.. v. 96, n. SM5, p. 1629-1653.

DUNCAN, J. M.; CLOUGH, G. W., (1971). Finite element analyses of Port Allen Lock, Journal of the Soil Mechanics and Foundation Division. ASCE.. v. 97, n. SM8, p. 1053-1067.

ELLISON, R. D. D’APPOLONIA, E.; THIERS, G. R.; (1971). Load- deformation mechanism for bored piles. Journal of the Soil Mechanics and Foundations Division. v.97, n. SM4 ,p. 661-678.April.

FARMER, I. W. (1975)Stress distribution along a resin grouted rock anchor. International Journal Rock Mechanical Mineral Science \& Geomechanical Abstract. v. 12, p. 347-351.

FIORAVANTE, V. (2002) On the shaft friction modeling of non-displacement piles in sand. Soils and Foudantions, v. 42, n.2, p. 23-33.

FRANK. R.; GUENOT, A.; HUMBERT, P. (1982). Numerical analysis of contacts in geomechanics. In proceedings of the fourth international conference on numerical methods in geomechanics. Edmonton. Canada.

GARRIDO, J.A.; FOCES, A.; PARIS, F.(1994). An incremental procedure for threedimensional contact problems with friction. Computers \& Structures, v. 50,n. 2 p. 201-215.

GEDDES, J. D. (1969). Stresses in foundation soils due to vertical subsurface loading. Géotechnique, v.16, n.3. p.231-255.

GENS, A.; CAROL, I.; ALONSO, E. E.; SALGADO, J. G. (1990). A constitutive model for rock joints formulation and numerical implementation. Computers and Geotechnics, v.9, p. 3-20.

GHIONNA, V. N.; MORTARA, G. (2002). An elastoplastic model for sand-structure interface behaviour. Géotechnique, v.52, n.1, p.41-50.

GÓMEZ, J. E. (2000). Development of an extended hyperbolic model for concrete-tosoil interfaces. PhD. Thesis. Virginia Polytechnic Institute. Blacksburg, Virgínia. 
GOODMAN, R. E (1976). Methods of geological engineering in discontinuous rocks. WEST PUBLISHING COMPANY, $472 \mathrm{p}$.

GOODMAN, R. E. (1977). Analysis in jointed rocks, Finite Elements in Geomechanics., Ed. By G. Gudehus, John Wiley \& Sons, New York, p. 351-376.

GOODMAN, R. E., ST. JOHN, C., (1977), Finite Elemente Analysis for Discontinuos Rocks, Numerical Methods in Geotechnical Engineering, Ed. By C. S. Desai and J. T. Christian, Mc Graw Hill, New York, p. 148-175.

GOODMAN, R.E., TAYLOR, R. L. E BREKKE, T. L., (1968), A Model for Mechanics of Jointed Rock. ASCE, 94, SM3, p. $637-659$.

GRILLO, O. (1948). Influence scale and influence chart for the computation of stresses due, respectively, to surface point load and pile load. In proceedings of the second international conference on soil mechanics and foundation engineering. Rotterdam, June, 1948. g11. p 70-72.

GUO, W. D. (2000) Vertically loaded single piles in gibson soil. Journal of Geotechnical of Geoenvironmental Engineering, v. 126, n. 2, p.189-193.

GUO, W. D. (2001). Pile Capacity in non-homogeneous softening soul. Soils and Foundations, v. 41, n.2, p.111-120.

GURUNG, N.; IWAO, Y. (1999). Pull-out test analysis for geo-reinforcement. Geotextiles and Geomembranes, v. 17, p. 157-170.

HIRD, C. C.; RUSSELL, D. (1990). A benchmark for soil-structure interface elements. Computers and Geotecnhics, v. 10, n. 2. p. 139-147.

HOULSBY, G. T. (1991). How the dilatancy of soils affects their behaviour. In proceedings of the tenth european conference on soil mechanics and foundations engineering. Florence, v. 4, p. 1189-1202.

JARDINE, R. J., POTTS, D. M., FOURIE, A. B.; BURLAND, J. B. (1986). Studies of the influence of non-linear stress-strain characteristics in soil-structure interaction. Geotechnique v. 36, n.. 3, p.377-396.

JARDINE, R. J.; OVERY, R. F.; CHOW, F. C. (1998). Axial capacity offshore piles in dense north sea sands. Journal of Geotechnical and Geoenvironmentel Engineering, v. 124, n. 2, p.171-178, February.

JEONG, S.; LEE, J.; LEE, C. J. (2004). Slip effect at the pile-soil interface on dragload. Computers and Geotecnhics, v. 31, p.115-126.

JIANG, M. J.; YU, HS.; HARRIS, D. (2005). A novel discrete model for granular material incorporating rolling resistance. Computers and Geotecnhics, v. 32, p. 340357.

KÉZDI, A. (1957). The bearing capacity of piles and pile groups. In proceedings of the Fourth international conference on soil mechanics and foundation engineering. London, 1957. v. 2. p 46 - 51.

KISHIDA, H.; UESUGI, M. (1987). Tests of the interface between sand and steel in the simple shear apparatus. Géotechnique, v. 37, n.1, p.42-52.

KRAFT, L. M.; RAY, R. P.; KAGAWA, T. (1981). Theorical $t$-z curves. Journal of Geotechnical Engineering Division, ASCE, v. 107. n. 11.p. 1543-1561.

LAMBE. T. W.; WHITMAN, R. V. (1969). Soil Mechanics. John Wiley \& Sons, New York.

LANDANYI, B., ARCHAMBAULT, G., (1970), Simulation of shear behavior of jointed rock mass, $11^{\text {th }}$ Symp. On Rock Mechanics: Theory and Practice, AIME, New York, p. 105-125.

LEE, C. J.; BOLTON, M. D.; AL-TABBAA, A. (2002). Numerical modeling of group effects on the distribution of dragloads in pile foundations. Géotechnique, v.52, n.5, p.325-335. 
LEHANE, B. M.; JARDINE, R. J.; BOND, A. J.; FRANK, R. (1993). Mechanisms of shaft friction in sand from instrumented pile tests. Journal of Geotechnical Engineering. v. 119, n. 1, p. 19-35.

LIU, J.; XIAO, H. B.; TANG, J.; LI, Q. S. (2004). Analysis of load-transfer of single pille in layered soil. Computer and Geotechnics. v.31, n 1, p.127-135.

LIU, S. H..; SUN, D. MATSUOKA, H. (2005). On the interface friction in direct shear test. Computers and Geotechnics, v. 32, n. 2 , p. 317-325.

LOPES, F. R.(1979). The undrained bearing capacity of piles and plates studied by finite element method. $\mathrm{PhD}$ thesis. Imperial College of Science, Technology and Medicine, University of London.

LUK, V. K.; KEER, L. M. (1980). Stress analysis of a deep rigid axially-loaded cylindrical anchor in an elastic medium. International Journal for Numerical and Analytical Methods in Geomechanics, v.4, n.2 , p.215-232.

MABSOUT, M.; SADEK, S.(2003). A study of the effect of driving on pre-bored piles. International Journal for Numerical and Analytical Methods in Geomechanics, v.27, p.133-146.

MABSOUT, M.; SADEK, S.; SMAYRA, T. E. (1999). Pile driving by numerical cavity expansion. International Journal for Numerical and Analytical Methods in Geomechanics, v. 23, 1121-1140.

MASSAD, F. (1992). Sobre a interpretação de provas de carga em estacas, considerando as cargas residuais na ponta e a reversão do atrito lateral. Parte I: solos relativamente homogêneos. Solos e Rochas, v. 15, n. 2, p. 103-115.

MERIAM, J. L. (1977). Estática. Livros Técnicos e Científicos, Rio de Janeiro. 1977.

MEYERHOF, G. G. (1973). Uplift resistance of inclined anchors and pile. $8^{\text {th }}$ International Conference of Soil Mechanics and Foundation engeneering, Moscow, URSS.

MINDLIN, R. D. (1936). Force at a point in the interior of a semi-infinite solid. Physics. v 7. p. 195 -202, May.

MISRA, A.; CHEN, C. H. (2004). Analytical solution for micropile design under tension and compression. Geotechnical and Geological Engineering, v. 22, p.199225.

NEVES, M. (1993). Análise elastoplastica pelo método dos elementos finitos de estacas escavadas. Tese de Doutorado. Departamento de Geotecnia. Escola de Engenharia de São Carlos, Universidade de São Paulo. Braisl. p.261.

NG, P. C. F.; PYRAH, I. C.; ANDERSON, W. F. (1997). Assessment of three interface elements and modification of the interface element in CRISP90.Computers and Geotechnics, v. 21, n. 4, p. 315-339.

OOI, L. H., CARTER, J. P. A, (1987), A Constant Normal Stiffness Direct Shear Device for Static and Cyclic Loading, Geotecnical Testing Journal, v. 10, n. 1, p. 312.

ORLANDO, C. (2000). Contribuição ao estudo de estascas tracionadas: análise comparativa da resistência lateral na tração e na compressão. ABMS. São Paulo. Fevereiro.

ORTIGÃO, J. A. R. (1993). Introdução à mecânica dos solos no estado crítico. Rio de Janeiro, Livros Técnicos e Científicos Editora Ltda.

PAIKOWSKY, S. G., PLAEYER, C. M., CONNORS, P. J., (1995), A dual interface aparratus for testing unrestricted friction of soil along solid surfaces, Geotecnical Testing Journal, v. 18, n.. 2, p. 168 - 193.

PALMEIRA, E. M. (1987). The study of soil reinforcement by means of large scale laboratory tests. Ph.D. thesis, University of Oxford, 237 p. 
PATTON, F. D. (1966). Multiple modes of shear failure in rock. $1^{\text {th }}$ International Conference of Rock Mechanics, p. 509 - 513.

PONCE, M., BELL, J. M., 1971, Shear strength of sand at estremely low pressures, Journal of the Soil Mechaniscs and Foundation Division, ASCE, SM4, v. 97, n. SM4 , p. $625-638$.

PORCINO, D.,FIORAVANTE, V., GHIONNA, V. N., PEDRONI, S., (2003), Interface behavior of sands from Constant normal stiffiness direct shear tests. Geotecnical Testing Journal, v. 26, n. 3, p. $289-231$.

POTTS, D. M. (2003). Numerical analysis: a virtual dream or practical reality? Geotechnique v. 50, n. 6, p. 535-573.

POTTS. D. M \& MARTINS, J. I. (1982). The shaft resistance of axially loaded piles in clay. Geotechnique v. 32, n. 4, p. 369386.

POTYONDY, J. G. (1961). Skin friction between various soils and construction materials Géotechnique, v.11, n.4, p. 339-353.

POULOS, H. G. (1979). Settlement of single piles in nonhomogeneous soil. Journal of the geotechnical engeering division, v. 105, n. GT5, p. 627-641, May.

POULOS, H. G.; DAVIS, E. H. (1974). Elastic solutions soil and rock mechanics, John Willey \& Sons. New York.

POULOS, H.G..(1967). Stresses and displacements in an elastic layer underlain by a rough rigid base. Géotechnique, v. 17, p.378-410.

POULOS, H.G.; DAVIS, E. H. (1968). The settlement behaviour of single axially loaded incompressible piles and piers. Géotechnique, v. 5 n.18, p.351-371.

POWRIE, W. (1997). Soil Mechanics: Concepts and Applications. E \& FN SPON, London.

RANDOLPH. M. F. (1985). Pile foundations for offshore structures. COPPE/UFRJ. Programa de Engenharia Civil. Notas de Aula.

REDDY, E. S. B.; O'REILLY, M.; CHAPMAN, D. (1997). A software to predict the behaviour of tension piles. Computers \& Structures, v.62, n.4, p.653-658.

ROWE, P. W., (1962), The Stress-Dilantancy of Media for Static Equilibrium of an Assembly of Particles in Contact, Proceedings, Royal Society of London, v. 269, Series A, p $500-527$.

SEED, H. B.; REESE, L. C., (1957). Action of soft clay along friction piles. Proceedings, ASCE, v. 81. paper no. 842, p. 18-38.

SHALLENBERGER, W. C.; FILZ, G. M. (1996). Interface strength determination using a large displacement shear box. In proceedings of the second international congress on Enviromental Geomechnics. Osaka. Japan, Ed. by M. Kamon. . A. A. Balkema, Totterdam, The Netherlands.

SHENG, D.; EIGENBROD, K. D.; WRIGGERS, P.(2005). Finite element analysis of pile installation using large-slip friction contact. Computers and Geotechnics, v. 32, p. 17-26.

SMITH, E. A. L. (1960). Pile-driving analysis by wave equation. Journal of the Soil Mechanics and Foundation Division. ASCE. v. 86, n.1, p. 25 - 61.

TABUCANON, J. T., AIREY, D. W., POUlOS, H. G., (1995), Pile skin friction in sands from constant normal stifiness tests, Geotecnical Testing Journal, v. 18, n. 3, p $350-364$.

TAYLOR, D. W. (1948). Fundamentals of soil mechanics, John Wiley, New York, 1948.

TEI, K. (1993). A study of soil nailing in sand. PhD thesis. Magdalen College, University of Oxford. 
TEIXEIRA, S. H. (2003). "Estudo da interação solo-geogrelha em testes de arrancamento e sua análise e aplicação em maciços reforçados". Tese de Doutorado. Escola de Engenharia de São Carlos. Universidade de São Paulo. 218p.

UESUGI, M., KISHIDA, H., (1986a), Frictional Resistance at Yield between Dry Sand and Mild Steel, Soils and Foundations, v. 26, n. 4, p. 139-149.

UESUGI, M., KISHIDA, H., (1986b), Influential Factors of Friction between Steel and Dry Sand, Soils and Foundations, v. 26, n. 2, p. 3-46.

VESIC, A. S. (1975). Principles of pile foundation design. Lecture Series On Deep Foundation. ASCE. MIT. 1975.

WERNICK, E., 1978. Stresses and strains and the surface of anchors, Revue Française de Géotechnique,.numéro spécial sur les tyrants d'ancrages. p. $113-119$.

WILSON, E. L. (1977). Finite elements for foundation, joints and fluids. Finite elemente in Geomecânics. Ed. By G. Gudehus, John Wiley \& Sons, New York, p. 319-350.

XIAO, H. B.; LUO, Q. Z.; TANG, J.; LI, Q. S. (2002). Prediction of load-settlement relationship for large-diameter piles. The Structural Design of Tall Building, v. 11, n.2 ,p. 285-293.

YOSHIMI, Y., KISHIDA, T., (1981a), A ring torsion apparatus for evaluating friction between soil and metal surfaces, Geotecnical Testing Journal, v. 4, n. 4, p. 145 152.

YOSHIMI, Y., KISHIDA, T., (1981b), Friction between soil and metal surfaces, $10^{\text {th }}$ International Conference of Soil Mechanics and Foundation engeneering, Stockholm, Sweden, p $831-834$.

YU, H. S.; HOULSBY, G. T. (1991). Finite cavity in dilatant soils: bading analysis. Géotechnique,v.41, n.2, p.173-183.

ZHU, H.; CHANG, M-F. (2002). Load transfer curves along bored piles considering modulus degradation. Journal of Geotechnical and Geoenvironmental Engineering, v. 128, n.. 9, September 1, p.764-774. 


\section{ANEXO A}

Linha de estados críticos em termos de variação de volume e variação de índice de vazios 


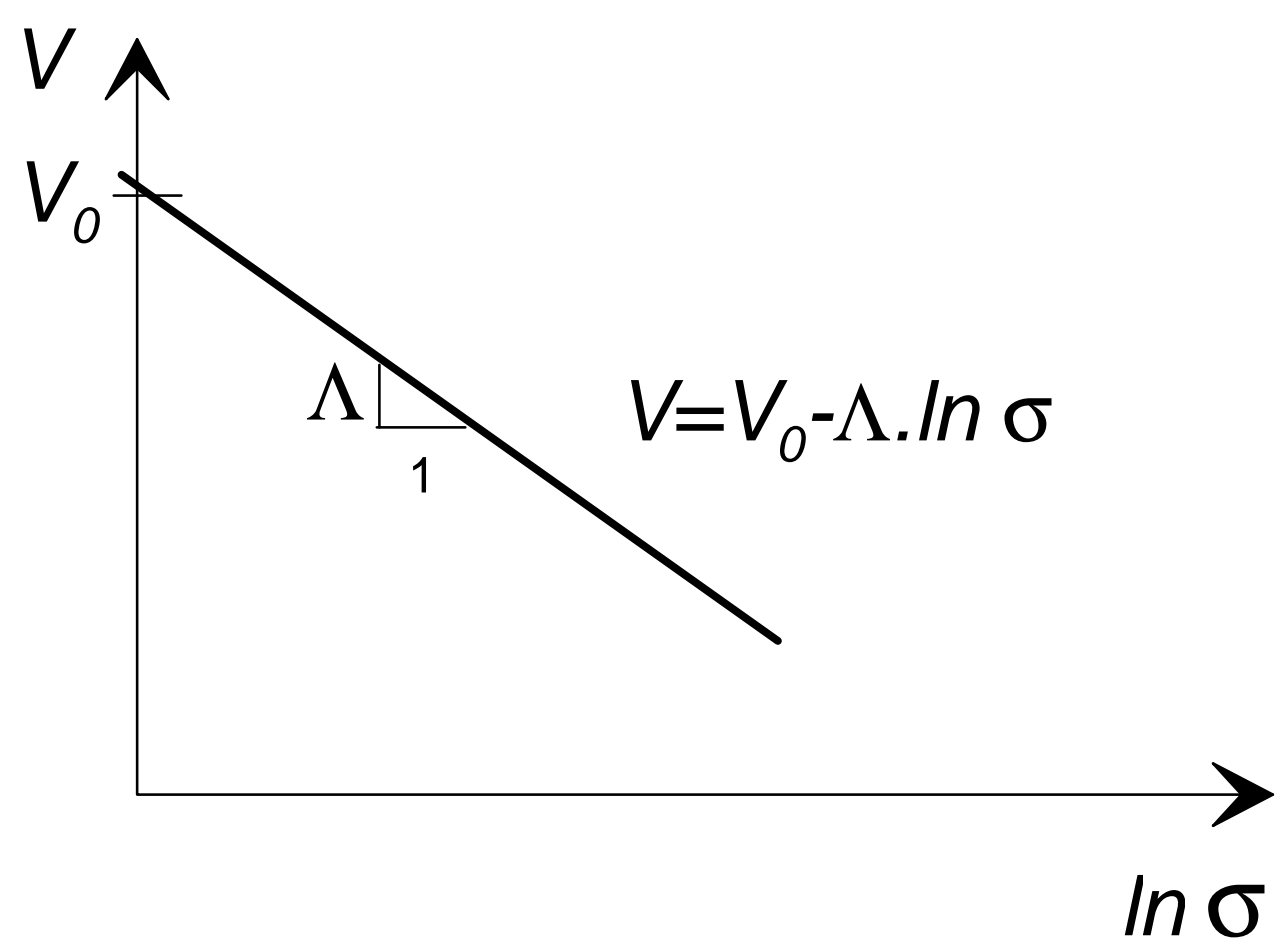

ANEXO A.1 - Linha de estados críticos em termos de variação de volume

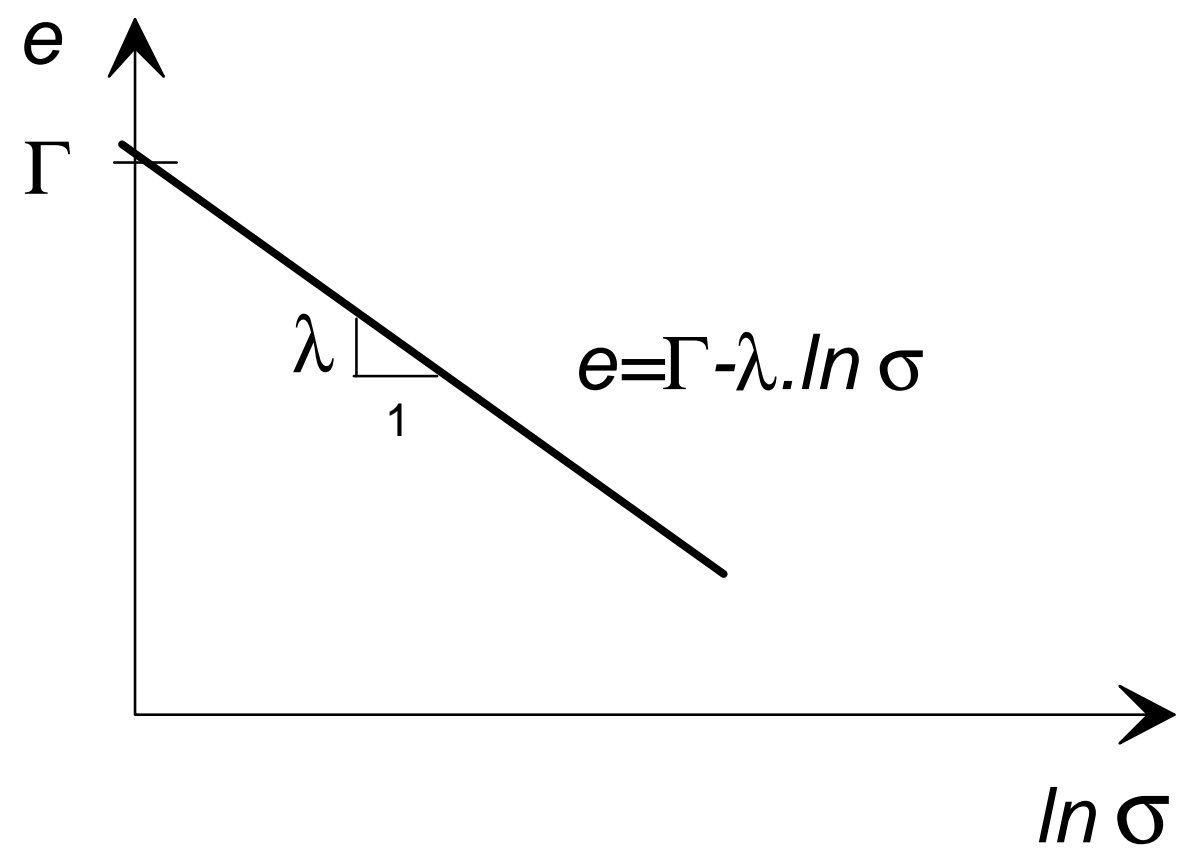

ANEXO A.2 - Linha de estados críticos em termos de variação de índice de vazios 


\section{ANEXO B}

Comparação entre resultados experimentais e a previsão através do modelo 

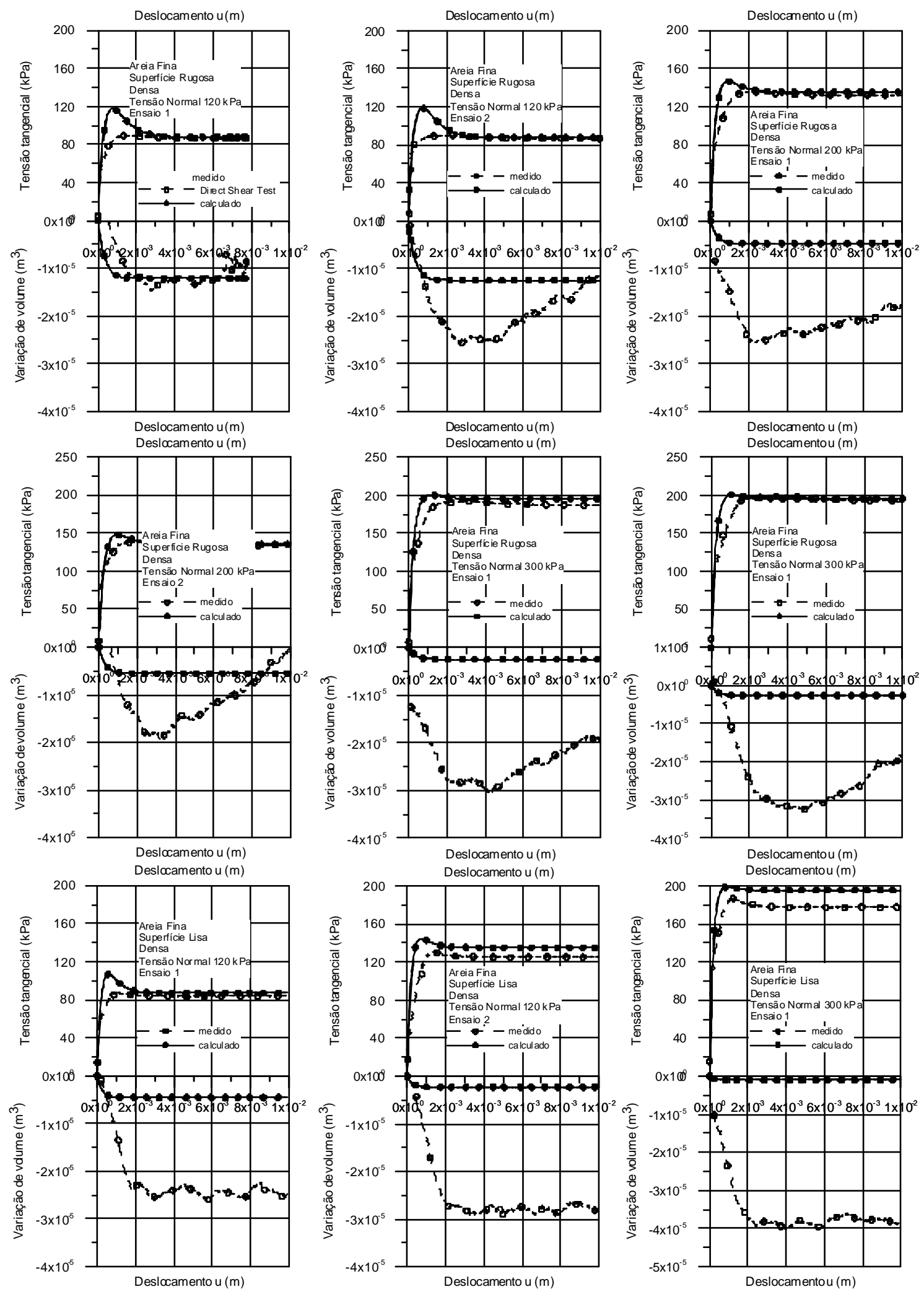

ANEXO B.1 - Comparação entre resultados experimentais e a previsão através do modelo para areia fina A1 compacta. 

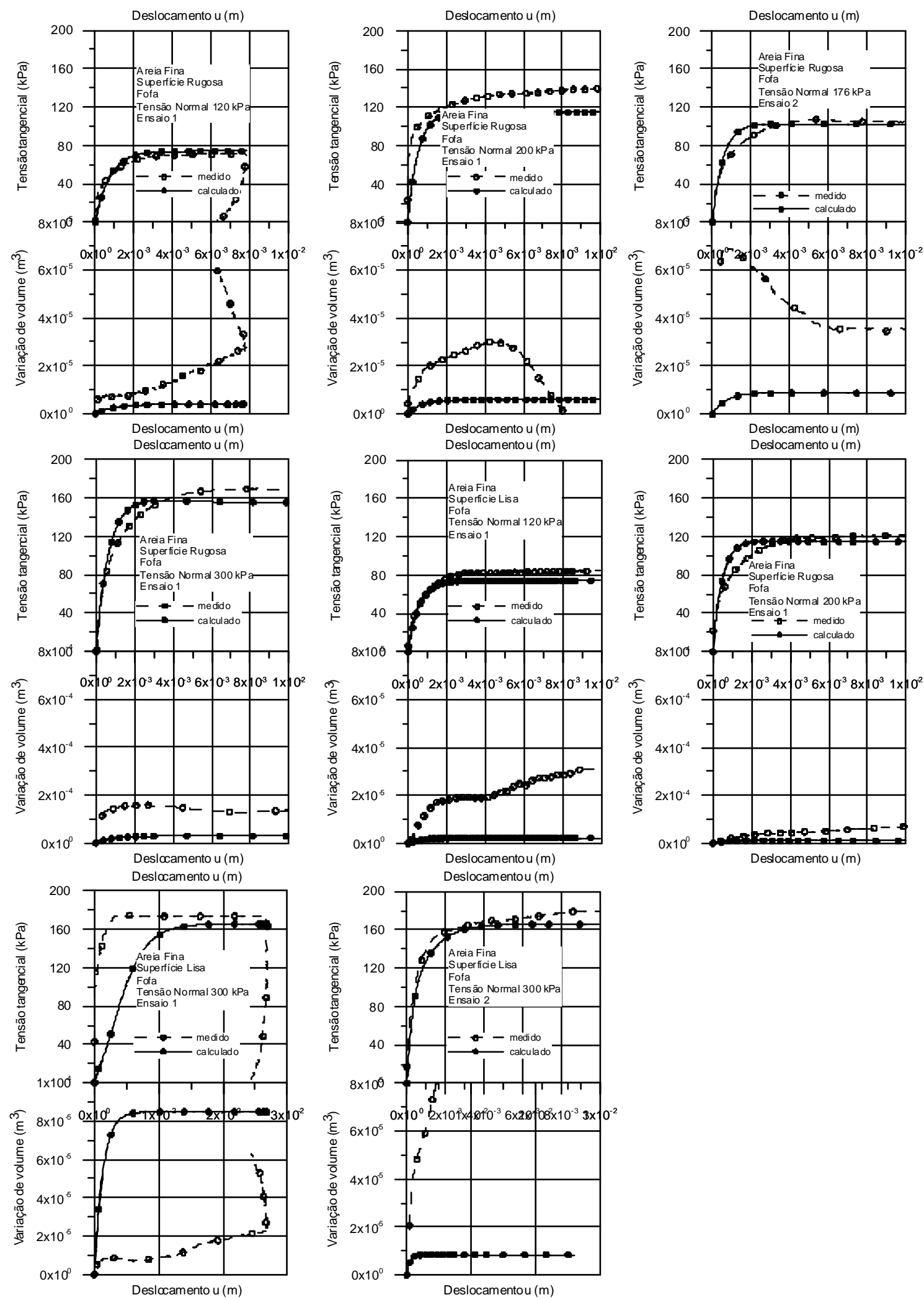

ANEXO B.2 - Comparação entre resultados experimentais e a previsão através do modelo para areia fina $\mathrm{A} 1$ fofa. 

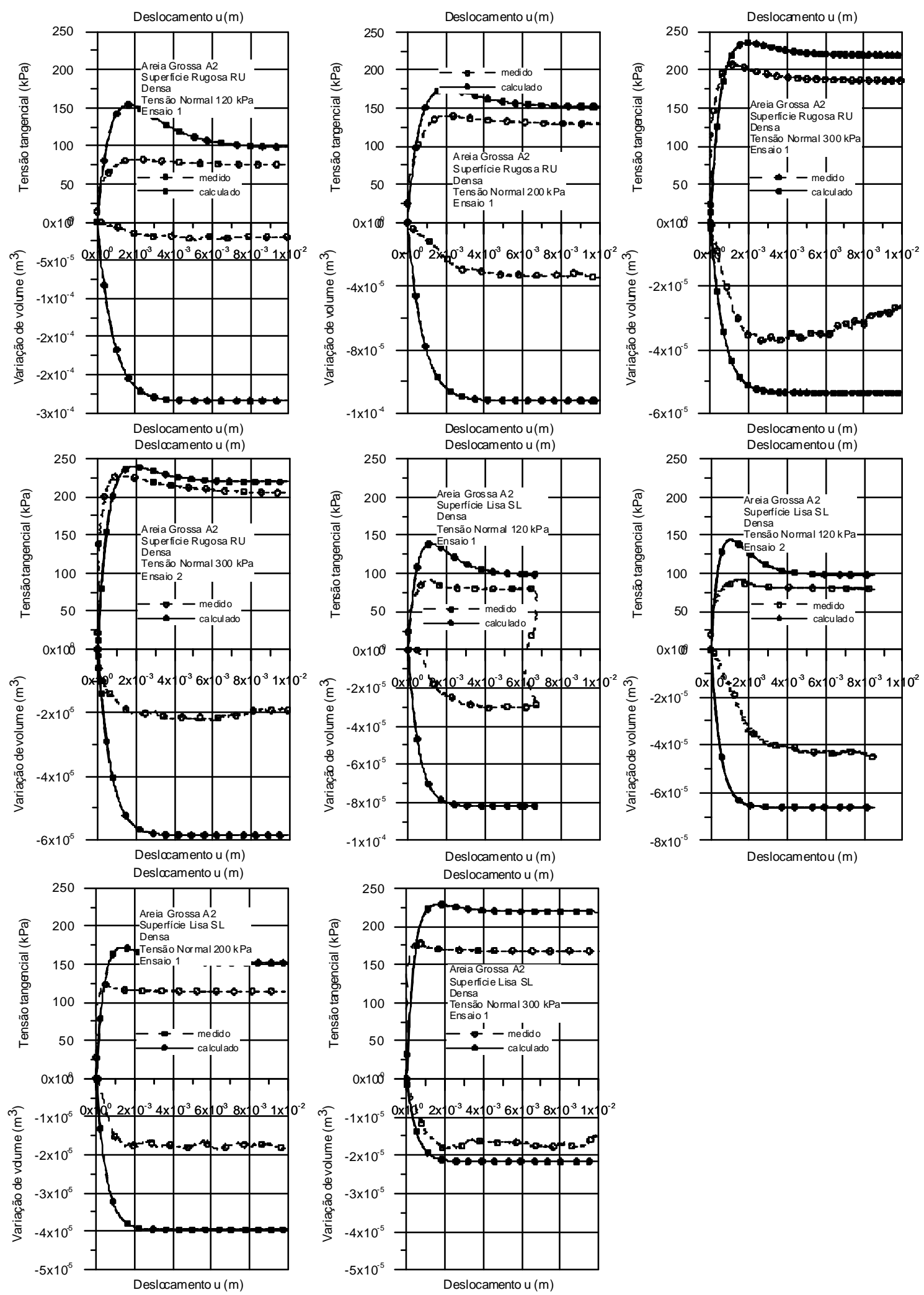

ANEXO B.3 - Comparação entre resultados experimentais e a previsão através do modelo para areia grossa A2 compacta. 

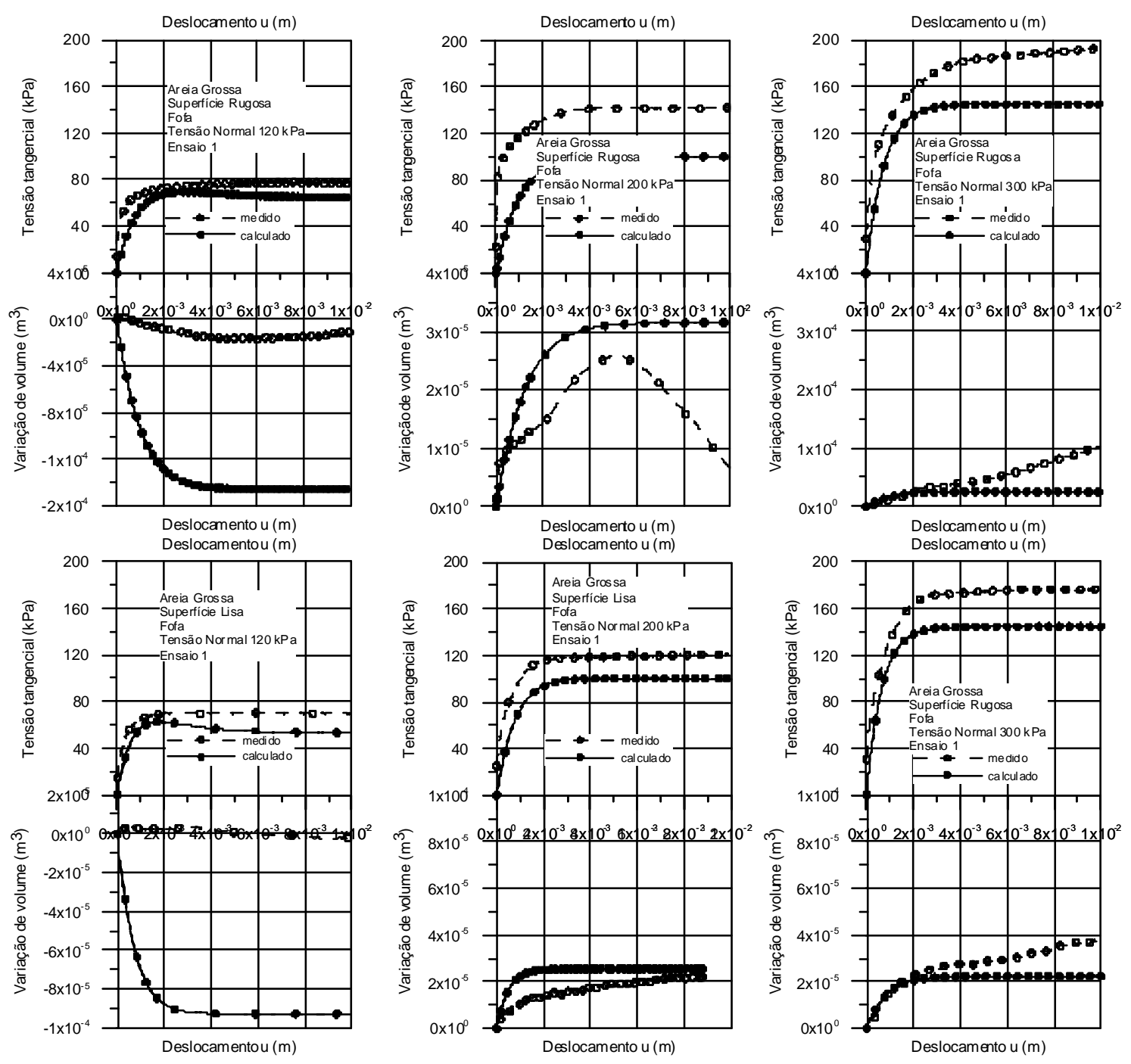

ANEXO B.4 - Comparação entre resultados experimentais e a previsão através do modelo para areia grossa A2 fofa. 